\title{
E-Learning in Information Management (IM) Education in
}

Sri Lanka: An examination of contextual issues

\section{By}

\section{Namali Suraweera}

A thesis submitted to the Victoria University of Wellington in fulfilment of the requirements for the degree of Doctor of Philosophy

Victoria University of Wellington

November, 2015 


\begin{abstract}
Information is considered a fundamental resource for improving the quality of governance and promoting socio-economic development in developing countries. In Sri Lanka, under the government's vision of higher education, Information Management (IM) education is seen as important for fostering the development of a high quality market-oriented and knowledge-based society. However, a number of barriers currently restrict access to IM education by Sri Lankan information workers: the provision of education is limited to face-to-face teaching at three institutions in the Colombo (capital city) area, and the country's physical infrastructure makes it difficult for full-time workers to attend classes without missing substantial work time. This results in IM employer reluctance to support education. Hence there is a growing need to provide equity of access to IM education.
\end{abstract}

In response to World Bank reports $(2007,2009)$ the Quality Assurance and Accreditation Council (QAAC) of Sri Lanka aims to foster transformative change in IM education with the goal of increasing equality of access to IM education through the use of e-learning. A number of early attempts to implement e-learning in Sri Lanka have already failed (Anderson, 2008). There is no rigorous research that investigates what factors have an impact on the introduction and use of elearning in tertiary-level IM education in the Sri Lankan context and what the barriers or enablers to doing so might be. Understanding of the cultural context is known to be critical for the success of e-learning (Siritongthaworn et al., 2006).

This research fills these gaps in the literature. It was guided by two questions: (i) what are the contextual factors that affect the introduction and use of e-learning in tertiary-level IM education in Sri Lanka? and (ii) how do these factors affect the introduction and use of e-learning? An interpretive case study research was conducted. Thirty semi-structured interviews were conducted with information management education providers, existing e-learning providers and relevant stakeholders, and three focus group discussions were conducted with information workers and academics. Relevant documents were also analysed: (i) official government documents, e.g. policies, reports, and announcements; (ii) official documents from private sources, e.g. administrative documents, proposals, progress reports, and other internal records; and (iii) relevant internet resources. Fullan's (1991) educational change theory and Hofstede, Hofstede, and Minkov's (2010) cultural dimensions provided a basis for a conceptual model to guide the process of data collection and analysis in this study to gain an understanding of factors affecting the introduction and use of e-learning in tertiary-level IM education in Sri Lanka.

Factors that are perceived to have an impact on the introduction and use of e-learning in tertiarylevel IM education in Sri Lanka were found at different levels. Macro-level factors included social and cultural factors, governmental factors, and technological factors. Meso-level factors included resistance to pedagogical change, lack of human and other resources, lack of collaboration/partnership among stakeholders and collective perception of e-learning acceptance.

A key outcome of this study is the development of a contextual framework to guide the introduction and use of e-learning in tertiary-level IM education in Sri Lanka. This study extends education and sociology research (including socio-technological innovation research) involving Fullan's educational change theory and Hofstede, Hofstede, and Minkov's cultural dimensions into a developing country context. In addition to the study contributing to theoretical understanding in education and sociology research, the findings of this study have implications for IM educators and practice in the forms of development of policies, implementation of elearning, and prioritization and allocation of resources. 


\author{
I dedicate this thesis to my mother and father \\ Lokumenike Subasinghe and Siriwardana Suraweera
}

who supported, inspired, and encouraged me to value education and think about things wisely

\title{
Acknowledgements
}

I am truly grateful and will forever be thankful to Dr. Chern Li Liew and Dr. Jocelyn Cranefield for enthusiastically guiding, advising, and supporting me throughout the completion of this thesis. You not only provided outstanding supervision by using your extensive experience, you also offered me encouragement and practical support which were central to my completion. Deep appreciation is also expressed to Professor Gary Gorman's direction into the proposal stage of this research as well as Dr. Dan Dorner, Professor Pak Yoong, and Dr. Val Hooper for their advice, encouragement, and hope. Thanks also to the other academic and administrative staff in SIM, especially Jean Grant and Usha Varatharaju and Student Learning Support staff, especially Karen Commons and Dr. Deborah Laurs who provided invaluable service and support to gain confidence in the formal academic setting.

I am very grateful to the School of Information Management, Victoria University of Wellington for the Nordin Bin Mohamed Memorial PhD scholarship that supported this research. I am also thankful to the School of Information Management as well as Victoria Business School for the grants that enabled me to attend a number of international conferences to present the findings of this study.

I also wish to acknowledge the great support of Professor Sunanda MaddumaBandara, Professor Piyadasa Ranasinghe, Professor AHMH Abayarathna, Professor WA Weerasooriya, Mr. Jayathunga Amaraweera and other academic and non-academic staff from the University of Kelaniya, Sri Lanka.

I feel the utmost gratitude to my husband Thilina, who was on many occasions deprived of my fullest attention due to my determination to finish this thesis. Special thanks to my family, my loving sister Syamali and my loving brother Indrasiri, for supporting me in this endeavour and to the friends who have provided me with support and companionship, especially Rashidah, Marta, Sai, Foilagi, and Dilmini.

My thanks to Jackie Bell for proofreading my thesis. 


\section{Table of Contents}

Abstract.
Acknowledgements.
Table of Contents
List of Tables
List of Figures.
Abbreviations
CHAPTER 1 - INTRODUCTION TO THE STUDY

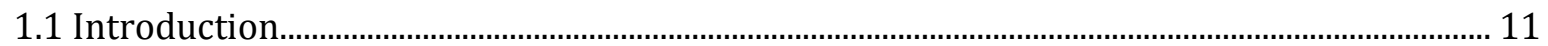

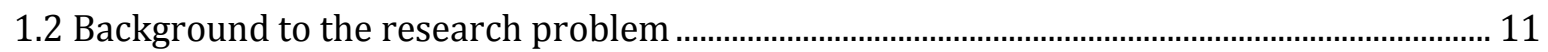

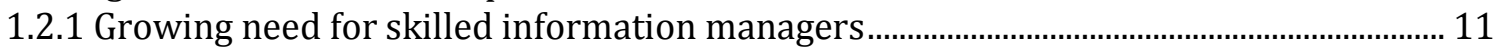

1.2.2 Current issues in information management education in Sri Lanka................................... 12

1.2.3 Need to develop a Sri Lankan tertiary education system relevant to the labour market

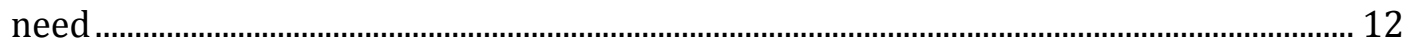

1.2.4 Drive for e-learning in IM in Sri Lanka................................................................................ 13

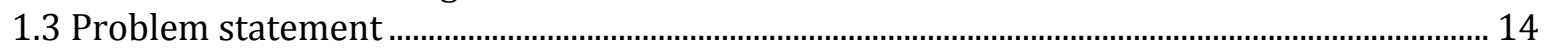

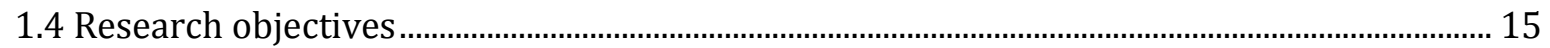

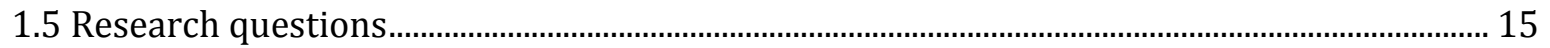

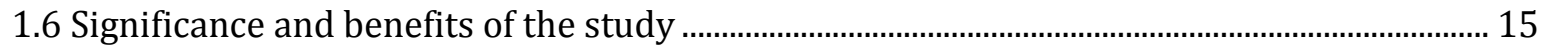

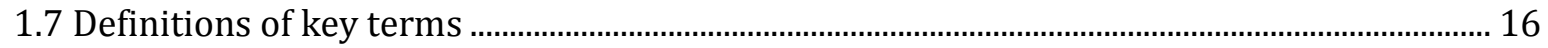

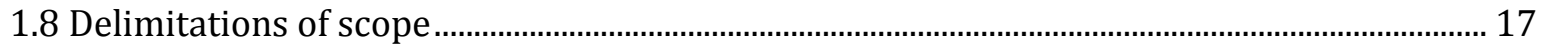

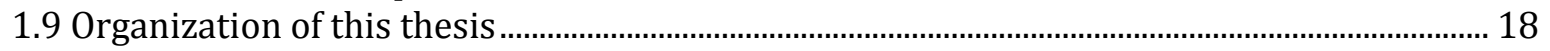

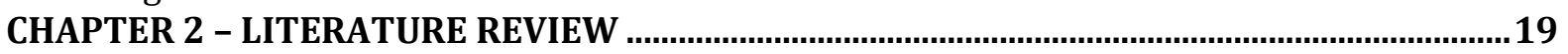

2.1 Need for skilled information managers - Global context ……………….................................. 20

2.1.1 Definition of information management............................................................................... 20

2.1.2 Need for skilled and educated information managers ......................................................... 21

2.2 Background on information management education in Sri Lanka ............................................. 23

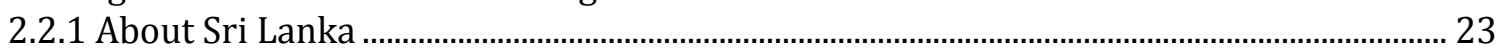

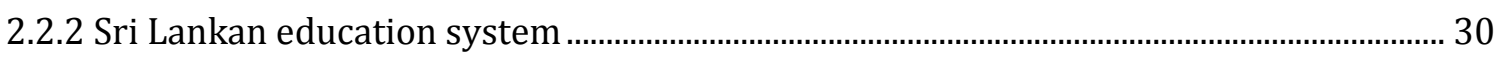

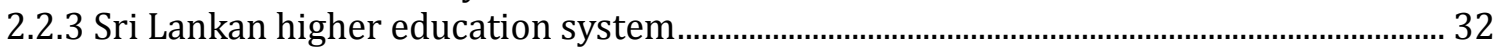

2.2.4 Tertiary-level Information Management (IM) education in Sri Lanka.............................. 37

2.2.4.1 Current limitations in tertiary-level IM education in Sri Lanka ...................................... 37

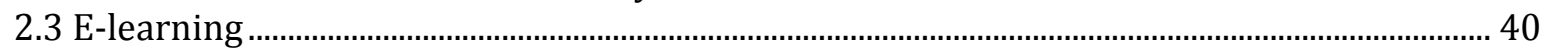

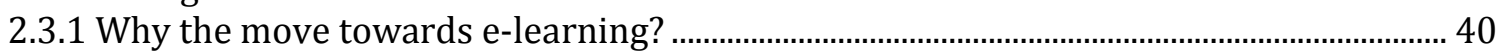

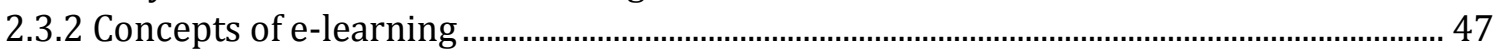

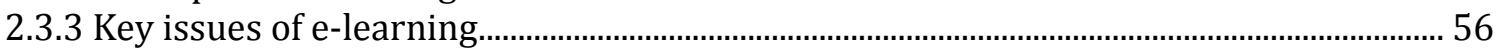

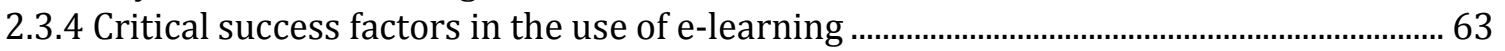

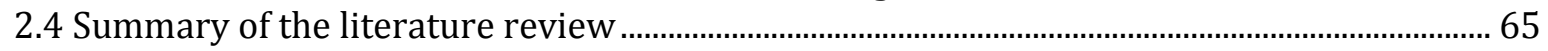

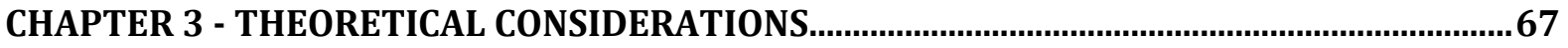

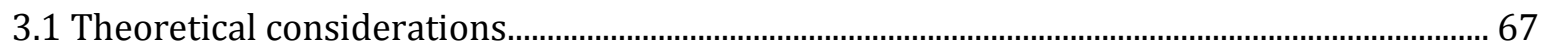

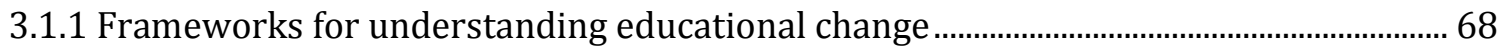

3.1.2 Dimensions of national culture .......................................................................................... 78

3.2 The conceptual model for understanding the factors that have an impact on the introduction of e-learning in tertiary-level IM education in Sri Lanka ............................................ 86

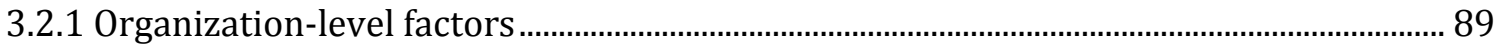

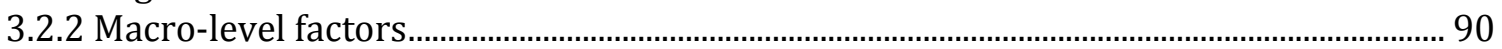

3.2.3 Organizational and macro-level factors .......................................................................... 95

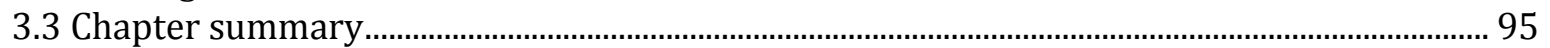

CHAPTER 4 - RESEARCH STRATEGY, DESIGN, AND METHODOLOGY …....................................97

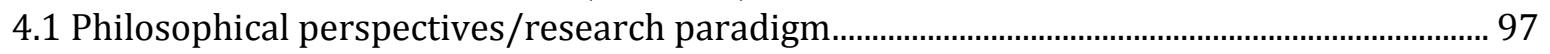

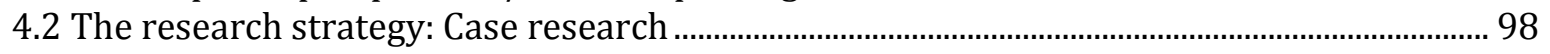

4.2.1 Case design: Single case (embedded) design .....................................................................100 
4.2.2 The unit of analysis

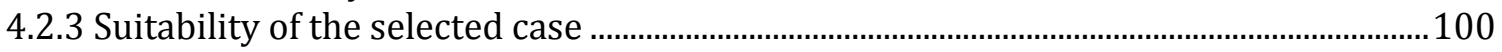

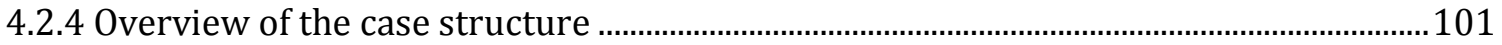

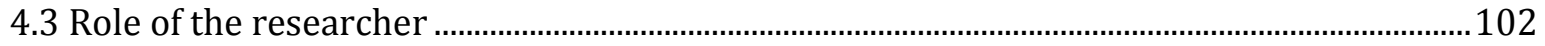

4.4 Methodology, research design and process ……............................................................................103

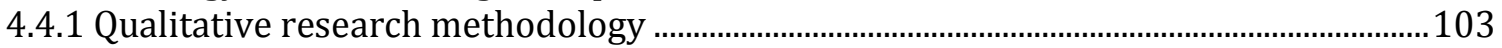

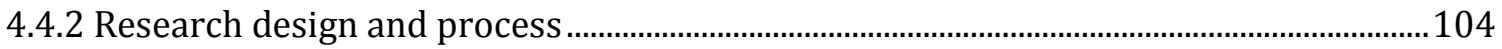

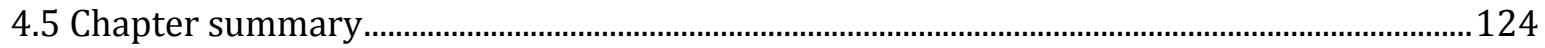

CHAPTER 5: MACRO-LEVEL FACTORS - SOCIAL AND CULTURAL, GOVERNMENTAL, AND

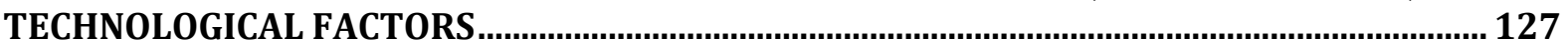

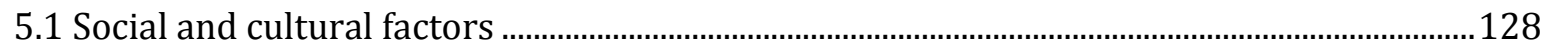

5.1.1 Readiness to move into student-centred e-learning ..........................................................129

5.1.2 Acceptance of e-learning programmes in Sri Lankan society ..........................................136

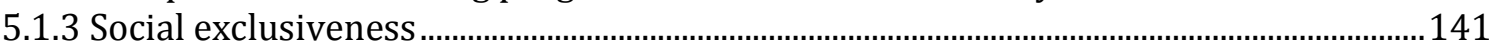

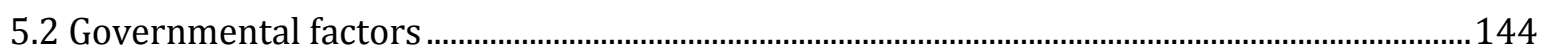

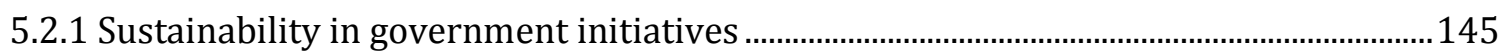

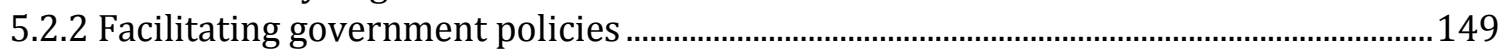

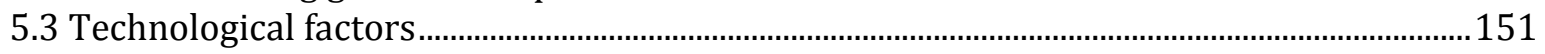

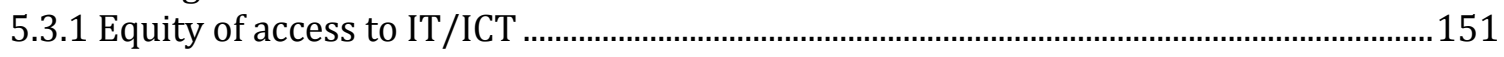

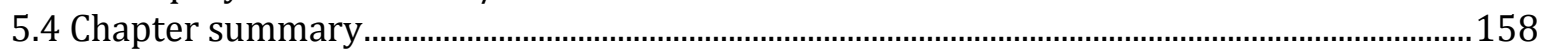

CHAPTER 6: MESO-LEVEL FACTORS - PEDAGOGICAL CHANGE, STAFF AND OTHER

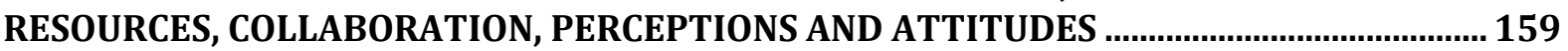

6.1 Pedagogical change (from instructivist to constructivist-based e-learning) .......................159

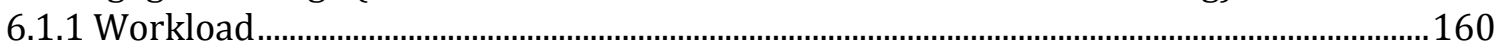

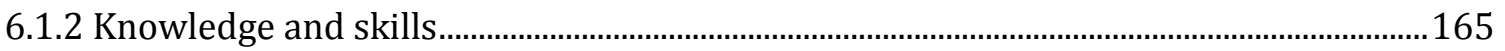

6.2 Human and other resources needed to facilitate e-learning...................................................174

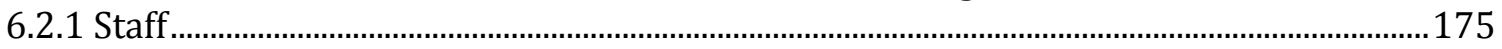

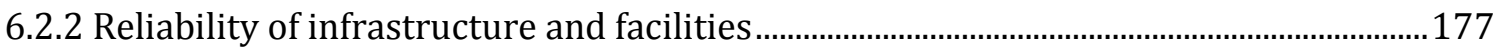

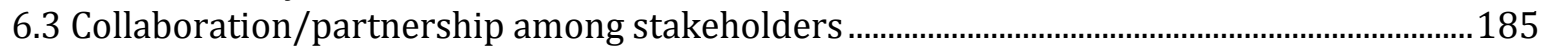

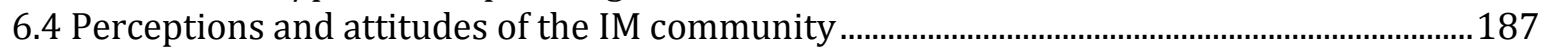

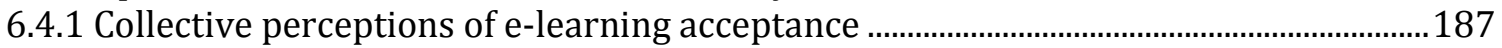

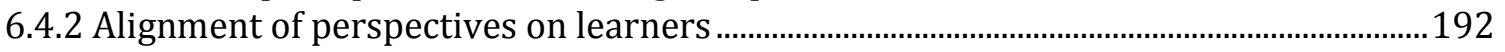

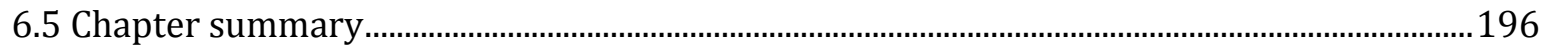

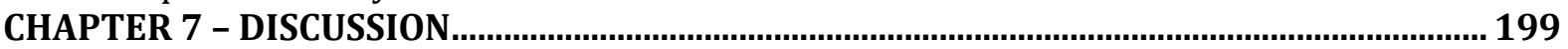

7.1 The contextual factors that have an impact on the introduction and use of e-learning in tertiary-level IM education in Sri Lanka............................................................................................199

7.2 How contextual factors affect the introduction and use of e-learning in tertiary-level IM

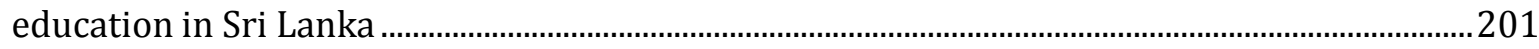

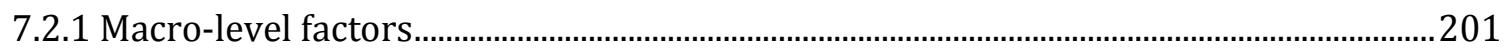

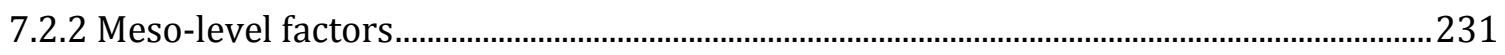

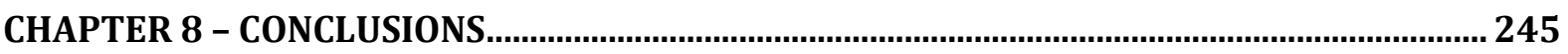

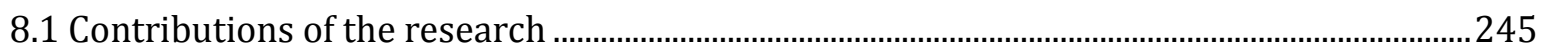

8.1.1 Practical contribution to the Sri Lankan education system and government ................250

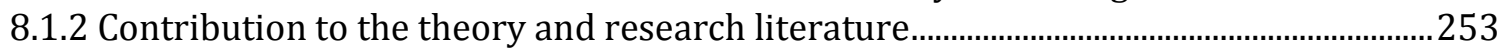

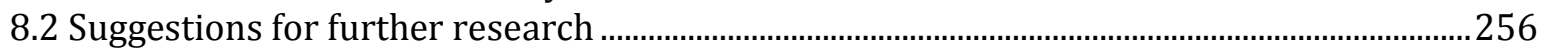

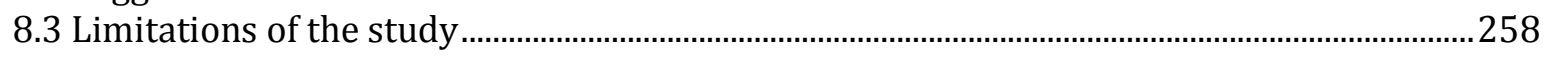

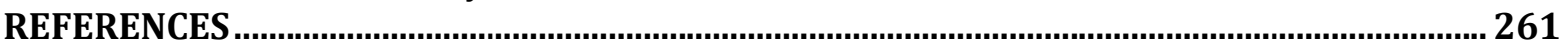


Appendix 1 Selected relevant studies that have cited Fullan's educational change theory ........287

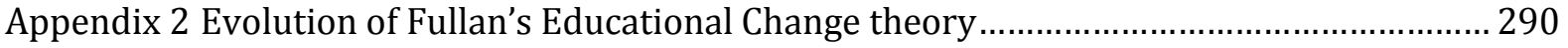

Appendix 3 Evolution of Hofstede's Cultural Dimensions.................................................. 291

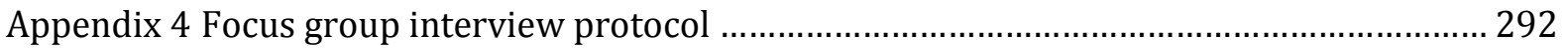

Appendix 5 Solutions in order to troubleshoot some problems while researcher is conducting

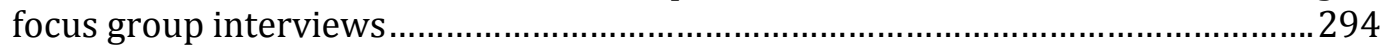

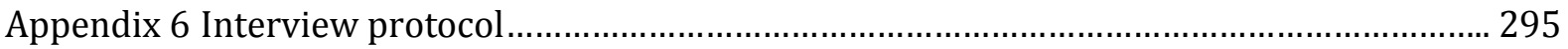

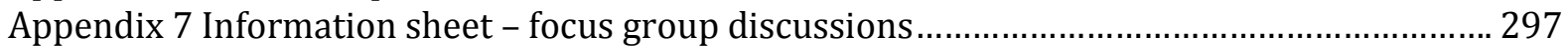

Appendix 8 Consent to Participation in Research (Focus Group Discussions) ........................... 301

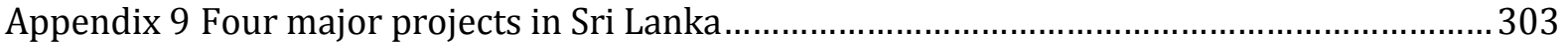

Appendix 10 Core activities of the specialized functional areas of Staff Development...............307

\section{List of Tables}

Table 1.1 - Key terms and definitions.......

Table 2.1 - Key statistics on availability of computers at home, use of home computers, email and internet services in Sri Lanka, 2009................................................. 24

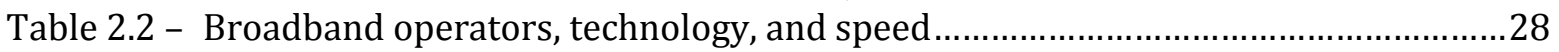

Table 2.3 - Universities and higher education institutes in Sri Lanka........................................33

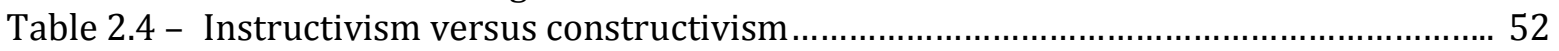

Table 2.5 - Bandwidth and e-learning application ................................................................58

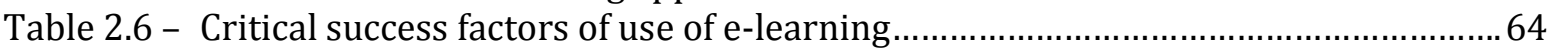

Table 3.1 - Overview of Elsworth's (2000) review of seven change frameworks and models 69

Table 3.2 - Influence of Hofstede's six cultural dimensions on other studies....................... $\quad 79$

Table 3.3 - Hofstede's six cultural dimensions ................................................................ 84

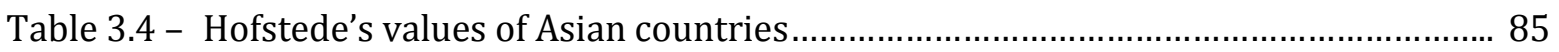

Table 3.5 - Identifying overlaps among the factors from the literature review and theories...88

Table 3.6 - Key differences between low and high power distance societies related to school91

Table 3.7 - Key differences between collectivist and individualist societies related to school \& ICT.

Table 3.8 - Key differences between weak and strong uncertainty avoidance societies related to education

Table 3.9 - Key differences between short-term and long-term orientation societies related

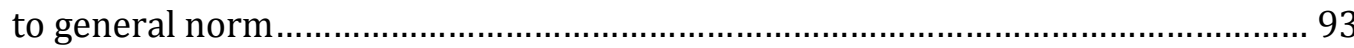

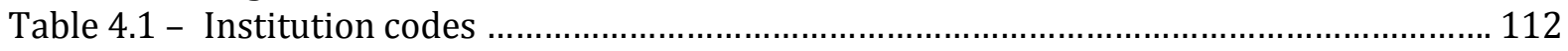

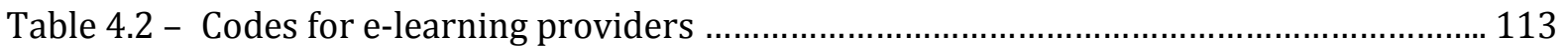

Table 4.3 - Characteristics of stratified purposeful sample - IMEP .......................................... 115

Table 4.4 - Characteristics of stratified purposeful sample - EEP ........................................... 115

Table 4.5 - Characteristics of stratified purposeful sample - Stakeholders............................... 116

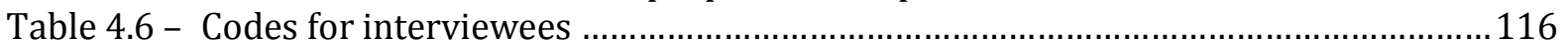

Table 4.7 - Example of Excel worksheet of data analysis........................................................ 122

Table 5.1 - Summary of the perceptions about social and cultural influences

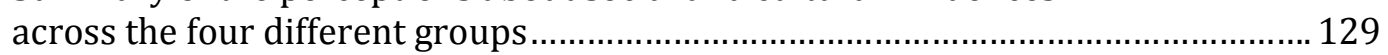

Table 5.2 - Summary of the perceptions of governmental factors........................................... 144

Table 5.3 - Summary of the perceptions of technological influences........................................151

Table 6.1 - Summary of the perceptions of lack of enthusiasm for change of pedagogy ............160

Table 6.2 - Summary of the perceptions of lack of human and other resources.........................175

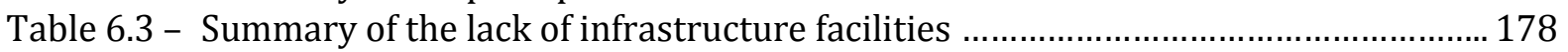

Table 6.4 - Summary of the perceptions and attitudes of the IM community ............................. 187

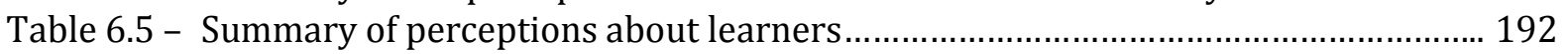

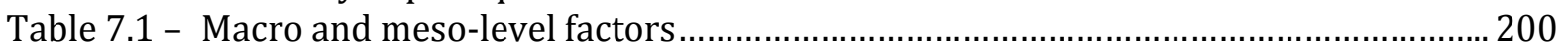


Table 7.2 - Nenasala involvement in the development Interventions of the community (ICTA,

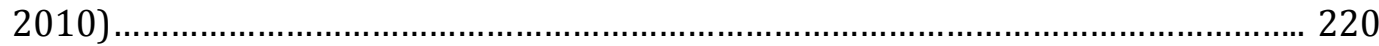

Table 7.3 - Nenasala services used by Nenasala users (ICTA, 2010)........................................220

Table 7.4 - Distribution of Nenasala and NODES access centres across the country ............... 225

Table 8.1 - Factors that have an impact on the introduction and use of e-learning.................. 247

\section{List of Figures}

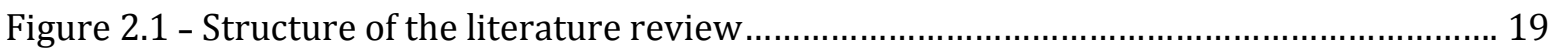

Figure 2.2 - T-shaped information managers...................................................................... 22

Figure 2.3 - Desktop or laptop computer-owning households (percentage) by sector: 2006/07 \& 2009

Figure 2.4 - Household population aged 5-69 years who were computer literate and who

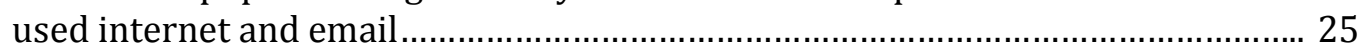

Figure 2.5 - e-Sri Lanka programme components............................................................... 26

Figure 2.6 - Internet and email subscribers growth (fixed and mobile) in Sri Lanka 1996-2014 Jun.

Figure 2.7 - Organizational structure showing three stages of the Sri Lankan education

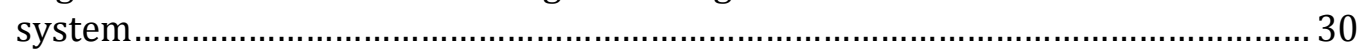

Figure 2.8 - The structure of the higher education sector in Sri Lanka....................................... 32

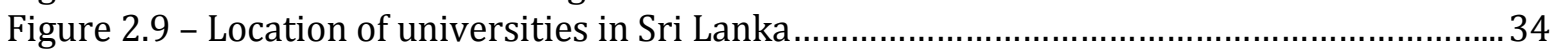

Figure 2.10 - Gap between students qualifying the A/L examination and students selected for

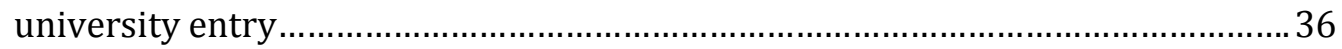

Figure 2.11 - Map of Sri Lanka which indicates long distances between IM educational centres

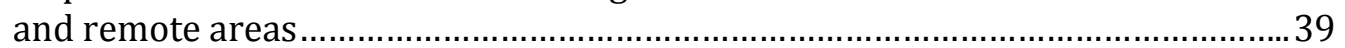

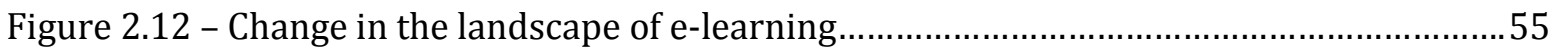

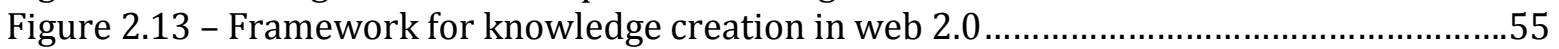

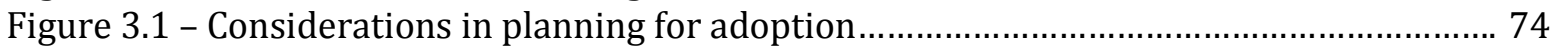

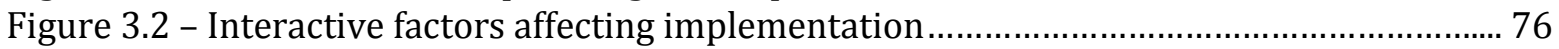

Figure 3.3 - Conceptual model of factors that might have an impact on the introduction of elearning in tertiary-level IM education in Sri Lanka............................................... 87

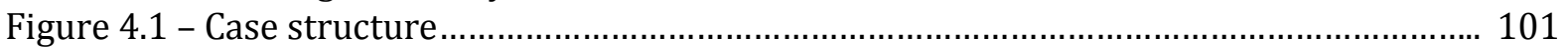

Figure 4.2 - Hutter-Hennink qualitative research cycle ....................................................... 104

Figure 4.3 - Overview of the proposed research design and data collection............................. 106

Figure 4.4 - The data analysis framework..................................................................... 120

Figure 5.1 - Outline of the Chapter 5 - Macro-level factors.................................................... 128

Figure 5.2 - Households population aged 5 - 69 years (\%) who used internet/ email by age group - 2009............................................................................................ 142

Figure 6.1 - Outline of Chapter 6 - Meso-level factors........................................................... 159

Figure 6.2 - Comparison of appropriation bills 2014 .......................................................... 184

Figure 7.1 - Summary of social and cultural factors (including within-level and cross-level

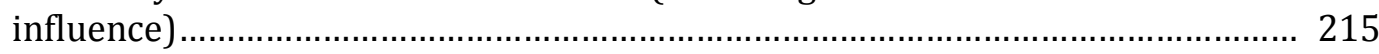

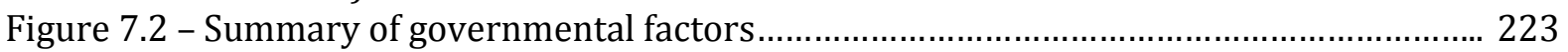

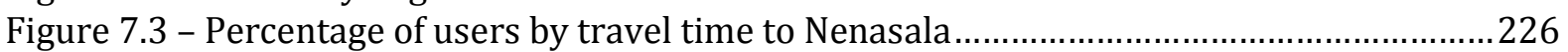

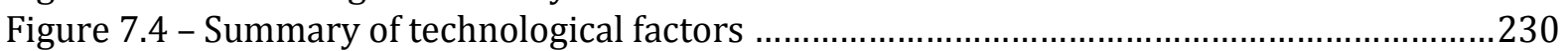

Figure 7.5 - Technological Pedagogical Content Knowledge (TPCK)........................................ 237

Figure 7.6 - Summary of organizational factors (including within-level and cross-level influence)

Figure 8.1 - Contextual model of factors that affect introduction and use of e-learning

Figure 8.2 - This study's contribution to Fullan's simplified overview of the change process...255 


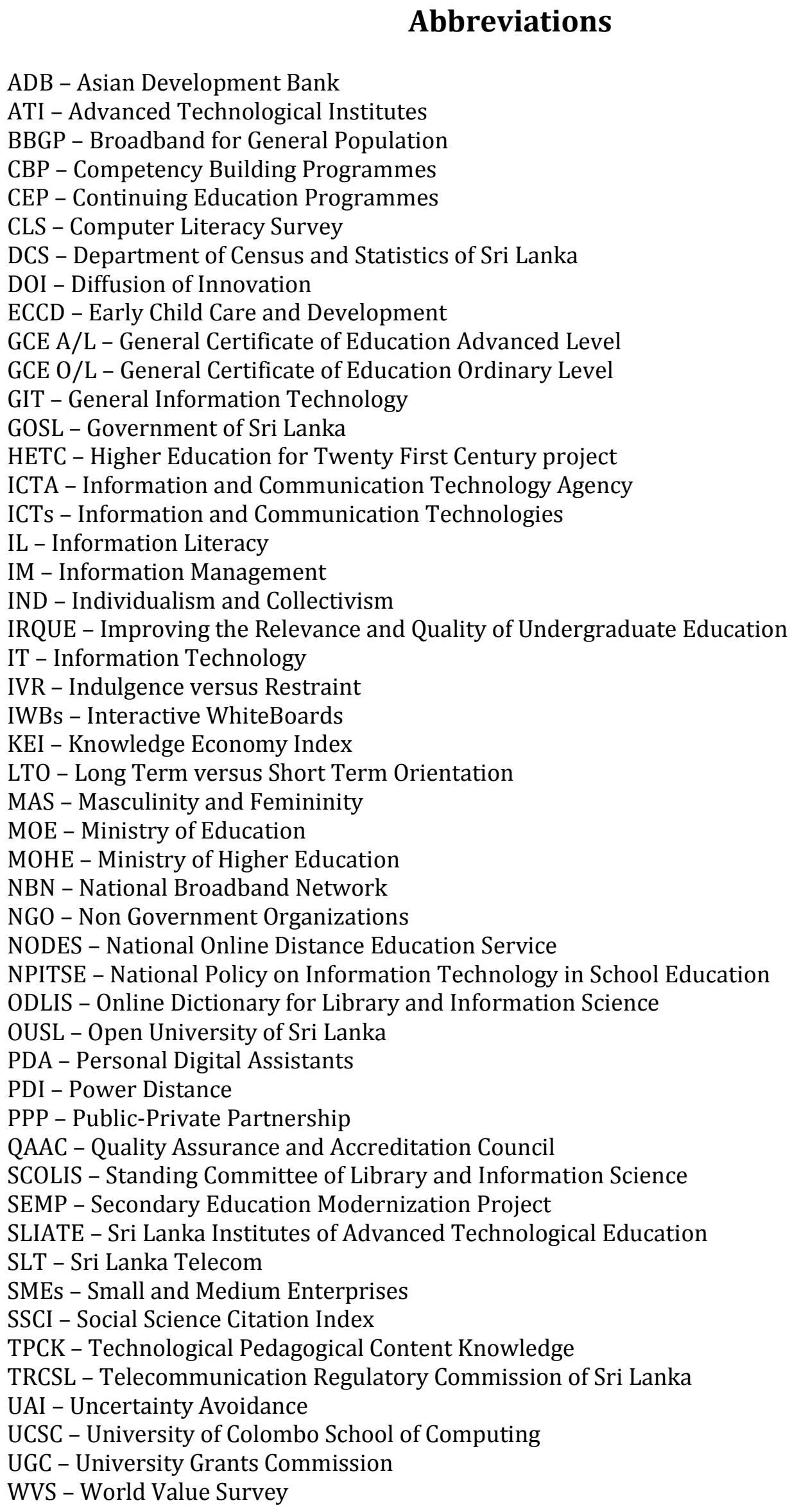

Abbreviations

ADB - Asian Development Bank

ATI - Advanced Technological Institutes

BBGP - Broadband for General Population

CBP - Competency Building Programmes

CEP - Continuing Education Programmes

CLS - Computer Literacy Survey

DCS - Department of Census and Statistics of Sri Lanka

DOI - Diffusion of Innovation

ECCD - Early Child Care and Development

GCE A/L - General Certificate of Education Advanced Level

GCE O/L - General Certificate of Education Ordinary Level

GIT - General Information Technology

GOSL - Government of Sri Lanka

HETC - Higher Education for Twenty First Century project

ICTA - Information and Communication Technology Agency

ICTs - Information and Communication Technologies

IL - Information Literacy

IM - Information Management

IND - Individualism and Collectivism

IRQUE - Improving the Relevance and Quality of Undergraduate Education

IT - Information Technology

IVR - Indulgence versus Restraint

IWBs - Interactive WhiteBoards

KEI - Knowledge Economy Index

LTO - Long Term versus Short Term Orientation

MAS - Masculinity and Femininity

MOE - Ministry of Education

MOHE - Ministry of Higher Education

NBN - National Broadband Network

NGO - Non Government Organizations

NODES - National Online Distance Education Service

NPITSE - National Policy on Information Technology in School Education

ODLIS - Online Dictionary for Library and Information Science

OUSL - Open University of Sri Lanka

PDA - Personal Digital Assistants

PDI - Power Distance

PPP - Public-Private Partnership

QAAC - Quality Assurance and Accreditation Council

SCOLIS - Standing Committee of Library and Information Science

SEMP - Secondary Education Modernization Project

SLIATE - Sri Lanka Institutes of Advanced Technological Education

SLT - Sri Lanka Telecom

SMEs - Small and Medium Enterprises

SSCI - Social Science Citation Index

TPCK - Technological Pedagogical Content Knowledge

TRCSL - Telecommunication Regulatory Commission of Sri Lanka

UAI - Uncertainty Avoidance

UCSC - University of Colombo School of Computing

UGC - University Grants Commission

WVS - World Value Survey 


\section{CHAPTER 1 - INTRODUCTION TO THE STUDY}

\subsection{Introduction}

In this Chapter, I outline the background to the research problem, research objectives, and research questions. Next, the significance and benefits of this study are described. I also define key terms that are used in this study. Following the delimitation of the scope of this research, I outline the organization of the remainder of the thesis.

\subsection{Background to the research problem}

This section outlines the contextual issues underpinning the problem. The final part of this section summarizes the problem of concern in this study.

\subsubsection{Growing need for skilled information managers}

Information is considered a fundamental resource for improving the quality of governance and promoting socio-economic development in developing countries (Goswami \& Jain, 2008; Kularatne, 1997; Meso, Musa, Straub, \& Mbarika, 2009; SrakuLartey, 2006). In Sri Lanka, information is rapidly growing as a result of governmental development initiatives (Wijetunge, 2011). For example, e-Sri Lanka, a national development project which includes a focus on rural development, meets a variety of information needs, while development initiatives in the service sector are raising the value of information as a commodity. Moreover, in the education sector there is a growing emphasis on resource-based independent learning, an approach that requires welldeveloped library and information services. Under these circumstances, the social responsibility of the information management sector has increased. There is therefore an increasing need for educated, skilled information managers to fulfil the growing information needs of the Sri Lankan citizens.

In this study Information Management (IM) refers to "management and control of the full lifecycle of the information process: acquisition, organization, storage, retrieval, access/lending, and dissemination" (Wilson, 2005) (See section 2.1.1 for full discussion of definition of IM). 


\subsubsection{Current issues in information management education in Sri Lanka}

In Sri Lanka, under the government's vision of higher education, Information Management (IM) education is seen as important for fostering the development of a high quality, market oriented, and knowledge-based society. Tertiary providers of IM education in Sri Lanka aim to provide education for their students in order to produce well educated, skilled and competent personnel necessary to deliver IM services in the country. These providers target two populations: tertiary-level diploma and degree level full-time students and part-time students who are full-time information workers in the information industry. However, a number of barriers currently restrict access to IM education by Sri Lankan information workers.

There are three providers of tertiary-level IM education in Sri Lanka, all in the greater Colombo area (Singh \& Wijetunge, 2006). The provision of IM education is limited to faceto-face teaching at three institutions in the Colombo (capital city) area, and the country's physical infrastructure makes it difficult for full-time workers to attend classes without missing substantial work time. For example, the long distances between the centre and peripheral areas of the country are a challenge in terms of geography, time and money (Wijetunge \& Willson, 1998). This results in IM employer reluctance to support education. Further, there is a lack of parity between education facilities for full-time students and information workers. For example, teaching institutions are not providing practical training or library facilities for information workers while all the facilities are available to full-time students (Wijetunge \& Willson, 1998). Hence there is a growing need for providing equity of access to IM education.

\subsubsection{Need to develop a Sri Lankan tertiary education system relevant to the labour market need}

The Sri Lankan government has identified its vision of higher education in the country as helping "Sri Lanka to be an international hub of excellence for higher education by 2020" (Ministry of Higher Education of Sri Lanka, 2015b). Under this vision, all public and private universities as well as other tertiary education institutions have identified a need to produce skilful, competent, and well-educated professionals for Sri Lanka. IM personnel can be seen as falling within one of these professional categories. 
However, Sri Lanka's tertiary education system has been unable to meet the labour market's needs (World Bank, 2007, 2009). As a result, the World Bank suggests a number of solutions to develop Sri Lankan university education to become relevant to the labour market need. For example, the World Bank (2007) suggests that Sri Lankan universities need to make their education system:

more demand driven, quality conscious and forward looking' by 'empowering institutions (with full accountability), utilizing resources optimally, mobilizing additional financial resources, establishing effective quality assurance mechanisms, facilitating the networking of institutions to enhance capacity, improve quality, and promote excellence, establishing better and closer linkages with industry and the community, and increasing access and reducing regional imbalances. (World Bank, 2007, p. 62)

The World Bank (2009) also suggests strategic initiatives for the development of the higher education sector that would make it more responsive to the needs of the labour market. One of these initiatives is expansion of access to higher education in areas of economic and social importance. Another is improving teaching and learning in higher education by strengthening the skills of academic staff in student-centred and activitybased teaching. However, as Sri Lanka is a developing country it is unclear how it can carry out these suggestions because it has limited resources. Specifically in the context of IM education, it is unclear how to establish better and closer linkages with the IM industry, increase access to IM education and reduce regional imbalances, and improve IM education.

\subsubsection{Drive for e-learning in IM in Sri Lanka}

In other contexts, e-learning has been used to solve problems similar to those faced by Sri Lankan tertiary-level IM education: for example, by increasing equity of access to education as well as improving quality of education. Various studies have shown that elearning is capable of: widening access to education (Engelbrecht, 2003; Fry, 2001; Gulati, 2008; Inglis, 1999; R. Oliver, 1999; Rajasinghham, 2009b; Ruiz, Mintzer, \& Leipzig, 2006; Siritongthaworn \& Krairit, 2006), improving social and educational equity (Gladieux \& Swail, 1999), reducing costs (Salmon, 2005; "What is electronic learning," n.d.), improving quality of learning (T. Bates, 2009; Fernando, 2008; Siritongthaworn, Krairit, Dimmitt, \& Paul, 2006), providing flexible learning (Bates, 2001; Collis \& Moonen, 2001; Collis \& van der Wende, 2002; Sun, Tsai, Finger, Chen, \& Yeh, 2008), and maintaining 
interactive learning (Garrison \& Anderson, 2003; Katz, 2002, 2000; Trentin, 1997). It seems e-learning has the potential to address the issues of tertiary-level IM education in Sri Lanka.

In this study e-learning refers to "learning and teaching that is facilitated by or supported through the smart use of information and communication technologies (ICTs)" (Ministry of Education of New Zealand, 2006, p. 2). The definitions of e-learning can be seen as comprising a spectrum. At one extreme is e-learning as a transmission mode based around instruction, emphasizing delivery of knowledge. At the other extreme is elearning as a facilitator of collaborative learning based around construction, emphasizing creation of knowledge. I will discuss these opposing views in section 2.3.2.

The next section discusses the research problem.

\subsection{Problem statement}

The Quality Assurance \& Accreditation Council (QAAC) of the University Grants Commission (UGC) in Sri Lanka was established to achieve excellence in higher education and to contribute to the government's vision for higher education in Sri Lanka. In order to redress the barriers to IM education and in response to the World Bank reports (2007, 2009) the QAAC of Sri Lanka has specific aims to foster transformative change in IM education with the goal of increasing equality of access to IM education through the use of e-learning. For example, in a 2008 departmental review of one tertiary-level IM education provider organization, QAAC recommended that it should "take necessary steps to commence e-learning courses for both internal and external students" (Quality Assurance and Accreditation Council (QAAC), 2008). However, it remains unclear what 'the necessary steps' might be and whether they are being taken. This is underpinned by a lack of knowledge about what factors affect e-learning development and what the barriers or enablers might be. A number of early attempts to implement e-learning in Sri Lanka have already failed. For example, a few universities have transformed their traditional face-to-face learning into e-learning, such as the Open University of Sri Lanka (OUSL) since 1999 and the University of Colombo School of Computing (UCSC) since 2002. However, Andersson (2008, p. 29) found through reviewing the eBIT course at UCSC that the dropout rate is higher in e-learning courses than traditional classroom based courses. This is because of the lack of understanding of how to use e-learning in the 
Sri Lankan context. Existing research has shown that context must be understood in order to successfully implement e-learning (Siritongthaworn et al., 2006).

The problems addressed in this research are two-fold: (1) there is no rigorous research that investigates what factors have an impact on the introduction and use of e-learning in tertiary-level IM education in the Sri Lankan context, and (2) there is a lack of understanding of how these significant factors affect the introduction and use of elearning in tertiary-level IM education in Sri Lanka. For tertiary providers of IM education to plan and adopt e-learning in order to improve IM education for their students and to achieve the government's vision of higher education in Sri Lanka, these problems need to be addressed.

\subsection{Research objectives}

In view of this research problem, this study has two objectives:

1. To understand the contextual factors that have significant impact on the introduction and use of e-learning in tertiary-level IM education in Sri Lanka.

2. To understand how these significant factors affect the introduction and use of elearning in tertiary-level IM education in Sri Lanka.

The expected outcome of this study is to develop a contextual model of factors that affect the introduction and use of e-learning in tertiary-level IM education in Sri Lanka.

\subsection{Research questions}

This study addresses the following research questions:

1. What are the contextual factors that have significant impact on the introduction and use of e-learning in tertiary-level IM education in Sri Lanka?

2. How do these factors affect the introduction and use of e-learning in tertiarylevel IM education in Sri Lanka?

\subsection{Significance and benefits of the study}

This study aims to contribute to understanding how the identified contextual factors affect the introduction and use of e-learning which may also resonate with conditions in other developing countries with similar social and cultural backgrounds, such as India, 
Nepal, Vietnam, Myanmar, and Maldives. Also, this understanding of factors may be of assistance to the Sri Lankan higher education system to improve teaching and learning by identifying the support and skills that academic staff need to prepare for studentcentred and activity-based teaching.

This study will help IM organizations as well as higher education systems to have a clear understanding of how e-learning will work and which factors need to be considered in order to develop appropriate policies and strategies, and to plan for funds and resource allocations.

To date, no empirical research has been conducted about e-learning in IM education in Sri Lanka.

The contextual model of factors needs to be developed and can be used by tertiary-level IM education provider organizations as well as others to understand barriers and enablers when planning and adopting e-learning in their organizations.

The government of Sri Lanka (GOSL) has introduced e-Sri Lanka, a major national development project (discussed in section 2.2.1.2). It consists of six programmes: i) Information and Communication Technology (ICT) policy, leadership, and capacity building, ii) the information infrastructure, iii) re-engineering government, iv) ICT Human Resource (HR) capacity building, v) ICT investment and private sector development, and vi) e-society. This research may have useful implications for some of the areas in the e-Sri Lanka national development project.

\subsection{Definitions of key terms}

Definitions for the key terms used in this study are listed below (See Table 1.1). The terms of e-learning and IM are examined in depth in Chapter 2. 


\begin{tabular}{|ll|}
\hline Term & Definition used in this research \\
& $\begin{array}{l}\text { Learning and teaching that is facilitated by or supported } \\
\text { through the smart use of information and communication } \\
\text { technologies (ICTs) (Ministry of Education of New Zealand, } \\
\text { 2006, p. 2) }\end{array}$ \\
\hline $\begin{array}{l}\text { Information Management } \\
\text { (IM) }\end{array}$ & $\begin{array}{l}\text { Management and control of the full lifecycle of the } \\
\text { information process: acquisition, organization, storage, } \\
\text { retrieval, access/lending, and dissemination (Wilson, } \\
\text { 2005) }\end{array}$ \\
\hline $\begin{array}{l}\text { Information Management } \\
\text { Education }\end{array}$ & $\begin{array}{l}\text { Information management education is a relatively new } \\
\text { discipline that has emerged from the fields of Library } \\
\text { Science, Computer Science, and Information Systems. It } \\
\text { aims to teach the competencies of managing information, } \\
\text { disseminating and delivering information, sourcing } \\
\text { information, and understanding user requirements } \\
\text { (Gorman \& Corbitt, 2002, p. 437) }\end{array}$ \\
\hline $\begin{array}{l}\text { A person who works full-time in the information industry } \\
\text { such as libraries, information centres, and media centres }\end{array}$ \\
\hline Stakeholder
\end{tabular}

Table 1.1 - Key terms and definitions

\subsection{Delimitations of scope}

This study seeks to explore and understand various factors that have significant impact on the introduction and use of e-learning in tertiary-level IM education in Sri Lanka. Thereby this research aims to develop a contextual model of factors to help guide the introduction and use of e-learning in tertiary-level IM education in Sri Lanka (it does not aim to prescribe the mechanism for implementing e-learning in IM education or to develop predictive theory).

Sri Lanka has a multi-ethnic and multi-religious population. The major ethnic group is Sinhalese. The remainder are Sri Lankan Tamil, Indian Tamil, Sri Lankan Moor and others (Department of Census and Statistics of Sri Lanka, 2012). Buddhism is the dominant religion, but there are other religions (Hinduism, Islam, and Roman Catholic and other forms of Christianity). However, I used higher level national culture as a lens for this study to explore and understand national cultural influence on the introduction and use of elearning in tertiary-level IM education in Sri Lanka rather than examining sub-cultures in detail. 


\subsection{Organization of this thesis}

This thesis is organized into nine Chapters. In the next Chapter, I review and synthesize the research literature that is relevant to this study.

Based on insights from theories and other key resources from the literature review, a conceptual model for this study is presented and described in Chapter 3.

In Chapter 4, I discuss the research strategy, design, and methodology including an overview of the institutions and individual participants of this study.

In the fifth and sixth Chapters, I present the study findings. Chapter 7 synthesizes and discusses the findings presented in Chapters 5 and 6.

In Chapter 8, I present the revised contextual model of factors, theoretical and practical implications and suggest areas for future research. 


\section{CHAPTER 2 - LITERATURE REVIEW}

This integrative literature review consists of three main sections. The first section considers the growing need for skilled information managers. The second section discusses Sri Lanka and its higher education system, particularly tertiary-level IM education. The last section provides rationales for using e-learning in tertiary education including key issues of e-learning. The literature review's structure is illustrated in more detail in Figure 2.1.

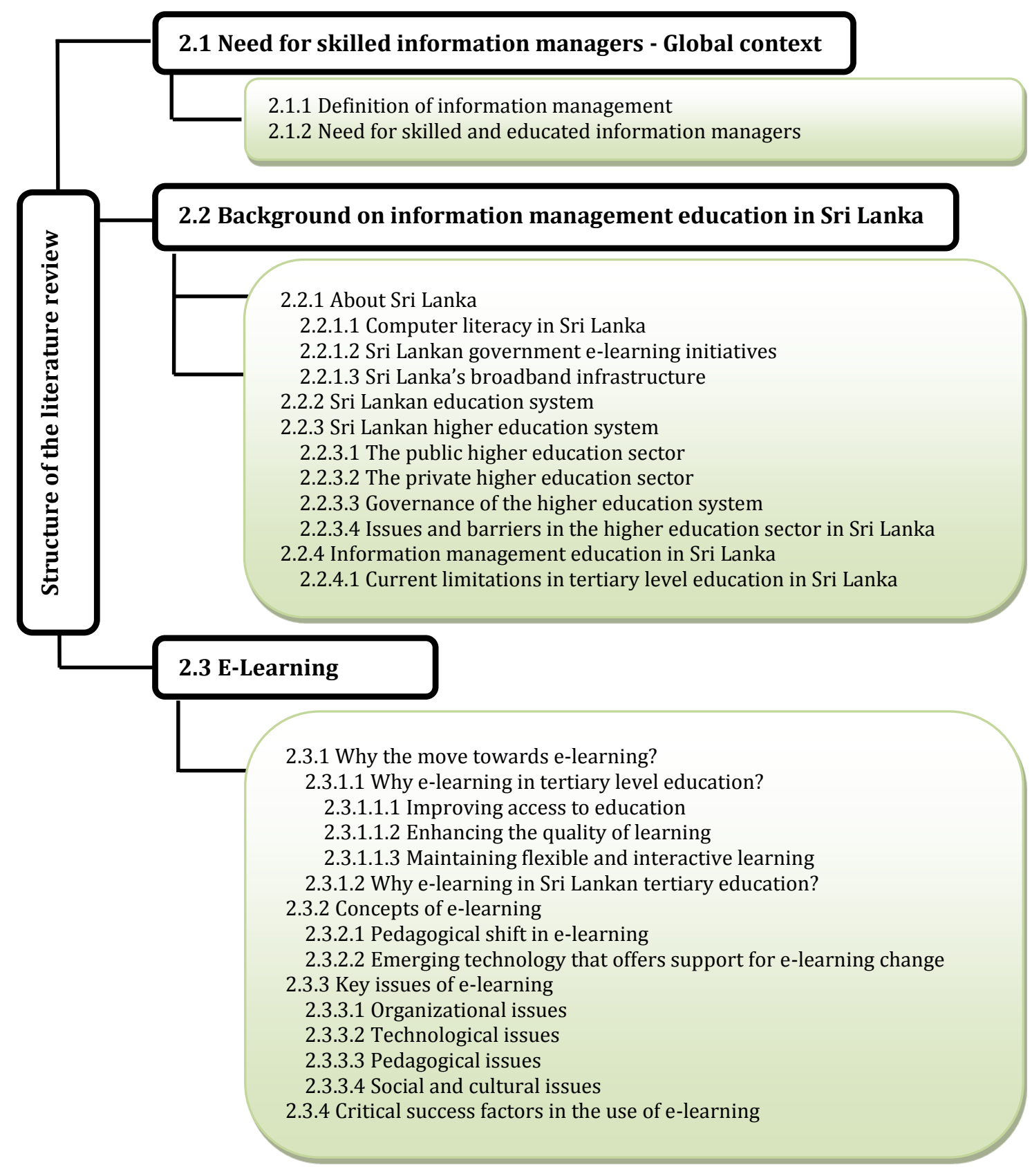

Figure 2.1 - Structure of the literature review 


\subsection{Need for skilled information managers - Global context}

\subsubsection{Definition of information management}

Information management (IM) is a broad conceptual term that has been defined differently by various authors, researchers, and educators. They have used different aspects and perspectives to define IM. Commonly used aspects/perspectives are IM's technical aspects (Somogyi \& Galliers, 1994), the concept of information resource management (Watson \& Omrani, 1988), its position within the 'business' domain (Galliers \& Baker, 1994), the nexus between business and technology (Earl, 1989; Skyrme \& Earl, 1990), the organizational, library, and personal perspectives (Detlor, 2010), and the process view of IM. The process-driven view is applied in this study because this study is looking at information management education. Therefore, understanding processes is important.

The process perspective on IM emerged in the early 1990s (Davenport, 1993; McGee \& Prusak, 1993) and advocates that a process model of information management should include all or some parts of the information value-chain or lifecycle (Detlor, 2010). The following definitions of IM demonstrate a process of information lifecycle.

In Harrod's Librarian's Glossary and Reference Book, Prytherch (2000) uses the term IM to mean the various activities that contribute to the effective production, co-ordination, storage, retrieval, and dissemination of information. This information could be represented in any format from internal or external sources that lead to more successful, efficient, and effective functioning of the organization (p. 372). In the Online Dictionary for Library and Information Science (ODLIS), Reitz (2010) defines IM as "the skilful exercise of control over the acquisition, organization, storage, security, retrieval, and dissemination of the information resources essential to the successful operation of a business, agency, organization or institution including documentation, records management and technical infrastructure". In addition, Detlor (2010) uses IM to mean "the management of the processes and systems that create, acquire, organize, store, distribute, and use information" (p. 103). The above three definitions imply information management is at least six discrete information related processes that need to be managed. Wilson (2005) identifies these processes as i) acquisition, ii) organization, iii) storage, iv) retrieval, v) access/lending, and vi) dissemination. 
It seems then, that IM concerns the management and control of the full lifecycle of the information process, ranging from creation to use. The next section discusses the need for skilled and educated information managers in the field.

\subsubsection{Need for skilled and educated information managers}

Information is a fundamental resource in developing countries (Kularatne, 1997; Meso et al., 2009; Sraku-Lartey, 2006) in terms of improving quality of governance and socioeconomic development (Kularatne, 1997; Meso et al., 2009). On the other hand, information is essential to all organizations for their success (Cairns, 1994; Karim \& Hussein, 2008; Kaye, 1995). For example, good quality information improves decisionmaking, enhances efficiency and also allows organizations to gain competitive advantages (Karim \& Hussein, 2008). Therefore, most organizations are looking for ways to effectively seek and handle information about their internal and external environments (p. 114).

In recent years, the amount of information available has increased exponentially (Omekwu, 2006) due to the "development of powerful telecommunications and computer systems, and by global trading coupled with increased competition and the freeing of markets" (p. 6). Moreover, the rapid expansion of large-scale digital libraries, database management systems, multimedia information systems and internet resources and services has also contributed to increasing the quantity of information (Omekwu, 2006). Therefore, managing information is not an easy task. As a result, users face problems of interpreting and digesting these data as well as complexity and uncertainty (p. 849). Since there are increasing problems of information overload and timely, accurate retrieval (Skyrme, 2004) the responsibilities of information managers/information professionals have increased (Skyrme, 2004; Smythe, 1999).

Information managers are one of the new information professional groups (Cairns, 1994; Feather, 2004) in the field of IM. Primarily, they select and classify information and provide access to information at the users' request (Jaen, Bohigas, \& Novell, 2007). However, information managers require diverse skills, new thinking, and broadened perspectives since they face rapidly changing corporate, regulatory, and technical challenges (Smythe, 1999). Further, they are required to develop innovative ideas, assume leadership roles, disseminate information widely and demonstrate good 
management practices to successfully tackle current and future issues (p. 44). This view is endorsed by Sraku-Lartey (2006) who claims that new information managers require a new level of skills, capabilities and talents to provide a better service to users because the effective management of information is dependent upon their quality and skills (p. 75). Asgary and Van den Heuvel (2013) argue that there is a direct and urgent need for T-shaped information managers with cross-domain knowledge and specialized knowledge (See Figure 2.2).

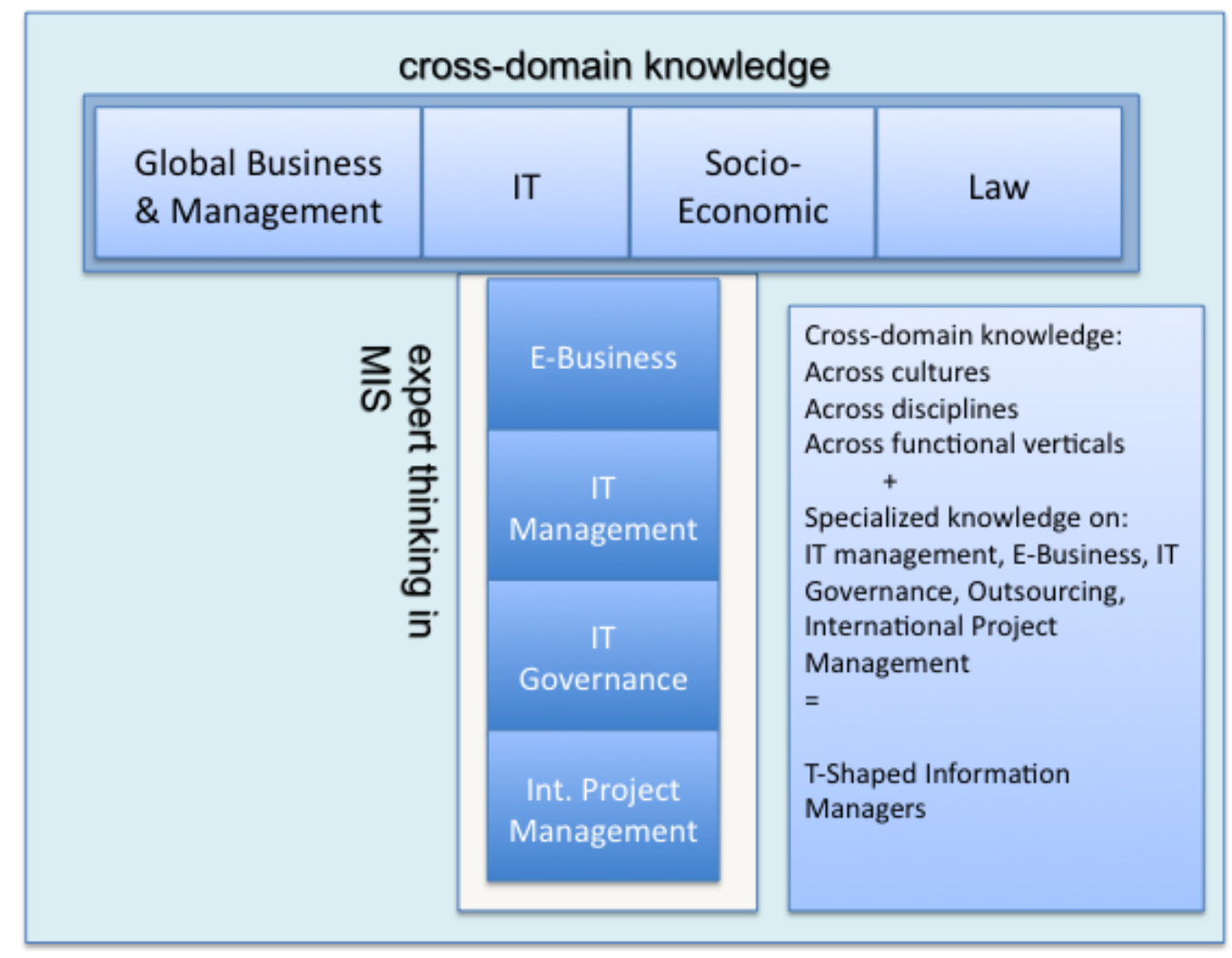

Figure 2.2 - T-shaped information managers (Asgary \& Van den Heuvel, 2013, p. 151)

These requirements highlight the need for skilled and educated information managers in the field as well as emphasizing the importance of information management education because it is important for students to become knowledgeable and skilled information managers. Moreover, there is a need for information managers to keep their professional knowledge current (Huwe, 2004) since "no professional degree programme in the world can impart the learning to be sufficient forever" (Ameen, 2011, p. 174). Ameen further argues that learning must remain continuous to keep professional knowledge up-to-date and it is a responsibility of both individuals and their employers (p. 174). Consequently, 
IM education is important to produce skilled and educated information managers and thereby to face the current and future challenges in the field of IM.

The next section discusses IM education in Sri Lanka.

\subsection{Background on information management education in Sri Lanka}

Since this research is qualitative and focuses on tertiary-level IM education in Sri Lanka, it is important to understand the relevant background information. Therefore, this section gives a brief introduction to Sri Lanka, including the country itself, the background of the Sri Lankan higher education system, tertiary-level information management education in the country and issues and problems in IM education in Sri Lanka.

\subsubsection{About Sri Lanka}

The formal name of Sri Lanka is the Democratic Socialist Republic of Sri Lanka, formerly known as 'Ceylon'. The administrative capital city is Sri Jayawardenapura Kotte which is five kilometres away from Colombo, the biggest and commercial capital city. Sri Lanka is approximately 65,610 square kilometres, around four times smaller than New Zealand. According to a recent census of population and housing, the population of Sri Lanka was 20,277,597 (Department of Census and Statistics of Sri Lanka, 2012). This is four and a half times larger than the population of New Zealand. With a literacy level of $95.6 \%$ Sri Lanka has one of the most literate populations in the South Asian region (Central Bank of Sri Lanka, 2014). Since the end of the civil war in mid-2009, Sri Lanka has been categorized as a middle-income country by the International Monetary Fund (Asian Development Bank, 2009). Moreover Sri Lanka ranks 101st in the Knowledge Economy Index (KEI) out of 145 countries (World Bank, 2012) and highest in KEI in the South Asian region.

Sri Lanka has a multi-ethnic and multi-religious population. The majority ethnic group is Sinhalese. Others are Sri Lankan Tamil, Indian Tamil, Sri Lankan Moor, Burgher, Malay and Veddha (Department of Census and Statistics of Sri Lanka, 2012). Buddhism is the dominant religion, but there are others including Hinduism, Islam and Christianity. Over $86 \%$ of Sri Lankans currently live in rural areas while $14 \%$ of the population lives in urban areas (Department of Census and Statistics of Sri Lanka, 2012). 


\subsubsection{Computer literacy in Sri Lanka}

The fourth household Computer Literacy Survey (CLS), conducted by the Department of Census and Statistics of Sri Lanka (DCS) in 2014, reported that on average at least one computer (desktop or laptop) was available in one out of every five households in Sri Lanka, i.e., the percentage of households having computers in Sri Lanka was $22.4 \%$. The urban sector had the highest percentage of households with computers (37.5\%). This is higher than in the rural sector, with only $20.1 \%$ (see Table 2.1 ).

\begin{tabular}{|l|c|c|c|}
\hline \multicolumn{1}{|c|}{ Indicators } & \multicolumn{3}{c|}{ Percentage } \\
\cline { 2 - 4 } & $\mathbf{2 0 0 6 / 0 7}$ & $\mathbf{2 0 0 9}$ & $\mathbf{2 0 1 4}$ \\
\hline Households having computers (national) & 8.2 & 11.4 & 22.4 \\
\hline Households having computers (urban sector) & 17.8 & 26.3 & 37.5 \\
\hline Households having computers (rural sector) & 6.9 & 9.8 & 20.1 \\
\hline $\begin{array}{l}\text { Computer literacy (percentage of household population } \\
\text { in the age group 5-69 who can use computers) - national }\end{array}$ & 16.1 & 20.3 & 25.1 \\
\hline $\begin{array}{l}\text { Computer literacy (percentage of household population } \\
\text { in the age group 5-69 who can use computers) - urban } \\
\text { sector }\end{array}$ & 25.1 & 31.1 & 36.4 \\
\hline $\begin{array}{l}\text { Computer literacy (percentage of household population } \\
\text { in the age group 5-69 who can use computers) - rural } \\
\text { sector }\end{array}$ & 15.1 & 19.3 & 23.6 \\
\hline
\end{tabular}

Table 2.1 - Key statistics on availability of computers at home, use of home computers, email and internet services in Sri Lanka, 2014 Source: Department of Census and Statistics of Sri Lanka, 2014

Computer ownership at household level increased in every surveyed sector during the period 2006 to 2014 (Figure 2.3). Similarly, the computer literacy of the Sri Lankan population in urban and rural sectors also increased (Table 2.1). For example, the national rate of computer literacy reported in 2014 was $25.1 \%$, which was a 5\% increase from 2009 (see Table 2.1). 


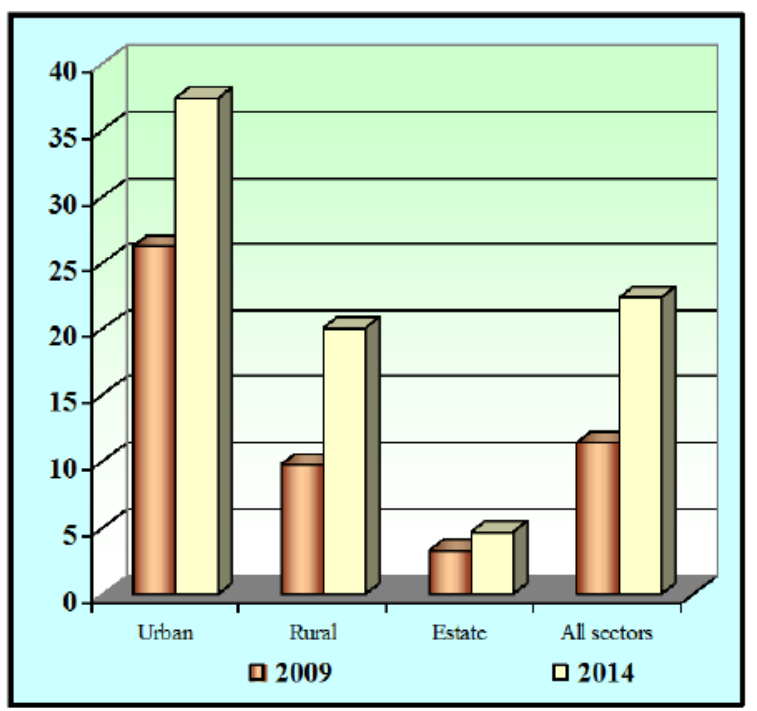

Figure 2.3 - Desktop or laptop computer-owning households (\%) by sector: 2009 and 2014 Source: Department of Census and Statistics of Sri Lanka, 2014

The younger generation (aged 15--24 years) was more computer literate; internet and email were more popular among them than all other age groups as shown in Figure 2.4.

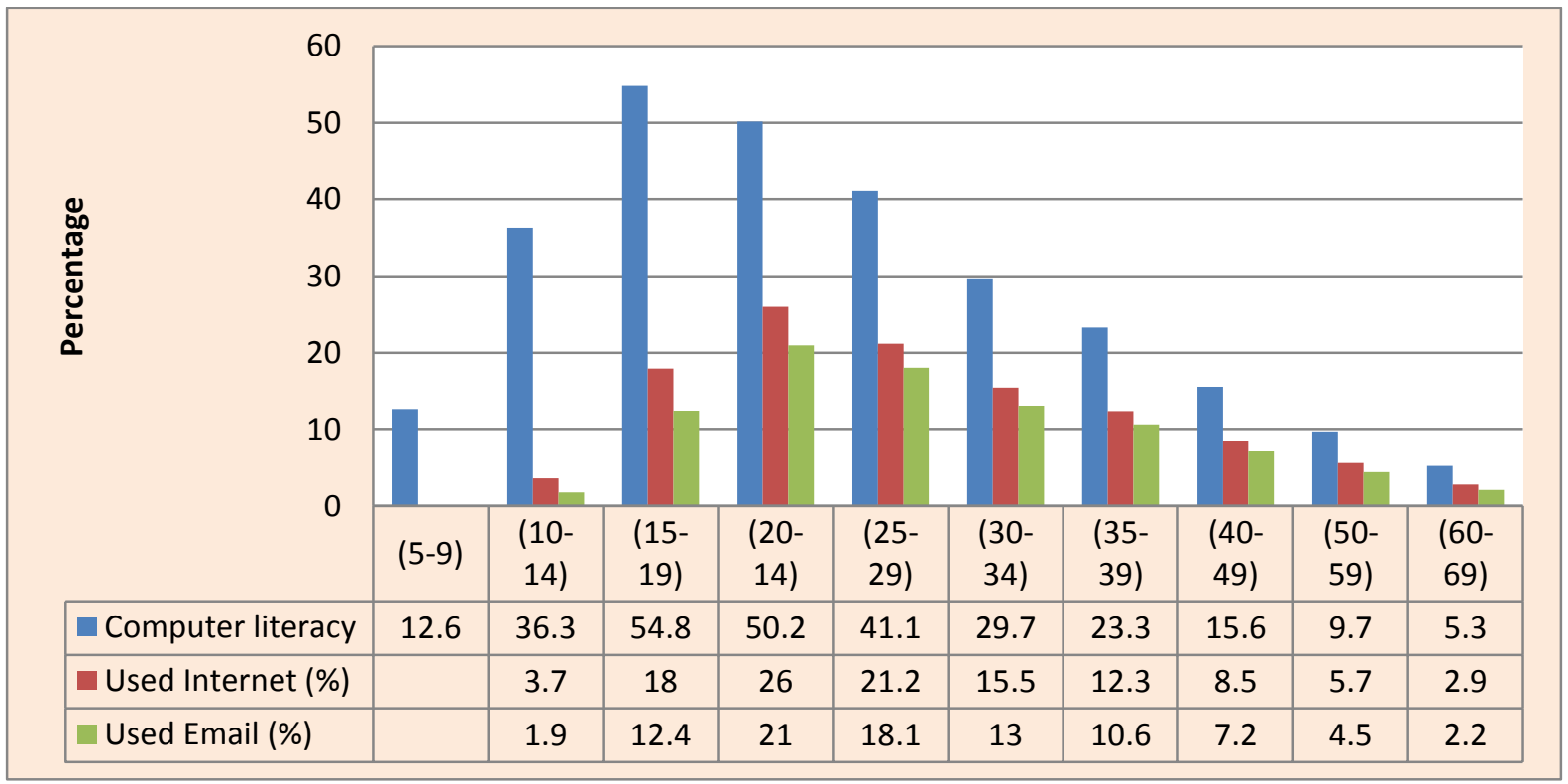

Figure 2.4 - Household population aged 5-69 years who were computer literate and who used internet and email

Adapted from Department of Census and Statistics of Sri Lanka, 2014

De Silva, Kodikara, and Somarathne (2013) conducted a survey among a randomly selected sample of 3000 household members aged 15-29 years distributed among 22 districts in Sri Lanka. They found that $57 \%$ of youth (aged 15-29 years) were computer 
literate and 33\% used the internet. Older adults in Sri Lanka (over 50 years) showed a comparatively lower computer literacy rate and lower use of internet and email (Figure 2.4).

However, the Sri Lankan government has taken several steps to increase computer literacy and IT usage among Sri Lankans through major development programmes.

\subsubsection{Sri Lanka's government e-learning initiatives}

The Government of Sri Lanka introduced e-Sri Lanka in 2003, a national development project, with the aim of enhancing growth and equity through: (1) improving access and use of information and communication technology; (2) giving access to and use of public services online by businesses and citizens; and (3) improving the competitiveness of the private sector and in particular of the knowledge industry and SMEs (ICTA, 2014) (ICTA is the implementation body of the e-Sri Lanka initiative). This e-Sri Lanka project consists of six programmes as shown in Figure 2.5.

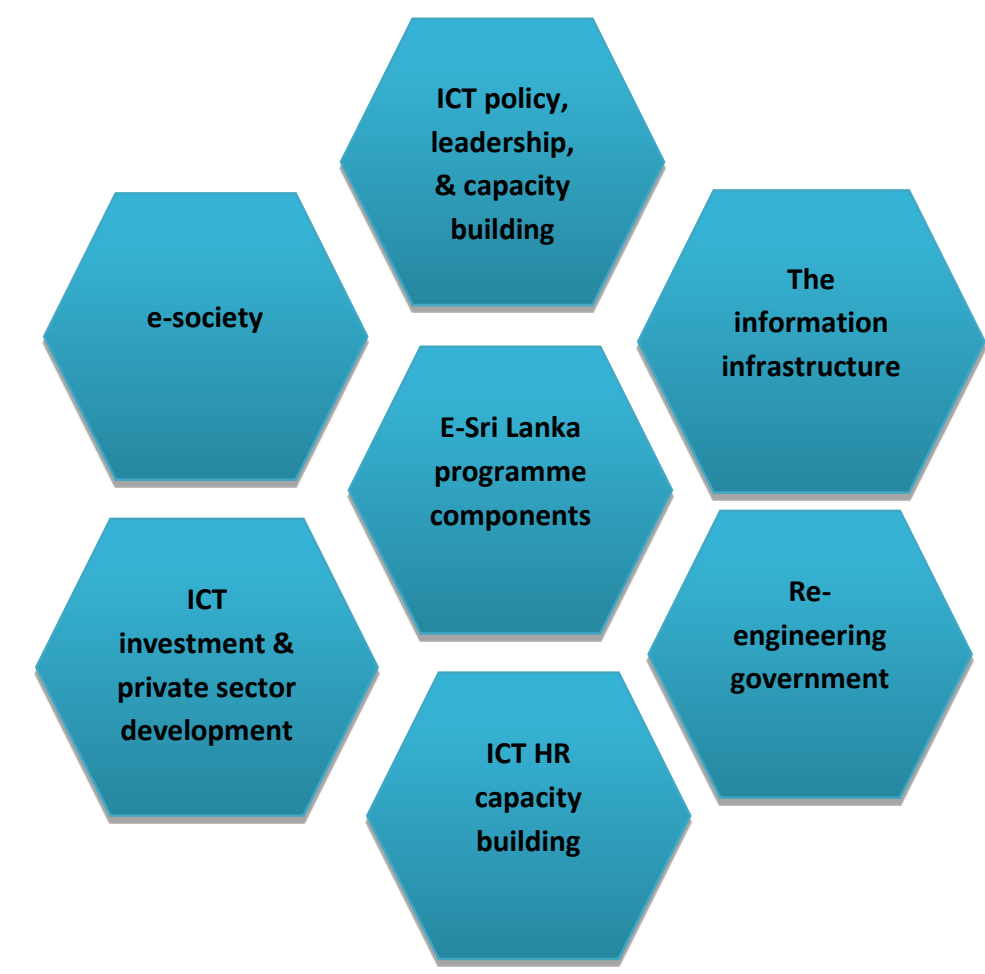

Figure 2.5 - e-Sri Lanka programme components (ICTA, 2014)

The e-Sri Lanka project has telecentre programmes called 'Nenasala' (knowledge centres or wisdom outlets) which aim to bridge the digital divide, particularly between urban and 
rural areas, by facilitating more balanced access to ICT. The aim of the Nenasala project was to establish 1000 centres (560 centres sponsored by the World Bank, 40 centres sponsored by India, and 400 centres sponsored by GOSL) throughout the country which would provide access to the internet, email, telephone, fax, photocopying, computer training classes and other ICT services with a view to significantly increasing the levels of computer literacy (ICTA, 2010). So far 777 centres have been established under this project.

Apart from the e-Sri Lanka major development project, the Ministry of Higher Education has started the "National Online Distance Education Service - NODES" as a national agency to coordinate delivery of online distance education (NODES, 2014). For this purpose NODES has 26 NODES access centres (NACs) island wide and each NAC is equipped with 25 multimedia PCs with printers and copiers, tablets and scanners and video conferencing facilities connecting 20 centres at any given time. This expands NODES' capacity to cater for education and can connect 500 students simultaneously. More importantly, NODES supports course design and development, instructional design, educational technology counselling, educational content development, and learning management system theme development through their content development unit (NODES, 2014).

Apart from the above discussed major government e-learning initiatives, the Ministry of Education (MOE) and Ministry of Higher Education (MOHE) in Sri Lanka have introduced various projects to improve IT literacy as well as to encourage the use of e-learning at all educational levels. For example, the MOE along with the Asian Development Bank (ADB) funded the Secondary Education Modernization project (SEMP) which has created a web portal for all public schools in Sri Lanka called 'SchoolNet Sri Lanka' (SchoolNet Sri Lanka, 2006). These SchoolNet services include provision of network connectivity, management and safe internet access, and services offered for learning and teaching activities (e.g. ethaksalawa, Nenasa education television programme). Under the MOE's SEMP II project, an e-village programme has started with the aim of empowering rural communities (students, school leavers, adults, etc.) by improving IT literacy, information sharing, and creating employment opportunities. 
The Ministry of Higher Education (MOHE) along with the World Bank has started the 'Higher Education for the Twenty First Century' (HETC) project to enhance the capacity of higher education systems and to deliver quality higher education services with the aim of developing equitable access, and meeting the social and economic development needs of the country (Ministry of Higher Education of Sri Lanka, 2015a). MOHE has further identified the importance of developing university students' IT skills to meet the labour market's needs. For this purpose, it is recognized that the students should be supported to learn on their own to improve their knowledge, skills, and capabilities in IT. As a result, MOHE launched a loan programme in 2011 with the support of public and private banks that enables students to obtain laptop computers with connectivity.

\subsubsection{Sri Lanka's broadband infrastructure}

The Sri Lankan government e-learning initiatives which were discussed earlier in section 2.2.1.2 (such as e-Sri Lanka, the Nenasala telecentre project, and NODES) along with egovernment and e-commerce have increased the heavy demand for broadband in Sri Lanka.

Broadband services were first introduced in Sri Lanka by Sri Lanka Telecom (SLT) in 2003. More recently, a number of fixed and mobile operators have joined the market to provide broadband services. Further information about these operators including the type of broadband connectivity, advertised bandwidth, and technology is given in Table 2.2 .

\begin{tabular}{|c|c|c|c|}
\hline $\begin{array}{c}\text { Type of } \\
\text { broadband } \\
\text { connectivity }\end{array}$ & Operators & Technology & $\begin{array}{l}\text { Maximum } \\
\text { bandwidth } \\
\text { advertised }\end{array}$ \\
\hline $\begin{array}{l}\text { Fixed wired } \\
\text { broadband }\end{array}$ & $\begin{array}{l}\text { Sri Lanka Telecom } \\
\text { (SLT) }\end{array}$ & ADSL 2+/WiMax & 4Mbps \\
\hline $\begin{array}{l}\text { Fixed wireless } \\
\text { (limited mobility) } \\
\text { broadband }\end{array}$ & $\begin{array}{l}\text { Lanka Bell } \\
\text { Suntel (now DBN) } \\
\text { Dialog Broadband } \\
\text { Network (DBN) } \\
\text { Sky networks }\end{array}$ & $\begin{array}{l}\text { CDMA 2000/WiMax } \\
\text { CDMA 2000/WiMax } \\
\text { CDMA 2000/WiMax } \\
\text { WiMax }\end{array}$ & $\begin{array}{l}\text { 4Mbps } \\
\text { 4Mbps } \\
4 \mathrm{Mbps} \\
\text { 4Mbps }\end{array}$ \\
\hline Mobile broadband & $\begin{array}{l}\text { Dialog Mobile } \\
\text { Mobitel } \\
\text { Etisalat } \\
\text { Airtel } \\
\text { Hutchison } \\
\end{array}$ & $\begin{array}{l}\text { GSM/W-CDMA } \\
\text { GSM/W-CDMA } \\
\text { GSM/W-CDMA } \\
\text { GSM/W-CDMA } \\
\text { GSM/W-CDMA }\end{array}$ & $\begin{array}{l}\text { 1 Mbps } \\
3.6 \mathrm{Mbps} \\
\text { 7.2Mbps } \\
3.6 \mathrm{Mbps} \\
3.6 \mathrm{Mbps}\end{array}$ \\
\hline
\end{tabular}

Table 2.2 - Broadband operators, technology, and speed Adapted from International Telecommunication Union (ITU), 2012 
Note:

ADSL2+: Asymmetric digital subscriber line 2 plus

CDMA 2000: Code division multiple access 2000

WiMax: Worldwide interoperability for Microwave Access

GSM: Global system for mobile communications

W-CDMA: Wideband code division multiple access

After the introduction of mobile broadband in Sri Lanka in 2009, internet and email growth has increased exponentially, as shown in Figure 2.6.

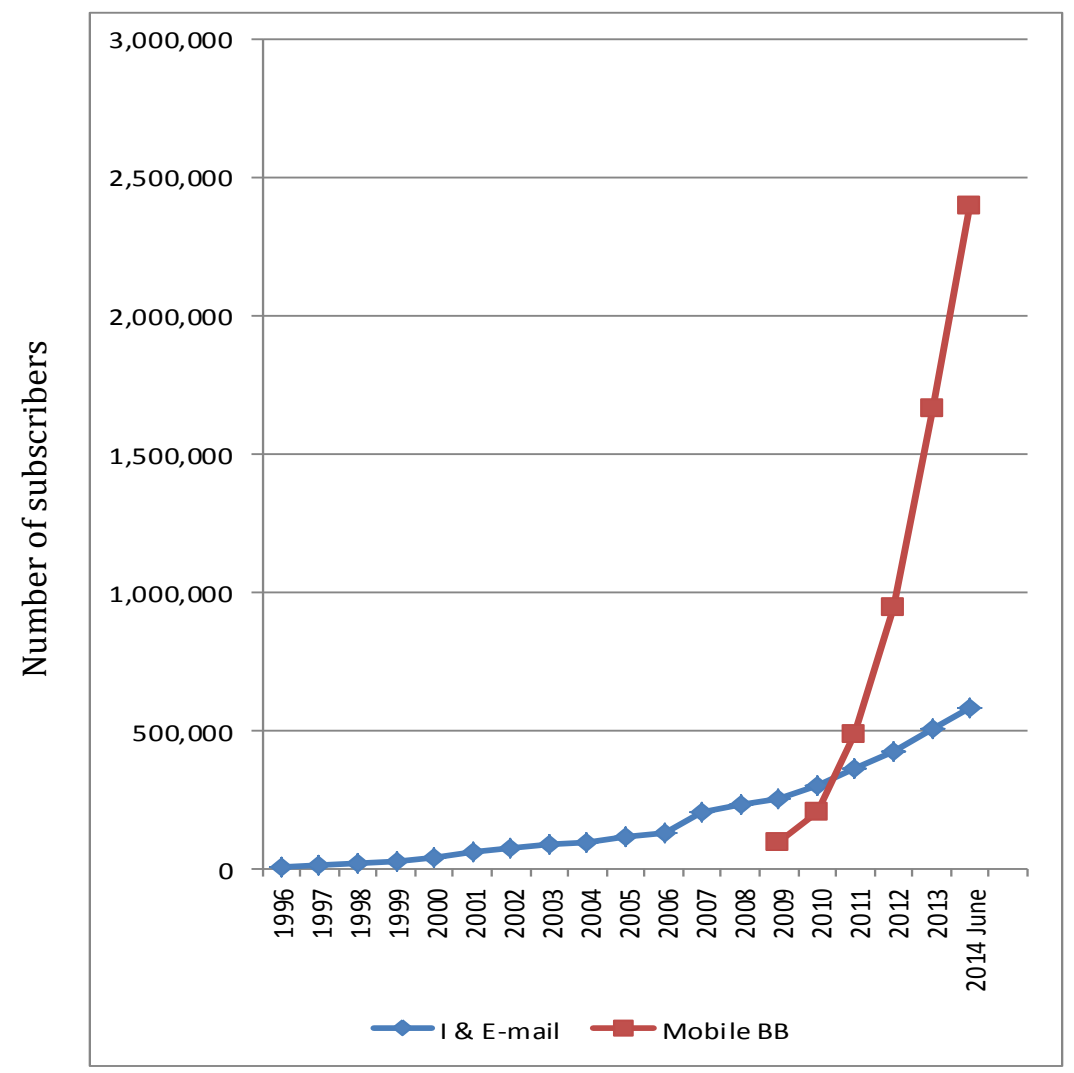

Figure 2.6 - Internet and email subscriber growth (fixed and mobile) in Sri Lanka 1996-2014 Jun. Source: Telecommunication Regulatory Commission of Sri Lanka, 2014, p. 4

The Telecommunication Regulatory Commission of Sri Lanka (TRCSL) planned to install nation-wide fibre backbone connectivity through a National Broadband Network (NBN) (Galpaya, 2011). The NBN service provider is Sri Lanka Telecom (SLT), the national telecommunication service provider. The aim of NBN is to facilitate high speed broadband connectivity across the entire country within 2013-2017. 


\subsubsection{Sri Lankan education system}

The Sri Lankan education sector consists of three major stages: early childhood education, school education (primary and secondary), and tertiary education (Figure 2.7). From school education to the first degree at university, education is free (Arunatilake, 2006). This helps to provide educational opportunities for all students in different socio-economic groups of Sri Lankan society.

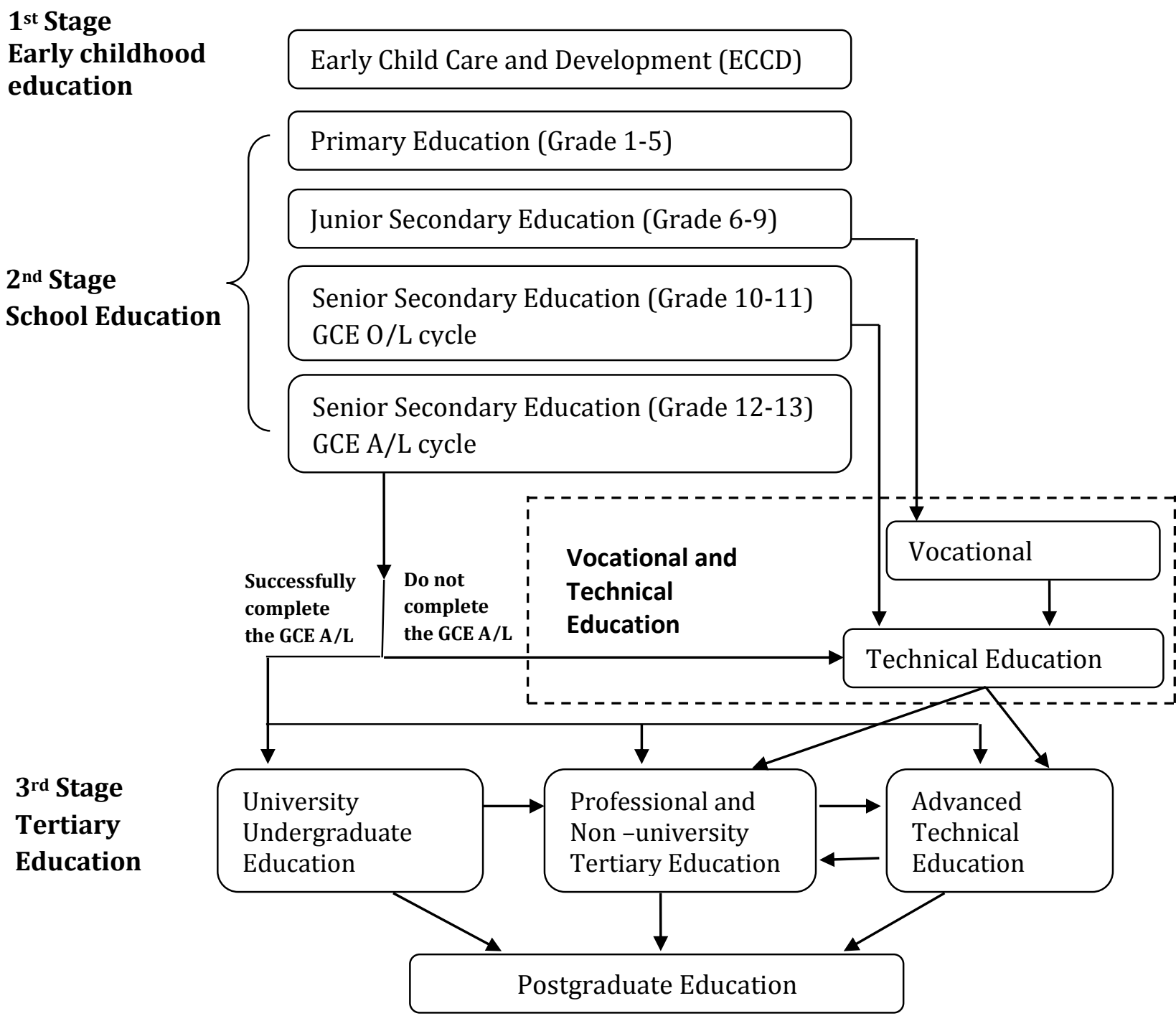

Figure 2.7 - Organizational structure showing three stages of the Sri Lankan education system (Adapted from World Bank, 2005)

The first stage is that of early childhood development, catering to children aged 3 and 4 . The second stage is school education including primary education, junior secondary education and senior secondary education. There are 9905 public schools available for 
school education. This number includes 342 national schools and 9563 provincial schools (Ministry of Education Sri Lanka, 2012). Public schools fall into four categories:

(i) $\quad 1 \mathrm{AB}(753)$ - Schools having advanced level Science stream classes

(ii) $\quad 1 \mathrm{C}(2,013)$ - Schools having advanced level Arts and/or Commerce streams but no Science stream

(iii) Type $2(3,869)$ - Schools having classes only up to grade 11

(iv) Type $3(3,270)$ - Schools having classes only up to grade 8 (Ministry of Education, 2012)

The compulsory education cycle in Sri Lanka ends at grade 9. Therefore, the Sri Lankan education system has introduced vocational education as an optional educational opportunity for students who leave school at grade 9. Senior secondary education includes two qualifications: General Certificate of Education Ordinary Level (GCE O/L) and General Certificate of Education Advanced Level (GCE A/L). Students who have not passed GCE 0/L can choose technical education while those who pass can continue their school education up to GCE A/L. The third stage is tertiary education; entry is restricted to students who have successfully completed the GCE A/L examination or graduated from a technical institution. However, entrance to public universities is restricted to eligible applicants who have passed the GCE A/L examination.

The Sri Lankan education sector has a complex governance framework combining the central government and provincial councils (World Bank, 2005). The central government is responsible for national education policy at all levels. This covers pre-schools, primary and basic education, secondary education, university education, vocational training and technical education (World Bank, 2005). Also, central government administers around 342 national schools and is responsible for establishing the school curriculum, publishing and distributing textbooks and administering the professional development programme. Provincial councils administer the schools within the province. Due to the distribution of power between central government and provincial councils, the World Bank (2005) suggests that in order to create an effective education system, Sri Lanka needs to give more autonomy to educational institutions. The unique features of the governance of the higher education system are discussed in section 2.2.3.3. 


\subsubsection{Sri Lankan higher education system}

The higher education sector in Sri Lanka consists of both public and private sector higher education institutes as shown in Figure 2.8.

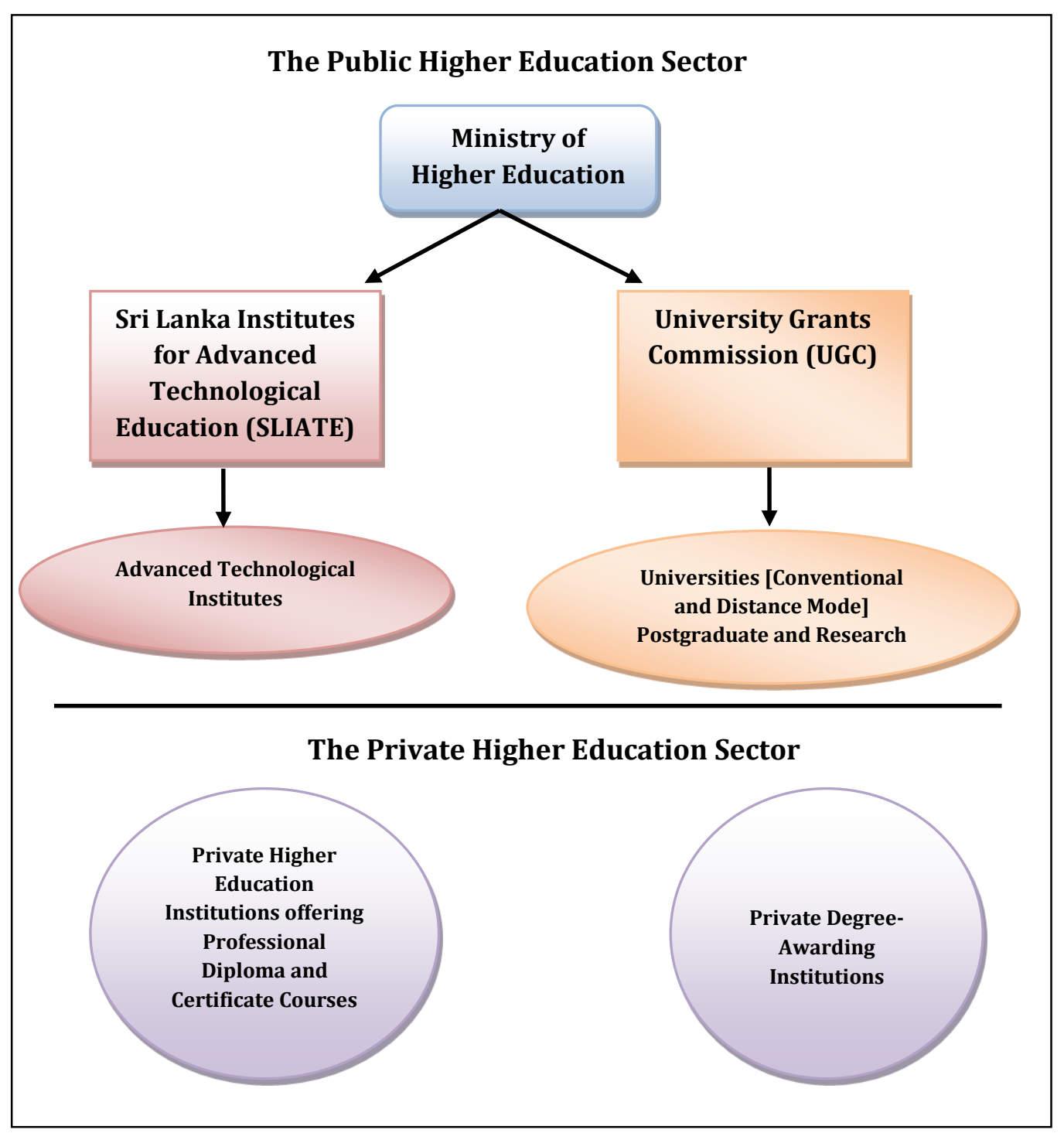

Figure 2.8 - The structure of the higher education sector in Sri Lanka (World Bank, 2009)

\subsubsection{The public higher education sector}

The public higher education sector consists of universities, research and postgraduate institutes, and advanced technical institutes. Both undergraduate and postgraduate degree programmes are conducted by universities. The postgraduate degrees range from diplomas to masters degrees and PhDs. All undergraduate degree programmes take three 
or four years, but medical degrees take five years. Further, universities offer conventional degree programmes as well as distance mode degree programmes (World Bank, 2009).

The public higher education sector consists of 15 universities. Also, there are a number of institutes in the public higher education sector as shown in Table 2.3.

\begin{tabular}{|l|c|}
\hline Category & $\begin{array}{l}\text { No. of Universities } \\
\text { and Institutes }\end{array}$ \\
\hline Universities & 15 \\
\hline Postgraduate Institutes & 7 \\
\hline Affiliated Institutes & 11 \\
\hline Degree Awarding Institutes & 7 \\
\hline Campuses & 3 \\
\hline $\begin{array}{l}\text { Other government universities which are not } \\
\text { under UGC }\end{array}$ \\
$\begin{array}{l}\text { - Under Ministry of Defence } \\
\text { - Under Ministry of Higher Education } \\
\text { - Under Ministry of Vocational and Technical }\end{array}$ \\
$\quad$ Training & 1 \\
$\quad$ Total & 1 \\
\hline
\end{tabular}

Table 2.3 - Universities and higher education institutes in Sri Lanka Adapted from University Grants Commission Sri Lanka, 2015b

The above universities and institutes provide higher education for a student population of more than 100,000, including Open University, external degree and postgraduate students. The Open University provides flexible higher education opportunities especially for two kinds of students (i) those who work and study part-time and (ii) those who enter higher education later in their lives.

Figure 2.9 shows that public universities are widely distributed across the country but not equally distributed. Most of the higher education providers are located in or around Colombo, the biggest city in the country.

The Sri Lanka Institutes of Advanced Technological Education (SLIATE) comprise a small segment of the public higher education sector which offers opportunities for increased access and for greater responsiveness to the needs of the labour market. SLIATE manages and supervises 11 Advanced Technological Institutes (ATIs) with 6000 students and seven sections housed in the technical colleges with 2100 students (World Bank, 2009) 


\section{Location of Universities}

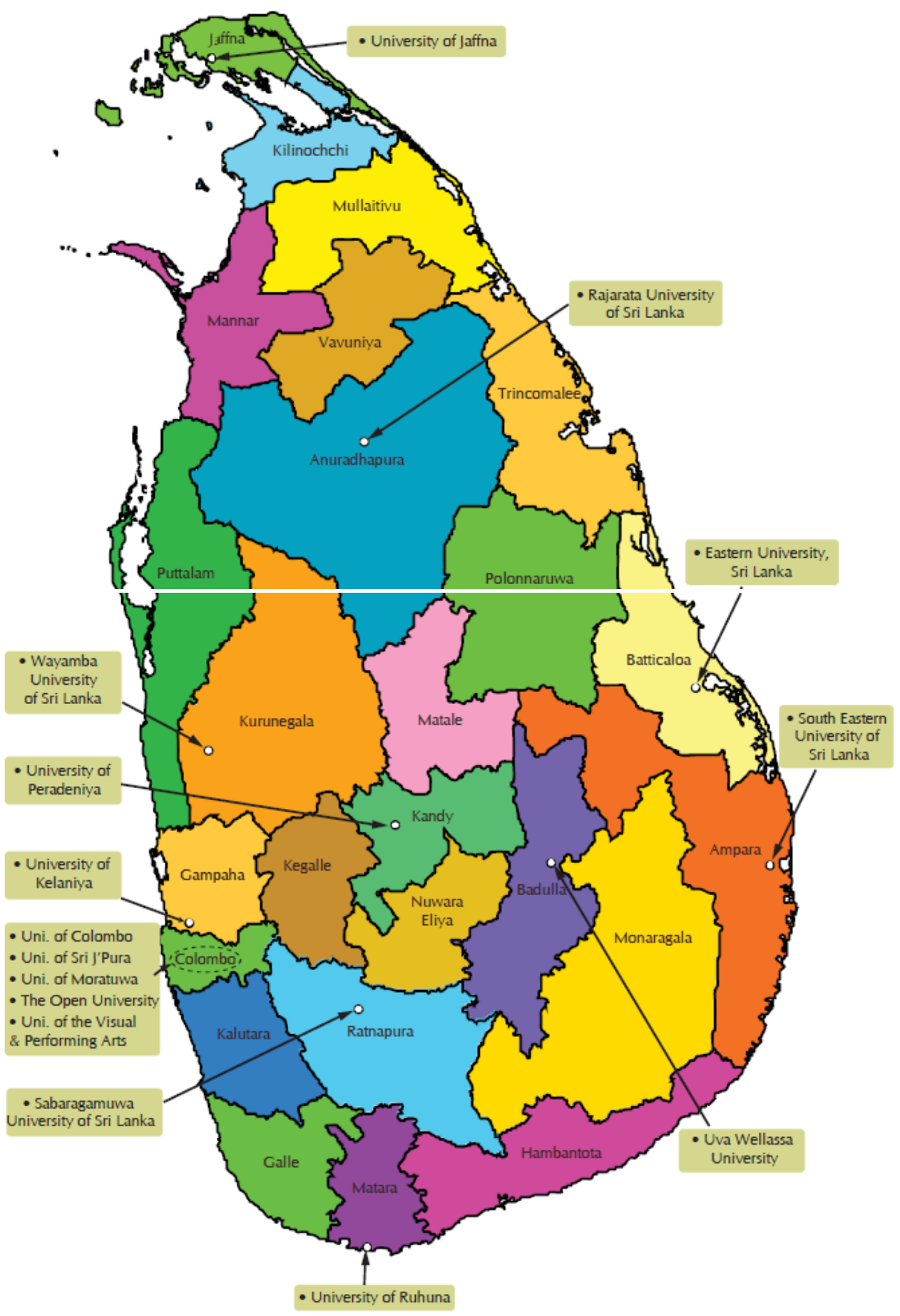

Figure 2.9 - Location of universities in Sri Lanka Source: University Grants Commission Sri Lanka, 2015a) 


\subsubsection{The private higher education sector}

The private higher education sector consists of: (i) degree-granting institutions, (ii) institutions offering lower-level diplomas, certificates, and short courses, and (iii) qualification-granting professional associations. They are all private fee-charging institutions and mostly located in large cities and towns such as Colombo and Kandy.

The private higher education sector in Sri Lanka is a relatively recent introduction. The World Bank (2009) states a number of factors which account for the growth in the private higher education sector in Sri Lanka. First is the limited number of places at public universities. Another factor is that private higher education institutes offer more joboriented curricula. They produce graduates with a better command of English, and develop 'soft skills' which are important to employers.

The degree-awarding institutions in the private higher education sector offer degrees through affiliations with foreign universities from countries such as the United Kingdom, the United States, Australia, China, Singapore, and Malaysia (World Bank, 2009).

\subsubsection{Governance of the higher education system}

In the public higher education sector, the Ministry of Higher Education (MOHE) is responsible for developing higher education operational policy and strategy. The University Grants Commission (UGC) plays a vital intermediary role between the MOHE and universities, for example, planning and coordinating university education, apportioning the funds to maintain academic standards, and regulating the admission of students (World Bank, 2009).

The Advanced Technological Institutes (12) and six sections in the technical colleges are presently governed by a SLIATE council.

However, private higher education policy in Sri Lanka is not fully developed. Also, there is no quality assurance and accreditation process (World Bank, 2009). Therefore, the World Bank suggests that the Sri Lankan higher education sector should develop "hybrid" models of educational delivery that involve private sector participation under the supervision of public higher education institutions. 


\subsubsection{Issues and barriers in the higher education sector in Sri Lanka}

Annually, around 200,000 candidates sit the GCE A/L (General Certificate of Education Advanced Level) examination and almost $1 / 3$ of that number become qualified to enter a university. But as the universities do not have the capacity to accommodate them all, only $20 \%$ of those who are eligible are admitted to the universities. For example, in 2012 the number of students who qualified for university study was 93,745 but only 15,393 students were selected for university admission (17\% of eligible applicants) (University Grants Commission Sri Lanka, 2015a). Therefore equity of access to universities for qualified students is a formidable problem in the Sri Lankan university system as shown in Figure 2.10.

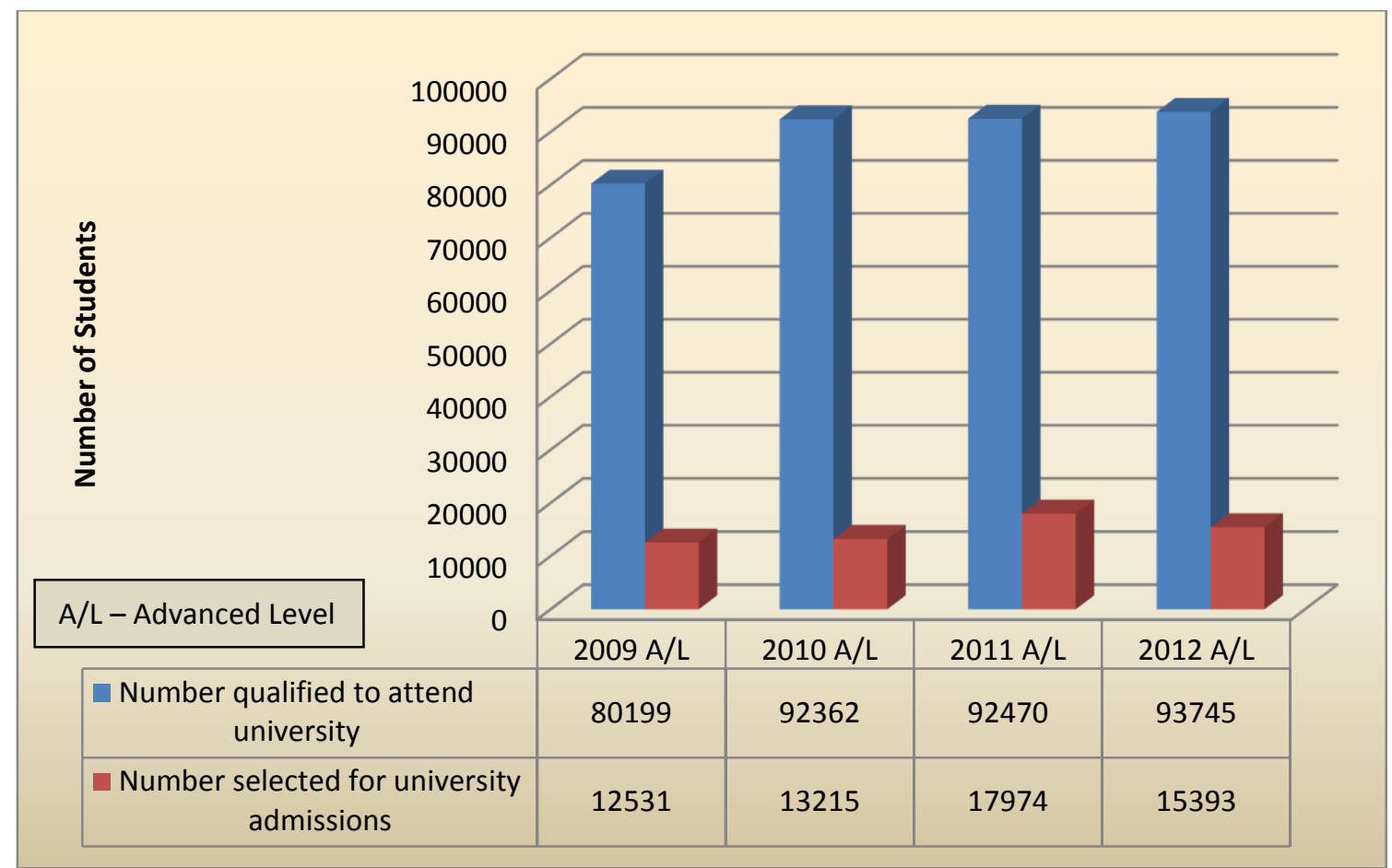

Figure 2.10 - Gap between students qualifying in the A/L examination and students selected for university entry (University Grants Commission Sri Lanka, 2015a)

Another problem is the unemployment of university graduates in Sri Lanka. According to the World Bank (2007) there is a mismatch between Sri Lanka's tertiary education system outputs and its labour market needs. This mismatch has led to unemployment of university graduates (World Bank, 2005, 2009). For example, Ramanayake and Jayamanne (2012) conducted a graduand employment survey for the HETC project and MOHE. They found that 4170 students were unemployed and 2050 students were 
underemployed (not having enough paid work or not doing work that makes full use of their skills and abilities) out of a total number of 15,489 study participants.

Due to the above issues and problems, the higher education sector in Sri Lanka is trying to improve the quality and relevance of university education. As a first step, the Ministry of Higher Education has launched the 'Improving the Relevance and Quality of Undergraduate Education' (IRQUE) project “to provide undergraduates with a complete and balanced tertiary education, which will mould them into responsible, educated citizens of Sri Lanka" (IRQUE, 2009). This project is supported by the World Bank. The World Bank (2007) also suggests that Sri Lankan universities need to make their education system 'more demand driven quality conscious and forward looking' in order to improve the quality and relevance of university education. Therefore, the University Grants Commission (UGC) has been concerned about the need to: expand reform and restructure the entire system, accommodate the increasing number of qualified people seeking to gain admission to a university, and improve the quality and relevance of university education.

\subsubsection{Tertiary-level Information Management (IM) education in Sri Lanka}

Formal IM education (usually called Library Science or Library and Information Science) in Sri Lanka started in 1961 (Wijetunge, 2011). Presently, 27 IM education programmes ranging from diplomas to masters degrees to PhDs are offered in Sri Lanka by five providers, all in the greater Colombo area. Among these providers there are three providers of tertiary-level IM education. They comprise a public university, a public institute, and a private university.

\subsubsection{Current limitations in tertiary-level IM education in Sri Lanka}

In Sri Lanka, IM education targets two distinct student populations: full-time students and part-time students who are full-time information workers. Full-time students have the GCE A/L qualification (See Figure 2.10) and are thus eligible to enter the public universities. Information workers are mainly full-time employees such as ministry officials, officials of statutory bodies, educators, librarians, officers in charge of cultural centres, Nenasalas (electronic information centres) staff, personnel from information sectors (mass media, book publishers, archives and record managers, information centre 
managers), ICT professionals, officials of local and foreign NGOs involved in community development through multipurpose community telecentres, and staff of village knowledge centres. These information workers are spread across the country. However the current system presents its potential customers with a number of equity issues.

Firstly, provision of IM education is limited to the greater Colombo area, i.e., the area around the capital city. Access to IM education is therefore a challenge for those who live in remote areas of the country. For example, officers from cultural centres in Ampara or Kilinochchi who wish to access IM education need to travel more than $200 \mathrm{~km}$ (see Figure 2.11), which takes over 12 hours, to attend the classes. The Department of Census and Statistics of Sri Lanka (2012) has shown that the majority of the population (over 86\%) is still living in rural areas. Therefore, it is time-consuming and costly for people in rural regions to make such journeys due to the long distances between the centre and peripheral areas (Wijetunge \& Willson, 1998).

The second problem relates to transport. In Sri Lanka the public transport services include trains and buses. However, some cities and towns are not connected by the Sri Lankan railways. For example there are no train services from Kilinochchi and Ampara to Colombo. Therefore, buses are only the option for long-distance travel. Since the highways in Sri Lanka are still under construction, travelling long distances by bus is not convenient for students and information workers and it is time-consuming. Travelling long distances presents a greater barrier for female students and female workers in the information field. According to Hansson, Mozelius, Gaiani, and Meegammana (2010) travelling at night can be dangerous for women in Sri Lanka due to the risk of theft and abuse and also it is not something women should do according to cultural norms.

Thirdly, tertiary-level IM education providers run programmes on weekends for parttime students while conducting weekday classes for full-time students. Therefore, learners who live in rural areas (for example, as shown in Figure 2.11, Ampara or Kilinochchi) would need an extra day, even if the classes are held during weekends, in order to attend classes. As a result, they require leave and this is another problem faced by information workers because organizations are reluctant to grant leave for them to attend classes (Wijetunge \& Willson, 1998). 


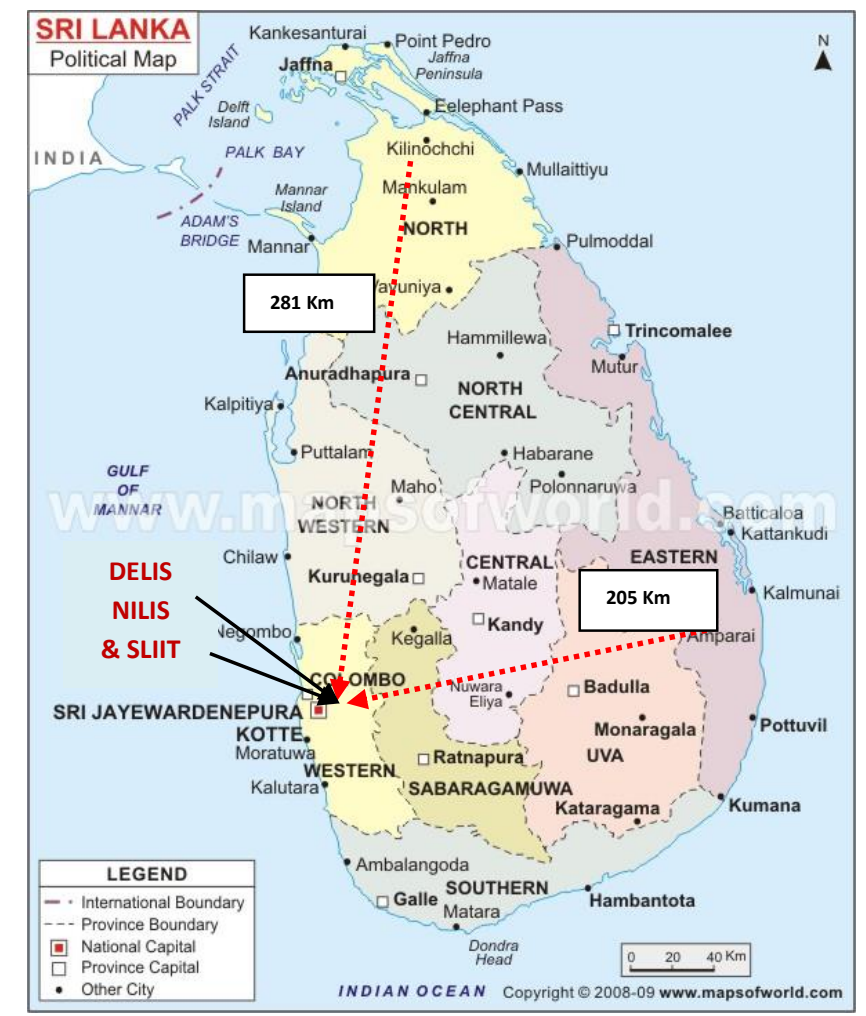

Figure 2.11 - Map of Sri Lanka which indicates long distances between IM educational centres and remote areas Adapted from Maps of World, 2009

Fourthly, there is a lack of parity in education facilities for students who are information workers. Teaching institutions do not provide practical training or even library facilities for part-time students (Wijetunge \& Willson, 1998) while all the facilities are available to full-time students. Wijetunge (2008) stated that the serious imbalances in the current programmes with respect to gender, income, regional and cultural inequity are key issues for the IM education programmes in Sri Lanka. Hence, there is a need to provide equity of access to IM education.

With regard to these issues and other problems, the Quality Assurance and Accreditation Council (QAAC) of the university grants commission (UGC) in Sri Lanka has recommended that one of the IM education provider organizations should 'take necessary steps to commence e-learning courses for both internal and external students' (Quality Assurance and Accreditation Council of Sri Lanka, 2008, p. 13) in the field of IM education. However it is unclear what 'the necessary steps' might be. 
The above argument indicates that there is an urgent need for studies that explore the appropriate solutions to equity issues in IM education in Sri Lanka. Also there is a need to identify how QAAC's recommendation can be implemented. The present study seeks to understand how to address these issues through e-learning because literature has highlighted that e-learning provides a potential method to deal with such issues.

\subsection{E-learning}

This integrative literature review on e-learning consists of three sections. The first section discusses why there has been a move towards e-learning, particularly in tertiary education and in the Sri Lankan context. The second section provides concepts of elearning and illustrates the pedagogical shift in e-learning. It also illustrates emerging technology that supports the change to e-learning. The last section considers key issues of e-learning and the final part of this section summarizes critical success factors for the use of e-learning.

\subsubsection{Why the move towards e-learning?}

This section discusses the potential value of e-learning in tertiary education, then considers the potential value of e-learning in Sri Lankan tertiary education.

\subsubsection{Why e-learning in tertiary education?}

In sections 2.2.3.4 and 2.2.4.1, the challenges relating to tertiary education and tertiarylevel IM education in Sri Lanka were mentioned. In addition, there are challenges for higher education systems all over the world due to shifts in learner expectations, changing demographics of learners, the rapid development of subject knowledge, and decreasing financial support (Alexander, 2001; Ryan, Scott, Freeman, \& Patel, 2000). It has been argued that if universities are unable to cope with these challenges of knowledge- based societies, they cannot survive in the changing paradigm of education (Engelbrecht, 2003). Therefore, in the present society, universities cannot avoid dealing with ICTs because studies show that ICTs have a huge impact (Collis \& Moonen, 2001; Guri-Rosenblit, 2005b, 2002; Harley et al., 2002; Littleton \& Light, 1999; Robinson \& Guernsey, 1999; Scott, Chenette, \& Swartz, 2002; Siritongthaworn \& Krairit, 2006; van 
der Wende, 2002) on universities' learning, teaching, research and administrative activities. Since e-learning is for a method of learning through the medium of ICTs, it has become an integral part of the higher education sector (Bates, 2009; Engelbrecht, 2003; Siritongthaworn \& Krairit, 2006).

In general, the worldwide e-learning market has a growth rate of 35.6\% (Arbaugh \& Duray, 2002; Sun et al., 2008; Wu, Tsai, \& Chen, 2006). Some authors have empirically demonstrated the high popularity of e-learning in higher education (Gunasekaran, McNeil, \& Shaul, 2002; Henry, 2001; Mishra, 2009). Among them Mishra (2009, p. iv) has presented global statistics estimated by Hazel Associates. According to these statistics, elearning is the fastest-growing sub-sector of a US\$2.3 trillion global education market, and the market for online higher education is estimated to exceed $\$ 69$ billion by 2015 . Therefore, it is important to identify why most higher education institutes are moving towards e-learning.

Many reasons have been suggested as to why universities and other teaching institutes in developed and developing countries are using e-learning. The three most commonly advanced rationales for using e-learning are to improve access to education, to enhance the quality of learning, and to create flexible and interactive learning.

\subsection{Improving access to education}

One of the main reasons universities implement e-learning initiatives is to increase learning opportunities, or in other words improve access to education (Oroma, Wanga, \& Fredrick, 2012; Bhuasiri et al., 2012; Essam \& Al-Ammary, 2013; Thowfeek \& Jaafar, 2012; Siritongthaworn \& Krairit, 2006; Fry, 2001; Inglis, 1999; Oliver, 1999; Engelbrecht, 2003; Rajasingham, 2009b; Gulati, 2008; Ruiz, Mintzer, \& Leipzig, 2006) especially for students who lack the opportunity to obtain a formal education (Siritongthaworn \& Krairit, 2006; Guri-Rosenblit, 2005a, 2005b).

Generally, the students who lack that opportunity or have physical and temporal obstacles to formal/higher education share some of the following characteristics: they may lack formal entry qualifications; they are usually older people and mature students (Guri-Rosenblit, 2005a, 2005b); they have physical/health constraints (Guri-Rosenblit, 2005a, 2005b; O’Neill, G. Singh, \& O’Donoghue, 2004; University of Leeds, 2001); they 
face geographical barriers and family obligations (Keller et al., 2009; Suri \& Sharma, 2012; Guri-Rosenblit, 2005a; O'Neill, Singh, \& O'Donoghue, 2004); they are often workers (Guri-Rosenblit, 2005a; O’Donoghue \& G. Singh, 2001) or they reside in closed institutions, such as prisons and hospitals (Guri-Rosenblit, 2005b). Gladieux and Swail (1999) use the term 'new student clienteles' to describe these groups. The new student clienteles include two large groups: adults studying for recreational purposes and professionals seeking to upgrade their professional knowledge and expertise on an ongoing basis. Adelman (2000), Matkin (2002), Ryan (2002), and Blumenstyk (2003) further suggest that e-learning is an important tool for professional training and professional development programmes. As discussed in section 2.2.3.4 and section 2.2.4.1, there are students who lack opportunities to access higher education and tertiarylevel IM education in Sri Lanka due to most of the above reasons.

E-learning by its nature opens up possibilities for widening access to higher education especially for disadvantaged groups. By doing so, e-learning helps to promote social equity (Gladieux and Swail, 1999). Further, new technologies are capable of providing virtually unlimited access to all kinds of information for all types of students at all educational levels (Guri-Rosenblit, 2005b) and addressing issues of educational equity (Gulati, 2008). Therefore, e-learning may help to address equity issues in tertiary-level IM education in Sri Lanka. These equity issues have been discussed in section 2.2.4.1.

The demand for higher education is always rising throughout the world. According to Goddard (1998), by 2025 more than 150 million people will be seeking higher education. This is because of the changing culture of employment and the 'knowledge-driven' society (Katz, 2001). Students seek part-time study and life-long learning as their study patterns change from 'learner-earners' to 'earner-learners' (Alexander, 2000). A traditional education system which locks participants into a specific time and place and sends a large group of staff to take a course outside the company could be problematic (Svensson, Ellström, \& Åberg, 2004; Wild, Griggs, \& Downing, 2002). Full-time workers for example, could have difficulty accessing education (Svensson et al., 2004, p. 483). Research indicates that e-learning has the potential to improve access to education particularly in meeting the needs of the workforce (Engelbrecht, 2003; Forman, Nyatanga, \& Rich, 2002; Gunasekaran et al., 2002; Wild et al., 2002). 
As a result of improving access to education through e-learning, higher education institutes seek to reduce costs including those associated with travel, classroom and facilities, printed materials, and labour (Ruiz, Mintzer, \& Leipzig, 2006). E-learning requires start-up costs similar to any pedagogical innovation (Salmon, 2005). The costs include the "capital and direct costs of the technology (hardware costs, software licenses), and the development of resources involving a number of professionals, academic staff, and technical staff" (p. 205). But Welsh et al. (2003) argue that after initial course development, e-learning has the potential to reduce costs compared to a face-to-face traditional classroom. E-learning is more cost-efficient than the traditional teaching and learning environment due to its flexibility (Suri \& Sharma, 2012). Salmon (2005) concludes that e-learning can be offered at a low cost if a large number of students continue to register (p. 204). Therefore, widening access reduces the cost of e-learning. Corporate bodies are moving towards to e-learning because cost saving is one of the benefits of e-learning (Forrester Research, 2000).

It seems then that e-learning improves access to education and thereby promotes social equity as well as reducing costs. Hence, e-learning can be a potential solution to address the issues of tertiary-level IM education in Sri Lanka. These issues have been discussed in section 2.2.4.1.

\subsection{Enhancing the quality of learning}

The second main reason that higher education institutes use e-learning is to enhance the quality of learning. Various authors (Becker, Newton, \& Sawang, 2013; Bhuassiri et al., 2012; Siritongthaworn et al., 2006; Bates, 2009; Fernando, 2008) have identified that elearning has the potential to enhance the quality of learning. However the critical questions are how to define quality in the context of e-learning (Blicker, 2005; Rajasingham, 2009a) and how to measure it (Blicker, 2005; McGorry, 2003; Sonwalkar, 2002). O'Neil, Singh, and O'Donoghue (2004) argue that the measurement of quality needs to be qualitative rather than quantitative. Blicker (2005) used outcome assessment for evaluating quality in online teaching and learning and found a correlation between learning effectiveness and the creation of a student-centred constructivist learning environment. It seems that this pedagogical strategy leads to academic improvement. There are quality frameworks for evaluation of online courses such as 'Standards for 
Quality Online Courses', 'Principles of Good Practice for Electronically Offered Academic Degree and Certificate Programmes', 'Solan-C's Quality Framework for Learning Effectiveness', and WebCT's 'Exemplary Course Project'. For example, Rajasingham (2009a) uses the framework of Solan-C's Five Pillars: "learning effectiveness, access, costeffectiveness, institutional commitment, and faculty and student satisfaction and suggests that e-learning has the potential to improve quality in higher education in what is taught and how it is taught in the knowledge society" (p. 64).

Measuring satisfaction is one of the ways to measure quality. Research indicates (Chumley-Jones, Dobbie, \& Alford, 2002; Gibbons \& Fairweather, 2000) that learners' satisfaction rates are higher for e-learning than traditional learning, along with perceived ease of use and access navigation, interactivity, and user-friendly interface design. It seems then that e-learning helps to enhance the quality of learning in some cases. As discussed in section 2.2.3.4, improving the quality of higher education is a major challenge for the Sri Lankan higher education system. Therefore, e-learning may help to fulfil this requirement.

\subsection{Maintaining flexible and interactive learning}

Flexibility refers to benefit gained from convenience of access in terms of time, place (McGorry, 2003; Oubenaissa, Giardina, \& Bhattacharya, 2002; Svensson et al., 2004), space, and learning pace (Harper, Chen, \& Yen, 2004). E-learning contributes to growing flexibility in academic study patterns (Ahmed, 2013; Li et al., 2012; Essam \& Al-Ammary, 2013; Thowfeek \& Jaafar, 2012; Bates, 2001; Collis \& Moonen, 2001; Collis \& van der Wende, 2002; Sun et al., 2008) since it offers "students many opportunities to adjust their interests, needs and learning styles to a variety of learning settings and media combinations" (Guri-Rosenblit, 2005a, p. 489). For example, those students who are fulltime workers (also known as earner-learners), those from remote areas, those with disabilities, and those with family responsibilities, no longer need to follow fixed patterns of engagement with their university and they can learn anytime, anywhere. Hence, flexibility is a key attribute of e-learning. E-learning provides teachers and learners with more flexibility to participate in educational activities (Arbaugh, 2000, 2002; McGorry, 2003; Oubenaissa et al., 2002) when compared to face-to-face instruction. Interestingly, conventional campus-based students also appreciate the flexibility of e-learning (Bates, 
2009, p. 17) because e-learning is not constrained by space, time and location. Industry and the corporate world prefer just-in-time training (Ryan, 2002) since the nature of their work makes it difficult to take time off to attend classes and e-learning meets that requirement due to its flexibility (Fry, 2001). As discussed in section 2.2.4.1, IM workers in Sri Lanka also face difficulties such as travelling long distances, family responsibilities, and finding time to attend classes. Hence, e-learning may meet their requirements because of its flexibility.

Interaction is an essential element in the learning process. In educational settings, interaction can be threefold: learner-instructor, learner-content, and learner-learner interaction (Laurillard, 2000; Moore \& Kearsley, 1995; Moore, 1993; Moore, 1989; Paloff \& Pratt, 1999). Face-to-face interaction is well-established in the traditional classroom and conventional university. However, e-learning also has the potential to enhance interaction since it uses multidimensional forms of communication and interaction, i.e., simultaneous intimacy and distance, multimedia presentations, and hyper-searching (Garrison \& Anderson, 2003). Interaction in e-learning can be either synchronous where teacher and learner engage in a certain topic simultaneously or asynchronous where participants control their own timetables and fit learning around their other commitments. The advantages of synchronous interaction are stimulating motivation, interactive participation, immediate feedback, user-friendly technological tools for effective learning, and costs and time savings (Kung-Ming \& Khoon-Seng, 2005). Synchronous interaction technologies include real-time two way text-based online chat, Internet Relay Chat (IRC), instant messaging, real-time audio, application sharing, voice and video conferencing, shared electronic whiteboards, live assessment testing, and voting and audience-controlled tools (p. 108). The advantages of asynchronous interaction are flexibility, time to reflect, anonymity or pseudonymity, no time-zone constraints, situated learning, and cost-effectiveness. Asynchronous interaction technologies include email, CD-ROMs, collaborative learning forums, listservs, bulletin boards, newsgroups, web pages, computer conferencing, video and audio streaming, and blogs (p. 106). All these forms of interaction give e-learning useful advantages (Katz, 2002, 2000; Trentin, 1997).

As stated above, e-learning has the potential to facilitate flexible and interactive learning. 
In sum, it seems then that e-learning has the potential to improve access to education, to enhance the quality of learning, and to maintain flexible and interactive learning, and therefore, it is small wonder that higher education institutes are moving towards elearning. As a result, e-learning can be seen as a potential solution to issues in the higher education system and tertiary-level IM education in Sri Lanka (these issues have been discussed in sections 2.2.3.4 and 2.2.4.1).

\subsubsection{Why e-learning in Sri Lankan tertiary education?}

One of the Sri Lankan government's goals is to improve the higher education sector and thereby achieve their vision of "Sri Lanka to be an international hub of excellence for higher education by 2020" (Ministry of Higher Education of Sri Lanka, 2015b).

As discussed in section 2.2.3.4, driven by problems of access, equity, relevance, and quality in higher education, the Government of Sri Lanka (GOSL) plans a modern online higher education system as a new approach to solving these problems (Abeywardane, 2009). By doing so, GOSL attempts to fulfil the demand for higher education and increase tertiary enrolments (Warnapala, 2009).

Since the Sri Lankan tertiary education system has been unable to meet the labour market's needs (World Bank, 2007, 2009) the World Bank suggests a number of solutions to develop the Sri Lankan higher education sector as well as to develop a university education more relevant to the labour market. One is to make university education 'more demand driven, quality conscious and forward looking' (World Bank, 2007). Another one is expansion of access to higher education in areas of economic and social importance (World Bank, 2009). Yet another is improved teaching and learning in higher education by strengthening the skills of academic staff in student-centred and activity based teaching (p. E16). Moreover the World Bank suggests the implementation of e-learning is an area where Sri Lanka can benefit (p. 37).

The above Sri Lankan government goals and the World Bank recommendations emphasize why it is worthwhile to consider e-learning in Sri Lankan tertiary education. However, there is currently very little understanding of how to carry out these suggestions. 
Apart from the above requirements of the higher education sector, tertiary-level IM education in Sri Lanka faces a number of equity issues (discussed in section 2.2.4.1). In order to minimize the barriers in the field of IM education, the QAAC in Sri Lanka has recommended that one of the IM education provider organizations should 'take necessary steps to commence e-learning courses for both internal and external students' (Quality Assurance and Accreditation Council of Sri Lanka, 2008, p. 13). However it is unclear what 'the necessary steps' might be and whether they are being taken.

In sum, it is obvious that e-learning is a widely recommended solution for access, equity, relevance, and quality problems in higher education (including tertiary-level IM education) in Sri Lanka. The previous section 2.3.2.1 has shown that e-learning has the potential to solve these problems.

\subsubsection{Concepts of e-learning}

E-learning is a very broad, inclusive term for learning which occurs through the medium of information and communication technologies (ICTs). Different terms are used to describe learning through ICT and these terms provide different/varying meanings - they are not synonyms. Commonly used terms are digital teaching and learning (DTL), virtual learning communities (VLC), technology enhanced learning (TEL), mobile learning, webbased learning, online learning, distributed learning, computer assisted instruction (also called computer-based training or internet-based learning), computer mediated communication, virtual classrooms, I-campus and computer-driven interactive communication. Different variations of the term are also used to represent electronic learning (Moore, Dickson-Deane, Galyen, 2011): e-learning, e-Learning, E-Learning, and elearning. Due to these inconsistencies of terms and their meanings and the range of educational issues which will be discussed later in this Chapter, there are diverse and conflicting definitions of e-learning (Boer \& Collis, 2002; Henry, 2001; Mont, 2005; Rajasinghham, 2009b; Siritongthaworn et al., 2006; Watkins, 2009). This makes it difficult to find a single definition of e-learning that would be agreed on by the majority of the scientific community (Sangra, Vlachopoulos, \& Cabrera, 2012). It is therefore necessary to define the meaning of e-learning as used in this research.

Sangra, Vlachopoulos, and Cabrera (2012) reviewed the literature on e-learning and its definitions in the field of education and ICT and developed a conceptual framework to 
build an inclusive definition of e-learning. They identified four general categories of elearning definitions: 1) technology-driven, 2) delivery system-oriented, 3) communication-oriented, and 4) educational paradigm-oriented. This section selects and reviews several definitions of e-learning from technological (technology-driven) and teaching/learning perspectives (educational paradigm-oriented) in order to understand the relationship between technology and teaching/learning. Then an appropriate definition of e-learning is selected to be used in this research.

The definitions of e-learning can be seen as comprising a spectrum. At one extreme is elearning as a transmission mode based around instruction, emphasizing delivery of knowledge. At the other extreme is e-learning as a facilitator of collaborative learning based around construction, emphasizing creation of knowledge. I will now give an overview of these opposing views.

Fry (2000) defines e-learning as "delivery of training and education via networked interactivity and a range of other knowledge collection and distribution technologies" while Wesley (2002) asserts e-learning to mean "dissemination of educational materials through the internet, an intranet, or extranet" (p. 41). In addition, Engelbrecht (2003) defines e-learning as "instruction delivered via all electronic media including the internet, intranets, extranet, satellite broadcast, audio/video tape, interactive TV, and CD-ROM" (p. 38). The above three definitions refer to e-learning as a transmission mode since they all emphasize delivery of education via various electronic forms or they use ICT primarily as a delivery mechanism.

It seems then, that in the early definitions of e-learning (e.g. Fry, 2000; Wesley, 2002; Engelbrecht, 2003) technology is used as the primary delivery mechanism. It seems they use communication in terms of receiving and transmitting information using a kind of mediating technological tool. This type of learning/teaching represents traditional instructivist-based pedagogy where the teacher communicates and transfers knowledge to students.

In contrast, Dabbagh (2005) defines e-learning as an "open and distributed learning environment that utilizes pedagogical tools enabled by internet and web-based technologies to facilitate learning and knowledge building through meaningful action and interaction" (p. 31). This definition centres attention on 'interaction', and the role of the 
teacher in "learning and knowledge building through meaningful action and interaction". The term 'interaction' acknowledges the importance of communication and relationships as a feature of the learning and the pedagogy. Hence, interaction is one of the key features of e-learning (Abrami et al., 2006; Dabbagh, 2005; Garrison \& Anderson, 2003; Ministry of Education of New Zealand, 2002) as well as an essential element in the learning process and the pedagogy (Weistra, 2000).

Sarmento and Durao (2009) define e-learning as "the use of new multimedia technologies and the internet to improve the quality of learning by facilitating access to resources and services as well as remote exchange and collaborations" (p. 45). This definition refers to technology as a facilitator of collaborative learning. The collaboration is a specific approach within the broader context of pedagogy (Collis \& Moonen, 2005, p. 277).

In addition, the New Zealand Ministry of Education's e-learning action plan defines the term e-learning as "learning and teaching that is facilitated by or supported through the smart use of information and communication technologies (ICTs)" (Ministry of Education of New Zealand, 2006, p. 2). These ICTs include tools such as interactive whiteboards (IWBs), handheld devices like cell phones, digital cameras or voice recorders, or PDAs (Personal Digital Assistants), as well as computers and specific software applications. Wright (2010, p. 7) uses the above definition in her report and emphasizes 'communication' as the most important word in ICT since it refers to the "ability to receive, create and transmit information and/or new knowledge using a mediating technological tool of some kind" (p.7). It also implies the collaborative nature of learning. Another theme of this definition is the interactive nature of communication brought about by ICTs. The term 'smart use' also implies "practices that are strategic, nimble, just in time and pedagogically appropriate" (Wright, 2010, p. 7). These smart use practices facilitate effective interaction. Moreover, the definition of e-learning in the New Zealand Ministry of Education's e-learning action plan encompasses the full range of possibilities, i.e., delivering and collaborative e-learning but with more emphasis on collaborative elearning based around construction.

It seems then, that in the latest definitions of e-learning (e.g. Dabbagh, 2005; Ministry of Education of New Zealand, 2006; Sarmento \& Durao, 2009) technology is used to facilitate collaborative learning and involves communication in terms of "receiving, 
creating, and transmitting information and/or new knowledge using a mediating technological tool of some kind" (Wright, 2010, p. 7), as well as using the interactive nature of communication brought about by ICTs (Earl \& Forbes, 2008). This type of learning/teaching emphasizes constructivist-based pedagogy where the teacher becomes a facilitator, the learner constructs knowledge through experience, and learning can be altered and negotiated in collaboration with others (Ally, 2008).

In the context of this research, I use the term e-learning from a collaborative and constructivist perspective, since higher education institutes around the world are shifting towards to more constructivist approaches (Owen, Grant, Sayers, \& Facer, 2006) because they understand that the new ways of teaching and learning are required to meet the needs of a new generation of learners (McLoughlin \& Lee, 2007). Developing countries, e.g., Sri Lanka, also understand the importance of new pedagogy. For example, the World Bank (2009) recommends that Sri Lankan universities need to move towards studentcentred and activity-based teaching and modern assessment. By doing thus, students will benefit from modern pedagogical and assessment methods (p. E 16). Based on key initiatives for the development of the higher education sector in Sri Lanka, I have selected the New Zealand Ministry of Education's definition of e-learning as an appropriate definition for this research. It represents the collaborative and constructivist-based approach to e-learning as well as encompassing the full range of possibilities, i.e., delivering and collaborative e-learning but with more emphasis on collaborative elearning based around construction.

In addition, in some cases Sri Lanka uses New Zealand as a point of reference. For example, to establish a quality assurance system for the higher education sector in Sri Lanka, the World Bank has recommended New Zealand as one of the reference points. Hence, it is appropriate to use the definition of e-learning of the New Zealand Ministry of Education. Therefore, this research uses the term 'e-learning' to denote "learning and teaching that is facilitated by or supported through the smart use of information and communication technologies (ICTs)".

However, a previous study confirmed that different countries continue to use the elearning term in very different ways (Moore, Dickson-Deane, \& Galyen, 2011). For example, in New Zealand, e-learning refers to the use of ICT to enhance learning which 
includes ICT in support of face-to-face teaching, face-to-face plus online learning (blended learning), and fully online learning (distance learning). In the context of this research, I will use the term e-learning in a narrower sense than the New Zealand version but focussing on the collaborative and constructive aspects. For example, in my study elearning includes face-to-face plus online learning and fully online learning but does not includes ICT in support of face-to-face teaching because one of the research issues is distance.

This section identified two contrasting educational practices in e-learning. The next section further discusses this pedagogical shift in e-learning.

\subsubsection{Pedagogical shift in e-learning}

Boer and Collis (2002) identify the pedagogical shift in e-learning in terms of a move from an acquisition orientation, i.e., instructivist, to a contribution orientation, i.e., constructivist, while Ehlers (2009) identifies the pedagogical shift in terms of acquisition to participation. Technology has also evolved to support this shift, for example, web 2.0, e-learning 2.0, and pedagogy 2.0. These pedagogical shifts and technology are discussed in detail in this section and the next section 2.3.2.2.

Pedagogy can be described as 'the art or science of teaching' (Boer \& Collis, 2002; Collis \& Moonen, 2005) and the "knowledge and skills that practitioners of the profession of teaching employ in performing their duties of facilitating desired learning in others" (Dunkin, 1987, p. 319). The fundamental differences between instructivist and constructivist-based pedagogies are their "pedagogical methods and the roles of the teacher and learner" (Porcaro, 2011, p. 40).

Instructivism refers to well-formulated, teacher-directed, and didactic practices (Porcaro, 2011, p. 40). Regarding pedagogical methods, instructivists communicate and transfer knowledge to students as efficiently and effectively as possible (Bednar, Cunningham, Duffy, \& Perry, 1991). This method is also known as the traditional or authoritarian transmission model of education (Dewey, 1916; Freire, 1970; Garrison \& Anderson, 2003). Since the teachers deliver predetermined pieces of information, the role of the students is to listen, recall facts and repeat what the teacher says (Dewey, 1916; Freire,1970; Garrison \& Anderson, 2003). Hence, students are passive recipients of teacher-delivered information and they are expected to work individually, so the only 
interaction that takes place is between the individual student and teacher. This is the traditional education model which was retained in early e-learning efforts.

Constructivism refers to "student-centred forms of instruction, including social, situated, knowledge-creating and intersubjective pedagogies" (Porcaro, 2011, p. 40). In constructivism, learners construct knowledge through experience and learning can be altered and negotiated in collaboration with others (Ally, 2008; Dewey, 1916; Rovai, 2004). Thus, the teacher's role becomes that of a facilitator, tutor, or mentor while the student's role becomes the centre of learning as a participant in a community of practice (Porcaro, 2011). This constructivist-based pedagogy is most advocated in e-learning (Garrison \& Anderson, 2003; Rovai, 2004). Table 2.4 further summarizes the clear distinction between instructivism and constructivism.

\begin{tabular}{|c|c|c|c|c|}
\hline & \multicolumn{2}{|c|}{ Instructivism } & \multicolumn{2}{|c|}{ Constructivism } \\
\hline & Behaviourism & Cognitivism & $\begin{array}{l}\text { Cognitive } \\
\text { constructivism }\end{array}$ & $\begin{array}{l}\text { Socio-cultural } \\
\text { constructivism }\end{array}$ \\
\hline \multicolumn{5}{|l|}{ Pedagogy } \\
\hline Learning goals & $\begin{array}{l}\text { Mapping the } \\
\text { structure of the } \\
\text { world onto the } \\
\text { learner; effective } \\
\text { and efficient } \\
\text { knowledge transfer }\end{array}$ & $\begin{array}{l}\text { Mapping the } \\
\text { structure of the world } \\
\text { onto the learner; } \\
\text { effective and efficient } \\
\text { knowledge transfer }\end{array}$ & $\begin{array}{l}\text { Creating } \\
\text { elaborations and } \\
\text { interpreting } \\
\text { knowledge }\end{array}$ & $\begin{array}{l}\text { Flexible thinking } \\
\text { skills and the } \\
\text { domain practices } \\
\text { for lifelong } \\
\text { learning }\end{array}$ \\
\hline $\begin{array}{l}\text { Pedagogy and } \\
\text { use of tools }\end{array}$ & $\begin{array}{l}\text { Computer-assisted } \\
\text { instruction, } \\
\text { programmed } \\
\text { instruction, } \\
\text { instruction } \\
\text { sequencing } \\
\text { behavioural } \\
\text { objectives, and } \\
\text { feedback }\end{array}$ & $\begin{array}{l}\text { Intelligent tutors, } \\
\text { advanced organizers, } \\
\text { learning hierarchies, } \\
\text { concept maps, and } \\
\text { instructional design }\end{array}$ & $\begin{array}{l}\text { Discovery learning, } \\
\text { Lego-LOGO, } \\
\text { negotiated } \\
\text { objectives, multiple } \\
\text { resources }\end{array}$ & $\begin{array}{l}\text { Authentic tasks; } \\
\text { cognitive } \\
\text { apprenticeships; } \\
\text { multiple } \\
\text { perspectives/ } \\
\text { argumentation; } \\
\text { CSCL; anchored } \\
\text { instruction; and } \\
\text { problem- } \\
\text { based/inquiry- } \\
\text { based learning }\end{array}$ \\
\hline Learner's role & $\begin{array}{l}\text { Recipient of } \\
\text { teacher's } \\
\text { instruction }\end{array}$ & $\begin{array}{l}\text { Recipient of teacher's } \\
\text { instruction }\end{array}$ & $\begin{array}{l}\text { Active constructor } \\
\text { of knowledge and } \\
\text { centre of learning } \\
\text { environment }\end{array}$ & $\begin{array}{l}\text { Centre of learning } \\
\text { and participant in } \\
\text { community of } \\
\text { practice }\end{array}$ \\
\hline Teacher's role & $\begin{array}{l}\text { Centre of } \\
\text { instruction; } \\
\text { controls instruction } \\
\text { process and content }\end{array}$ & $\begin{array}{l}\text { Centre of instruction; } \\
\text { controls instruction } \\
\text { process and content }\end{array}$ & $\begin{array}{l}\text { Ranges from } \\
\text { minimally guided } \\
\text { to facilitator }\end{array}$ & $\begin{array}{l}\text { Facilitator, tutor, } \\
\text { and mentor }\end{array}$ \\
\hline Assessment & $\begin{array}{l}\text { Individual, } \\
\text { criterion- } \\
\text { referenced }\end{array}$ & $\begin{array}{l}\text { Individual, criterion- } \\
\text { referenced }\end{array}$ & $\begin{array}{l}\text { Multiple goals, } \\
\text { contextual, } \\
\text { authentic } \\
\text { assessment }\end{array}$ & $\begin{array}{l}\text { Multiple goals, } \\
\text { contextual, } \\
\text { authentic } \\
\text { assessment }\end{array}$ \\
\hline
\end{tabular}

Table 2.4 - Instructivism versus constructivism Adapted from Porcaro, 2011, p. 42 
Boer and Collis (2002) argue this pedagogical change is a pedagogical shift in e-learning from an acquisition orientation to a contribution orientation. They argue that in the traditional learning model of distance education, objectives exist separately from the learner (p. 415). Hence learners are the recipients/consumers of predetermined material (Reeves \& Reeves, 1997) because "most courses are structured to transmit knowledge putting disciplines in to bite-sized units that are to be taught [in] lectures across a series of weeks" (Nicaise \& Crane, 1999, p. 29). These characteristics emphasize the acquisition orientation, i.e., instructivist-based pedagogy. In contrast, contribution-oriented pedagogy represents different kinds of learning activities, different methods of student assessment and different uses of computer technology (Boer \& Collis, 2002; Collis \& Moonen, 2005). For example, in the contribution-oriented approach i.e., constructivistbased pedagogy, students engage more directly with the learning process as contributors and they learn from realistic and peer-created materials as much as or more than professionally developed materials (Boer \& Collis, 2002). Technology facilitates all aspects of the activities to make the contributions accessible to and reusable by other learners. Some typical activities/examples that follow the collaborative or constructivist approach are searching for information (Collis \& Moonen, 2001, pp. 99-101), "creating a report to be used as a learning resource, testing one's insight through the development of test questions to be used by others" (pp. 99-101), having task-directed discussions (Dineen, Mayes, \& Lee, 1999), collaborative knowledge construction (Fischer, Troendle, \& Mandl, 2003), peer mentoring (LaMaster \& Tannehill, 1999), role-play games (Jasinski \& Thiagarajan, 2000), and participating in peer-assessment activities (Tsai, Lin, \& Yuan, 2002).

Boer and Collis (2002) refer to a pedagogical shift in e-learning from an acquisition orientation to a contribution orientation, reflecting a shift from instructivist to constructivist-based pedagogy.

In sum, it is obvious that there has been a pedagogical shift in e-learning and there is more and more literature based on constructivist-based learning. However, technology has also evolved to support this shift as discussed in the next section. 


\subsubsection{Emerging technology that offers support for e-learning changes}

New technologies have evolved to support active participation, collaboration, sharing and development of knowledge among learners. Therefore, technology supports e-learning's transition from transferring knowledge to creating knowledge.

The evolution of the web can be divided into the personal computer (PC) era (19801990), web 1.0 (1990-2000), web 2.0 (2000-2010), web 3.0 (2010-2020), and web 4.0 (2020-2030) (Dominic, Francis, \& Pilomenraj, 2014). However, this section discusses web 2.0 as it encompasses the current use of technology and web 3.0 is still at the development stage.

The term 'Web 2.0' was coined by O'Reilly in 2005 for collaborative, user-centric content production and interactive content access (O'Reilly, 2005). It can also be defined as "second generation or more personalized, communication form of the World Wide Web that emphasises active participation, connectivity, collaboration and sharing of knowledge and ideas among users" (McLoughlin \& Lee, 2007, p. 665) and further described as the 'Read-Write Web' (Price, 2006; Richardson, 2006).

Web 2.0 applications include web logs (blogs), wikis, Really Simple Syndication (RSS), podcasting, social networking sites, tag based folksonomies and peer-to-peer media sharing utilities (Alexander, 2006; Allen, 2004). This new social software has the potential to address the needs of today's students by enhancing their learning experiences through customization, personalization and rich opportunities for networking and collaboration (Bryant, 2006) and fostering interaction. As a result, web 2.0 supports new e-learning pedagogy, i.e., a social-constructivist pedagogical strategy where learners interact and learn together.

Downes (2005) coined the term 'e-learning 2.0' for the application of the web 2.0 ideas in both e-learning technology and methodology. This is a new and innovative learning environment and represents the next stage after e-learning 1.0 (Ehlers, 2009). Ehlers (2009) sees this development as a pedagogical shift from acquisition to participation. Elearning 1.0 emphasized the metaphor of 'acquisition' - learning was perceived as an acquisition of learning content, for example, information and materials were distributed, presented, and made available to students - while e-learning 2.0 emphasizes the 
metaphor of 'participation' and is perceived as a social process (p. 298). Thus web 2.0 tools are used to develop a student-centred learning environment through collaboration and communication among participants. Figure 2.12 shows the distinctions between elearning 1.0 and e-learning 2.0. It illustrates the pedagogical shift from acquisition to participation.

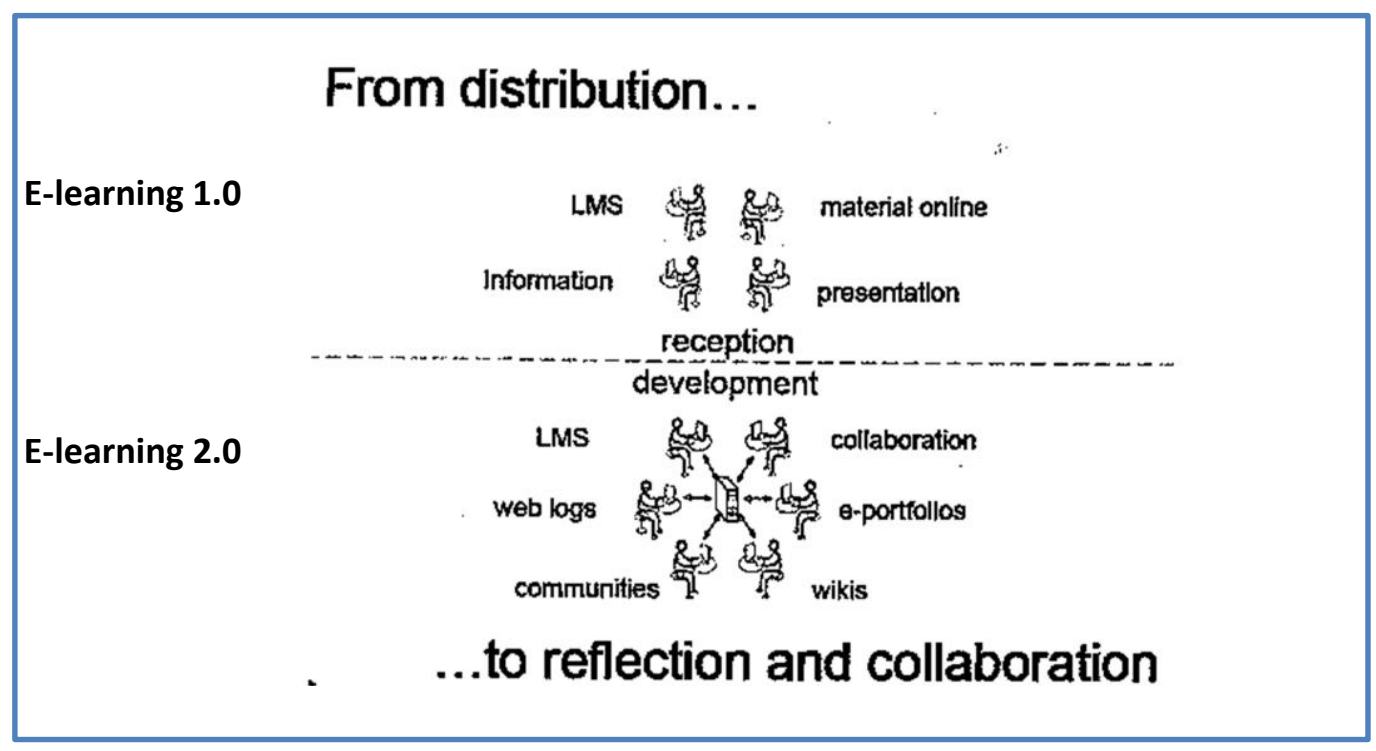

Figure 2.12 - Change in the landscape of e-learning Adapted from Ehlers, 2009, p. 298

Pedagogy 2.0 represents new landscapes of teaching and learning. Efimova's (2004) framework for knowledge creation in web 2.0 (see Figure 2.13) describes how pedagogy 2.0 is formed.

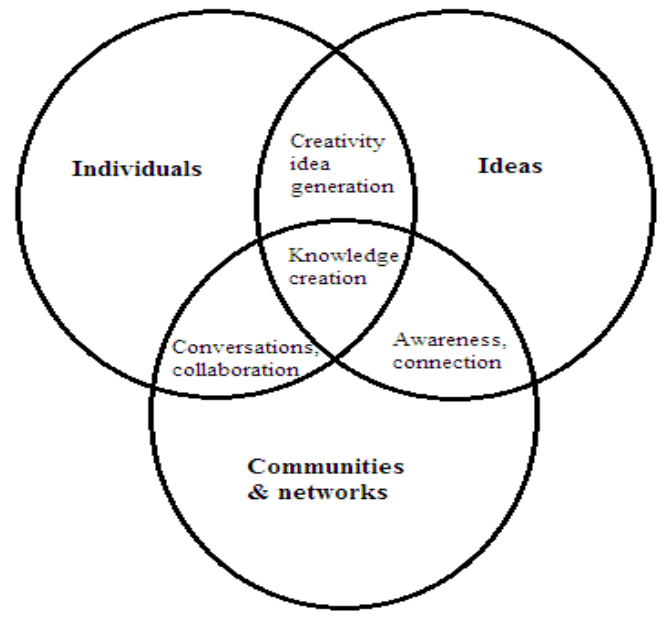

Figure 2.13 - Framework for knowledge creation in web 2.0 Adapted from Efimova, 2004, p. 12 
Figure 2.13 shows how individuals combine with communities and networks in the process of knowledge sharing and construction and understanding. The "interdependence between ideas, individuals, communities and information networks, supported by technology, underpins the demands of pedagogy 2.0" (McLoughlin \& Lee, 2007 , p. 668). This includes a number of dimensions in order to offer a wide range of choices to individuals to suit their personal needs and goals (p. 668). They are: content, curriculum, communication, process, resources, scaffold, and learning tasks (p. 669).

Pedagogy 2.0 technologies include iPod photos, podcasts, bilingual podcast feeds and blogs, and wiki-based encyclopaedias. These technologies support constructivist pedagogy such as peer-to-peer learning, and resource-based and collaborative learning. They illustrate the power of social software to support learner-centred pedagogies and improve learners' freedom to decide how to engage in personally meaningful learning through connection, collaboration, and shared knowledge building. Therefore, pedagogy 2.0 has the potential to enhance e-learning pedagogy, i.e., constructivist-based pedagogy/social-constructivist pedagogy.

According to the discussion in sections 2.3.1.1 and 2.3.1.2, there has been a pedagogical shift in e-learning. The rapid expansion and proliferation of technologies has created a new platform for e-learning. For example, social software encourages collective contribution/active collaboration (Jenkins, 2006).

\subsubsection{Key issues of e-learning}

There are a number of issues when it comes to introducing e-learning in a developing country like Sri Lanka. Sri Lanka has its own unique social and cultural contexts that may considerably affect the adoption and use of e-learning.

The literature has highlighted many issues of e-learning that are especially related to developing countries. These issues fall into four categories: organizational issues, technological issues, pedagogical issues, and social and cultural issues.

\subsubsection{Organizational issues}

Undertaking e-learning requires change (Meyer, 2001; Petrusa et al., 1999) but changes cannot be easily made especially within the traditional learning environment (Rajasinghham, 2009b, p. 19). One of the main barriers is resistance to change including 
staff resistance (Gunn, 2000; Guri-Rosenblit, 2005b; Meyer, 2001; Mont, 2005; O’Neill et al., 2004; Petrusa et al., 1999). This barrier occurs with e-learning programme development and implementation (Childs et al., 2005). For example, some teaching staff are reluctant to use new technologies (Guri-Rosenblit, 2005b), adopting and developing e-learning programmes is time-consuming (Grigg \& Stephens, 1998) and quality standards are lacking (D’Alfonso \& Halvorson, 2002; Goddard, 2000; Rajasingham, 2009a). Hence, universities require extensive change management strategies (Watkins, 2009, p. 590).

In addition, organizations in most third world countries/developing countries lack the appropriate infrastructure to use the new technologies (Bernath \& Hulsmann, 2004; Fernando, 2008; Gunawardana, 2005) since the governments of these countries have to prioritize their funds for meeting basic needs, i.e., food, water supply, clothing, roads and transportation, and therefore IT infrastructure is a relatively low priority (Fernando, 2008). As a result, equipment such as servers, routers, cabling, laboratories, computers, etc., are usually obtained under special university budgets or grants and loans from funding agencies but frequent upgrades are unlikely (p. 1884). Siritongthaworn et al. (2006) explain this barrier as insufficient support systems or resources which include hardware (D’Alfonso \& Halvorson, 2002; Gonce-Winder, Kidd, \& Lenz, 1993), software/equipment (D’Alfonso \& Halvorson, 2002; Daugherty \& Funke, 1998; Turchin \& Lehmann, 1999), technical support (Keller et al., 2009, D’Alfonso \& Halvorson, 2002; Daugherty \& Funke, 1998; Meyer, 2001; Schleyer, 1998) the time required to learn how to use the technology (Becker, Newton, \& Sawang, 2013; Keller et al., 2009) and the time required for developing and monitoring courses, training, and funding (Pajo \& Wallace, 2001; Chung, Lee, \& Liu, 2014).

In order to overcome these organizational issues, Chung, Lee, and Liu (2014), Childs et al. (2005) and Guri-Rosenblit (2005b) suggest that there should be a national approach and support policy initiatives.

\subsubsection{Technological issues}

Technology is fundamental to e-learning (Engelbrecht, 2003) because e-learning is dependent on access to electronic communication technologies. However access to IT is a major barrier in developing countries and it is widening the digital divide between 
haves and have-nots (Gulati, 2008). E-learning could disadvantage those on the wrong side of the digital divide (Gladieux \& Swail, 1999; Kawachi, 2003). Latchem and Jung (2010) see Asia's digital divide as a part of a broader social and economic divide. However, Khafagi (2004) points out that a number of factors can affect access to IT. They are: i) problems of internet and broadband supply and access; ii) the high connection costs for households, businesses, and the public sector; and iii) a lack of expertise and experience.

The internet is a major driver of e-learning advancement. Hence, bandwidth becomes an important factor in access to e-learning (What is electronic learning, n.d.). For example, Table 2.5 shows the required bandwidth for various e-learning applications.

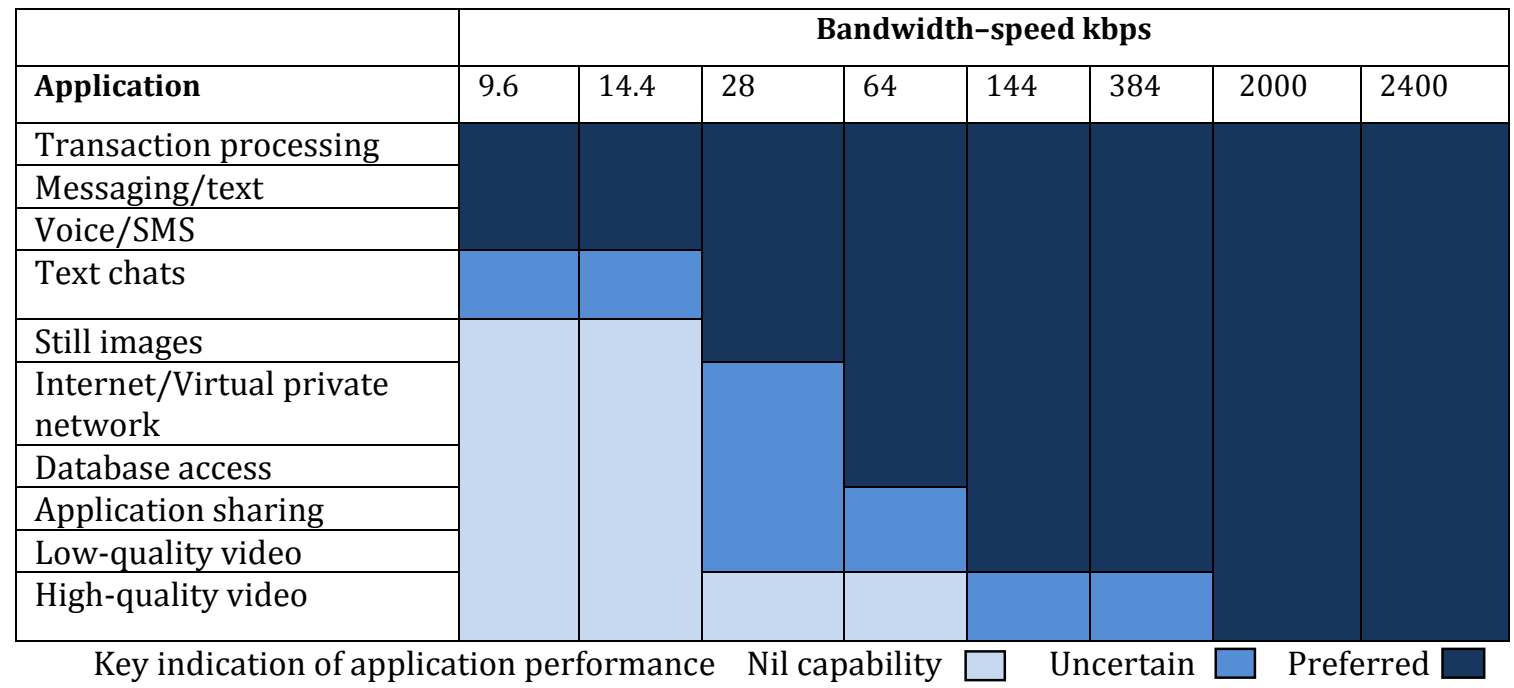

Table 2.5 - Bandwidth and e-learning application (What is electronic learning, n.d., p. 15)

Limited bandwidth is also an issue for developing countries (Daniel et al., 2006). For example, the university sector in Sri Lanka normally maintains 128 or 64 kbps links (Fernando, 2008). This can cause downloading to be very slow and have a negative effect on the learning process (Takalani, 2008). However, as a result of technology development, wireless technologies can be used to minimize these barriers (What is electronic learning, n.d.) but cost is still a problem.

E-learning costs more than conventional face-to-face teaching (Bates, 2001; GuriRosenblit, 2001, 2004; Hulsmann, 2004; Matkin, 2002; Ryan, 2002; Salmon, 2005) due to its wide range of associated costs. One of the associated costs is hardware costs. These include start-up costs and providing sufficient equipment, as well as ongoing costs of keeping this equipment up to date (D’Alfonso \& Halvorson, 2002; Gonce-Winder et al., 
1993; Grigg \& Stephens, 1998; Guri-Rosenblit, 2005b; Schittek, Mattheos, Lyon, \& Attstrom, 2001; Schleyer, 1998).

Another cost is software, mainly for licences (D'Alfonso \& Halvorson, 2002; Grigg \& Stephens, 1998; McAuley, 1998; Schittek et al., 2001). Henderson (1998) and McAuley (1998) highlight the programme development cost in e-learning.

The establishment of some kind of support system for students as well as teachers is important (Guri-Rosenblit, 2005b); in particular, ongoing support is needed for students, particularly weak students (Collis \& Moonen, 2001; Littleton \& Light, 1999; Scott et al., 2002; Somekh \& Davis, 1997). This creates costs for training and development (D'Alfonso \& Halvorson, 2002; Grigg \& Stephens, 1998; Rafferty, 2003) and costs of building and materials (Bates, 1999, 2001; Rafferty, 2003). In addition, electricity and internet access are unavoidable costs (Bates, 2001).

Since the adoption of e-learning is constrained by high costs (Kawachi, 2003), Watkins (2009) emphasizes that long term funding for e-learning is essential. This is an important factor for developing countries since they lack education infrastructure as well as economic structures (Gulati, 2008). Nonetheless Gulati (2008) suggests that "e-learning does have the potential to meet the educational needs of masses of poor people in developing countries" (p. 11).

Furthermore, power outages can also pose a serious threat to e-learning in developing countries (Eke, 2010).

\subsubsection{Pedagogical issues}

Using new technology, e-learning will require teachers to take on new roles such as facilitator and mediator. For example, Thiele, Allen, and Stucky (1999) suggest that teachers need to prepare for changing roles, from being an instructor who dispenses knowledge to being a facilitator who guides and supports learning. Ouellette and Briscoe (2002) suggest that learners need to be reassured by teachers as they confront technological challenges. However the major issue is resistance to the need for change in teaching methods with unclear or no guidance or good practice (Govindasamy, 2002; Ouellette, 2000; Sosabowski, Herson, \& Lloyd, 1998). This barrier again creates a number of issues. For example, this affects students' e-learning adoption. Van Lee et al. (2002), 
Pailing (2002), and Govindasami (2002) found that students are reluctant to use elearning due to the failure of educators and organizations to provide quality content and to create effective, interactive e-learning experiences.

Academic staff are naturally reluctant to change their pedagogical approach without a deeper understanding of the impact on quality and any resultant benefits (Salmon, 2005). On the other hand, staff members who lack experience in e-learning may think of elearning as a 'technical solution' rather than a pedagogical innovation (p. 205).

Assessment (Salmon, 2005; Collis \& Moonen, 2005), quality assurance, and dissemination of best practice in e-learning are other issues because the quality of e-learning is still variable (Blicker, 2005; Ehlers, 2004; McGorry, 2003; Salmon, 2005). In addition, focus on quality is recommended for e-learning initiatives (Bhuasiri, 2012; Megatrends Project $2007,2007 a)$, and therefore quality assurance strategies need to be chosen carefully.

Another issue is the workload of the lecturers (Moore, 2000) who lack the experience and training in online course development. E-learning requires teachers and learners to have a specialized set of skills. Teachers may lack appropriate skills, i.e., information literacy (Hrtoňová et al., 2015) and require training in course design, development and delivery of e-learning, IT, and information management (Schittek et al., 2001). Similarly, learners may lack the necessary skills to participate fully in e-learning: IT skills (Suri \& Sharma, 2012), e-learning methodology, critical evaluation, and internet searching (Mamary \& Charles, 2000; Thiele et al., 1999). Thus, Copeland (2001) points out that if e-learning is a key element of the university's education, there should be a programme of staff development and training.

Teachers need to know how learning and teaching processes change when incorporating new technologies, and when teachers and students are not present together at the same time and place (Orly, 2007). This is a prerequisite for successful implementation (Engelbrecht, 2003), and therefore, needs careful consideration of underlying pedagogy (Govindasami, 2002).

\subsubsection{Social and cultural issues}

Fernando (2008) examined the issues of e-learning in third world countries and discussed the influence of the social-cultural setting, especially in South Asian countries, 
on how people engage in learning activities (p. 1885). For example, Fernando identified verbal and physical interaction as the most significant factors in the South Asian context when dealing with education. Adeoye and Wentling (2007) also discussed the effects of cultural differences on individuals' use of e-learning systems. Moran and Myringer (1991) state that new technology and learning methods, i.e., socio-constructivist and collaborative learning, change teachers' roles and relationships with their students. In some Asian contexts, introducing new technology and learning methods into existing systems could be a problem because of the behaviour and attitudes such as cultural respect for the teacher, textbook dependency, and the test/exam-focused style of learning (Latchem \& Jung, 2010).

Hofstede's Power Distance Index (PDI) has been used extensively to measure how culture affects the nature of organizations and relationships (Hofstede, 1980, 1991; Hofstede, Hofstede, \& Minkov, 2010). According to this index, high power distance countries have centralised political power, hierarchical organizations and large differences in status and income while low power distance countries have flatter organizations and greater equality. Asian countries score highly on the power distance index. This explains why Asian learners have great respect for their teachers. Therefore, they regard themselves as inferior and prefer passive, instructivist learning rather than interacting with their teachers in person or online (Wang, 2007). Keller et al. (2009) examined the impact of national culture on e-learning implementation and identified that high power distance countries prefer one-way teaching and therefore, education there is teacher-centred. This could pose a problem for the introduction of constructivist e-learning.

Another of Hofstede's (1980, 1991, 2010) cultural dimensions is individualism and collectivism. In an individualist society the ties between individuals are loose: "everyone is expected to look after himself/herself and his/her immediate family only" (Hofstede, Hofstede, and Minkov, 2010, p. 92). In collectivist societies "people from birth onwards are integrated into strong, cohesive in-groups, which throughout people's lifetimes continue to protect them in exchange for unquestioning loyalty" (p. 92). Richer countries are generally categorized as individualistic whereas poorer countries are more collectivist. Sri Lanka is one of the collectivist countries. The same theory applies to people from a rural background; they tend to be more collectivist than those from an urban background (Hofstede, 1991; Hofstede et al., 2010). This dimension affects 
learning style, i.e., a learner's behaviour and responses (Toland, Frank, \& Schenk, 2005). For example, students in collectivist cultures prefer to listen and they are reluctant to speak up in the class since communication is expected to be teacher-centred (Toland, Frank, \& Schenk, 2005; Keller et al., 2009). Further, they prefer face-to-face contact, reliance on textbooks, and passive learning (Kawachi, 2003; Siritongthaworn et al., 2006). Young, Young, Kuo and Myers (2012) found that in a strong collectivist culture having a conversation with teachers is to do with 'face-work'. These cultural characteristics are a potential problem when introducing e-learning in developing countries like Sri Lanka because one of the fundamental requirements of constructivist e-learning is that students should be active learners, not passive recipients of prepackaged information (Andersson, Hedstorm, \& Gronlund, 2009).

Catterick (2007) also points out similar issues and emphasizes that constructivism can be a disadvantage for non-Western students since they are unfamiliar with constructivist-oriented education. This view is shared by Burn and Thongprasert (2005), Pagram and Pagram (2006), and Usun (2004) who claim that most developing countries have an authoritarian educational culture (i.e., instructivism) and students are accustomed to a transmission-based pedagogical model. This is a potentially significant problem in introducing e-learning to countries like Sri Lanka.

Porcaro (2011) develops a conceptual model to help non-Western societies to introduce constructivism to their instructivist-oriented learning cultures. It shows that "innovations or pedagogical methods and learning environments are at the intersection of teachers' and students' educational philosophies, institutional systems and national context" (p. 45). Porcaro's framework highlights that the national context and institutional factors including resources, policies, and institutional culture have an influence on innovation in education, especially teaching.

Cultural differences between Western and Asian ways of communicating may also be an important factor (Latchem \& Jung, 2010). According to Hall (1976, 2000), communication in low-context Western culture is logical, precise, and action-oriented while in highcontext Asian cultures, it is more indirect and formal. Meaning is gathered through tone of voice, use of silence, facial expression, body language, and the status of speakers. These 
characteristics may lead Asian teachers to resist aspects of technology use where context is not easily communicated (Latchem \& Jung, 2010, p. 15).

Porcaro's framework highlights that the national context and institutional factors including resources, policies, and institutional culture influence innovation in education. These factors can be seen as success factors for the use of e-learning. However, Porcaro's model has not been tested in practice, therefore there is no way of assessing how suitable this model would be in the Sri Lankan context.

In sum, it is obvious that there are organizational, technological, pedagogical, and social and cultural issues that affect e-learning. However, it remains unclear what factors or how these factors would affect the introduction and use of e-learning in tertiary-level IM education in Sri Lanka. For tertiary providers of IM education in Sri Lanka to plan and adopt e-learning to provide equitable access to IM education and to achieve the government's vision of higher education, potential issues and problems need to be identified.

\subsubsection{Critical success factors in the use of e-learning}

The previous section (2.3.3 - Key issues of e-learning) has identified critical factors that influence the success and failure of e-learning. Table 2.6 presents a synthesis of the issues identified in the literature.

\begin{tabular}{|c|c|}
\hline Factors/Issues & References \\
\hline 1. Organizational issues & \multirow{9}{*}{$\begin{array}{l}\text { Guri-Rosenblit (2005), O'Neill, Singh \& Donoghue (2004), } \\
\text { Meyer (2001), Petrusa et al. (1999), Mont (2005), Gunn, } \\
\text { (2000) } \\
\text { Fernando (2008), Bernath \& Hulsmann (2004), } \\
\text { Gunawardana (2005) } \\
\text { D'Alfonso (2002), Goncewinder (1993) } \\
\text { D'Alfonso (2002), Hayne (1989), Turchin \& Lehmann, } \\
\text { (1999), Daugherty \& Funke (1998) } \\
\text { Keller et al., 2009, Daugherty \& Funke (1998), Meyer } \\
\text { (2001), D'Alfonso (2002), Schleyer (1998) } \\
\text { Keller et al., 2009, Chung, Lee, \& Liu, 2014, Pajo \& } \\
\text { Wallance (2001), Becker, Newton, \& Sawang, } 2013 \\
\text { Child et al. (2005), Guri-Rosenblit (2005b), Porcaro } \\
\text { (2011) } \\
\text { Chung, Lee, \& Liu, 2014, Porcaro (2011) }\end{array}$} \\
\hline 1.1 Resistance to change & \\
\hline $\begin{array}{l}\text { 1.2 Lack of infrastructure/ insufficient } \\
\text { support systems or resources }\end{array}$ & \\
\hline - Hardware & \\
\hline - Software/equipment & \\
\hline - $\quad$ Technical support & \\
\hline - $\quad$ Time, training, and funding & \\
\hline 1.3 National approach & \\
\hline 1.4 Policy & \\
\hline 2. Technological issues & \multirow[b]{2}{*}{$\begin{array}{l}\text { Gulati (2008) } \\
\text { Khafagi (2004) } \\
\text { Khafagi (2004) }\end{array}$} \\
\hline $\begin{array}{l}\text { 2.1 Access to IT } \\
\text { - Digital divide } \\
\text { - Internet, broadband supply, \& access } \\
\text { - High connection costs }\end{array}$ & \\
\hline
\end{tabular}




\begin{tabular}{|c|c|}
\hline & \\
\hline - lack of expertise and experience & Khafagi (2004) \\
\hline 2.2 Limited bandwidth & What is electronic learning (n.d.) \\
\hline 2.3 High costs & $\begin{array}{l}\text { Bates (2001), Guri-Rosenblit (2001, 2004), Matkin } \\
\text { (2002), Ryan (2002), Hulsmann (2004), Salmon (2005) }\end{array}$ \\
\hline \multirow{2}{*}{$\begin{array}{l}\text { 2.3.1 Hardware costs } \\
\text { - Start-up, equipment, ongoing } \\
\text { costs }\end{array}$} & \\
\hline & $\begin{array}{l}\text { Grigg \& Stephens (1998), D'Alfonso (2002), Thomas } \\
\text { (1986), Goncewinder (1993), Hayne (1989), Schleyer } \\
\text { (1998), Schittek (2001), Guri-Rosenblit (2005b) }\end{array}$ \\
\hline $\begin{array}{l}\text { 2.3.2 Software costs } \\
\text { - Licences }\end{array}$ & $\begin{array}{l}\text { Grigg \& Stephens (1998), D'Alfonso (2002), Thomas } \\
\text { (1986), McAuley (1998), Hayne (1989), Schittek (2001), } \\
\text { Henderson (1998), McAuley (1998) }\end{array}$ \\
\hline - Programme development cost & \\
\hline $\begin{array}{l}\text { 2.3.3 Establishment of support system } \\
\text { - Training and development }\end{array}$ & $\begin{array}{l}\text { Grigg \& Stephens (1998), D'Alfonso (2002), Thomas } \\
\text { (1986), Rafferty (2003) }\end{array}$ \\
\hline - Building and materials & $\begin{array}{l}\text { Thomas (1986), Olson (2000), Rafferty (2003), Bates } \\
\text { (1999, 2001) } \\
\text { Bates (2001) }\end{array}$ \\
\hline - Electricity and internet access & \\
\hline \multicolumn{2}{|l|}{ 3. Pedagogical issues } \\
\hline 3.1 Resistance to change & $\begin{array}{l}\text { Govindasami (2002), Ouellette (1999), Sosabowski, } \\
\text { Herson, \& Lloyd (1998) }\end{array}$ \\
\hline 3.2 Lack of quality measurement & Salman (2005) Collis\&d Moonen (2005) \\
\hline $\begin{array}{l}\text { - Assessment } \\
\text { - Quality assurance, and } \\
\text { dissemination of best practice }\end{array}$ & $\begin{array}{l}\text { Ehlers (2004), Salmon (2005), Blicker (2005), McGorry } \\
\text { (2003), Megatrends project (2007, 2007a), Bhuasiri, } 2012\end{array}$ \\
\hline $\begin{array}{l}\text { 3.3 Subject related issues } \\
\text { 3.4 For teachers }\end{array}$ & Megatrends project 2007 (2007a) \\
\hline $\begin{array}{l}\text { - Lack appropriate skills \& } \\
\text { require training }\end{array}$ & Schittek (2001), Hrtonova et al. (2015) \\
\hline 3.5 For learners & \\
\hline $\begin{array}{l}\text { - Lack the necessary skill } \\
\text { - IT skills } \\
\text { - E-learning methodology } \\
\text { - Critical evaluation } \\
\text { - Internet searching }\end{array}$ & $\begin{array}{l}\text { Mamary \& Charles (2000), Thiele, Allen, \& Stucky (1999) } \\
\text { Suri \& Sharma (2012) }\end{array}$ \\
\hline \multicolumn{2}{|l|}{ 4. Social and cultural issues } \\
\hline 4.1 Power distance & $\begin{array}{l}\text { Hofstede (1980, 1990), Hofstede et al. (2010), } \\
\text { Wang (2007), Keller et al. (2009) }\end{array}$ \\
\hline 4.2 Individualism and Collectivism & $\begin{array}{l}\text { Hofstede (1980, 1990), Hofstede et al. (2010), Toland, } \\
\text { Frank, \& Schenk (2005), Keller et al. (2009) }\end{array}$ \\
\hline & Young, Kuo \& Myers (2012) \\
\hline 4.3 Ways of communication & Latchem \& Jung (2010), Hall $(1976,2000)$ \\
\hline 4.4 Language & Fernando (2008) \\
\hline
\end{tabular}

Table 2.6 - Critical success factors of use of e-learning

The factors identified in Table 2.6 will be used to develop a conceptual model of factors that are likely to affect the introduction and use of e-learning in tertiary-level IM education in Sri Lanka. 


\subsection{Summary of the literature review}

This Chapter has summarized theoretical and research-based literature of relevance to the research problem.

Section one has summarized the growing need for skilled and educated information managers in the field of information management in the global context and the importance of information management education is highlighted.

Section two has outlined relevant background information about Sri Lanka, its tertiarylevel education system, particularly tertiary-level IM education and its issues. Section two has also identified equity issues in tertiary-level IM education and presents QAAC's recommendation to commence e-learning.

The final section of the literature review has discussed the potential of e-learning and the reasons for moving towards e-learning, particularly for tertiary education in the Sri Lankan context. It has also discussed key issues in e-learning and the final part of the Chapter presents the critical success factors for the use of e-learning. The key findings of this section are that there is a lack of understanding of what factors and how these factors have an impact on the introduction and use of e-learning in tertiary-level IM education in Sri Lanka. 


\section{CHAPTER 3 - THEORETICAL CONSIDERATIONS}

A conceptual framework or model can serve as a useful guide for the researcher when conducting a study. It also helps readers to understand the pertinent concepts and issues that the researcher has set out to study (Creswell, 2003; Powell \& Connaway, 2004). The

previous Chapter summarized a number of factors of potential relevance to this study (See Table 2.6). The current Chapter reviews a number of relevant theories and identifies those that are most relevant to this study. It combines insights from these theories with insights gained from the literature review to develop the conceptual model that helped frame and guide this research project.

\subsection{Theoretical considerations}

While this study focuses on socio-technological innovation in the field of information management education, the problem and research questions that underpin it are relevant to other fields in the social sciences including education and sociology. It is, therefore, necessary to consider insights that can be gained from theories from these related disciplines. In the first section of this Chapter, I consider several theories of potential relevance. Among the theories considered, two theoretical frameworks are identified as particularly pertinent. They are Fullan's educational change theory $(1982,1991,2001$, 2007), and Hofstede's expanded dimension of cultures (1980, 1991, 2001, 2005, 2010).

Fullan's educational change theory can be seen as fitting the educational aspect of this study while Hofstede's cultural dimensions are relevant given the Sri Lankan context and findings that e-learning success relates to cultural understanding. This aspect is absent from most educational change frameworks and models (See section 2.3.3.6). Sub-sections 3.1.1 and 3.1.2 discuss each of these theories and their relevance to the current research project.

In the second part of this Chapter, I discuss how I combined insights from these two theories with those derived from the literature review. 


\subsubsection{Frameworks for understanding educational change}

\subsubsection{Choice of change model}

A number of change frameworks and models can be used to understand educational change. For example, Ellsworth (2000) reviewed seven change frameworks and models (See Table 3.1) in his book Surviving change: A survey of educational change models to provide a theoretical road map for researchers and practitioners who seek guidance from educational change literature.

Based on Ellsworth's review of change frameworks, I reviewed two change models Rogers' and Fullan's models - to select the most relevant one to this study. Ellsworth (2000) noted that research in educational change has widely used both Rogers' and Fullan's models.

Ellsworth's book has been recognized as a comprehensive guidebook of change frameworks (Roberts, 2010; Johnson, Zhang, \& Gallagher, 2002). For example, Roberts (2010) in his book review highlighted that Ellsworth's survey of change frameworks has been used in research for decades. Johnson, Zhang, and Gallagher (2002) identified that the primary strength of Ellsworth's review of change frameworks was being descriptive, not prescriptive. They further recognized that Ellsworth's analysis of change frameworks is useful for researchers to help with their theoretical frameworks. For example, in each chapter, the change models are discussed by citing individual studies which helps researchers (as well as readers) to understand the applicability of each change model. According to Google Scholar, from 2000 to September 2015, Ellsworth's review of change frameworks has been cited by 299 researchers in their studies which were published mostly in peer-reviewed journals and focus on introducing new technologies at the organizational level, in order to select suitable change theories. 


\begin{tabular}{|l|l|l|}
\hline \multicolumn{1}{|c|}{$\begin{array}{c}\text { Name of the change } \\
\text { framework/model }\end{array}$} & \multicolumn{1}{|c|}{$\begin{array}{c}\text { Author(s) and year of } \\
\text { publication }\end{array}$} & \multicolumn{1}{|c|}{ Main focus } \\
\hline Diffusion of Innovation & Rogers, E.M. (1995) & $\begin{array}{l}\text { Innovation attributes and their effect } \\
\text { on adoption rate }\end{array}$ \\
\hline Conditions of Change & Ely, D.P. (1990) & $\begin{array}{l}\text { Environmental conditions and their } \\
\text { influence on the change process }\end{array}$ \\
\hline Meaning of Educational Change & $\begin{array}{l}\text { Fullan, D.P. } \\
\text { Stiegelbauer, S.M. (1991) }\end{array}$ & $\begin{array}{l}\text { Implications of educational change } \\
\text { for people or organizations } \\
\text { promoting or opposing it at particular } \\
\text { levels }\end{array}$ \\
\hline Change Agent's Guide & $\begin{array}{l}\text { Havelock, R. } \\
\text { Zlotolow, S. (1995) }\end{array}$ & $\begin{array}{l}\text { The process by which change agents } \\
\text { determine when their work with a } \\
\text { given innovation and change agents } \\
\text { can guide its successful transition } \\
\text { from implementation to } \\
\text { institutionalization }\end{array}$ \\
\hline $\begin{array}{l}\text { Concerns-Based Adoption } \\
\text { Model (CBAM) }\end{array}$ & $\begin{array}{l}\text { Hall G. } \\
\text { Wallace, R. } \\
\text { Dossessing and tracking change's } \\
\text { adogress at the level of individual }\end{array}$ \\
\hline Strategies for Planned Change & $\begin{array}{l}\text { Zaltman, G. } \\
\text { Duncan, R.B. (1977) }\end{array}$ & $\begin{array}{l}\text { Eighteen issues in four major } \\
\text { categories (cultural, social, } \\
\text { organizational, psychological) }\end{array}$ \\
\hline Systematic Change in Education & $\begin{array}{l}\text { Reigeluth, C.M. } \\
\text { Garfinkle, R.J. (1994) }\end{array}$ & $\begin{array}{l}\text { Understanding the complex, nested } \\
\text { interdependencies among system } \\
\text { components that allow the system to } \\
\text { function as more than the sum of its } \\
\text { parts or leave it unable to function }\end{array}$ \\
\hline
\end{tabular}

Table 3.1 - Overview of Elsworth's (2000) review of seven change frameworks and models

Rogers' (2003) theory on Diffusion of Innovation (DOI) is among the most frequently applied and has been extensively used in studies that examine ICT uptake at the level of a social system (Hassan, 2010). Rogers identified five attributes of innovations which affect the decision to adopt an innovation: i) relative advantage, ii) compatibility, iii) complexity, iv) trialability, and v) observability. Further, Rogers classifies the members of a system on the basis of their innovativeness because the characteristics of individuals or groups can affect the rate of adoption. He categorized these types of adopters as i) innovators, ii) early adopters, iii) early majority, iv) late majority, and v) laggards.

However, some critics have pointed out that Rogers' DOI theory conceptualizes an innovation as a fixed/discrete 'thing' and mainly focuses on simple, product-based innovations where the unit of adoption is the individual. For example, Greenhalgh et al. 
(2004) argued that Rogers' DOI theory is inappropriate to use for process-based innovations in service organizations, for which the unit of adoption is the team, department, or organization. Cranefield (2009) also argued that the theory is less applicable to the 'adoption' of a programme (e.g., an e-learning programme) because unlike a specific technology (which can be seen as a 'fixed entity', e.g., smart phone), an ICT programme varies in its local application. For example, ICT programmes which integrate ICT with new practices or approaches like a student-centred, ICT-enabled teaching approach (i.e., an e-learning programme) need to be better suited to the organizational and individual contexts. Therefore, adoption of an ICT programme has multiple variables that depend on the context. The current study focuses on adoption of an ICT programme (i.e., e-learning) in a specific organizational context (i.e., tertiary-level IM education in Sri Lanka). Therefore, Rogers' theory is limited in its ability to guide this study because the DOI theory ignores the role of organizations and relies on individual adoption issues. This study focuses on the introduction of e-learning in tertiary-level IM education and various changes in structures and/or ways of working will be required in the organizations.

Similarly, the Boston University School of Public Health (2013) in the US also reported that Rogers' DOI was not meant to explicitly apply to adoption of new behaviours or new programmes. Moreover, Lyytinen and Damsgaard (2001) examined the usefulness and applicability of DOI to theoretical constructs that help address adoption of complex and networked IT solutions. They recognized that the DOI theory is not suited for developing theoretical constructs "to understand the local complex, network, and learning intensive features of technology" (p. 14). For example, DOI does not include four key areas: “1) analysing the impact of the nature and meaning of the technology, 2) the role of institutional policies and regimes, 3) the impact of the industrial policies and strategies, and 4) the importance of the installed base and learning inertia" (p. 14). Due to these limitations, some researchers avoid using the DOI theory for research examining adoption of a programme which not only involves technology but also new behaviours and practices. For example, Salmon (2005) conducted research to develop a strategic framework for e-learning and pedagogical innovation in higher education institutions. Salmon did not use Rogers' DOI theory, arguing that it is too simple to be useful as a 
framework for considering the complexity involved in e-learning in higher education institutions.

The current study focuses on the introduction of e-learning in tertiary-level IM education in the social and cultural context of Sri Lanka which involves more than the introduction of new technology. It entails adoption of a programme (i.e., e-learning) that includes educational aspects and new practices. These new practices relate to pedagogy and changing attitudes and behaviour. Fullan's educational change theory is a more suitable theory as discussed below.

Fullan's educational change theory (also known as educational technology and change theory, or innovation theory) is one of the most comprehensive and up-to-date views of innovation in education (Lopez, 2010). Fullan has been recognized as a well-published international leader on educational change; he has been studying, leading, and writing about educational change since the 1970s (Lopez, 2010; Ellsworth, 2000). His personal experiences as a practitioner engaged in training, consulting, and evaluating change projects around the world, as well as in reviewing literature on educational change over the past 25 years, led him to propose three stages of the change process: initiation, implementation, and institutionalization. Fullan's educational change theory has been widely used in studies (Beeharry-Konglar, 2013; Brummelhuis, 1995; Foster et al., 1999; Hargreaves, 2005; Huan, 2013; Neumann, 2013; Tondeur et al., 2009; Williams \& Williams, 2007; Wong et al., 2008) that examined the introduction of technology to educational organizations at secondary and tertiary levels. Although Fullan's focus when developing his theory was on secondary school education in a western developed country setting, some of these studies applied Fullan's theory in a tertiary education setting and/or developing country contexts (See Appendix 1). Among these studies, those of Brummelhuis (1995) and Foster et al. (1999) provide more central themes that relate to my study and are discussed below. Other recent studies that have made use of Fullan's educational change theory are outlined in Appendix 1.

Brummelhuis (1995) conducted research with the aim of exploring, testing, and respecifying a model for the implementation of computers in Dutch schools (as a specific case of educational change) while taking the interrelatedness of influencing factors into account. For this purpose, Brummelhuis developed a statistical model based on a review 
of the literature on educational change and added Fullan's three Rs: readiness, relevance, and resources. Brummelhuis' study confirmed that a model including a set of factors derived from theories on educational change (including Fullan's three Rs) fits the data on implementation of computer use in education. Foster et al. (1999) did a survey and evaluation of the views of a variety of stakeholders (academics, management and support staff) on the readiness of a traditional research-led university for implementing ICTbased learning and teaching (largely at the initiation stage). They used the initiation stage of Fullan's change theory as a guide for analysing a number of factors relevant to a discussion of institutional readiness for networked collaborative learning. Foster et al. (1999) found that a university's readiness to implement networked learning needs to be identified at an early stage and more attention needs to be paid both to the internal infrastructure within the institution and to collaboration with external agencies to support the delivery of networked learning.

According to Fullan (2007), there are three aspects of educational change in practice which are essential to achieve an educational goal or set of goals. They are: (1) the possible use of new or revised materials (direct institutional resources such as curriculum materials or technologies); (2) the possible use of new teaching approaches (e.g., new teaching strategies or activities); and (3) the possible alteration of beliefs (e.g., pedagogical assumptions and theories underlying particular new policies or programmes) (p. 30). This study involves all three of these changes because this study focuses on introduction of e-learning in the Sri Lankan tertiary-level IM educational sector where face-to-face teaching is still practised in the conventional classroom and where there is little familiarity with e-learning.

Use of IT in education involves not only a change of teaching resources but also of teaching strategies and beliefs (Scott \& Robinson, 1996). Research further shows that new practices (including new educational practices) cannot be sustained without changes of values and beliefs (Handal, 2004; Handal \& Herrington, 2003; Richardson \& Placier, 2001; Smith et al. 2005). Unlike Rogers' model, Fullan's model explicitly focuses on educational change and provides useful insights to guide the study since all three of these change elements (materials, teaching strategies, and beliefs) are major dimensions of educational change. 
Research in the educational field reflects two broad ways to look at educational reform. One is an innovation-focussed approach which examines specific innovations to see how they fare and to determine which factors are associated with success. The other one has a capacity-building focus and examines how to develop the innovative capacity of organizations and systems to engage in continuous improvement (Hall, 2013; Grossman, 2013; Harris \& Jones, 2013; Fullan, 2007). Educational change in this study is viewed from an innovation perspective because this study looks at e-learning as a large-scale system innovation and seeks to identify the factors and to understand how these factors affect the introduction of e-learning in tertiary-level IM education in Sri Lanka. Because of the focus on educational change in the innovation-focussed approach and the importance of the organizational context of this study, Fullan's educational change theory is used as the main theoretical framework to guide this study.

\subsubsection{Fullan's Educational Change Theory (1982, 1991, 2001, 2007)}

Fullan's framework for understanding and managing educational change was published in his first edition of The meaning of educational change in 1982. For his second edition, Stiegelbauer joined as a co-author. To date Fullan has published four editions of The meaning of educational change and the evolution of this theory is depicted in Appendix 2.

Fullan (2007) introduced three stages of the change process in relation to outcomes as a means of helping "make sense" of planning, implementation strategies, and monitoring in the process of educational change. As Fullan (2001) points out, as educational change is multidimensional and involves many levels (e.g. classroom, school, district, and government), his theory operates at the macro level (system level) as well as at organizational level.

Fullan (2007) states that there are number of factors operating at each stage and he also stresses it is not a linear process. The first stage of Fullan's change theory is initiation (variously labelled as mobilization or adoption). It refers to "the process that leads up to, and includes a decision to adopt or proceed with a change" (2007, p. 65). Fullan argues that the source of an innovation should always be investigated before it is put forward for adoption. He therefore introduced eight sources affecting initiation: 1) existence and quality of innovations; 2) access to innovation; 3) advocacy from central administration; 
4) teacher advocacy; 5) external change agents; 6) community pressure/support/apathy; 7) new policy funds; and 8) problem-solving and bureaucratic orientations. Fullan discusses each of these sources in turn and in his second edition (1991, p. 63), he concluded that the best ways to begin the initiation stage combine the three Rs, i.e., relevance, readiness, and resources. The second stage is implementation (or initial use). It involves "the first experiences of attempting to put an idea or reform into practice" (2007, p. 65). Institutionalization (or continuation, incorporation, or routinization) refers to "whether the change gets built in as an ongoing part of the system or disappears by way of a decision to discard, or through attrition" (p. 65). The outcomes refer to the complete overview of the change process.

The initiation stage and the implementation stage of Fullan's change theory are the most relevant components for this study as discussed below.

The initiation stage represents a combination of the three Rs - relevance, readiness, and resources (Figure 3.1) - which are critical factors prior to implementation. Thus, the three Rs are useful for identifying factors/issues that have an impact on the adoption decision in this study which seeks to understand factors which may influence change in the Sri Lankan tertiary-level IM education sector.

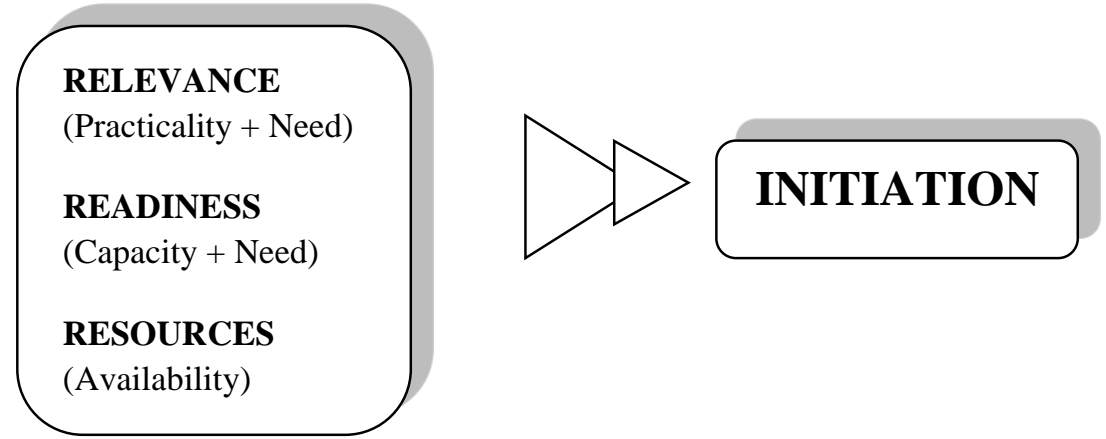

Figure 3.1 - Considerations in planning for adoption Source: Fullan, 1991, p. 63 (copied with permission)

'Relevance' includes need, clarity of innovation (about goals and means), and utility (Fullan, 1991, p. 63). For example, relevance can be identified as "practitioners' understanding or being agreeable to innovation" (p. 63). 'Readiness' involves the “organizations'/individuals' practical and conceptual capacity to initiate, develop, or 
adopt a given innovation or capacity to use reform" (p. 63). 'Resources' concern the "accumulation of, and provision of, support as a part of the change process" (Fullan, 1991, p. 64). The three Rs of the initiation stage, therefore, include discussion of clarity of the innovation (i.e., about goals and means, for example, understanding of essential features of the innovation), agreeability of the innovation and practical and conceptual capacity to initiate a given innovation, all of which are relevant to the context of Sri Lankan tertiarylevel IM education for identifying practitioners' understanding of e-learning, identifying IM education providers' practical and conceptual capacity to initiate e-learning, and identifying resources to introduce and use e-learning. Foster et al. (1999), who used Fullan's change model to understand institutional readiness for implementing ICT-based learning and teaching, found that a combination of the three Rs should exist before putting into practice an idea, programme, or set of activities and structures that is new to the people attempting or expected to change.

Fullan (2007) argued that the required changes cannot all occur and be resolved at the initiation stage (i.e., adoption decision) and therefore, some of the changes and lack of resolution continue in the implementation stage. They become much more noticeable/clearer at this stage. Therefore, the implementation stage of Fullan's change theory is also selected for this study because it identifies potential post-adoption issues in the early stages of e-learning implementation in the tertiary-level IM educational sector (including IM education) in Sri Lanka. Fullan (2007) argued that the identified factors have an impact on initiation and implementation, operating over many innovations as well as many levels of the system.

The implementation stage represents critical factors that commonly influence changes in practice. These critical factors as shown in Figure 3.2 are divided into three categories. They are a) characteristics of change, b) local characteristics (roles), and c) external factors. 


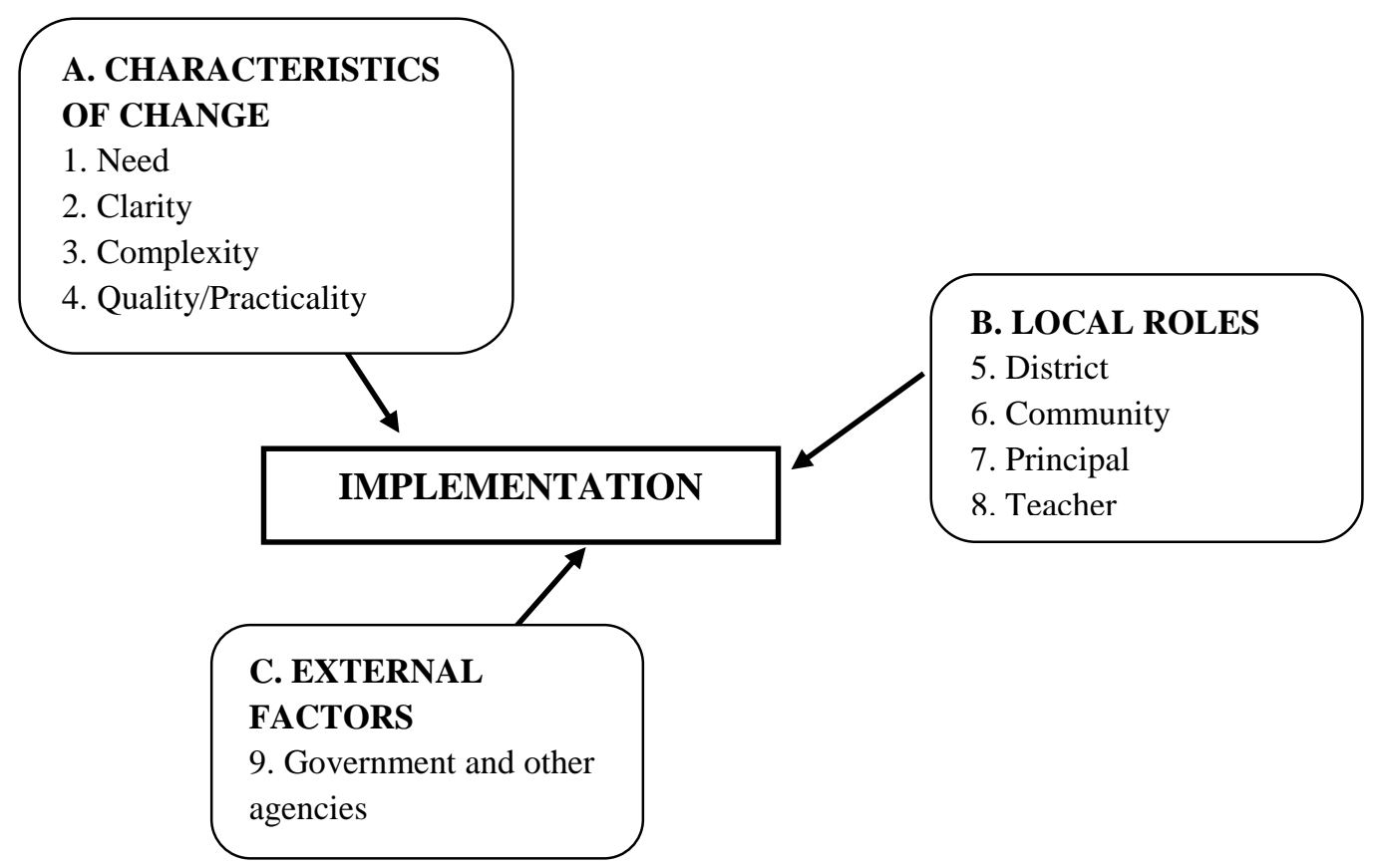

Figure 3.2 - Interactive factors affecting implementation Source: Fullan, 2007, p. 87 (copied with permission)

The first category of the implementation stage is characteristics of change. It includes four factors: 1) need (what are the perceived priority needs?), 2) clarity (clarity of innovation, i.e., about goals and means, 3) complexity (difficulty and extent of change required of the individuals responsible for implementation), and 4) quality/practicality (understanding the quality and practicality of the change project) (Fullan, 2007, pp. 88-92). These factors are similar to the three Rs: relevance (practicality and need), readiness (capacity and need), and resources (availability). However, in the implementation stage, the factors are identified when practitioners actually start doing things, that is, during the early stages of implementation.

The second category of the implementation stage is local characteristics/roles. Fullan emphasized that these roles are based on social level. They include district level roles (district administrators), community level roles (parents and school boards), principal, and teacher. Fullan used them to identify the meaning of change for people in the role under discussion and to generate ideas as to what they could/should do about change. The current study focuses on tertiary-level IM education in Sri Lanka. Therefore, this study selected local roles at the university level in Sri Lanka. They are academics, 
administrative staff (head of the department/director of the institution), support staff (technical officers, librarians), and existing e-learning providers. I used these roles as participants in this study to identify what factors have an impact on the introduction and use of e-learning and how these factors affect the introduction and use of e-learning in tertiary-level IM education in Sri Lanka.

The third category of Fullan's implementation stage is external factors. It includes government and other agencies and identifies their role in the implementation.

Accordingly, the initiation stage (three Rs) and the implementation stage of Fullan's change theory were used to develop the conceptual model of this study. The identified factors could have an impact on the introduction of e-learning in tertiary-level IM education in Sri Lanka.

However, Fullan's educational change theory only briefly discusses changing cultures and working conditions in organizations (2007, p. 291) and pays no attention to cultural aspects on a broader level such as the national level. Studies done by Ma (2010), Olaniran (2007), and Downey et al. (2005) show that cultural context matters when introducing or implementing e-learning. This will be discussed in section 3.1.2.1. Further, there is literature that also shows that culture is an important facet of the e-learning system. For example, Adeoye and Wentling (2007) and Strother (2003) consider that the appropriate awareness of cultural differences and their effects on the individual user are vital to the success of e-learning systems. McLoughlin (1999) reported that e-learning systems often appear to be modified to the needs of a particular cultural group, recognizing the specific learning needs, preferences and styles of a single, perhaps homogeneous, group of learners. As discussed in section 2.3.3.6, culture is an important facet in the Sri Lankan context especially when introducing constructivist-based e-learning. Therefore, when understanding how e-learning can be utilized to facilitate education in a specific context, there is a need to understand cultural influences on behaviour, especially in teaching and learning. 


\subsubsection{Dimensions of national culture}

3.1.2.1 Choice of culture model

A number of cross-cultural studies, frameworks and models can be used to analyse the cultural differences among nations or organizations. For example, there are cultural models that deal with multiple dimensions: Hofstede's (1980, 1991, 2001, 2005, 2010) has six, Hampden-Turner and Trompenaars' (1993) has seven, House et al.'s (2004) has nine and Minkov's (2007) has three. Table 3.2 outlines the cultural dimensions of four models and overlaps among the factors with Hofstede's model. 


\begin{tabular}{|c|c|c|c|c|c|c|}
\hline \multirow[b]{2}{*}{ Cultural models with multiple dimensions } & \multicolumn{6}{|c|}{ Hofstede's Six Cultural Dimensions (2010) } \\
\hline & $\begin{array}{l}\text { Power } \\
\text { Distance }\end{array}$ & $\begin{array}{l}\text { Masculinity } \\
\text { vs. Femininity }\end{array}$ & $\begin{array}{l}\text { Uncertainty } \\
\text { Avoidance }\end{array}$ & $\begin{array}{l}\text { Individualism } \\
\text { and Collectivism }\end{array}$ & $\begin{array}{l}\text { Long- vs. } \\
\text { Short-Term } \\
\text { Orientation }\end{array}$ & $\begin{array}{l}\text { Indulgence } \\
\text { vs. Restraint }\end{array}$ \\
\hline \multicolumn{7}{|l|}{$\begin{array}{l}\text { Hampden-Turner and Trompenaars' } \\
\text { Seven Cultural Dimensions (1993) }\end{array}$} \\
\hline 1. Universalism vs. Particularism & & & $\sqrt{ }$ & & & \\
\hline 2. Neutral vs. Emotional & $\sqrt{ }$ & $\sqrt{ }$ & $\sqrt{ }$ & & & \\
\hline 3. Individualism vs. Collectivism & $\sqrt{ }$ & $\sqrt{ }$ & & $\sqrt{ }$ & & \\
\hline 4. Specific vs. Diffuse & $\sqrt{ }$ & & $\sqrt{ }$ & & & \\
\hline 5. Achievement vs. Ascription & & $\sqrt{ }$ & & & & \\
\hline 6. Attitudes to time & & $\sqrt{ }$ & $\sqrt{ }$ & & & \\
\hline 7. Attitudes to the environment & & & $\sqrt{ }$ & & & \\
\hline \multicolumn{7}{|l|}{$\begin{array}{c}\text { House et al.'s } \\
\text { Nine Cultural Dimensions (2004) }\end{array}$} \\
\hline 1. Power Distance & $\sqrt{ }$ & & & & & \\
\hline 2. Assertiveness & & $\sqrt{ }$ & & & & \\
\hline 3. Gender Egalitarianism & & $\sqrt{ }$ & & & & \\
\hline 4. Uncertainty Avoidance & & & $\sqrt{ }$ & & & \\
\hline 5. Institutional Collectivism & & & & $\sqrt{ }$ & & \\
\hline 6. In-group Collectivism & & & & $\sqrt{ }$ & & \\
\hline 7. Future-Orientation & & & & & $\sqrt{ }$ & \\
\hline 8. Humane Orientation & & $\sqrt{ }$ & & & & \\
\hline 9. Performance Orientation & & $\sqrt{ }$ & & & & \\
\hline \multicolumn{7}{|l|}{$\begin{array}{c}\text { Minkov's } \\
\text { Three Cultural Dimensions (2007) }\end{array}$} \\
\hline 1. Exclusionism vs. Universalism & & & & $\sqrt{ }$ & & \\
\hline 2. Monumentalism vs. Flexumility & & & & & $\sqrt{ }$ & \\
\hline 3. Indulgence vs. Restraint & & & & & & $\sqrt{ }$ \\
\hline
\end{tabular}

Table 3.2 - Influence of Hofstede's six cultural dimensions on other studies

$\sqrt{ }$-Definitional / conceptual similarities $\sqrt{ }$-Derived from $\sqrt{ }$-Inspired by $\sqrt{ }$-Correlation 
Although the terminology used in these four models differs (Table 3.2), there are overlaps among the factors with Hofstede's model. Among these four models, Hofstede's work was a pioneering attempt to study national cultures (Minkov, 2007; Ma, 2010). HampdenTurner and Trompenaars published seven cultural dimensions in 1993. As demonstrated by Krumbholz and Maiden (2001), there are commonalities between Hofstede's and Trompenaars' cultural dimensions and their definitions are similar. As shown in Table 3.2, black ticks show the shared definitions. Each dimension overlaps with at least one other, showing considerable similarity between Hofstede and Trompenaars.

House et al. identified nine cultural dimensions through their GLOBE research project in 2004. This GLOBE project expanded the five Hofstede dimensions to nine for conceptual reasons (House et al., 2004). For example, the first six cultural dimensions of the GLOBE project were derived from the four identified by Hofstede. This relationship is shown by green ticks in Table 3.2. House et al. identified that future orientation is conceptually similar to the dimension Hofstede called long-term versus short-term orientation. This is shown by black ticks in Table 3.2. Hofstede argued that the other two dimensions of the GLOBE project (i.e., humane orientation and performance orientation) are also inspired by his masculinity-femininity dimensions. This relationship is shown by red ticks in Table 3.2 .

Based on the World Value Survey (WVS) Minkov introduced his three cultural dimensions in 2007. Then Minkov became one of the authors of Hofstede's third edition of Culture and organizations: Software of the mind and integrated his research results with those of Hofstede. Of the three Minkov dimensions, two dimensions are strongly correlated (in statistics, the degree of common variation of two sets of numbers) with two of Hofstede's dimensions as shown by pink ticks in Table 3.2. Subsequently, one of Minkov's cultural dimensions, indulgence versus restraint, was added to Hofstede's third edition and expanded his formerly five-dimensional model of cultures to six.

Hofstede's culture model has been the most frequently replicated, tested and validated (Oliver, 2011; Kirkman, Lowe, and Gibson, 2006). According to the Social Science Citation Index (SSCI), Hofstede's work is more widely cited than other culture studies. Moreover, Hofstede's cultural dimensions have been widely used in many fields and have been used in studies on implementing or introducing e-learning in specific cultures. For example, 
Ma (2010) conducted deductive research to find out the driving factors and barriers to elearning implementation in traditional universities in China and Sweden and how these factors are influenced by national culture. For this purpose, Ma collected primary data through questionnaires from teachers in two Chinese universities and one Swedish university. Hofstede's culture dimension model was used to analyse the difference between Chinese and Swedish e-learning education. Ma found that as China is a high power distance society, its teachers were experiencing barriers such as lack of e-learning strategy or leadership and lack of support compared to Swedish teachers in their low power distance society. Teachers in China therefore expect universities to lead and support their e-learning initiatives by funding them and recognizing and rewarding individual factors. Similarly, Ma found that national culture is a significant factor that affects e-learning implementation in higher educational institutions.

Olaniran (2007) discussed challenges to implementing e-learning in lesser-developed countries based on a review of the literature, and used Hofstede's cultural dimensions to explore significant challenges created by learning preferences and adoption of innovation. Olaniran found that different implications for e-learning are required for different cultures. For instance, e-learning in collectivistic cultures needs to integrate more interpersonal interactions where students and instructors get to explain ideas to one another while self-paced independence-focussed e-learning is suited to individualistic cultures.

Downey et al. (2005) conducted a study to investigate possible relationships between national culture and the usability of an e-learning system. They used two theoretical frameworks to guide their study: Hofstede's cultural dimensions and Nielsen's usability attributes. By collecting quantitative data from 24 attendees who represented 14 different countries from Africa, Asia, Europe, and North America, they found that participants from high uncertainty avoidance cultures find use of an e-learning system frustrating because they make more errors in navigating the e-learning system and therefore, they are least likely to accept risk. In addition, in Hofstede's book Culture and organizations, he categorized key differences of each dimension in different societies, for example, the differences in families, schools or educational systems, workplaces or organizations. Hofstede's cultural dimensions therefore provide a useful guide for 
understanding cultural influences on the introduction of e-learning in tertiary-level IM education in Sri Lanka.

However, there have been criticisms of Hofstede's work on cultures and nations. For example, McSweeney (2002) argued that Hofstede's cultural model was based on five false assumptions: i) national, organizational, and occupational levels of culture are discrete, ii) the national is identifiable in the micro-local (IBM samples), iii) national culture creates questionnaire response (response differences between the classifications/stratifications), iv) national culture can be identified by response difference analysis, and v) Hofstede's analysis of national culture is not situation-specific. Baskerville (2003) argued that nations are not the best units for studying cultures, because cultures are not countries and there are generally multiple cultures in one country at any one time. For example, there are 98 different cultures recognized in 48 countries in Africa and 81 cultures identified in 32 countries in Western Europe. In addition Fang (2003), based on his indigenous knowledge of Chinese culture and philosophy, argues that Hofstede's fifth national cultural dimension, i.e., long-term vs. short-term orientation is philosophically flawed in interpreting Chinese culture. In Chinese culture protecting your face (yao mianzi) and having a sense of shame (Zhi chi) are not different concepts but share a common Confucian moral base, i.e., face-caring or face-need. Fang therefore argued that (as one example) it is inappropriate to operationalize 'having a sense of shame' and 'protecting your face' as two separate and opposing values in Hofstede's fifth dimension. Sondergaard (2002) has followed the debate on Hofstede's culture model from 1986 and summarized the criticisms into five points: i) surveys are inappropriate instruments to measure culture, ii) nations are not the best unit for studying culture, iii) participants from one company (IBM) cannot represent entire national cultures, iv) the IBM data is old and obsolete, and v) four dimensions cannot tell the whole story.

Hofstede has responded to these criticisms. For instance, Hofstede (2003) addressed Baskerville's (2003) criticism, i.e., nations are not the best units for studying cultures and said "True, but they (nations) are usually the only kind of units available for comparison and better than nothing" (Hofstede, 2003, p. 812). Then he noted the validity of his study on two levels, i.e., micro-level and macro-level. For example, Hofstede found over 400 micro-level significant correlations, i.e., country-culture dimension scores against data 
from a wide variety of other sources. Hofstede maintained that, at the macro level, a number of researchers and authors have used and have continued to use his work for understanding the problems they address. In fact, Hofstede has also responded to criticism through his new edition of Cultures and organizations: Software of the mind (2010). Hofstede argued that, even though regional, ethnic, and religious cultures account for differences within countries, they are learned from birth onward, and therefore can be described under the same terms as national cultures. Therefore, he argued that the same dimensions that were identified as differentiating national cultures can also be applied to identifying differences within countries. In addition, with regard to criticisms of Hofstede's fifth national culture dimension, Hofstede integrated Minkov's (2007) analysis of World Values Survey (WVS) data in his third edition and showed that Minkov's research results significantly correlated with his fifth dimension. For example, Minkov's third dimension of monumentalism versus flexhumility is conceptually similar to the long-term orientation and correlates significantly with long-term orientation.

Despite the limitations identified by other researchers, as noted in Table 3.2, large crosscultural studies have been published since Hofstede's work that have sustained and reinforced Hofstede's conclusions rather than contradicting them. By reviewing empirical research that incorporated Hofstede's cultural values framework and was published in top-tier journals, Kirkman, Lowe, and Gibson (2006) show that researchers preferred Hofstede's cultural dimensions due to their clarity, parsimony, rigor, and relative accuracy. They suggested that Hofstede's values are relevant for studies in which culture is an important facet of the research context. Therefore, this study uses Hofstede, Hofstede, and Minkov's (2010) cultural dimensions to understand cultural factors that have an impact on the introduction of e-learning in tertiary-level IM education.

\subsubsection{Hofstede's cultural dimensions (1980, 1991, 2001, 2005, 2010)}

Hofstede's first culture-related study was carried out (with IBM) from 1967-1969 and repeated from 1971-1973. The study received 117,000 questionnaires from over 88,000 IBM employees in over 66 countries. Based on the surveys' results, he explored four dimensions of culture in his first edition of Culture's consequences: International differences in work related values in 1980, while the first edition of Cultures and organizations: Software of the mind was published in 1991. From the second edition of 
Culture and organizations (2005), Gert Jan Hofstede (Hofstede's son) joined as a coauthor. For Hofstede's third edition of Culture and organizations (2010), Minkov also joined as co-author and Hofstede integrated his research results with Minkov's exploration of the World Values Survey (WVS). Consequently, Hofstede explores six dimensions of culture (Table 3.3) and these dimensions are used in this study as the latest expansion of Hofstede's model. (The evolution of Hofstede's cultural dimensions (from 1980 to 2010) is visualized in Appendix 3).

\begin{tabular}{|c|c|}
\hline Dimension & Definition \\
\hline Power Distance (PDI) & $\begin{array}{l}\text { The extent to which the less powerful members of institutions and } \\
\text { organizations within a country expect and accept that power is } \\
\text { distributed unequally (p. 61) }\end{array}$ \\
\hline $\begin{array}{l}\text { Individualism and } \\
\text { Collectivism (IND) }\end{array}$ & $\begin{array}{l}\text { Individualism means a society in which the ties between individuals are } \\
\text { loose: everyone is expected to look after himself/herself and her/his } \\
\text { immediate family only. } \\
\text { Collectivism means a society in which people from birth onwards are } \\
\text { integrated into strong, cohesive in-groups, which throughout people's } \\
\text { lifetime continue to protect them in exchange for unquestioning loyalty } \\
\text { (p. 92). }\end{array}$ \\
\hline $\begin{array}{l}\text { Masculinity and Femininity } \\
\text { (MAS) }\end{array}$ & $\begin{array}{l}\text { Masculinity indicates a society in which social gender roles are clearly } \\
\text { distinct: men are supposed to be assertive, tough, and focused on } \\
\text { material success, whereas women are supposed to be more modest, } \\
\text { tender, and concerned with the quality of life. } \\
\text { Femininity indicates a society in which social gender roles overlap: both } \\
\text { men and women are supposed to be modest, tender, and concerned with } \\
\text { the quality of life (p. 140). }\end{array}$ \\
\hline $\begin{array}{l}\text { Uncertainty } \\
\text { (UAI) }\end{array}$ & $\begin{array}{l}\text { The extent to which the members of a culture feel threatened by } \\
\text { ambiguous or unknown situations (p. 191) }\end{array}$ \\
\hline $\begin{array}{l}\text { Long-Term versus Short- } \\
\text { Term Orientation (LTO) }\end{array}$ & $\begin{array}{l}\text { Long-term orientation entails the fostering of virtues oriented toward } \\
\text { future rewards - in particular, perseverance and thrift. } \\
\text { Short-term orientation entails the fostering of virtues related to the past } \\
\text { and present - in particular, respect for tradition, preservation of 'face', } \\
\text { and fulfilling social obligations (p. 239). }\end{array}$ \\
\hline $\begin{array}{l}\text { Indulgence versus } \\
\text { Restraint (IVR) }\end{array}$ & $\begin{array}{l}\text { Indulgence involves a tendency to allow relatively free gratification of } \\
\text { basic and natural human desires related to enjoying life and having fun. } \\
\text { Restraint reflects a conviction that such gratification needs to be curbed } \\
\text { and regulated by strict social norms (p. 281). }\end{array}$ \\
\hline
\end{tabular}

Table 3.3 - Hofstede's six cultural dimensions

Source: Hofstede, G.H, Hofstede, G.J., and Minkov (2010)

An analysis of the Sri Lankan culture was added to Hofstede's official web site in 2012. Table 3.4 shows national culture dimension scores for Sri Lanka compared to Morocco, China, India, Sweden, Canada, Brazil and New Zealand. For this study, I have included the rankings of the other countries for comparison purposes. They are randomly selected according to the continent i.e., Africa, Asia, Europe, North America, South America, and 
Oceania. However, three countries are selected under Asia (including Sri Lanka) since this study represents the Asian context.

\begin{tabular}{|l|l|c|c|c|c|c|c|}
\hline \multicolumn{1}{|c|}{ Continent } & \multicolumn{1}{|c|}{ Country } & PDI & IDV & MAS & UAI & LTO & IVR \\
\hline Africa & Morocco & 70 & 46 & 53 & 68 & 14 & 25 \\
\hline Asia & China & 80 & 20 & 66 & 30 & 87 & 24 \\
\hline & India & 77 & 48 & 56 & 40 & 51 & 26 \\
\hline & Sri Lanka & 72 & 28 & 35 & 53 & 49 & 64 \\
\hline Europe & Sweden & 31 & 71 & 05 & 29 & 53 & 78 \\
\hline North America & Canada & 39 & 80 & 52 & 48 & 36 & 68 \\
\hline South America & Brazil & 69 & 38 & 49 & 76 & 44 & 59 \\
\hline Oceania & New Zealand & 22 & 79 & 58 & 49 & 33 & 75 \\
\hline
\end{tabular}

Table 3.4 - Hofstede's values of Asian countries (score out of 100)

Source: Hofstede Web Site http://www.geerthofstede.nl/dimension-data-matrix

As shown in Table 3.4, Sri Lanka has a high degree of power distance (72). Unlike countries in Europe, North America, and Oceania, countries in Asia (including Sri Lanka), Africa, and South America are more collectivist. According to Table 3.4, Sri Lanka has a considerably lower degree of masculinity than other countries except Sweden. Sri Lanka has a slightly higher value for uncertainty avoidance and a mid-level value for long-term versus short-term orientation compared to other Asian countries. Interestingly, Sri Lanka has a considerably higher degree of indulgence (especially since after the civil war) than other Asian, African, and South American countries.

In the current study, five out of Hofstede's six cultural dimensions were selected. They are power distance, individualism and collectivism, uncertainty avoidance, long- versus short-term orientation, and indulgence versus restraint. The relevance of these cultural dimensions to this study will be discussed in section 3.2.2. The other dimension, masculinity versus femininity, was not selected for this study for the following reason.

Strother (2003), Downey et al. (2005), and Ma (2010), who used Hofstede's cultural dimensions for their studies, found that the masculinity or femininity of cultures is not important for e-learning implementation. For example, Strother (2003) pointed out that e-learning delivery modes are, by their very nature, more gender independent. Also, Ma (2010) did not identify gender as a driving factor or a barrier for implementing e-learning in traditional universities in China and Sweden. Similarly, Downey et al. (2005) found that there was no significant relationship between femininity/masculinity and the usability of an e-learning system. Further, there is no research that indicates gender as a critical 
factor that influences the success or failure of e-learning. Therefore, this dimension was not selected in this research.

After carefully looking at the two theories, i.e., Fullan's educational change theory and Hofstede's cultural dimensions, the conceptual model was developed by combining relevant elements from each theory with those derived from the literature review. This will be discussed in detail in the next sub-section.

\subsection{The conceptual model for understanding the factors that have an impact on the introduction of e-learning in tertiary-level IM education in Sri Lanka}

The conceptual model is presented as a framework to guide the process of data collection and analysis in this study to enable understanding of factors affecting the introduction of e-learning in tertiary-level IM education in Sri Lanka.

Figure 3.3 illustrates a conceptual model of this study. It was developed by combining insights from the two theories with insights gained from the literature review. All the factors are presented according to two levels, i.e., macro level and organizational level, while some factors are presented at both levels, e.g., technological factors. However, none of the factors is presented under the individual level since it is out of the scope of this study due to the nature of the research problem and research questions which focus on the organizational level and macro level (or national level). 


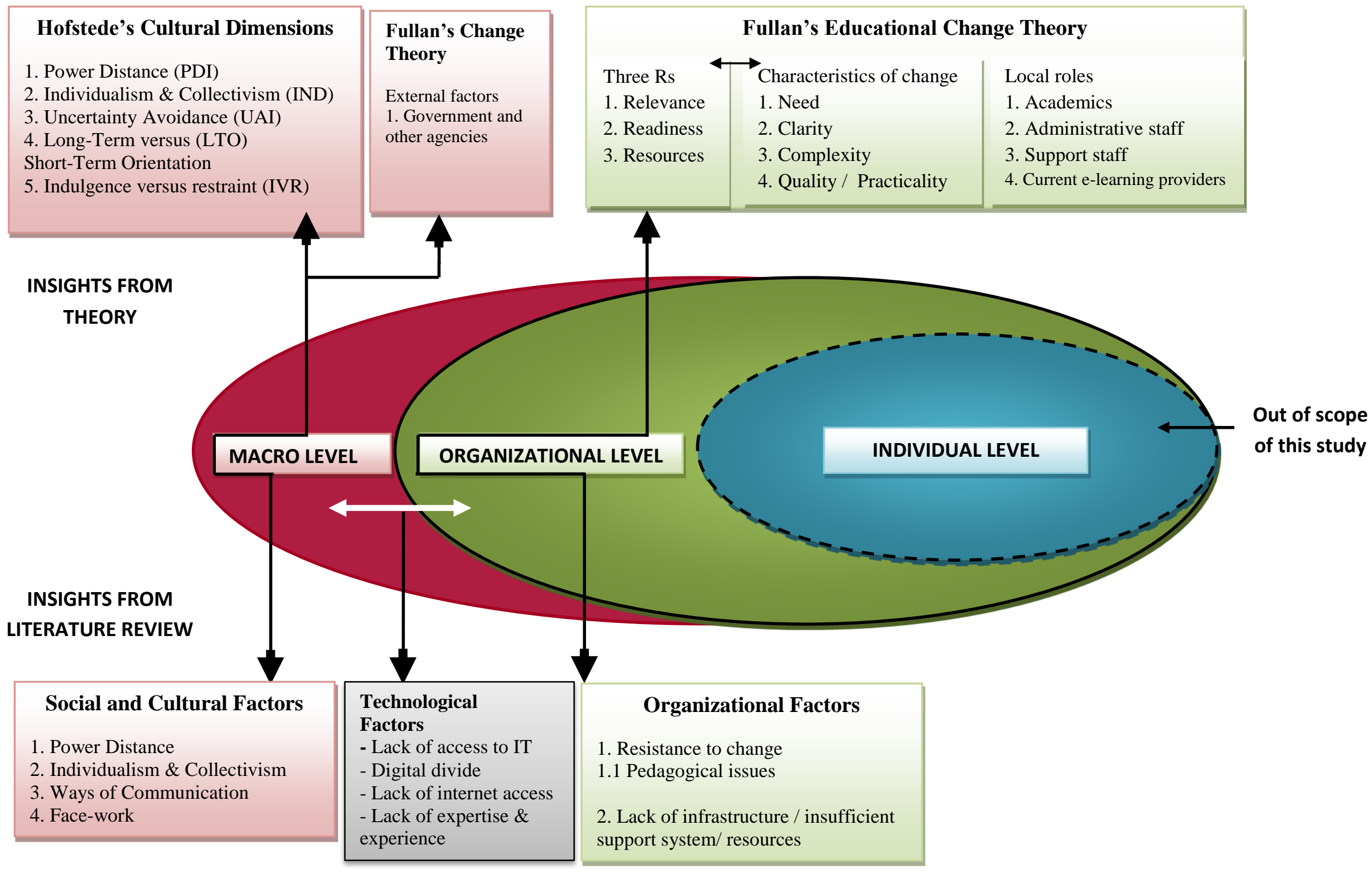

Figure 3.3 - Conceptual model of factors that might have an impact on the introduction of e-learning in tertiary-level IM education in Sri Lanka 
The factors of the conceptual model include three categories: organization-level factors, macro-level factors, and both organizational and macro-level factors. Each factor is discussed in sections 3.2.1 to 3.2.3.

Overlaps among the factors from the literature review and some of the insights from theories are identified in this study and shown in Table 3.5.

\begin{tabular}{|c|c|c|c|c|c|c|c|c|}
\hline \multirow{3}{*}{$\begin{array}{l}\text { Factors/issues from the } \\
\text { literature review }\end{array}$} & \multicolumn{8}{|c|}{ Insights from two theories } \\
\hline & \multicolumn{5}{|c|}{$\begin{array}{c}\text { Macro-level Factors } \\
\text { Hofstede's cultural dimensions }\end{array}$} & \multicolumn{3}{|c|}{$\begin{array}{c}\text { Organization-level factors } \\
\text { Fullan's educational change theory } \\
\text { Three Rs }\end{array}$} \\
\hline & PDI & IND & UAI & LTO & IVR & Relevance & Readiness & Resources \\
\hline \multicolumn{9}{|l|}{ Social and cultural factors } \\
\hline 1. Power distance & $\sqrt{ }$ & & & & & & & \\
\hline $\begin{array}{l}\text { 2. Individualism vs. } \\
\text { collectivism }\end{array}$ & & $\sqrt{ }$ & & & & & & \\
\hline 3. Way of communication & & & & $\sqrt{ }$ & & & & \\
\hline 4. Face-work & & & & $\sqrt{ }$ & & & & \\
\hline \multicolumn{9}{|l|}{ Organizational Factors } \\
\hline 1. Resistance to change & & & & & & & $\sqrt{ }$ & \\
\hline 2. Pedagogical issues & & & & & & & $\sqrt{ }$ & \\
\hline $\begin{array}{l}\text { 3. Lack of infrastructure/ } \\
\text { insufficient support system/ } \\
\text { resources }\end{array}$ & & & & & & & & $\sqrt{ }$ \\
\hline \multicolumn{9}{|l|}{ Technological Factors } \\
\hline 1. Lack of access to IT & & & & & & & & $\sqrt{ }$ \\
\hline 2. Digital divide & & & & & & & $\sqrt{ }$ & \\
\hline 3. Internet access & & & & & & & & $\sqrt{ }$ \\
\hline $\begin{array}{l}\text { 4. Lack of expertise and } \\
\text { experience }\end{array}$ & & & & & & & $\sqrt{ }$ & \\
\hline
\end{tabular}

Table 3.5 - Identifying overlaps among the factors from the literature review and theories

As shown by ticks $(\sqrt{ })$ in Table 3.5, factors from the literature review similarly represent insights from the two theories. Therefore, by synthesizing factors from the literature review and the two theories, insights from the theories are discussed under organizationlevel factors in section 3.2.1 and under macro-level factors in section 3.2.2. In the literature review, technological issues are identified at both organizational and macro levels. But as shown in Table 3.5, in relation to theories, technological factors only overlap with resources at the organizational level. This factor is discussed in section 3.2.3. 


\subsubsection{Organization-level factors}

As mentioned in section 3.1.1.2, Fullan's three Rs of relevance, readiness, and resources are used in this study. They relate to the first stage of Fullan's change theory, the 'initiation stage' which involves preparation for change.

\subsubsection{Relevance}

In the context of this research, relevance can be identified as what e-learning can potentially offer teachers, information workers, and others in IM organizations. Therefore, focusing on relevance will be useful in identifying students', staff's, and stakeholders' needs and understanding of innovation (i.e., about goals and means, for example, understanding of essential features of e-learning).

\subsubsection{Readiness}

In the context of this research, readiness is used to explore IM organizations' practical and conceptual capacity to initiate, develop, or adopt e-learning or capacity to use reform.

\subsubsection{Resources}

As discussed in section 2.3.3.1, lack of infrastructure or inadequate resources in the organization can be major obstacles to the use of e-learning.

In the Sri Lankan context, lack of IT infrastructure is one of the problems faced by universities. Hence, the World Bank (2009, p. 39) suggested that, due to the limited infrastructure for access to ICT, the Ministry of Education (MOE), University Grants Commission (UGC), and Sri Lanka Institutes for Advanced Technological Education (SLIATE) in discussion with the Ministry of Finance and Planning need to set out a national strategy for the provision of ICT infrastructure on campus. Therefore, 'resources' from Fullan's three Rs fit with organizational factors because they are related to the provision of support as a part of the change process. This will help to understand how resources affect the introduction and use of e-learning in tertiary-level IM education in Sri Lanka.

As mentioned in section 3.1.1.2, the second stage of Fullan's change theory is also used in this study. It is the 'implementation stage' and represents critical factors that influence 
changes in practice. Two of these factors - characteristics of change and local roles -fit with organizational factors while external factors fit with macro-level factors.

\subsubsection{Characteristics of change}

These characteristics include four factors: need, clarity, complexity, and quality/practicality. As noted in section 3.1.1.2, these factors also revisit similar issues related to the three Rs because these issues cannot be resolved at the initiation stage only and therefore carry over into the implementation stage.

In the context of this research, 'need' is used as a concept to help clarify priority needs for e-learning. 'Clarity' will be useful for identifying essential features such as goals of elearning. 'Complexity' is used to examine difficulties and to identify the extent of change required of the individuals responsible for e-learning implementation. For example, change can relate to difficulty, skill required, and extent of alterations in beliefs, teaching strategies, and use of materials. Quality/practicality will be useful for identifying the quality and practicality of the e-learning programme in the Sri Lankan context.

\subsubsection{Local roles}

In the context of this study, local roles are represented by academics, administrative staff (head of the department/director of the institution), and support staff (technical support team members, librarians). These roles may be useful to understand the meaning of change for these individuals and also to bring about what they would/should do about change i.e., from face-to-face learning and teaching to e-learning in tertiary-level IM education in Sri Lanka.

\subsubsection{Macro-level factors}

As discussed in section 2.3.3.6, introduction of e-learning can be a drastic shift for countries which use a traditional face-to-face educational structure like Sri Lanka. Therefore, it is important for Sri Lankan IM education organizations to understand their willingness to embrace the change from face-to-face education to e-learning and the expected effort required on their part to make the change. This will help mitigate failure of e-learning in IM education. It is worth noting, as discussed in section 1.8, that Sri Lanka has a multi-ethnic and multi-religious population. However, I used higher level national cultures as a lens of this study to explore and understand national cultural influence on 
the introduction and use of e-learning in tertiary-level IM education in Sri Lanka rather than examining sub-cultures in detail. The chosen macro-level factors include social and cultural factors: power distance, individualism and collectivism, uncertainty avoidance, long-term versus short-term orientation, and indulgence versus restraint.

\subsubsection{Power distance}

As discussed in section 2.3.3.6, Asian learners tend to prefer passive learning because their countries represent high power distance and they have great respect for the teacher. Therefore, they regard themselves as inferior and prefer passive instructivist learning rather than interacting with their teachers in person or online. This could pose a problem for the introduction of constructivist e-learning. Sri Lanka is also one of the Asian countries, and as shown in Table 3.4, has a higher degree of power distance, and learners may have similar characteristics. Therefore, it is important to identify how these factors may affect the introduction of e-learning in tertiary-level IM education in Sri Lanka.

As outlined by Hofstede, key differences between low and high power distance societies related to schooling are shown in Table 3.6.

\begin{tabular}{|l|l|}
\hline \multicolumn{1}{|c|}{ Low Power Distance } & \multicolumn{1}{c|}{ High Power Distance } \\
\hline Students treat teachers as equals & $\begin{array}{l}\text { Students give teachers respect, even outside } \\
\text { class }\end{array}$ \\
\hline $\begin{array}{l}\text { Teachers are experts who transfer impersonal } \\
\text { truths }\end{array}$ & $\begin{array}{l}\text { Teachers are gurus who transfer personal } \\
\text { wisdom }\end{array}$ \\
\hline $\begin{array}{l}\text { Quality of learning depends on two-way } \\
\text { communication and excellence of students }\end{array}$ & $\begin{array}{l}\text { Quality of learning depends on excellence of the } \\
\text { teacher }\end{array}$ \\
\hline $\begin{array}{l}\text { Less educated people hold more authoritarian } \\
\text { values than more educated people }\end{array}$ & $\begin{array}{l}\text { More educated and less educated people show } \\
\text { equally authoritarian values }\end{array}$ \\
\hline Educational policy focuses on secondary schools & Educational policy focuses on universities \\
\hline
\end{tabular}

Table 3.6 - Key differences between low and high power distance societies related to schools Source: Hofstede, Hofstede, \& Minkov (2010, p. 72)

\subsubsection{Individualism and collectivism}

The majority of Asian countries are categorized as collectivist cultures in Hofstede's study. According to Macon Markar, Madurapperuma and Maroulis (2006, p. 6) the Sri Lankan education system, especially the school education system, is individualistic, i.e., focused on individual achievement and competition, but the social culture is collectivist. 
Therefore, it seems there is a surprising tension between Sri Lankan school culture and social culture. In higher education, it is unclear how these educational or school cultures can be shifted to align with the national culture. Therefore, this needs to be identified, and particular research needs to be done to find out how these factors affect the use of elearning.

As outlined by Hofstede, key differences between collectivist and individualist societies related to school and ICT are shown in Table 3.7.

\begin{tabular}{|l|l|}
\hline \multicolumn{1}{|c|}{ Collectivist } & \multicolumn{1}{c|}{ Individualist } \\
\hline $\begin{array}{l}\text { Students speak up in class only when sanctioned } \\
\text { by the group }\end{array}$ & $\begin{array}{l}\text { Students are expected to individually speak up in } \\
\text { class }\end{array}$ \\
\hline The purpose of education is learning how to do & $\begin{array}{l}\text { The purpose of education is learning how to } \\
\text { learn }\end{array}$ \\
\hline Diplomas provide entry to higher-status groups & $\begin{array}{l}\text { Diplomas increase economic worth and / or self- } \\
\text { respect }\end{array}$ \\
\hline
\end{tabular}

Table 3.7 - Key differences between collectivist and individualist societies related to school \& ICT Source: Hofstede, Hofstede, \& Minkov (2010, p. 124)

\subsubsection{Uncertainty avoidance}

According to Hofstede's cultural dimensions, strong uncertainty avoidance countries prefer structured learning situations with definite objectives, detailed assignments, and strict timetables. Further, students from highly-structured learning environments expect their teachers to be experts who have all the answers. Also, learning a subject is more important rather than learning how to learn. As shown in Table 3.4, Sri Lanka is ranked as a high uncertainty avoidance country and learners may have similar characteristics. Therefore, it is important to identify how these factors may affect the introduction of constructivist e-learning in tertiary-level IM education in Sri Lanka.

As outlined by Hofstede, key differences between weak and strong uncertainty avoidance societies related to education are shown in Table 3.8 .

\begin{tabular}{|l|l|}
\hline \multicolumn{1}{|c|}{ Weak Uncertainty Avoidance } & \multicolumn{1}{c|}{ Strong Uncertainty Avoidance } \\
\hline $\begin{array}{l}\text { Students are comfortable with open-ended } \\
\text { learning situations and concerned with good } \\
\text { discussions }\end{array}$ & $\begin{array}{l}\text { Students are comfortable in structured learning } \\
\text { situations and concerned with the right answers }\end{array}$ \\
\hline Teachers may say, “I don't know” & Teachers are supposed to have all the answers \\
\hline Results are attributed to a person's own ability & Results are attributed to circumstances or luck \\
\hline Teachers involve parents & Teachers inform parents \\
\hline
\end{tabular}

Table 3.8 - Key differences between weak and strong uncertainty avoidance societies related to 


\subsubsection{Long-term versus short-term orientation}

Hofstede's long-term versus short-term orientation relates to the choice of focus for people's efforts: the future or the present and past. As shown in Table 3.4, Sri Lankan social culture is ranked in the middle level (49) of Hofstede's LTO scale. Therefore, this dimension will be useful in identifying students', staff's, and stakeholders' attitude towards the future, i.e., use of e-learning: being comfortable with sacrificing now for longterm benefit (long-term orientation) or more focused on immediate results (short-term orientation).

As outlined by Hofstede, key differences between short-term and long-term orientation societies related to the general norm are shown in Table 3.9.

\begin{tabular}{|l|l|}
\hline \multicolumn{1}{|c|}{ Short-Term Orientation } & \multicolumn{1}{c|}{ Long-Term Orientation } \\
\hline Efforts should produce quick results & $\begin{array}{l}\text { Perseverance, sustained efforts towards slow } \\
\text { results }\end{array}$ \\
\hline Concern with social and status obligations & Willingness to subordinate oneself for a purpose \\
\hline Concern with 'face' & Having a sense of shame \\
\hline Respect for traditions & Respect for circumstances \\
\hline
\end{tabular}

Table 3.9 - Key differences between short-term and long-term orientation societies related to general norm

Source: Hofstede, Hofstede, $\&$ Minkov (2010, p. 243)

\subsubsection{Indulgence versus restraint}

Indulgence versus restraint is Hofstede's sixth (new) dimension national culture (2010) and derived from Minkov's (2007) study (See Appendix 2). According to this dimension, more indulgent countries have higher percentages of very happy people. As shown in Table 3.4, Sri Lanka is ranked as a more indulgent country than other Asian countries. It is therefore important to identify how these factors may have an impact on the introduction of e-learning in tertiary-level IM education in Sri Lanka where face-to-face teaching is still practised in the conventional classroom and there is little familiarity with e-learning. Further, the key relationship of this dimension (indulgence versus restraint) with school or education systems is not discussed in Hofstede's third edition of Cultures and organizations: Software of the mind. Therefore, this needs to be identified, and particular research needs to be done to find out how these dimensions affect the education system, i.e., the introduction of e-learning in tertiary-level IM education in Sri Lanka. 


\subsubsection{External factors}

As mentioned in section 3.1.1.2, the third category of Fullan's implementation stage is external factors (government and other agencies) which is used to identify their role in e-learning implementation.

\section{Government system and higher education governance}

Literature has highlighted that national context and policies influence innovation (discussed in sections 2.3.3.1 and 2.3.3.4). Long-term funding for e-learning is essential for developing countries because e-learning is more expensive especially at the initial stage and developing countries lack economic structures (discussed in section 2.3.3.2). Therefore, the government system and higher education governance are used to understand their role in e-learning implementation in tertiary-level IM education in Sri Lanka.

The Sri Lankan government system controls all areas of the political and economic system in the country, including education. As discussed in sections 2.2.3 and 2.2.4 in Chapter 2, IM education organizations are administered by the government, Ministry of Higher Education (MOHE), and University Grants Commission (UGC). Some IM education activities are directly controlled by universities. An example of such activities would be introducing new course units or modules. However, UGC and MOHE are directly involved with university education when universities expand or change their learning system (National Education Commission of Sri Lanka, 1997). Based on government policies and strategies, the Ministry of Higher Education (MOHE) develops their own policies and strategies (National Education Commission of Sri Lanka, 1996) and the National Education Commission makes recommendations to the president about these policies with a view to ensuring continuity in educational policy and enabling the education system to respond to changing needs in society (National Education Commission of Sri Lanka, 1991). At the end of the process, approved policies come directly to the universities. Consequently, governance of the higher education system leads to development of policies relating to university education. The UGC plays an intermediary role between the MOHE and universities to plan and coordinate university education in order to conform to national policy and to allocate the funds for universities. Further, the UGC gives official permission for universities to conduct staff development programmes 
for newly appointed lecturers. Accordingly, government systems and governance of the higher education system are included in this study to reflect how these factors have an impact on the introduction of e-learning in tertiary-level IM education in Sri Lanka.

\subsubsection{Organizational and macro-level factors}

\subsubsection{Technological factors}

As discussed in section 2.3.3.2 in Chapter 2, lack of access to IT, the digital divide, lack of internet access, and lack of expertise and experience are major barriers to using e-learning. E-learning is dependent on access to electronic communication technologies. However, access to IT is a major barrier in developing countries and it is widening the digital divide between haves and have-nots (Gulati, 2008). Lack of IT infrastructure is also one of the major problems faced by Sri Lankan universities as noted in section 3.2.1.3 in this Chapter. Therefore, it is important to identify how technological factors affect the introduction of e-learning in tertiary-level IM education in Sri Lanka.

\subsection{Chapter summary}

This Chapter has reviewed theories and discussed two theories - Fullan's educational change theory and Hofstede's cultural dimensions- that are of relevance to this study. Factors related to the initiation stage (three Rs: relevance, readiness, and resources), and factors related to the implementation stage from Fullan's educational change theory and five out of Hofstede's six cultural dimensions have been discussed in depth. At the end of this Chapter, a conceptual model was developed by synthesizing factors from the literature review and the two theories. It includes three categories: organizational factors, macro-level factors, and organizational and macro-level factors. 


\section{CHAPTER 4 - RESEARCH STRATEGY, DESIGN, AND METHODOLOGY}

This Chapter outlines the research design and methodology used in carrying out the study. Firstly, it provides the philosophical context of the research. Secondly, it outlines the research methodology and research strategy, giving special emphasis to the analysis of data. The Chapter ends with a summary of issues and challenges relating to the research and my approach to managing these.

\subsection{Philosophical perspectives/research paradigm}

It is important for researchers to clarify their high-level theoretical perspectives or paradigm in the beginning of their research process (Lincoln \& Guba, 2000; Mertens, 1998) as that guides the investigation. The term 'paradigm' derives from the history of science. Bryman (2008, p. 696) defines paradigm as a term "to describe a cluster of beliefs". Bryman states that a paradigm affects study topic and content, research methods, as well as interpretation of results. Creswell $(2003$, p. 6) uses the term 'knowledge claim' to explain a paradigm. Creswell states that researchers begin their project with certain assumptions about how they will learn and what they will learn during their inquiry.

For this study, it was necessary to select the most appropriate research paradigm based on the characteristics of the research project and its goal. I now review the suitability of two alternative paradigms: positivism and interpretivism.

There is no difference between the fundamental goals of research based on the two paradigms of positivism and interpretivism (Weber, 2004). Both are trying to enhance understanding of the world. However, there is a difference in the nature of information they acquire. Lin (1998) states that the positivist approach aims to create information that is broadly applicable (breadth of description). The interpretivist approach is to create more in-depth understanding but the associated findings are generally less broadly applicable (Lin, 1998). The current study required in-depth understanding of the phenomenon under investigation (i.e., the Sri Lankan tertiary-level IM education system). There was little existing knowledge about the research context and the issues identified in the research problem. Hence, interpretivism was used as a suitable method owing to 
the practical goal of this research which was to be able to apply findings in the Sri Lankan context.

While it would be possible to undertake the study from within a positivist paradigm, the interpretivist paradigm would provide good depth of understanding of the unique context, and its relationship to the research questions. This study sought depth of understanding of the unique context, tertiary-level IM education in Sri Lanka: what and how contextual factors could have an impact on the introduction and use of e-learning in tertiary-level IM education. Therefore, I saw interpretivism as providing me with the best opportunity to gain deep insights into the research phenomenon.

At an epistemological level, positivism is objectivist while interpretivism is subjectivist (Pickard, 2007). Therefore, in the positivist paradigm the researcher is detached from the research situation (Fitzgerald \& Howcroft, 1998). According to the interpretivist paradigm, the results of the investigation are a product of interaction between the subject and the researcher (Pickard, 2007). In this research, I was directly involved with the phenomenon under investigation and the research process.

Interpretive research has become important in the Information Systems (IS) field (Walsham, 2006, p. 320). It can assist IS researchers to "understand human thought and action in social and organizational contexts" (Klein \& Myers, 1999, p. 67). Implementation of e-learning in IM in Sri Lanka can be seen as an information system within the tertiarylevel IM education in Sri Lanka. To understand how users perceive such a system in the Sri Lankan context of tertiary-level IM education, an interpretive theoretical perspective was adopted in this study.

\subsection{The research strategy: Case research}

Creswell (2003, p. 14) introduced five types of research strategies which are suitable for linking with a qualitative approach: ethnographies, grounded theory, case studies, phenomenological research, and narrative research. These strategies of inquiry provide a guide for the researcher to frame their research.

I employed a case research strategy, or case study research method as an appropriate research strategy for conducting this study, as the research question focused on a contemporary event (Stake, 1995; Yin, 2009): i.e., what and how contextual factors could 
have an impact on the introduction and use of e-learning in tertiary-level IM education in Sri Lanka. There is much confusion about the definition of case studies (Gerring, 2007; Yin, 2009) because the term has been defined variously in different contexts. In this study, I used the term 'case research' to denote a spatially delimited phenomenon (unit or units) observed at a point in time (Gerring, 2007, p. 19) that creates boundaries within which to observe a contemporary phenomenon in depth (Yin, 2009, p. 18).

According to Yin (2009, p. 2), case research is the appropriate research strategy when (a) "how" or "why" questions are being posed, (b) the investigator has little control over events, and (c) the focus is on a contemporary phenomenon within a real-life context. All three of these conditions were present in this study. Firstly, one of the main research questions was a 'how' question while the other main question was a 'what' question. However, Yin (2009) states that if the "what" question is exploratory, case research can be applied (p. 9). Therefore, I used a case research strategy for this study since both research questions belonged to the exploratory type. The term 'exploratory' means to investigate little-understood phenomena or to identify important variables (Gorman \& Clayton, 2005). Secondly, the events studied were learning organizations over which I had little or no control. Thirdly, the focus of this study was a contemporary phenomenon: what and how contextual factors could have an impact on the introduction and use of elearning in tertiary-level IM education in Sri Lanka, which was new to the country. Further, Pickard (2007) states that case research is most suitable for studying a very specific phenomenon within a particular context.

Other researchers have used case study research methods in the field of e-learning. For example Govindasamy (2002) used case research for studying successful implementation of e-learning. Freitas and Oliver (2005) used a case study in order to identify the relationship between e-learning policy, organizational change and the implementation of e-learning. In addition, Rossiter (2006) used case studies for analysis and conceptualization of the change process in universities when embedding e-learning. There are many more examples (Alonso, Lopez, Manrique, \& Vines, 2005; Newton \& Ellis, 2005; Newton, Hase, \& Ellis, 2002; Smith \& Hardaker, 2000).

Therefore, the case study was chosen as both a well-tested and well-established appropriate strategy for this research. 


\subsubsection{Case design: Single case (embedded) design}

Yin $(2009$, p. 46) has classified the design of case studies into four types: single-case (holistic) designs, single-case (embedded) designs, multiple-case (holistic) designs, and multiple-case (embedded) designs. According to Yin (p. 47) single case is the appropriate design if the case is: (i) a critical case in testing a well-formulated theory; (ii) extreme or a unique case; (iii) a representative or typical case; (iv) a revelatory case; or (v) a longitudinal case. In this study, the case selected was unique, i.e., the tertiary-level IM education system of Sri Lanka and therefore, I used single case as an appropriate case design. A single case can have a single unit of analysis or an embedded unit of analysis (Yin, 2009, p. 46). In this study, the case had a number of embedded sub-units. Thus, I selected single case embedded design for this study. Next the unit of analysis will be outlined.

\subsubsection{The unit of analysis}

Yin $(2009$, p. 28) explains that the primary unit of analysis for case research may be an individual, an event, or an entity. The unit of analysis in this study was an entity: the tertiary-level IM education system of Sri Lanka. The study focused on 'technology innovation', looking at e-learning to facilitate IM education. Within this I was looking at IM education providers, IM education programme participants, existing e-learning providers and stakeholders. These four groups were considered as sub-units of this case. The selection criterion of the sample will be outlined next.

\subsubsection{Suitability of the selected case}

The tertiary-level IM education system of Sri Lanka was considered as a suitable case for investigating the research questions of this study because it aimed to foster transformative change in IM education with the goals of increasing equity of access as well as improving quality through the introduction and use of e-learning. This system presented a unique opportunity: it was the only tertiary-level IM education system in Sri Lanka. As a unique case, the tertiary-level IM education system of Sri Lanka met Yin's (2009) criteria for the use of a single case. It was also an ideal case for studying issues related to IM education because it supported diversity. There were three tertiary-level providers of IM education in Sri Lanka and they targeted two populations: tertiary-level diploma and degree level full-time students, and part-time students who are full-time 
information workers in the information industry. The Sri Lankan government, as well as providing governance of higher education, leads the development of policies, allocates the funds and conducts staff development programmes. The advantage of this system is that it offers a rich range of primary and secondary data sources.

\subsubsection{Overview of the case structure}

The case structure of this study is illustrated in Figure 4.1. The case boundaries were the tertiary-level IM education system in Sri Lanka. The sub-units of analysis included IM education providers (IMEP), IM education programme participants, and stakeholders. There were three providers of IM education, and each provider had administrative staff, teaching staff, and support staff. IM education programme participants consisted of a group of part-time students who were full-time information workers in the information industry. Other stakeholders consisted of government officials.

Incorporating the views of existing e-learning providers is useful for considering potential future e-learning initiatives (Megatrends Project 2007, 2007a, 2007b). Therefore, in the current study the sub-units of analysis also included existing e-learning providers of tertiary education in Sri Lanka. They consisted of programme directors, educational technology support staff, and learning resource support staff.

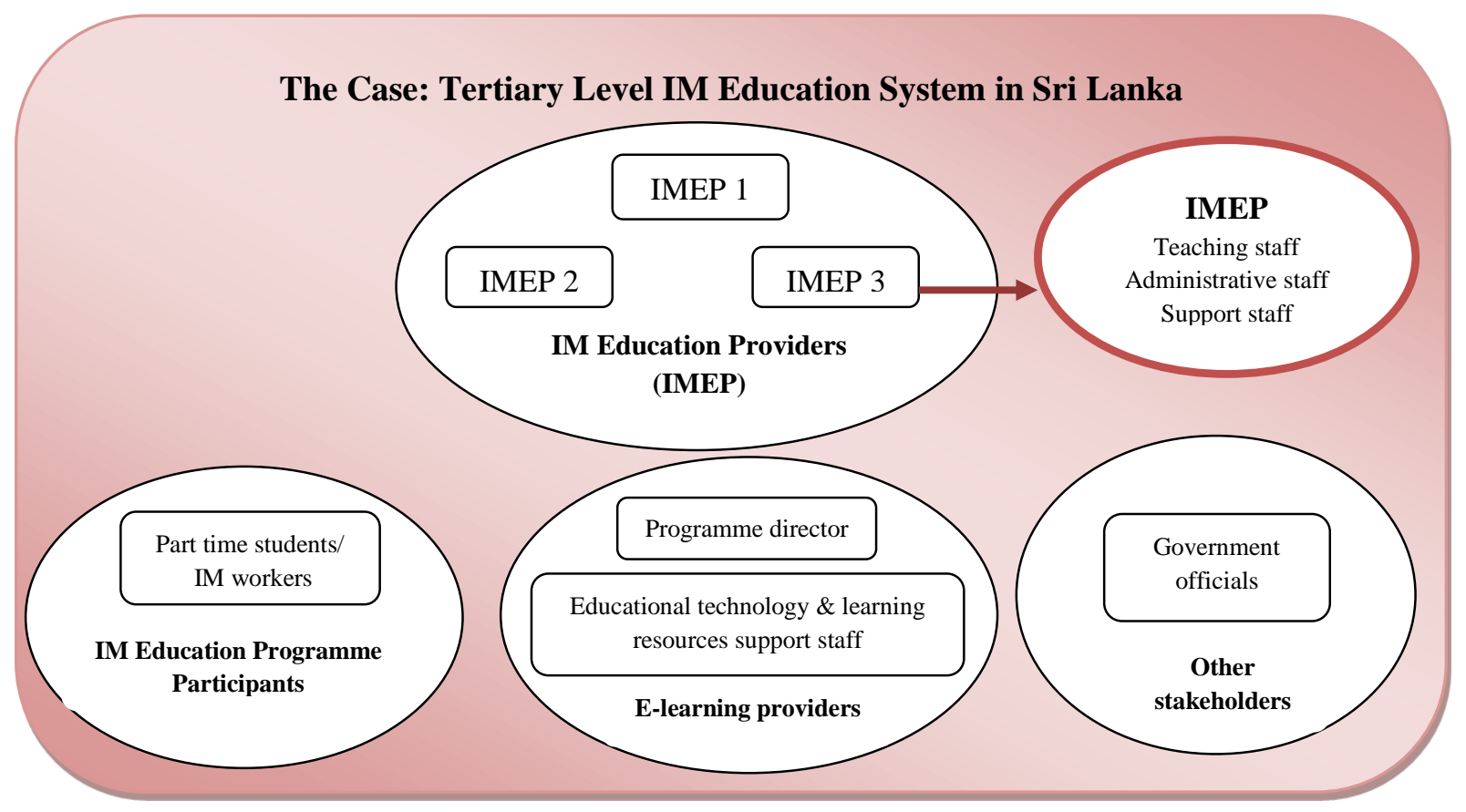

Figure 4.1 - Case structure 


\subsection{Role of the researcher}

I was born and bred in Sri Lanka. I had all my education including at tertiary (university) level in Sri Lanka. Hence, I am very familiar with the socio-cultural context of the country and have a very good understanding of the Sri Lankan educational and political system.

After graduating from university, I worked for the same university as an academic in Library and Information Science. With more than 10 years' experience as an academic as well as having been a student in the same field, I am aware of the challenges and difficulties faced by IM education. My research has therefore been motivated by interesting challenges arising from providing equity of access to IM education, making the implementation of e-learning my passion.

A basic principle of any interpretive study is the setting up and carrying out of fieldwork (Walsham, 2006, p. 321). As a researcher I had would enter the natural setting of the subjects. According to Walsham (2006, p. 321), the researcher needs to choose a style of involvement. The researcher needs to think about how they will gain and maintain access, how they will collect field data, and how they will work in different countries.

I spent three months in Sri Lanka (from September to December 2011) to gather interview data by engaging with the participants in their own setting. The setting for this study was the Sri Lankan tertiary-level IM education system. Most semi-structured interviews were conducted with professionals in IM organizations. My background and experiences were an advantage because the issues and concepts that relate to IM education and its day-to-day challenges were easily understood. I believed this understanding of the context and role enhanced my awareness, knowledge and sensitivity to many of the challenges, decisions and issues encountered in the field and assisted me in working with the participants in this study. Also, my tacit knowledge helped me to understand participants' views and experiences, helping to elicit rich data.

As a researcher, I brought certain biases to this study because of my cultural and national background and also I represented one of the IM organizations and knew some of the respondents. Because I am a Sri Lankan who had grown up in and shared the culture of the research participants it was easy for me to understand and explain issues related to the socio-cultural environment such as the nature of the social system, the relationship 
between individualism and collectivism, and long-term orientation. I was aware this cultural familiarity might lead me to interpret issues based on my own experience. Hence, I was careful to document the participants' views and to conduct member checking. On the other hand, this cultural familiarity helped me to probe and interpret participants' views which enabled me to develop an in-depth understanding of the factors that influence the introduction and use of e-learning in tertiary-level IM education in Sri Lanka.

\subsection{Methodology, research design and process}

This section outlines the methodology of this study, the research design, and process. First the research approach of this study will be discussed.

\subsubsection{Qualitative research methodology}

In this study, qualitative research methodology was used to gather and analyse data in order to answer the research questions. This study addressed two questions focusing on what contextual factors could have significant impact on the introduction and use of elearning and how these factors could affect the introduction and use of e-learning in tertiary-level IM education in Sri Lanka. These research questions were exploratory in nature since the target was to investigate little-understood phenomena. Neuman (1994, p. 18) points out that when little is known about a topic (and therefore everything is potentially important), the most relevant approach is a qualitative method. Creswell (2003, p. 22) further emphasizes that qualitative methods are appropriate if a concept or phenomenon has been under-investigated. There was no research that indicated what and how contextual factors have an impact on the introduction and use of e-learning in tertiary-level IM education in Sri Lanka.

Qualitative methods facilitate the collection of rich, deep data with potential for revealing complex interactions (Miles \& Huberman, 1994, p. 10). Patton (1987, p. 9) also states that to study selected issues, cases, or events in depth and detail, the most suitable approach is a qualitative method as opposed to quantitative methods which aim to provide a broad, generalizable set of findings and therefore aim for parsimony. In addition, qualitative methods typically produce a wealth of detailed data using a smaller number of people 
(Patton, 1987). The qualitative method met the study's needs as rich understanding of phenomena in a specific context was required.

In qualitative research, the researcher's tacit and explicit knowledge helps to obtain detailed data (Flick, 2006; Pickard, 2007). In this case, I used my tacit and explicit knowledge of the research context to understand participants' views and experiences in order to elicit rich data, particularly while undertaking semi-structured interviews and focus group interviews.

\subsubsection{Research design and process}

The overview of the research design is illustrated in Figure 4.2. The research process was based on the Hutter-Hennink qualitative research cycle which illustrates the cyclical nature of qualitative research. This research cycle consisted of three interlinked cycles: the design cycle, the ethnographic cycle, and the analytic cycle. The Hutter-Hennink qualitative research cycle was used in this study as a useful tool for providing structure and transparency to achieve coherence and scientific rigor as well as to ensure confirmability.

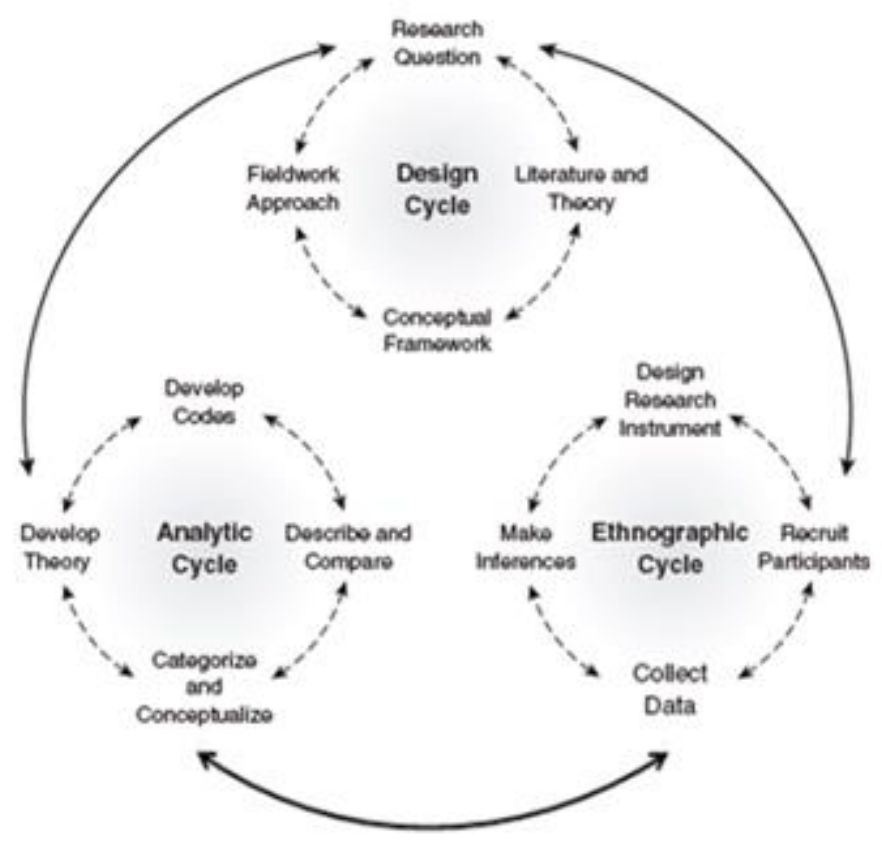

Figure 4.2 - Hutter-Hennink qualitative research cycle Source: Hennink, Hutter, \& Bailey, 2011, p. 4, copied with permission 
The following section is structured according to this model. Firstly the design cycle is described in detail.

\subsubsection{The design cycle}

The first component of the Hutter-Hennink qualitative research cycle is the design cycle. It consists of four interlinked tasks: the formulation of research question, reviewing research literature and incorporating theory, developing a conceptual framework for the study, and selecting an appropriate fieldwork approach (Hennink, Hutter, \& Bailey, 2011,

p. 5). Based on the research problem of the current study, two research questions were formulated and presented in section 1.5 in Chapter 1. To develop a preliminary model concerning factors that could have an impact on the introduction and use of e-learning in tertiary-level IM education in Sri Lanka, I conducted a literature review in Chapter 2. Then I reviewed relevant theories and selected two theories that could have potential relevance to the study in Chapter 3.

The next task in the design cycle is to develop a conceptual framework. In this study, the preliminary model concerning the factors that could have an impact on the introduction and use of e-learning in tertiary-level IM education in Sri Lanka was developed by combining insights from the two theories with insights gained from the literature review and presented in section 3.2 in Chapter 3.

The fourth task in the design cycle is to select a fieldwork approach appropriate for the study. The fieldwork approach refers to both how the data is collected and which research method is used. Also, it reflects the paradigm underlying the research (Hennik et al., 2011, p. 45). As discussed earlier in this Chapter, an interpretive theoretical perspective was chosen as an appropriate epistemology for this study through the use of qualitative methods and case research. This study used qualitative data collection techniques. This is discussed next along with the ethnographic cycle.

\subsubsection{The ethnographic cycle}

The second component of the Hutter-Hennink qualitative research cycle is the ethnographic cycle. It consists of four core tasks in qualitative data collection: design research instrument, recruit participants, collect data, and make inductive inferences (Hennink, Hutter, \& Bailey 2011, p. 81). 
In qualitative research, the researcher is the primary instrument in data collection (Marshall \& Rossman, 2006).

The overview of the research design and data collection procedure is summarized in Figure 4.3.

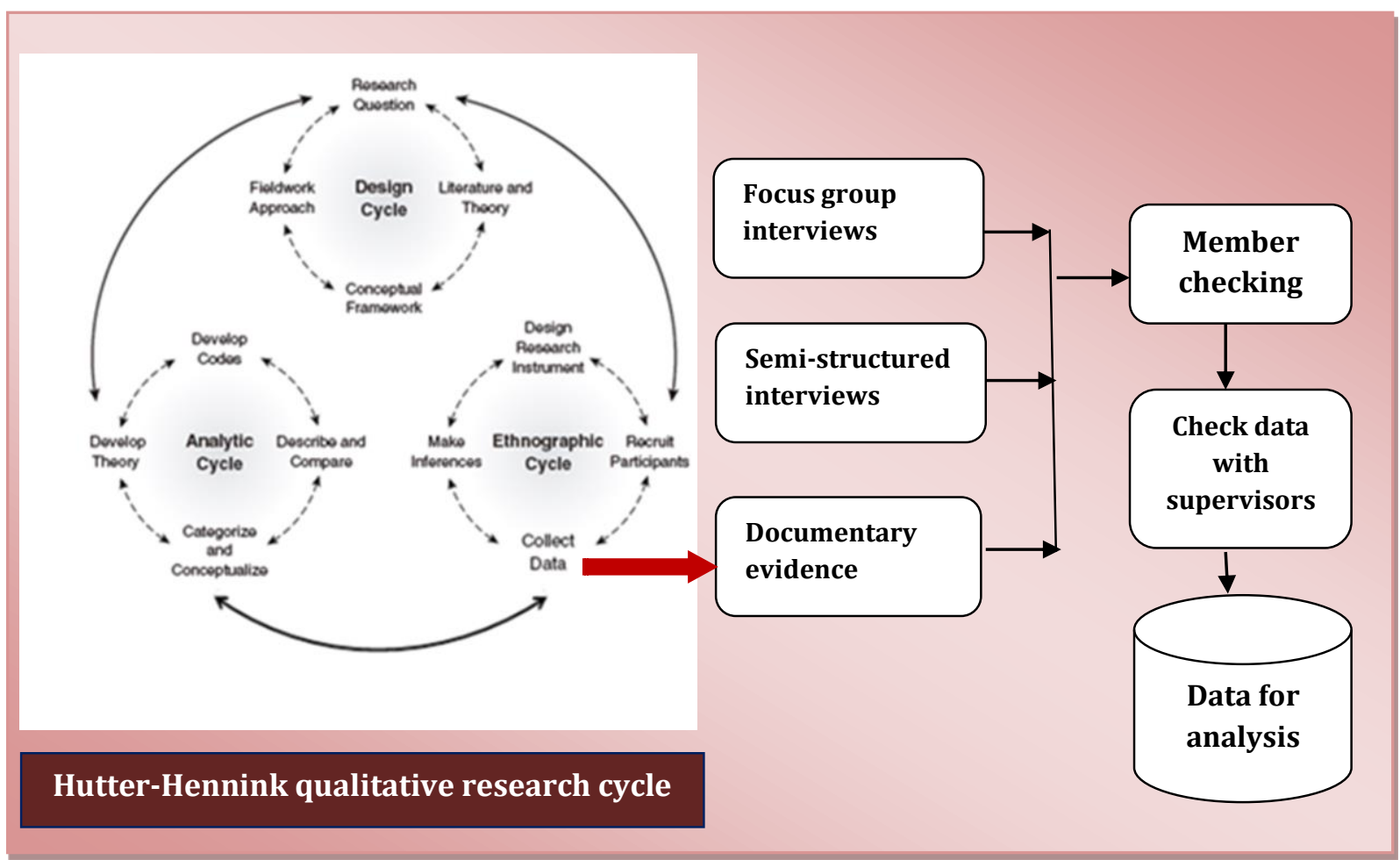

Figure 4.3 - Overview of the proposed research design and data collection

Modified from Hennink, Hutter, \& Bailey, 2011

\subsection{Data collection method}

Qualitative data collection techniques include observations, interviews (Creswell, 2003; Gorman \& Clayton, 2005), documents, audiovisual materials (Creswell, 2003), group discussion techniques, and historical investigations (Gorman \& Clayton, 2005). This study used group discussion techniques, interviews, and documentary evidence. Different types of triangulation data helped to enhance the credibility of this study.

The primary data collection techniques for this study were group discussion techniques (focus group) and semi-structured interviews. 


\section{Focus group discussions}

A focus group discussion is a form of group interview. According to Kitzinger (1995) focus group interviews are used as a quick and convenient way to collect data from several people simultaneously. Thus, it enabled me to gather data from participants in a quick and convenient way because I used focus group discussions in the first phase of this study. After the group discussions, I then moved to individual interviews.

According to Reviere (1996, p. 61), focus group interviewing is appropriate if the topic is impersonal enough or if there is benefit to be derived from hearing the issues discussed in a group setting. In this study, I first aimed to discuss issues in a group setting. Because I had a preliminary model prior to beginning my research, the group setting provided by a focus group gave me a good opportunity to investigate the most significant contextual factors that could have an impact on the use of e-learning in tertiary-level IM education in Sri Lanka. For this purpose, two separate focus group discussions were conducted. One involved IM education programme participants (i.e., part-time students who were fulltime information workers in the information industry). The other involved academics in IM education. The group setting resulted in the production of ideas regarding the most significant factors that could have an impact on the introduction and use of e-learning. These identified issues were later used in semi-structured interviews in order to explore a more in-depth understanding of the issues.

The focus group interview is one of the qualitative methodologies suitable for gaining an understanding of participants' attitudes and perceptions relevant to a particular topic (Gorman \& Clayton, 2005; Kitzinger, 1995; Liamputtong, 2009; Schensul, Lecompte, Nastasi, \& Borgatti, 1999). In the current study, I was looking at the participants' attitudes and perceptions on the introduction and use of e-learning and other related issues. Therefore, I used focus groups for this study. Further, this method is appropriate for exploring people's knowledge and experiences and can be used to examine not only what people think but also how they think and why they think that way (Liamputtong, 2009; Kitzinger 1995). Hence, the focus group interview method was used in this study to understand (from the participants' views) what factors have significant impact on the use of e-learning and how these affect the use of e-learning in tertiary-level IM education in Sri Lanka. This method also helped me to understand why participants think the way they 
do. Moreover, a focus group interview was able to produce more ideas than individual interviews (Williamson, 2002, p. 257). Krueger (1994, p. 36) states that the qualitative researcher can increase the sample size without increasing the cost in terms of time and money. I was interested in reaping the same benefits. These data collection techniques have also been used by other researchers in the field of e-learning for their research. Examples include Rossiter (2006), Smith and Hardaker (2000) and McPherson and Nunes (2006).

\section{Focus group discussion procedure}

Care was taken to address ethical issues as required by the Victoria University School of Information Management Human Ethics Committee (HEC). I applied for and was granted HEC approval.

I aimed to assemble two focus groups consisting of six to eight participants. There is no fixed figure of how many participants should be involved in focus group interviews. In general, researchers use six to ten participants in one focus group session, but some sessions can have up to 12 people (Bloor, Frankland, Thomas, \& Robson, 2001; Krueger, 1994; Krueger \& Casey, 2000; Liamputtong, 2009). However, Liamputtong (2009, p. 73) points out that focus groups work well with six to eight people, since this number minimizes low-level involvement and maximizes high-level involvement. Therefore, I used the six to eight range suggested by Liamputtong as the number of participants for each focus group in this study.

The first focus group comprised six information workers who work in rural and urban areas. They were mainly full-time employees such as Ministry officials, officials of statutory bodies, librarians, officers in charge of cultural centres, Nenasala (electronic information centres) staff, information sector staff (mass media, book publishers, archives and record managers, information centre managers), ICT professionals, officials of local and foreign NGOs involved in community development through multipurpose community telecentres, and village knowledge centres. They represented a mixture of older and younger workers as well as male and female workers. Also, they represented three career stages: early, middle, and later.

Further, the focus group individuals were not representing their organizations. They were only being asked about their personal experience. 
To maintain the confidentiality of this study, I assigned codes to each focus group discussion, i.e., focus group discussions with information workers were FGDIMW and focus group discussions with academics were FGDAC.

Stratified purposive sampling was used in order to select participants. For example, the population in this study was tertiary-level IM education and this was stratified into the student category (part-time students who are full-time information workers), tertiarylevel education providers (IM education providers, e-learning providers), the staff category (teaching, administrative, and support staff), and higher education system-level support (GOSL, UGC, QAAC). Focus discussions were conducted with IM workers and academics because I needed to obtain a sufficient number of participants to satisfy the research objectives. To identify research participants, I used personal contacts via my informal educational and industry networks. All initial contacts were made via email, telephone or face-to-face conversations. For all categories of participants, I met with the potential participants, talked with them, explained the purpose of the research and sought their consent to participate.

A comfortable setting is needed for focus group interviews to establish the right atmosphere where participants can be encouraged to share their opinions (Kitzinger, 1995; Liamputtong, 2009). Hence, focus group interviews were conducted separately for the two groups: IM workers in rural and urban areas, and academics in IM education. At the participants' convenience, interviews took place at two university premises in Sri Lanka. The faculty boardroom in one university was used as a venue for the focus group discussion with academics. They were more comfortable to express and share their perceptions when they were sitting in the formal meeting room with a small number of people. However, this boardroom was not a comfortable place for IM workers to gather and discuss the topic because they were not familiar with the venue. By talking to IM workers, I recognized that they were more likely to share their opinions in an informal setting. A small lecture room was therefore used as a venue for the focus group discussion with IM workers. Each group discussion lasted approximately two hours; all interviews were audio-visually digitally recorded (with the permission of the interviewees) and notes were taken during the interviews. 
It is important to have a discussion guide for focus group interviewing in order to run the interview and collect data smoothly. Hennink, Hutter, and Bailey (2011, p. 142) have produced a well-structured design guide. It follows a funnel structure. It assists researchers to "introduce the topic, open the discussion, develop group rapport, focus on key topics and bring the discussion to a close" (p. 142). I used the Hennink et al. funnel design to conduct my focus group interviews as well as to develop a focus group interview protocol (See Appendix 4). Schensul et al. (1999, p. 84) have suggested solutions for some typical problems which can arise in focus group interviews. For example, if some members of the group do not speak or speak too much, what should the researcher do? I therefore applied those suggestions (See Appendix 5) in order to resolve some problems while I was conducting the focus group interviews. For example, when some of the group members did not speak, I made sure to ask them, 'what do you think about X?'

A pilot focus group was conducted with IM workers to test the questions and the protocol. After the pilot study, I sent the focus group interview data as well as the interview protocol to my supervisors and received their comments. I then revised my interview guidelines and interviewing technique.

For example, in the pilot focus group discussion, first I asked participants to write down the key factors that they think have significant impact on the use of e-learning in tertiarylevel IM education in Sri Lanka. Then I asked them to read out the factors and I wrote them on the whiteboard. Next, as a group, I asked them to put the factors into groups. I also asked them to group identified factors according to the conceptual model of this study and then discussed factors in detail. After I received my supervisors' comments, I realized that I brought some biases to the data by asking participants to group factors identified in the discussion based on the conceptual model of this study. Thus, I then revised my interview guidelines and interviewing techniques and conducted two focus groups with IM workers and academics (See focus group interview protocol Appendix 4). For example, I asked participants to group and rank the factors they have come up with in their discussion and then started more in-depth discussion. At the end of the focus group, I introduced some of the factors from the conceptual model but without showing them the actual model and grouping. For this purpose, I said something like 'Thank you for these factors you have identified. The literature shows that there are other factors 
$\mathrm{x}, \mathrm{y}, \mathrm{z}$. Have you thought about any of these? Do you think any of them are relevant in the Sri Lankan context?" If so, I discussed them.

\section{Semi-structured interviews}

One of the most important sources of case study information is the interview (Williamson, 2002; Yin, 2009). Yin (2009, p. 106-109) has classified interviews into three types: in-depth/ semi-structured interviews, focused interviews, and structured interviews. This study used semi-structured interviews. These interviews included a standard list of questions that were developed based on significant factors found in the focus group discussions. For example, in the second stage of each focus group discussion, I asked participants to vote for factors using 5-point Likert scales (e.g., 5-highly significant, 4-significant, 3-neutral, 2-not significant, 2-completely insignificant). I then started an in-depth discussion of significant factors that I identified from the discussions. The significant factors I identified from the focus group discussions helped me to frame individual interview questions and guide the discussions.

I also used the conceptual framework (Figure 3.3) to guide the process of data collection (focus group discussions as well as semi-structured interviews) and analysis in this study. Since this is a qualitative study, I was aware that I needed to interview and listen to participants to get the information from them without restricting or guiding them. Thus, the conceptual framework gave me the background that I needed. It also helped me to frame the interview questions and guide the discussions. Moreover I also acknowledged the subjectivity of the participants and I was more open to their opinions and other information, as an inductive and deductive process. Semi-structured interviews also allow a researcher to follow up on leads provided by participants for any of the questions (Williamson, 2002, p. 243). These types of interviews helped me to explore the research questions in greater depth.

\section{The participating institutions}

\section{IM education providers}

As discussed in section 4.2.4, which focused on the case structure, three tertiary-level IM education providers in Sri Lanka, all in the greater Colombo area, participated in this study. These providers offered qualifications ranging from diplomas to masters degrees 
to PhDs in Information Management (or Library and Information Science education). To maintain confidentiality, I assigned codes for each institution as shown in Table 4.1.

\begin{tabular}{|l|c|}
\hline \multicolumn{1}{|c|}{ Type of Institution } & Code \\
\hline IM Education Provider - public university & IMEPDE \\
\hline IM Education Provider - public institute & IMEPNI \\
\hline IM Education provider - private university & IMEPSL \\
\hline
\end{tabular}

Table 4.1 - Institution codes

IMEPDE aims to provide students with an intellectual and professional foundation for careers in information services and to provide the skills and competencies necessary for information services.

IMEPNI aims to expand the higher educational opportunities for those who do not gain entry to universities and to provide an information workforce essential for Sri Lanka in its journey towards globalization through a diploma in Library and Information Management.

IMEPSL aims to produce educated information management professionals, especially to utilize information systems effectively within organizations and to evaluate and select appropriate methods and technologies for people managing and disseminating information.

\section{E-learning providers}

As discussed in section 4.2.4, which focused on the case structure, three current elearning providers in Sri Lanka participated in this study. These providers represented a Centre for Educational Technology and Media in an Open University, an E-learning Centre in a School of Computing in one of the prominent universities in the Colombo area, and the National Online Distance Education Service of Sri Lanka run by the Ministry of Education. All these providers were supported in the use of ICT for national development as part of the e-Sri Lanka programme (See section 2.2.1.2) by promoting e-learning. These providers targeted tertiary-level students and government and non-government organizations, in universities, government organizations, and private partner organizations. All the e-learning programmes in these three e-learning provider 
organizations were blended courses (face-to-face plus online learning). They largely used face-to-face teaching while e-learning was used as a supplementary tool.

To maintain the confidentiality of this study, I assigned codes for each e-learning provider as shown in Table 4.2 .

\begin{tabular}{|l|c|}
\hline \multicolumn{1}{|c|}{ Types of E-Learning Providers } & Code \\
\hline Existing E-learning Providers - Centre for Educational Technology and Media & EEPOU \\
\hline Existing E-learning Providers - E-learning centre in School of Computing & EEPUC \\
\hline $\begin{array}{l}\text { Existing E-learning Providers - National Online Distance Education Service of Sri } \\
\text { Lanka }\end{array}$ & EEPNO \\
\hline
\end{tabular}

Table 4.2 - Codes for e-learning providers

\section{Semi-structured interviews procedure}

Similar to the focus group discussion procedure, I applied for and was granted HEC approval for semi-structured interviews. These ethical requirements were presented in the information sheet (see Appendix 7). Before commencing data collection, I provided an information sheet for interviewees and sought consent from them (see Appendix 8). Moreover, I also obtained a letter of introduction from the Vice Chancellor of the University of Kelaniya (where I worked as an academic staff member) explaining the purpose of the study and seeking permission from tertiary-level IM education providers, existing e-learning providers, and government departments to conduct the research among the staff in their institution. Then I received letters from the participating institutions authorizing me to interview their personnel.

This study used stratified purposeful sampling in order to select the sample for the semistructured interviews. A stratified purposeful sample is appropriate when it is important to illustrate sub-groups as well as to do comparisons (Miles \& Huberman, 1994; Patton, 1990). Interpretivist researchers' preferred method of sampling is purposive (Williamson, 2002, p. 232). According to Gorman and Clayton (2009), a purposive sample is one that is chosen by the researcher to include representatives from within the population being studied who have a number of characteristics relevant to the research project. Fullan's educational change theory and my personal experience of the research context helped me to determine which people to include as participants in this study. For example, in Fullan's educational change theory, the second category of the 
implementation stage is local characteristics/roles. Fullan used district-level roles, community-level roles, principal, and teacher to identify the meaning of change for people in the role under discussion and to generate ideas as to what they could/should do about change. Similarly, I selected local roles at university level in Sri Lanka to explore and understand what factors have an impact on the introduction and use of e-learning in tertiary-level IM education in Sri Lanka. The selected stratified sample in this study is discussed under the focus group discussion procedure and the characteristics of the stratified purposive sample are discussed next and shown in Tables 4.1, 4.2 and 4.3.

As opposed to focus group interviews, I conducted semi-structured interviews with IM education providers, existing e-learning providers and other stakeholders as key informants of this study. Hence, I needed to capture their opinions individually in order to gather in-depth data. Krueger (1994, p. 11) states that in face-to-face interviews, individuals form opinions in isolation and really know how they feel. But in focus groups "people may need to listen to opinions of others before they form their own personal viewpoints" (p. 11).

Using the case structure of this study (see Figure 4.1), 18 face-to-face semi-structured interviews were conducted with three tertiary-level IM education providers. The characteristics of the interview participants are presented in Table 4.3. These groups of participants were able to understand enablers for, and barriers to, the introduction and use of e-learning in IM education in Sri Lanka. Furthermore, they were able to understand the vision and mission, strategies, policies, requirements and needs of their departments, institutions and universities that may affect the introduction and use of e-learning. As a result, they were able to provide an understanding of what factors have significant impact on the introduction and use of e-learning and how these factors affect the introduction and use of e-learning in tertiary-level IM education in Sri Lanka. 


\begin{tabular}{|l|l|l|l|l|l|}
\hline $\begin{array}{l}\text { Semi-structured } \\
\text { interviews with }\end{array}$ & \multicolumn{2}{|c|}{ Category } & IMEP 1 & $\begin{array}{l}\text { I MEP } \\
\mathbf{2}\end{array}$ & $\begin{array}{l}\text { IMEP } \\
\mathbf{3}\end{array}$ \\
\cline { 2 - 6 } $\begin{array}{l}\text { IM education } \\
\text { providers (IMEP) }\end{array}$ \\
\cline { 2 - 6 } $\begin{array}{l}\text { No. of } \\
\text { interviews -18 }\end{array}$ & Teaching staff & Junior & 1 & 1 & 1 \\
\cline { 2 - 6 } & Senior & 1 & 1 & 1 \\
\cline { 2 - 6 } & Support staff & $\begin{array}{l}\text { Head of the Department } \\
\text { / Director of the } \\
\text { Institution }\end{array}$ & 1 & 1 & 1 \\
\cline { 2 - 6 } & Dean of the Faculty & 1 & 1 & 1 \\
\hline & $\begin{array}{l}\text { Technical Support Staff } \\
\text { in Department or } \\
\text { Faculty }\end{array}$ & 1 & 1 & 1 \\
\cline { 2 - 6 } & Librarian & 1 & 1 & 1 \\
\hline
\end{tabular}

Table 4.3 - Characteristics of stratified purposeful sample - IMEP

Further, nine face-to-face semi-structured interviews were conducted with current elearning providers (Table 4.4). As mentioned earlier in this Chapter (see section 4.2.4) incorporating the views of existing e-learning providers is useful for considering potential future e-learning initiatives. In selecting the e-learning providers from a tertiary-level education system, care was taken to include initiatives of the Ministry of Higher Education as well as initiatives of the tertiary-level IM organizations or their parent organizations that provided the platform to use e-learning. The programme director, educational technology support staff, and learning resource support staff were selected from each e-learning provider as participants in this study. These groups of participants were able to provide practical understanding of what factors have significant impact on the introduction and use of e-learning and how these factors affect the introduction and use of e-learning in tertiary-level education in Sri Lanka.

\begin{tabular}{|c|c|c|c|c|}
\hline \multirow{4}{*}{$\begin{array}{l}\text { Semi-structured } \\
\text { interviews with } \\
\text { existing e-learning } \\
\text { providers (EEP) in Sri } \\
\text { Lanka } \\
\text { No. of interviews } \mathbf{- 9}\end{array}$} & Category & EEP 1 & EEP 2 & EEP 3 \\
\hline & Programme director & 1 & 1 & 1 \\
\hline & $\begin{array}{l}\text { Educational technology } \\
\text { support staff }\end{array}$ & 1 & 1 & 1 \\
\hline & $\begin{array}{l}\text { Learning resource support } \\
\text { staff }\end{array}$ & 1 & 1 & 1 \\
\hline
\end{tabular}

Table 4.4 - Characteristics of stratified purposeful sample - EEP

Moreover, three face-to-face semi-structured interviews were also conducted with stakeholders (Table 4.5), i.e. government officials. As mentioned in section 3.2.2.6 in Chapter 3, the Sri Lankan government controls the education system in the country. Hence, government officials were sampled to explore their views on the introduction and use of e-learning and issues regarding policies and funding allocation for e-learning. This sample comprised the government officials as shown in Table 4.5. 


\begin{tabular}{|l|l|c|}
\hline $\begin{array}{l}\text { Semi-structured } \\
\text { interviews with } \\
\text { stakeholders }\end{array}$ & \multicolumn{1}{|c|}{ Category } & $\begin{array}{c}\text { No. of } \\
\text { participants }\end{array}$ \\
\cline { 2 - 3 } & Officials from Government of Sri Lanka (GOSL) & 1 \\
\cline { 2 - 3 } $\begin{array}{l}\text { No. of } \\
\text { interviews - 3 }\end{array}$ & Officials from University Grants Commission (UGC) & 1 \\
\cline { 2 - 3 } & Officials from Quality Assurance and Accreditation Council (QAAC) & 1 \\
\hline
\end{tabular}

Table 4.5 - Characteristics of stratified purposeful sample - Stakeholders

\section{* Total no. of semi-structured interviews - 30}

To maintain confidentiality, I also assigned codes for each interviewee as shown in Table 4.6. Codes were created by combining abbreviations (Abbr.) of sub-units, type of the organization, and characteristics of the sub-units.

\begin{tabular}{|c|c|c|c|}
\hline $\begin{array}{c}\text { Abbr. of } \\
\text { sub-units }\end{array}$ & $\begin{array}{c}\text { Abbr. of type of } \\
\text { organization }\end{array}$ & $\begin{array}{l}\text { Abbr. of the characteristics } \\
\text { of the sub-units }\end{array}$ & $\begin{array}{c}\text { Code for } \\
\text { interviewee }\end{array}$ \\
\hline \multirow{18}{*}{$\begin{array}{c}\text { IMEP } \\
\text { (IM Education } \\
\text { Providers) }\end{array}$} & \multirow[t]{6}{*}{ DE (DELIS) } & TSS (Teaching Staff Senior) & IMEPDETSS \\
\hline & & TSJ (Teaching Staff Junior) & IMEPDETSJ \\
\hline & & $\begin{array}{l}\text { ASH (Administrative Staff - Head of the } \\
\text { Department) }\end{array}$ & IMEPDEASH \\
\hline & & $\begin{array}{l}\text { ASD (Administrative Staff - Dean of the } \\
\text { Faculty) }\end{array}$ & IMEPDEASD \\
\hline & & SST (Support Staff - Technical) & IMEPDESST \\
\hline & & SSL (Support Staff - Librarian) & IMEPDESSL \\
\hline & \multirow[t]{6}{*}{ NI (NILIS) } & TSS & IMEPNITSS \\
\hline & & TSJ & IMEPNITSJ \\
\hline & & $\mathrm{ASH}$ & IMEPNIASH \\
\hline & & ASD & IMEPNIASD \\
\hline & & SST & IMEPNISST \\
\hline & & SSJ & IMEPNISSL \\
\hline & \multirow[t]{6}{*}{ SL (SLIIT) } & TSS & IMEPSLTSS \\
\hline & & TSJ & IMEPSLTSJ \\
\hline & & $\mathrm{ASH}$ & IMEPSLASH \\
\hline & & ASD & IMEPSLASD \\
\hline & & SST & IMEPSLSST \\
\hline & & SSJ & IMEPSLSSL \\
\hline \multirow{9}{*}{$\begin{array}{c}\text { EEP } \\
\text { (Existing } \\
\text { E-Learning } \\
\text { Providers ) }\end{array}$} & \multirow[t]{3}{*}{ OU (OUSL) } & PD (Programme Director) & EEPOUPD \\
\hline & & $\begin{array}{l}\text { MET (Educational Technology Support } \\
\text { Staff) }\end{array}$ & EEPOUMET \\
\hline & & MLRS (Learning Resource Support Staff) & EEPOUMLRS \\
\hline & \multirow[t]{3}{*}{ UC (UCSC) } & $\mathrm{PD}$ & EEPUCPD \\
\hline & & MET & EEPUCMET \\
\hline & & MLRS & EEPUCMLRS \\
\hline & \multirow[t]{3}{*}{ NO (NODES) } & $\mathrm{PD}$ & EEPNOPD \\
\hline & & MET & EEPNOMET \\
\hline & & MLRS & EEPNOMLRS \\
\hline \multirow{3}{*}{$\begin{array}{c}\mathrm{SH} \\
\text { (Stakeholders) }\end{array}$} & \multirow{3}{*}{$\begin{array}{c}\text { GO } \\
\text { (Government } \\
\text { officials) }\end{array}$} & IC (ICTA) & SHGOIC \\
\hline & & UG (UGC) & SHGOUG \\
\hline & & QA (QAAC) & SHGOQA \\
\hline
\end{tabular}

Table 4.6 - Codes for interviewees 
To guide the interviews, a protocol was created (see Appendix 6) as a research instrument based on factors found in the focus group discussions and factors of the preliminary model which was developed based on the literature review and two theories of potential relevance, i.e., Fullan's educational change theory (2007) and Hofstede's expanded cultural dimensions (2010).

The questions covered the themes and issues that I sought to explore but were not asked in the same order in all interviews. After introducing the researchers and the purpose of the study, all interviews began with warm-up questions such as "please tell me about yourself" or "please share with me your e-learning experiences". Further questions were based on the initial responses from each interviewee and focused on understanding the factors affecting the use of e-learning, i.e., how teacher and student relationships affect the introduction of collaborative e-learning, and how change can occur in your organization given the diversity of perspectives. Checking the themes listed in the protocol, the interviewees were asked about any themes not already covered.

All semi-structured interviews were digitally audio-recorded (with the permission of the interviewee) and notes were taken during the interview. Regardless of whether a researcher records interview data or not, it is good to keep a database of interviews including this minimal information: who, when and where (Gorman \& Clayton, 2005, p. 138). I maintained a Microsoft Excel worksheet of interviews. The worksheet included the following column headings:

1. Abbreviation of the name of the participating institute/organization

2. Category

3. Pseudonym of participant

4. Contact telephone number

5. Contact email

6. Date for interview

7. Time for interview

8. Place for interview

9. Check list $\mathrm{i}$ - Send information sheet and consent form

10. Check list ii - Send $1^{\text {st }}$ reminder

11. Check list iii - Send $2^{\text {nd }}$ reminder

12. Check list iv - Receive signed consent form

13. Check list v - Finish member checking 


\section{Documentary evidence}

Complementary data was gathered through analysis of relevant documents. According to Yin (2009, p. 101), documentary information is relevant for every case study topic except for studies of preliterate societies.

The term 'documents' covers a wide range of different kinds of sources: personal documents, official government documents, official documents from private sources, mass media outputs, and virtual outputs (Bryman, 2008; Yin, 2009). In this research, relevant documents included (i) official government documents: policies, reports, and announcements, (ii) official documents from private sources: administrative documents, proposals, progress reports, and other internal records, and (iii) relevant internet resources.

This documentary evidence was important for this study in order to verify information that was mentioned in interviews. Yin (2009) explains that documents can provide specific details to corroborate information from other sources. Thus, the analysis and review of documents could provide a rich source of information with which to complement and supplement data collected through interviews. Documentary evidence was also important for this study because it had the potential of holding additional information that was not available from participants. I requested access to any relevant documents from government officials, particularly documents that could be obtained from IM education providers. The gathering of some of the documents was undertaken along with the interviews. I requested relevant documentation from interviewees during the interviews. I also visited the libraries and web sites of the tertiary providers of IM education, tertiary providers of e-learning, and government ministries/departments. This sought to complement and triangulate data gathered through the focus group discussions and semi-structured interviews. This, therefore, added credibility to the study.

Further, descriptive field notes were maintained. I used these field notes to record preinterview discussion details and background information about organizations, research participants, and their role in the organization. This data collection technique was important for the study as written evidence. For example, I used descriptive field notes 
to cross-check some of the data in the transcriptions and to provide rich background information when I interpreted participants' perceptions about the factors.

After I finished data collection activities at one site, I transcribed the interviews using 'Express Scribe' transcription software. I then checked the data with the participants with the aim of enhancing the credibility of this study. I also contacted my supervisors and checked data with them and read their comments. At the end of the data collection at one site, I began to learn more about key issues in this study which enabled me to make inductive inferences. Making inductive inferences assists the researcher to go deeper into the research issues and gain rich detailed data (Hennik, Hutter, \& Bailey, 2011, p. 82). The data analysis process of this study is discussed next.

\subsubsection{The analytic cycle}

The third component of the Hutter-Hennink qualitative research cycle is the analytic cycle. It consists of four core tasks of qualitative data analysis: to develop codes, describe and compare, categorize and conceptualize, and develop theory. Within the analytic cycle, I used Miles and Huberman's data analysis process (1994), since it has been widely used in qualitative research.

Miles and Huberman (1994, p. 10) defined analysis as "consisting of three concurrent flows of activities: data reduction, data display, and conclusion drawing/verification". I mainly used Miles and Huberman's (1994) guidelines for analysing the case study data. The whole procedure of data analysis in this study is illustrated in Figure 4.4. 


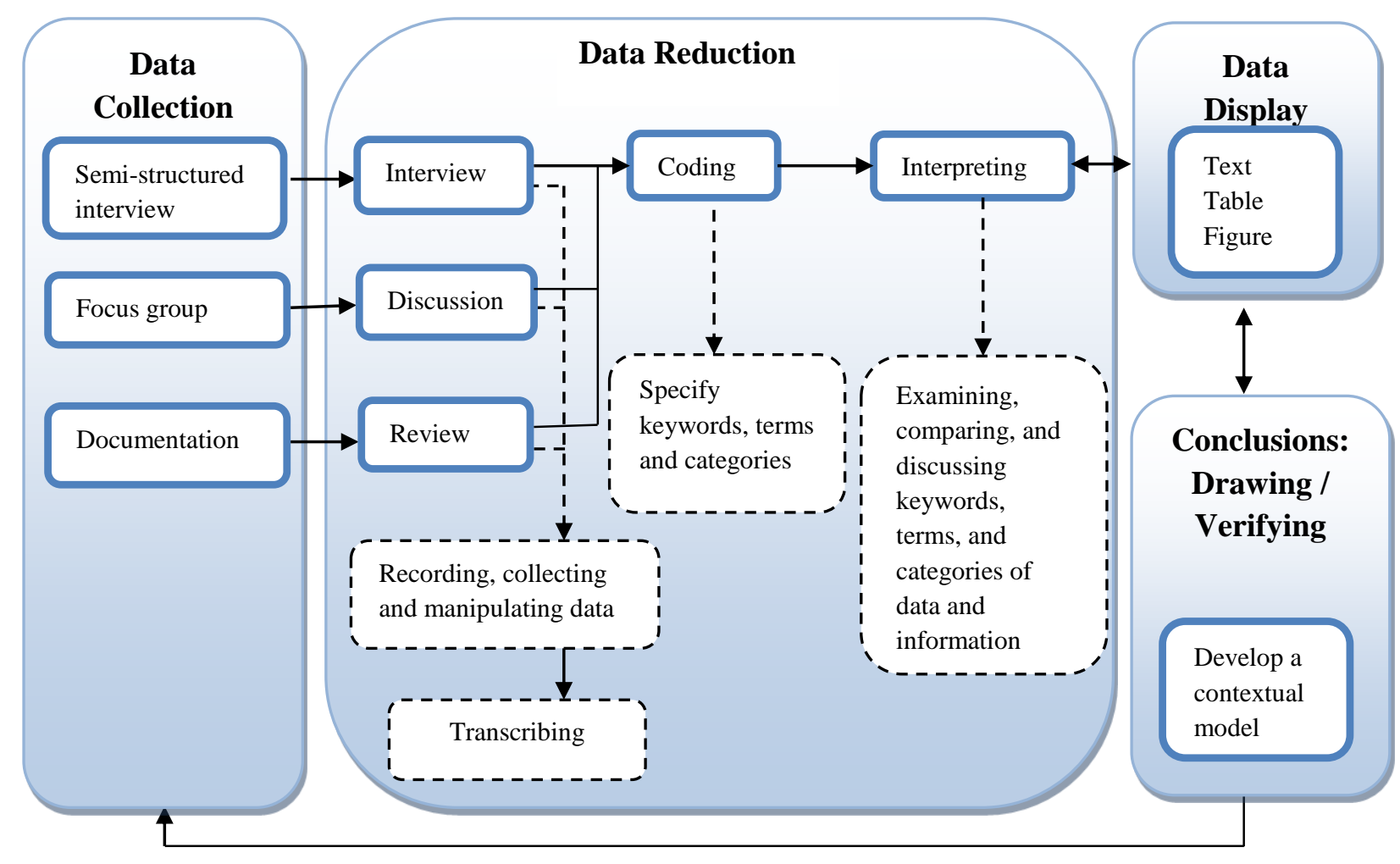

Figure 4.4 - The data analysis framework

Modified from Miles \& Huberman, 1994

\subsection{Data reduction}

The activity of data reduction involves selecting, focusing, simplifying, abstracting, and transforming the data. This happens "when writing summaries, coding, teasing out themes, making clusters, making partitions, and writing memos" (Miles \& Huberman, 1994, p. 10). Data reduction is a form of analysis that "sharpens, sorts, focuses, discards, and organizes data in such a way that "final" conclusions can be drawn and verified" (Miles \& Huberman, 1994, p. 11).

According to Pickard (2007, p. 20) and Creswell (2003, p. 196), credibility is demonstrated by "prolonged engagement with the research participants, persistent observation of those participants, triangulation of the techniques used to study those participants and their context, peer debriefing and member checks". Hence, to enhance the credibility of this study, I also used member checks: i.e., interview transcriptions were sent to the research participants for confirmation. I also compared the data collected through the semi-structured interviews and focus group interviews with what was in policy documents, reports, administrative documents, progress reports and any other 
relevant documents for triangulation. In addition, I clarified the bias that I brought to the study (discussed under section 4.3) and I also paid attention to the requirements embodied in Victoria University of Wellington's Code of Human Ethics.

In this study, I used Microsoft Word and Excel to help the process of data reduction. After the completion of data collection, I transcribed every interview. Almost half (14 out of 30) the individual interviews and one of the two focus group discussions were conducted in the Sinhala language but the study is presented in English. Hence, this generated issues of equivalence in the translation process. In order to minimize these issues, I translated and interpreted the meaning and views of interviewees into English from the original transcripts. Since Sinhala is my native language, it was easy for me to carry out the translation process. However, I used assistance from a native English speaker to check the English translation with respect to vocabulary, idioms, grammar, and syntax aspects. I translated the Sinhala language transcripts into English and organized all the transcriptions according to interviewee codes (see Table 4.6). Interviewee codes were used as transcript identification numbers/codes. Each transcription included a table with three columns: row number, initial codes/open codes, and transcribed data. Then I carefully read and reread the transcripts several times, typing key terms or phrases in the initial code column, and highlighting relevant concepts (within transcribed data) that related to key terms/phrases for answering the research questions. Key terms were identified from the transcriptions. For example, when participants expressed their perceptions about issues, barriers or enablers to the introduction and use of e-learning, such as problems related to the internet, broadband speed, IT usage, and teaching experience, I selected them (in the participants' own words) as key terms to represent the relevant set of data in the transcriptions.

I used Microsoft Excel to manage and analyse data. I created four Excel worksheets: one each for IM education providers, current e-learning providers, other stakeholders, and focus group discussions. Each worksheet had columns for initial code, descriptive code, pattern code and I divided the rest of the columns according to the categories of each subunit (see Tables 4.3-4.5). For example, the current e-learning providers' worksheet included columns as shown in Table 4.7. 


\begin{tabular}{|c|c|c|c|c|c|c|c|c|c|c|c|}
\hline \multicolumn{3}{|c|}{ Codes } & \multicolumn{3}{|c|}{ EEP1 } & \multicolumn{3}{|c|}{ EEP2 } & \multicolumn{3}{|c|}{ EEP3 } \\
\hline $\begin{array}{l}\text { Initial } \\
\text { code }\end{array}$ & $\begin{array}{l}\text { Descriptive } \\
\text { code }\end{array}$ & $\begin{array}{l}\text { Pattern } \\
\text { Code }\end{array}$ & 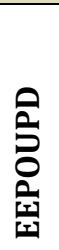 & 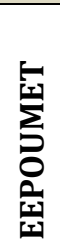 & 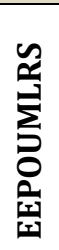 & 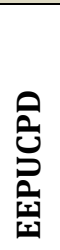 & 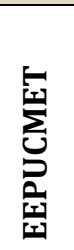 & 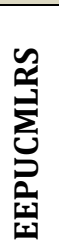 & 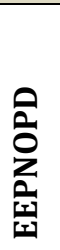 & 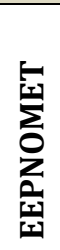 & 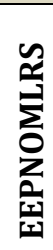 \\
\hline & & & & & & & & & & & \\
\hline & & & & & & & & & & & \\
\hline
\end{tabular}

Each cell included selected quotations from the interviews about the main themes of factors influencing the introduction and use of e-learning

Table 4.7 - Example of Excel worksheet of data analysis

I copied highlighted text (quotations from the interviews) from the Word documents and pasted them into relevant columns in the relevant worksheet. These four worksheets consisted of all key terms and phrases identified in the transcripts.

Next sub-categories were assigned to represent groups of key terms and phrases. These sub-categories were used as descriptive codes. For example, the phrase 'traditional educational cultural values' was used as the descriptive code for any text concerning educational cultures in the initial coding, such as school culture, teacher-centred educational culture, and tuition culture.

I again regrouped common themes into broader categories. These categories were used as pattern codes. For example, 'social and cultural factors' was used as the pattern code for all ideas related to the social system and culture.

In the final stage, I used the filter option in Microsoft Excel to sort broad categories with the relevant quotations. As a result, I ended up with another four worksheets for four broad categories containing interviewees' diverse perceptions about factors influencing the introduction and use of e-learning in tertiary-level IM education in Sri Lanka. Since I used interviewee codes (see Table 4.6), I easily identified each interviewee's quotations as well as differences and similarities between the data. Although I had data between subunits - IM education providers, IM education programme participants, e-learning providers, and stakeholders - there was no significant difference among sub-units. Thus, 
before I discuss the findings in Chapters 6 and 7, for each factor, the IM education providers' perceptions are discussed first, followed by the perceptions of current elearning providers, other stakeholders, and IM education programme participants.

\subsection{Data display}

The second main activity of the analysis process is data display. It consists of an organized, compressed assembly of information that allows conclusion drawing and action (Miles \& Huberman, 1994, p. 11).

In this study, I used text, tables, and figures for displaying data. These multiple methods helped me to justify the conclusions of this study.

\subsection{Conclusion drawing and verification}

The final activity of the analysis process is drawing conclusions and verification. The Hutter-Hennink qualitative research cycle (Figure 4.2) and its combination of deductive and inductive analysis helped me to revise the conceptual model of this study. For example, I moved from the design cycle to the ethnographic cycle to the analytic cycle, and I also moved back and forth between these three cycles and then changed the conceptual model. Throughout, I brought back data from my analysis and then saw what they meant for the model, then adjusted the model, and the contextual model of factors in this study was developed (see section 9.1). The conclusions of this study are presented in Chapter 8.

Transferability can be identified by answering the question: "do the findings apply to other contexts?" (Bryman, 2008, p. 34). According to Lincoln and Guba (1985), Marshall and Rossman (2006), Bryman (2008), and Gagnon (2010), transferability or generalizability of qualitative findings to other settings may be problematic or impossible. Marshall and Rossman argue that qualitative research can be generalized to theory rather than to population (p. 202). Therefore, the qualitative findings of this study were generalized to make theoretical inferences and provide rich contextual information.

There is one additional strategic choice which can be used to enhance a study's generalizability: triangulating multiple sources of data (Marshall \& Rossman, 2006, p. 202). In this study, triangulation was used. For example, different types of data collection 
techniques were used in this study, i.e., focus group discussions, individual interviews, and documentary evidence. I also compared the data collected through the semistructured interviews and focus group discussions with what was in the policy documents, reports, administrative documents, progress reports, and any other relevant documents including descriptive field notes.

Dependability can be identified by answering the question: "are the findings likely to apply at other times?" (Bryman, 2008, p. 34). According to Pickard (2007), Bryman (2008), and Lincoln and Guba (1985), dependability can be established by an inquiry audit', where an external 'auditor' examines the research process. In this study, I used peers as auditors during the course of the research in order to confirm my procedures. For this purpose, the researcher needs to maintain an audit trail (Pickard, 2007; Lincoln \& Guba, 1985). I maintained an audit trail including complete records of all phases of the research process in an accessible manner.

Confirmability is the ability to demonstrate how the research results or conclusions were reached. Lincoln and Guba (1985) propose that this can also be done using an audit trail that consists of "raw data, analysis notes, reconstruction and synthesis products, process notes, and preliminary development information" (p. 320-321).

To ensure confirmability, I presented a rich description of the context of the study and the participants in this study. I used the Hutter-Hennink qualitative research cycle to ensure confirmability. Further, I thoroughly explained the data collection and data analysis of this study.

\subsection{Chapter summary}

In this Chapter, section one has outlined an interpretive theoretical perspective as the philosophical context of this study.

Section two has summarized the case research strategy and the selected single case embedded design for this study, while section three has discussed the researcher's role.

Section four has identified qualitative research methodology as an appropriate research approach and has explained the selection of the Hutter-Hennink qualitative research cycle - design cycle, ethnographic cycle, and analytical cycle - as a research design. It also discussed the data collection techniques - i.e., semi-structured interviews, focus group 
discussions, and documentary evidence - of this study. I also outlined my approach to managing issues related to data analysis and drawing conclusions from the data.

The interpretation of the perceptions of participants about the factors affecting the introduction and use of e-learning in tertiary-level IM education in Sri Lanka is presented in the next three Chapters. 


\section{CHAPTER 5: MACRO-LEVEL FACTORS - SOCIAL AND CULTURAL, GOVERNMENTAL, AND TECHNOLOGICAL FACTORS}

The main objective of this study is to develop a contextual model of factors to guide the introduction and use of e-learning in tertiary-level IM education in Sri Lanka, based on the perceptions of the participants. This Chapter and the next one address this objective. Based on the interview data, they answer the two research questions and provide a base for reviewing and revising the conceptual model.

RQ 1 What are the contextual factors that have significant impact on the introduction and use of e-learning in tertiary-level IM education in Sri Lanka?

RQ 2 How do these factors affect the introduction and use of e-learning in tertiary-level IM education in Sri Lanka?

This Chapter identifies and discusses the macro-level factors that were found to have an impact on the introduction and use of e-learning in tertiary-level IM education in Sri Lanka (Figure 5.1). The macro level can be defined as an "overarching pattern of ideology and organization of the social institutions common to a particular culture or sub-culture" (Bronfenbrenner, 2005). In this research, 'macro-level factors' consist of social and cultural factors, governmental factors, and technological factors in the Sri Lankan context. 


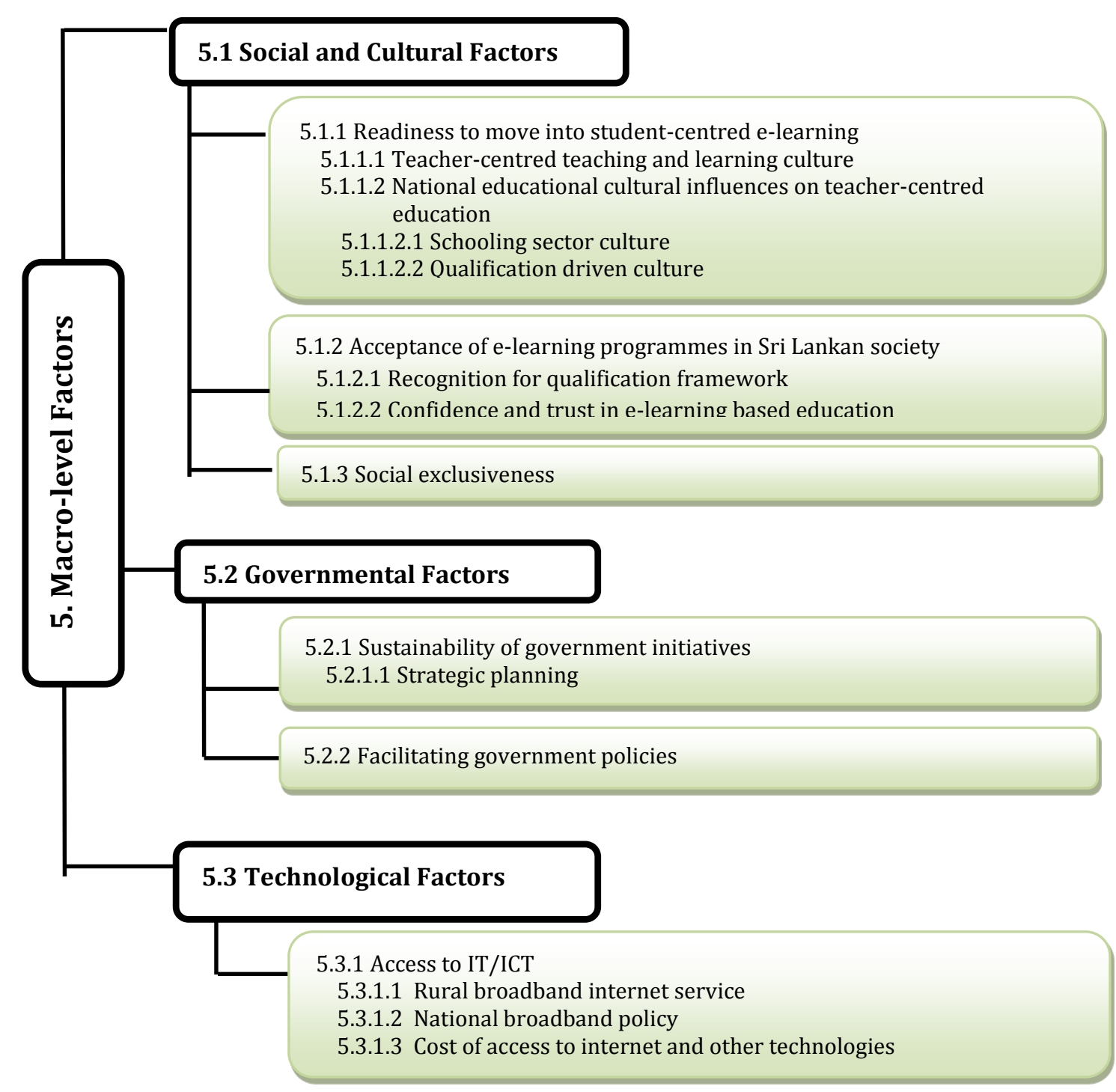

Figure 5.1 - Outline of Chapter 5 - Macro-level factors

For each factor, the IM education providers' perceptions (public university, public institute, and private university) are discussed first, followed by the perceptions of current e-learning providers, other stakeholders (government officials), and IM education programme participants. In some cases, these perceptions are discussed simultaneously.

\subsection{Social and cultural factors}

Analysis of the data in this study reveals that a range of social and cultural factors have an impact on the introduction and use of e-learning in tertiary-level IM education in Sri Lanka. These are grouped into three categories: readiness to move into student-centred 
e-learning; lack of acceptance of e-learning programmes in Sri Lankan society; and social exclusiveness. Table 5.1 summarizes participants' perceptions.

\begin{tabular}{|c|l|}
\hline \multicolumn{1}{|c|}{ Contributing Factors } & \multicolumn{1}{c|}{ Summary } \\
\hline $\begin{array}{c}\text { 5.1.1 Readiness to move into } \\
\text { student-centred e-learning }\end{array}$ & $\begin{array}{l}\text { There was a lack of readiness to move towards pure student- } \\
\text { centred e-learning in tertiary-level IM education in Sri Lanka. } \\
\text { This was because a teacher-centred teaching and learning } \\
\text { culture was dominant in Sri Lanka and national culture also } \\
\text { had an influence on teacher-centred education. }\end{array}$ \\
$\begin{array}{c}\text { 5.1.2 Acceptance of e-learning } \\
\text { programmes in Sri Lankan } \\
\text { society }\end{array}$ & $\begin{array}{l}\text { Established recognition for qualifications gained through face- } \\
\text { to-face education and lack of confidence and trust toward } \\
\text { e-learning programmes had a strong influence on lack of } \\
\text { acceptance of e-learning programmes. }\end{array}$ \\
5.1.3 Social exclusiveness & $\begin{array}{l}\text { The generational divide in Sri Lankan society along with cost of } \\
\text { access to the internet and other related technologies had an } \\
\text { influence on the introduction and use of e-learning in tertiary- } \\
\text { level IM education. }\end{array}$ \\
\hline
\end{tabular}

Table 5.1 - Summary of the perceptions about social and cultural influences across the four different groups

\subsubsection{Readiness to move into student-centred e-learning}

Two-thirds of the participants in each category - i.e., IM education providers, current elearning providers, other stakeholders (such as government officials), and IM education programme participants - of this study mentioned that there was a readiness to move towards pure student-centred (constructivist) e-learning in tertiary-level IM organizations in Sri Lanka.

\subsubsection{Teacher-centred teaching and learning culture}

There was a lack of social and cultural values supporting student-centred education in tertiary-level IM organizations in Sri Lanka. Although the Sri Lankan general education system as well as the higher education system changed to a policy of student-centred education in 2009, the teacher-centred educational method was still dominant in the Sri Lankan context. One of the administrative-level staff in a private university described this situation as "...in the Sri Lankan culture, learning means mostly teacher-centred" (IMEPSLASD).

Five out of six senior and junior lecturers in three IM education provider organizations expressed their preference for instructivist-based pedagogy. Among them, a male junior 
academic in the public institute explained why he preferred the teacher-centred method. He noted:

I can retain full control of the classroom and its activities. I can also use the entire class time for my teaching in order to cover a large syllabus. (IMEPNITSJ)

A male senior academic in the public institute reported that administrative-level staff such as Deans of the faculties and others generally reported a belief that the teachercentred style is the recognized method in Sri Lankan society. Similar perceptions were also reported by five out of six senior and junior academics in three IM education provider organizations. They said as a result, the teacher-centred education system was still dominant. There was also the perception that, as a result, students tend to be passive learners. They were recipients of teachers' instruction. One male junior academic at the public institute said:

We still use the traditional educational system and in that system everything is teachercentred. Thus, students $100 \%$ depend on lecturer notes and they are not used to searching for extra or new information on their own. (IMEPNITSJ)

The participants from the e-learning provider category reported a number of examples to show how teacher-centred educational culture negatively affected the use of e-learning programmes. All the participants in the e-learning provider category agreed that students were not used to asking questions even at face-to-face sessions because of the absence of freedom or flexibility in the traditional method of teaching and learning. An educational technology support staff member said the teacher-centred educational method discourages students from asking questions and this could be a barrier in an e-learning platform where online discussion forums were a major feature.

Another educational technology support staff member reported that traditional methods of teaching and learning affect students' expectations and behaviour in the Sri Lankan context. For example, he stated that students were reluctant to post their answers in online forums because they assumed that somebody would criticize their answers. He explained:

According to our culture, there is a different notion called respect. Because of that there is a tendency for students not to ask questions of the teachers. Because of that, having online discussions is little bit difficult. Secondly, students think there is somebody looking 
at them and therefore they may not be ready to talk or write freely. So they are a little bit hesitant, even to write answers to their main questions, assuming that somebody might be criticizing their work as a foolish answer or something like that. (EEPUCMET)

As mentioned earlier in this section, most senior and junior lecturers in the three IM education provider organizations prefer to continue their familiar instructivist-based pedagogy and they have not tried to use constructivist-based pedagogy yet. This study further found that academics' preference towards teacher-centred education was also a problem for current e-learning providers' efforts to provide collaborative e-learning based around construction. For instance, an educational technology support staff member said, "teachers are not happy to teach online because they may not be able to continue their role as a centre of instruction" (EEPNOMET). Another participant who was a lecturer and a learning resource support staff member in the e-learning provider category echoed this opinion:

My idea is academics will use the e-learning method if it is compulsory in the system. Otherwise they won't. This is because they are very familiar with the traditional way and they will continue that way. (EEPUCMLRS)

The government officials who represent stakeholders in this study also shared a similar view that academics' preference is for instructivist-based pedagogy. Among them one director who had more than ten years of experience working with academics said, "most of the lecturers were still very much geared to lecture notes and the normal lecturing system in the universities" (SHGOQA).

Analysis of the data also reveals that academics continue with their familiar method of teaching not only because of their personal interest or their administrative-level staff' encouragement but also because of their lack of understanding of and practice in studentcentred pedagogy. For example, one of the directors of an e-learning provider said that they were still in the transition period although they started e-learning programmes a couple of years back. She said “...teachers also don't know how to do it online. So they are just using teacher-centred learning methodologies". I will further discuss academics' lack of understanding of and practice in student-centred pedagogy at the meso level in section 6.1 in Chapter 6. 
A librarian at the public institute IM education provider reported a different view and perspective regarding teacher-centred education. This participant had experimented with student-centred face-to-face learning and had been happy with it. Therefore he explained that current teacher-centred practices should be changed to provide an environment for students to learn by themselves. He said:

I am actually happy with student participation and attitudes. They very much like the student-centred system because they can do their study on their own and freely. ...But using our traditional method what we do is we try to limit students' own style by our style. If we let them use their style they will do it very happily. Actually lecturers have to change their method. Most lecturers don't like to change. (IMEPNISSL)

It is also worth noting that a young female junior academic in the private university explained that many conversations between teachers and students took place face-toface outside formal classroom teaching. Thus, students often individually met their teachers after classes. However, they were not encouraged to ask questions during the class and lecturers also did not encourage them to do so.

Furthermore, analysis of the data revealed that learners seemingly lacked certain important skills to perform well in collaborative e-learning based around constructivism due to the Sri Lankan national educational culture, i.e., schooling sector culture, and qualification-driven culture. These are discussed in the following sub-sections.

\subsubsection{National educational cultural influences on teacher-centred education}

The next two sub-sections (sections 5.1.1.2.1 and 5.1.1.2.2) discuss how national educational cultures, i.e., schooling sector culture, and qualification-driven culture, influence teacher-centred education and how these national educational cultures have an effect on students' learning approaches.

\subsection{Schooling sector culture}

The teacher-centred method is dominant in the secondary education system, i.e., the schooling sector culture in Sri Lanka. Because of this, most participants agreed that when students leave school they may lack certain important skills such as critical and creative thinking, and problem solving. 
To overcome the above problems, in 2009 the national committee formulating a new Education Act for general education introduced a set of new student-centred education approaches to learning and teaching into the Sri Lankan system. The aim was to shift learners' attitudes towards a different platform where they can generate their own knowledge and meaning to revise the known, explore the undetermined and construct what is, as preparation for constructing what might be (National Educational Commission of Sri Lanka, 2009).

However, the teacher-centred educational method is still prominent in the school system. A female junior academic staff member from the private university commented:

When students come out from school and enter university they really expect us to give answers to everything. I think this is because of the school environment. (IMEPSLTSI)

This means that in Sri Lankan schools, whatever the teachers say, students must learn. One participant described it as a 'spoon-feeding culture' (EEPNOMET).

A programme director from an e-learning provider explained how students' lack of skills affected the use of e-learning. He said:

Students are not comfortable to solve their problems through this e-learning mechanism. It's a cultural issue with respect to Sri Lanka. Because of the Sri Lankan secondary education, teachers don't encourage the student to ask questions. If they ask questions the teacher will punish them... So students have to just listen and revere their teachers. (EEPUCPD)

In the focus group discussion IM workers (as a student group) affirmed the opinion that they lacked some important skills. They said before they came to university they had been conditioned by the school culture for more than 13 years, and the experience they had during their school time had influenced their approach to tertiary education. Therefore, they suggested 'there should be an attempt at school level to develop students' skills; school curricula needed to be updated according to the present situation" (FGDIMW).

There was no evidence showing successful implementation of the new Education Act in the country. One of the government employees interviewed in this study said the change required to see the policy through into practice had not happened. He noted: 
We need to have a big mental change like change management in our educational system. It should start even from the schools. We need to work with students from the beginning, like after grade 6 . So then they will practise learning without face-to-face contact with teachers. They will also learn with the computer once there is content and a Learning Management System (LMS). Therefore, we need change management from the beginning. (SHGOIC)

\subsection{Qualification-driven culture}

Two participants from the IM education provider category, five out of nine participants in the e-learning providers' category, and two out of three participants in the stakeholders' category (government officials) mentioned that students were not used to learning by themselves and they followed teachers' instructions with the purpose of getting a certificate or degree. A government officer who was a content manager for one the government initiatives related to e-learning described this situation by saying “students don't think about anything which is not related or not in their syllabus. Each and every letter in the syllabus they will look at. If the ' $z$ ' is out of the syllabus they won't learn it" (SHGOIC). Another government officer who also had more than ten years of experience working with academics in the university sector said "our students always go for certificates only. They are not highly motivated to learn something" (SHGOQA).

Analysis of the data reveals that teacher-centred private tuition culture was dominant in the Sri Lankan context and influenced the qualification-driven culture. Private tuition classes are an unofficial education industry in Sri Lanka and include three types: one-toone tuition classes, group tuition classes, and hall tuition classes (Pallegedara, 2011). The new Education Act for general education in Sri Lanka had noted the demand for private tuition. For example, parents and students had a strong belief that tuition was necessary for examination success in order to get the certificates since teachers of the tuition classes teach how to answer examination questions.

One of the administrative-level participants from a private university claimed that students were used to private tuition from kindergarten up to degree level. He said:

From grade 1 or kindergarten students are being sent for private tuition. Even for a general knowledge exam you can go for private tuition. (IMEPSLASH)

Similarly, a programme director from an e-learning provider said parents sent their 
children for private tuition although it was expensive because private classes prioritized exam performance. Exam performance is more important to them than other aspects of learning such as critical thinking. He also explained how the teacher-centred educational method was prominent in tuition classes and how students were influenced by this culture. He said:

Anyone you know, whatever the amount Rs. 30,000/40,000 for a 30 hours class, they pay and go because still they have the idea that in front of the teacher they can learn. In front of the teacher they will feel that they get something. But in front of the computer they don't feel that they are getting something. So that is one of the biggest barriers. So faceto-face teaching is still valid. (EEPNOPD)

Even though the government had introduced information technology (IT) as an elective subject for the GCE 0/L and GCE A/L examinations, students were not encouraged to take IT because, like their parents, they wanted to see better exam results rather than learning skills. This situation was reported by one of the programme directors from a e-learning provider who also had experience working with people at school level. He said:

Even the parents say 'don't do it (subjects like IT) because you won't get grade 'A' results'. So parents say 'no, no...do something else rather than doing IT'. So they go for general health care or other general subjects because they are looking for A's for all subjects. (EEPNOPD)

Employees in the IM industry tend to do courses that were perceived to be easy to help them with promotion at work. An educational technology support staff member at an elearning provider explained this situation:

Most of the time employees just get qualifications to get paper certification because they want to show it to their employers to prove they deserve a raise in salary. So there is no big learning outcome achievement at the end of the day. (EEPNOMET)

The data discussed in section 5.1.1 showed lack of readiness to move towards studentcentred e-learning as a factor affecting the introduction and use of e-learning in tertiarylevel IM education in Sri Lanka. The academics' preference and their administrative-level staffs' preference towards using teacher-centred education as well as academics' lack of understanding of student-centred pedagogy appear to have had a strong influence on the avoidance of constructivist e-learning. Further, national educational cultures - i.e., 
schooling sector culture, and qualification-driven culture - in the Sri Lankan context reinforced teacher-centred education, which affects students' lack of experiences and skills that suit constructivist education and therefore had a strong impact on the use of elearning.

The next section discusses the lack of acceptance of e-learning programmes in Sri Lankan society.

\subsubsection{Acceptance of e-learning programmes in Sri Lankan society}

Nine out of 18 participants in the IM education provider category, five out of nine participants in the e-learning providers' category, two out of three participants in the stakeholders category (government officials), and all the IM workers in the focus group (the student group) in this study pointed out that there was a lack of acceptance of elearning programmes in Sri Lankan society. Analysis of the interview data reveals two main reasons:

i. Lack of recognition for the qualification framework (for online qualifications)

ii. Lack of confidence and trust in e-learning-based education.

\subsubsection{Lack of recognition for the qualification framework (for online qualifications)}

In the focus group discussion IM workers (as a student group) mentioned that even though e-learning courses were cheap compared to traditional courses, learners were accustomed to going to a classroom and learning in front of the teacher. One participant explained:

First thing is recognition. In the Sri Lankan context, we are used to learning by sitting in the classroom and we need to see our teacher and fellow students. Otherwise we feel the learning is not recognized or less recognized because physical presence is very important according to our education system. (FGDIMW)

The findings presented in section 5.1.1 also showed how the traditional method of teaching and learning was dominant. Due to the well-established face-to-face teaching and learning culture, there was a lack of recognition for the qualifications gained through e-learning as compared with qualifications gained the traditional way. Another information worker who participated in the focus group discussion stated: "people used 
to compare qualifications, especially in an interview. For example, administrative-level staff may see the qualifications gained through the traditional way and qualifications gained through e-learning as having two statuses" (FGDIMW). The following quote from a support staff member in a private university provided a personal example. He said "one of my friends went to an interview and during the interview she showed her certificate (gained through e-learning). Then they told her, 'this is not a valid certificate' " (IMEPSLSST).

The same participant and all the IM workers who participated in the focus group discussion similarly suggested that there should be an attempt at government level to develop an e-learning policy in order to establish equal recognition for qualifications gained through the traditional educational system and those gained by e-learning.

However, different views and perspectives were identified in the interviews. For example, administrative-level staff, especially Deans of the faculties in the public and private universities, said that there is no difference in knowledge and skills whether we learn through traditional ways or e-learning. They further noted that lack of recognition for e-learning is made an issue in society by various people because of their attitudes.

A Dean in the public university explained his view with a positive attitude:

If we think traditionally, I don't think we can go for e-learning. We have to think about our tradition but it should not always come first. We have to open our minds and go for new things. (IMEPDEASD)

The Deans of the public and private universities and other administrative-level staff highlighted that there was a need for attitude change in the academic environment to accept recognition for qualifications gained through the traditional educational system and e-learning.

\subsubsection{Lack of confidence and trust in e-learning-based education}

Analysis of the data reveals that quality issues and the lack of a sound authentication process in e-learning-based education affected confidence and trust in the Sri Lankan context. Except for the participants from public institutes and IM workers as a student group in this study, two-thirds of all participants in other groups mentioned that elearning was not fully recognized in the Sri Lankan context due to malpractices such as 
plagiarism, copying, and impersonating. Among them a junior academic in the public university explained how plagiarism was a problem even in their traditional university education system. He said:

Cut-and-paste culture is still going on. Most of our students submit their assignments by copying our textbooks. There is no computer software for us to check the documents which are written in the local language. (IMEPDETSJ)

One of the administrators at the same public university described how this situation could be worse in the e-learning environment as "...within more facilities, I mean using internet and other technologies they [students] can do more plagiarism" (IMEPDEASH). Therefore he highlighted the requirement for use of anti-plagiarism software to audit education quality. Another administrator at the private university echoed that suggestion and he further said "the quality assurance process must be very strict and that can be assured" (IMEPSLASH).

At the public university, a technical support team member who was responsible for overall infrastructure systems and had experience of maintaining learning management systems (LMS) at the university level reported that, not only plagiarism, but sometimes authentication was also a big issue for them and there was still no understanding of how to deal with it. He said:

Students can share their password with someone else. We have no system to verify the exact student, especially in the LMS. We can't do it. (IMEPDESST)

One programme director from an e-learning provider added her personal experience regarding the problem of authentication in their e-learning programme; she said this happened a few times but there was still discussion on how to minimize these problems.

Ten out of 18 participants in the IM education provider category further reported that there was a lack of e-learning best practices in the Sri Lankan context and that affected their confidence in e-learning because they were unsure about the quality of the current e-learning programmes. They mentioned that most current e-learning programmes were started because of sudden interest due to provision of project funding but without proper planning or long-term strategic goals. Among them a senior academic at the public university explained his perceptions regarding current e-learning programmes: 
No e-learning programme has been formed for the purpose. Here and there a few courses are available but I don't think that they serve the purpose of the majority. Even though they upload the programmes there are no personnel to take care of the learning process. (IMEPDETSS)

The participants from the e-learning providers reported a number of examples to show how their e-learning programmes were running at present. Those views affirmed that there were some problems regarding quality. For example, one of the directors of an elearning provider said that they had not yet incorporated interactive activities into their e-learning programmes and she said lack of instructional design guidance was a major problem:

We are using teacher-centred mechanisms, even online. We just give the content only and we think, OK there is content so it's up to the students to study. (EEPOUPD)

An educational technology support staff member working with the same e-learning programme further explained that their goal was to use the e-learning system to provide simple student support and yet they were not capable of developing interactivity in their e-learning programme. He said:

I don't know whether we should spend a lot of time to develop an interactive part or whether we should spend a lot of money to deliver that kind of higher stuff the students are not using. Then the other question is if we don't have such interaction [in our elearning programme] then students don't come. We are not doing animations. We are not up to that. We are thinking of simple student support using the system. (EEPOUMET)

This e-learning provider organization has a quality assurance unit in their institution. But participants reported that the quality assurance unit does not assess their e-learning programme at the higher level. A learning resource support staff member in that same organization explained according to her understanding why their quality assurance unit does not assess their programme at a higher level. She said "I don't think they (the quality assurance unit staff) can read and set the content because they are not the subject experts" (EEPOUMLRS). She further stated:

They review the format, for example, whether the essential announcements are there as well as how accurate existing URLs are. That happens only at the beginning of the course. Whatever we add later, there is no review process. (EEPOUMLRS) 
A programme director at another e-learning provider organization explained that their problem was giving assurance to learners and maintaining a continuous response to learner effort. He explained:

There will be facilitators who should be online all the time. It is very difficult to get them (facilitators) to interact online. If they are like that, how can we expect the learners to do that? So effectiveness is the issue. (EEPUCPD)

Similar problems were also echoed by a programme director at another e-learning provider organization and he said their major problem was insufficient staff members solely dedicated to e-learning programmes, i.e., not also doing traditional teaching. He said that affected the quality of the content in their e-learning programmes:

...level of quality is coming into our mind. That is the thing we have not realized. What assurance can we give to the students? I don't think that has been considered in any of these institutions, even here. Monitoring is a problem. Adding our views online is not $100 \%$ practical...someone can question whether we care equally for our students [in elearning programmes] as we do for our internal students. (EEPNOPD)

As mentioned earlier in this section, academics in the three IM education provider organizations agreed that there was a lack of quality content in the current e- learning programmes in Sri Lanka. Some participants in the e-learning provider category affirmed that e-learning content developed in this country was not up to the standard level. Among them one of the programme directors reported how their e-learning content looks:

There are just a couple of simple paragraphs and then a couple of pictures here and there. There are pages of text on computer e-learning environments. However, normally, we have to chunk into readable pieces. And then we must add information to others with pictures, videos, or animations. So that part is missing in the Sri Lankan context. (EEPNOPD)

An educational technology support staff member mentioned that lack of customization was a major issue in the e-learning programme and affected the quality of e-learning content. He said that was also a reason why e-learning was not recognized yet in Sri Lanka. He said customization was vital to the adaptation of various instructional elements to meet learner preferences and needs. He noted: 
We have to think about the target audience. Accordingly, we have to customize the instructional elements of the e-learning programme. That is what is lacking in Sri Lanka. That is why our e-learning programmes are not popular. These are not user-friendly and not customizable. If you compare our Sri Lankan [e-learning] courses with foreign [elearning] courses you will see why students prefer the foreign courses. Those are customizable. (EEPNOMET)

The data discussed in the section 5.1.2 shows that except for the participants in public institutes, all the participants across four different groups identified lack of acceptance of e-learning programmes in Sri Lankan society as a factor affecting the introduction and use of e-learning in tertiary-level IM education in Sri Lanka. The established face-to-face teaching and learning culture and recognition for the qualifications gained via traditional ways appear to have an influence on the lack of recognition in Sri Lankan society for qualifications gained through e-learning. Further, quality issues in the current e-learning programmes and lack of authentication affected the confidence and trust in e-learningbased education in Sri Lanka.

The next section discusses social exclusiveness issues and their impact on the introduction and use of e-learning in tertiary-level IM education in Sri Lanka.

\subsubsection{Social exclusiveness}

Two-thirds of the participants in each category - i.e., IM education providers, current elearning providers, other stakeholders, and IM education programme participants (IM workers) - of this study mentioned that there was a generational divide in terms of digital and IT literacy in Sri Lankan society and that could potentially influence the use of elearning in tertiary-level IM education.

This was also supported by the documentary evidence. For example, the Department of Census and Statistics of Sri Lanka (2014) revealed that email and internet are more popular among youth in the age group 15-29 years (Figure 5.2). 


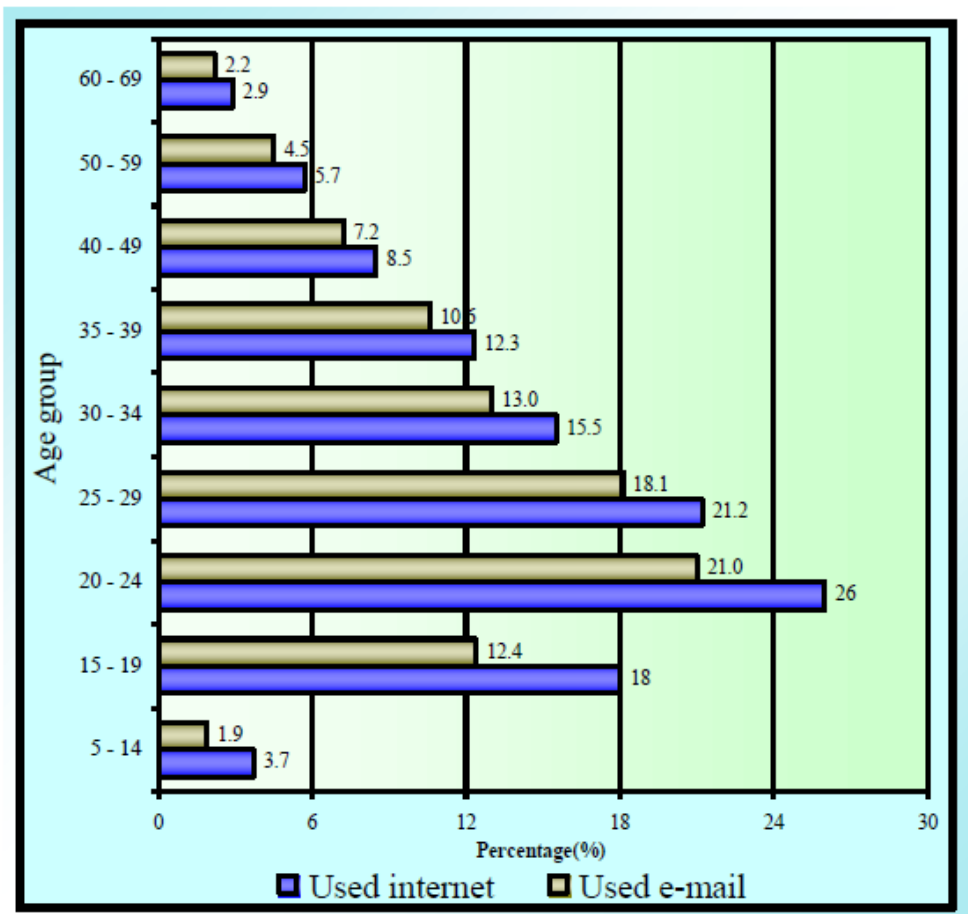

Figure 5.2 - Household populations aged 5-69 years (\%) who used internet/ email by age group - 2014 Source: Department of Census and Statistics of Sri Lanka, 2014, p.4

The above-mentioned age gap and the gap in technology usage in the Sri Lankan context had an influence on the use of e-learning in tertiary-level IM education. In this study, ten out of 18 participants from the IM education provider category stated that the use of elearning was compromised by computer literacy problems among older staff members. For example, a young junior academic staff member at the private university (where an e-learning system was used as a supplementary tool) said:

Senior lecturers are pretty reluctant to use those technologies and so on. ...For example, some people don't know how to operate the learning management system, Moodle, how to use it, and what kind of things can be done with Moodle. ...most of the time instructors do that work for the senior lecturers. (IMEPSLTSI)

In the public university, a technical support team member who was responsible for the overall infrastructure system and who had experience of conducting workshops on learning management systems (LMS) for academics also reported a similar view:

Three years back we provided training facilities as well. Young staff members catch on to the things quickly but seniors can't catch on to technology-related things easily. Maybe that is because of the level of IT literacy. Though we teach them, they still can't use it properly. (IMEPDESST) 
This study further found that some of the older staff members identified that they had computer literacy problems. For example, an older female librarian at the private university said “...at my age, I am very backward in learning technology-related things”. She provided a personal example to show her unwillingness:

Actually I am a bit reluctant to take the 'Kindle' eBook reader into our university. My professor is even more reluctant than me. But students, they ask whether this Kindle is available in our library. They (students) quickly become familiar with it rather than old people. (IMEPSLSSL)

A junior but older academic staff member at the public institute said "as a lecturer I am also not an expert in using technology. But when I compare with other countries, people who are in similar positions have very good knowledge and I am not at that level" (IMEPNITSJ).

As well as IM organizations, current e-learning providers also experienced the generational divide. For example, one older staff member working in educational technology support reported that (through his personal observation) their students were very reluctant to participate in online discussion forums. He knew how to create groups, how to assign topics and activities, and how to create competition among students. However, he did not know how to create the best type of forums to attract students. He explained: “I never try to develop the creative part because owing to my age I can't handle the technology that much".

Not only older academics, but also older students experienced greater computer literacy problems. For example, a senior lecturer who was a member of the learning resource support team for the e-learning programme said:

The problem is only for the mature people. For young students, getting into a Moodle class and browsing through it and getting to know it is not a problem. Sometimes students ask staff to give an introduction. But this introduction is always for mature students, not for the young people. I mean, we have some mature students who are also working. Even they want us to give an introduction, like do this introduction session for Moodle. But the young people they have used and browsed email and all and there's no problem using the Moodle e-learning class. (EEPOUMLRS)

In the focus group discussion, IM workers as a student group affirmed the opinion that older students lacked computer literacy skills. For example, two older IM workers in the 
focus group indicated that their age might be a factor affecting their use of e-learning because they were unwilling to learn about IT as compared with young students. Among them one IM worker mentioned:

The younger generation is more advanced in technology usage, maybe because they were born and grew and developed in the digital age. Most of the time, I get my younger friends' support to use technology. (FGDIMW)

The data discussed in this section shows that there is a generational divide in Sri Lankan society and that has influenced the introduction and use of e-learning in tertiary-level IM education in Sri Lanka. The use of e-learning was compromised by computer literacy problems among older staff members. Further, older students were also attributing their lack of e-learning use to greater computer literacy problems.

\subsection{Governmental factors}

Analysis of the interview and focus group data reveals that government-related factors are perceived to have an influence on the use of e-learning in tertiary-level IM education in Sri Lanka. The participants mentioned that there was a lack of sustainability in the government initiatives related to e-learning, and lack of government policies on the introduction and use of e-learning. Table 5.2 summarizes participants' perceptions of governmental factors.

\begin{tabular}{|ll|l|}
\hline \multicolumn{2}{|c|}{ Factors } & \multicolumn{1}{c|}{ Summary } \\
\hline 5.2.1 & $\begin{array}{l}\text { Sustainability in government } \\
\text { initiatives }\end{array}$ & $\begin{array}{l}\text { Nenasala telecentre project, as an example of } \\
\text { governmental e-learning initiatives, had not been } \\
\text { implemented with a long-term view. Lack of strategic } \\
\text { planning and poor management practices are perceived } \\
\text { to have a strong influence on lack of sustainability. }\end{array}$ \\
\hline 5.2 .2 & Facilitating government policies & $\begin{array}{l}\text { Lack of national policies such as national information } \\
\text { policy, and national policy on e-learning are perceived } \\
\text { to have an influence on the introduction and use of e- } \\
\text { learning in tertiary-level IM education in Sri Lanka. }\end{array}$ \\
\hline
\end{tabular}

Table 5.2 - Summary of the perceptions of governmental factors

The next two sections (5.2.1 and 5.2.2) discuss each of the factors and consider their influences on the introduction and use of e-learning in tertiary-level IM education in Sri Lanka. 


\subsubsection{Sustainability in government initiatives}

There was a lack of sustainability in Sri Lankan government initiatives related to elearning as pointed out by 10 of the 18 participants in the IM education provider category, five out of the nine participants in the e-learning provider category, two out of the three participants in the stakeholders category (government officials), and the IM education programme participants in the focus group. Among them, a senior academic at the public university selected the Nenasala telecentre project as an example of governmental elearning initiatives and said that it did not have a long-term view. He noted:

The government has certain initiatives for introducing IT to people, for example, Nenasala telecentre projects. Unfortunately, all these things have political agendas. Thus, without having a proper understanding/long-term view they established some of the Nenasala centres in religious places and these are not functioning properly. According to my experience, most of these centres are closed during the day because a priest is not there to open the centre. (IMEPDETSS)

These perceptions were supported in the focus group discussions. Information workers from rural areas said that most Nenasala centres in their areas were closed. Among them one IM worker from Monaragala district (a rural area) said, "in Monaragala divisional council, there may be four or five Nenasalas. One in Monaragala town is still operating. But the other centres are closed right now" (FGDIMW).

Moreover, in the focus group discussion, academics also noted that although the government had implemented a number of projects like Nenasala, they were not successful in a practical sense. They said they appreciate Nenasala but the long-term sustainability of that project was questionable. They explained that "there is a gap between theory and practice" (FGDAC).

Analysis of the data reveals lack of strategic planning as a major reason for the lack of sustainability in government initiatives related to e-learning.

\subsubsection{Strategic planning}

As noted earlier in this section, participants mentioned that ongoing strategic planning was missing in governmental e-learning initiatives. Some of the problem was related to political influences and poor management practices, i.e., lack of management of the staff. A librarian at the public university explained the general situation. He pointed out, "in Sri 
Lanka, most government projects start with some sudden necessity or huge interest. But they are not planned strategically. As a result within a year or two years there is a breakdown" (IMEPDESSL).

A senior academic at the same public university also explained how poor planning or poor management practices affected governmental e-learning projects. He noted:

Most governmental e-learning initiatives started with the funds from various projects or institutions. When funds are steady, projects are well-planned. When funds are finished, there is no interest and project people never think of the output. That always happens in the projects. (IMEPDETSS)

A director of the public institute selected the Nenasala telecentre project as an example to show how lack of strategic planning affected government-level e-learning initiatives. As discussed in section 5.2.1, there were failures in the Nenasala telecentre project. Thus, his director explained what the failures were:

At the moment there are more than 650 Nenasalas. The Information and Communication Technology Agency (ICTA), an implementation body of the e-Sri Lanka initiative, initially [first two years of a Nenasala) provides computers and internet facilities free of charge. The next two years [ $3^{\text {rd }}$ and $4^{\text {th }}$ years of Nenasala] they subsidize rates. But in my experience, in some areas after the $4^{\text {th }}$ year nobody is funding it and there is no forward planning to continue Nenasala centres, so some centres close. (IMEPNIASD)

The same director further explained the nature of the failures. He said it did not mean that Nenasalas were sustainable just by providing funds or facilities for up to three or four years because project implementers had to establish tangible steps to achieve the targets even during the period of self-funding. He therefore pointed out that the sustainability of the Nenasala project is questionable due to the absence of strategic planning.

It is interesting to note that lack of strategic planning was also an existing issue among the e-learning providers attached to governmental e-learning initiatives. Therefore, sustainability of their e-learning programmes was the concern. For instance, a programme director said:

Once the project was over, there was no money to continue. We got money to develop, design, and post everything. But now it's a self-funding programme and the university has 
to find takers for that. However, we found that there are fewer takers for completely online courses because there is something missing in between. That is lack of planning. (EEPOUPD)

Similarly, a member of the learning resource support team in another e-learning provider organization also explained how unsustainable her institution was. She said, even though they had 26 NODES Access centres (NAC centres) island-wide with video conferencing facilities, still they did not get the expected income from NAC centres owing to poor management practices. She explained this situation as follows:

We have appointed one person for each NAC centre. Unfortunately they do not work autonomously. From early in the morning they do personal Skype, Facebook...they don't do anything and at the end of the month they get a salary. Thus, I am very sad to talk about our income. It is very low. Monthly we spend 5.5 million to run this organization but our monthly income is only 400,000 rupee. Sometimes NAC centres earn only Rs40, Rs25, per month. I am embarrassed to say, currently, photocopying is the main income of the NAC centres. (EEPNOMLRS)

The same participant explained why NAC centre staff did not make an effort to market NAC centre facilities among the community and thereby increase the income for NAC centres to ensure their sustainability. One reason was the politically-based appointments of NAC centre assistants. She pointed out NAC centre assistants were sometimes unable to use the facilities in the centres. They were incapable of carrying the message to the public about NAC facilities as well as being inexperienced at assisting people to use NAC facilities. Other reasons were practices such as lack of management of the staff and lack of strategic planning. She noted:

As a head office we must give targets for our NAC centre assistants. However, even we don't have clear direction on the long path from where things are now to where we hope we will be. We don't even have an action plan. (EEPNOMLRS)

She further pointed out (due to the above-mentioned reasons) "NODES has not yet performed as big a role in Sri Lanka as the project expected" (EEPNOMLRS).

Two out of three government officials interviewed in this study also shared a similar view that there was a lack of strategic planning at the government level and this negatively affected not only the projects but also the educational system (especially at secondary 
and tertiary levels). Among them, one chairman directly responsible for the government initiatives said:

We do not have a proper plan. When we get everything we don't know what to do. So the resources are wasted. We do not get the proper or maximum use of the resources. That is a major barrier. So if we have a proper plan then we know what to do, how to do it and when to do it. (SHGOUG)

Another director who also had years of experience working with different national projects at university level said:

Even though we have given a lot of funds to the university sector for various projects to improve their IT infrastructure, it is still not at the required level. The reason is there is no strategic planning from the top level downwards. This is the most important issue that we have to address. (SHGOQA)

Similar views were also echoed by participants from the IM education providers, especially those who represented the public university and institute. Among them a senior academic at the public university explained this situation, "I think university and government have spent money for IT in the millions now. Unfortunately, final benefits do not go to people because they are just spending money and not utilizing it properly" (IMEPDETSS).

One of the administrators at a private university described government support as 'ad hoc'. He also said "...the ad hoc things will not go a long way" (IMEPSLASH). He expressed this view according to his general experience regarding the secondary-level education system. He provided an example of unplanned government programmes:

For schools, computers are provided with the support of different international bank loans, like ADB [Asian Development Bank]. However, it doesn't mean that IT literacy levels will go up just by providing computers because there is no existing plan given to the schools to link these resources with teaching or learning. (IMEPSLASH)

The data discussed in this section showed that lack of strategic planning as well as poor management practices were perceived to have an influence on lack of sustainability in government initiatives related to e-learning. All the participants across the four different 
groups identified that this lack of sustainability in e-learning initiatives affected the use of e-learning in tertiary-level IM education in Sri Lanka.

\subsubsection{Facilitating government policies}

The data revealed significant effects of the lack of government policies on the introduction and use of e-learning in tertiary-level IM education in Sri Lanka. These include national policies on information and e-learning.

Eleven out of 18 participants in the IM education provider category pointed out that there was a huge gap in policy-making in the Sri Lankan context. Among them, a junior academic at the public university explained the current situation regarding national information policy:

Five or six years ago, there was one attempt to draft a national information policy but it is still not completed, it is only a concept. There is no conference or seminars to draft the national information policy here. Without this policy how can we do other things? (IMEPDETSJ)

Participants from IM education providers said that absence of a national information policy was one of the major barriers to implementation and operation of information resources, services, and systems. They said that this negatively affected the use of elearning regarding access to up-to-date, relevant and reliable data and information.

A librarian at the public institute from the IM education provider category explained why a national information policy was important:

A national information policy is vital to streamline the nature and format of information resources that will be made available to Sri Lankans. It will also help to strengthen information infrastructure by specifying how resources will be organized and managed. (IMEPNISSL)

Except for the government officials, 11 out of 18 participants in the IM education provider category, six out of nine participants in the e-learning provider category and the IM education programme participants in this study pointed out that the absence of national policy on e-learning also negatively affected the use of e-learning in tertiary-level IM education in Sri Lanka. Among them a Dean of the public university explained why: 
In Sri Lankan society, there is still a lack of recognition for the qualifications gained through e-learning as compared with qualifications gained via the traditional way. Therefore, government should definitely intervene to develop an e-learning policy in order to give the qualifications equal recognition. This assurance is urgent. Then people will accept e-learning and take the courses. (IMEPDEASD)

In the focus group discussion, IM education programme participants shared similar perspectives, and they said lack of e-learning policy was a major issue for them when choosing e-learning courses. They further explained this situation:

Before we move into e-learning we think what the rewards and opportunities are. This means if we gain qualifications via e-learning, they should be recognized by others. Thus, there should be policy from the government level to confirm that. If we don't have an elearning policy, then it is a problem for us to choose an e-learning course. (FGDIMW)

A technical support staff member at the private university mentioned further reasons:

If there is a government or national policy on e-learning implementation, it will be accepted by all IM education providers. In particular, as an institution it will help us to gain positive responses from the higher authorities. (IMEPSLSST)

The same participant explained e-learning policy initiatives generally include provision of support and guidance for learners, professional development and support for tertiary teachers, as well as development of high-quality e-learning content. Thus, he suggested that e-learning policy is vital for the enhancement of e-learning quality in Sri Lanka.

Quality issues and lack of authentication affecting the confidence and trust in e-learning in the Sri Lankan context were discussed in section 5.1.2.2. All the participants across the four different groups expressed concerns about these two main issues. They said an elearning policy could be a framework for improving e-learning quality in Sri Lanka.

The data discussed in this section shows that the lack of national policies such as a national information policy and a national policy on e-learning was perceived by participants in this study to have had an influence on the use of e-learning in tertiarylevel IM education in Sri Lanka.

Analysis of the interview and focus group data further reveals that there was no national broadband policy, which also had an influence on the introduction and use of e-learning 
in tertiary-level IM education. This factor will be discussed under technological factors in the next section (See section 5.3.1.2).

\subsection{Technological factors}

Participants mentioned that there was unequal, or lack of access to information technology (IT) or information and communication technology (ICT). Table 5.3 summarizes perceived issues relating to technological influences. The other technological factors at the meso level will be discussed in section 6.2.2 (lack of infrastructure facilities) in Chapter 6.

\begin{tabular}{|c|l|}
\hline \multicolumn{1}{|c|}{ Factors } & \multicolumn{1}{c|}{ Summary } \\
\hline 5.3.1 Equity of access to IT/ICT & $\begin{array}{l}\text { There was unequal or lack of access to IT/ICT for students } \\
\text { in rural areas. Even though various access centres were } \\
\text { available around the country, students still faced } \\
\text { traditional problems, i.e., travelling, opening hours, and } \\
\text { environmental problems when accessing those centres. }\end{array}$ \\
5.3.1.1 Rural broadband service & $\begin{array}{l}\text { There was lack of access to broadband service especially in } \\
\text { the rural areas. Internet service providers' shared } \\
\text { bandwidth option was one of the factors that affected the } \\
\text { rural broadband internet service. }\end{array}$ \\
5.3.1.2 National broadband policy & $\begin{array}{l}\text { There was urgent need for a national broadband policy to } \\
\text { stimulate broadband development in all sectors in Sri } \\
\text { Lanka. }\end{array}$ \\
5nd other technologies & $\begin{array}{l}\text { There was a problem with the high price of fixed } \\
\text { broadband internet service and absence of standard costs } \\
\text { among internet service providers in Sri Lanka. Further, the } \\
\text { availability of all these facilities, i.e., fixed broadband } \\
\text { service and computers, depended on the socioeconomic } \\
\text { status of individuals. }\end{array}$ \\
\hline
\end{tabular}

Table 5.3 - Summary of the perceptions of technological influences

The next section discusses how equity of access to IT/ICT influences the use of e-learning in tertiary-level IM education in Sri Lanka.

\subsubsection{Equity of access to IT/ICT}

As discussed in Chapter 2, the Department of Census and Statistics of Sri Lanka (2014) revealed that the average percentage of households with computers in Sri Lanka was $22.4 \%$. The urban sector had the highest percentage of households with computers (37.5\%) while the rural sector had the lowest percentage (20.1\%). 
The above-mentioned gap in access to IT/ICT in the Sri Lankan context was perceived by participants of this study to have an influence on the use of e-learning in tertiary-level IM education. Twelve out of 18 participants from the IM education provider category (including academics, administrative-level staff, and support staff) mentioned that there was unequal access to computers and internet facilities among students in urban and rural sectors. This unequal access can also be referred to as the digital divide (International Telecommunication Union, 2001). A director of the public institute explained how this unequal access affected their current programmes. He said:

We try to upload our lessons from here (from the institutions) and ask students to access them from their places. We also ask them (students) to send completed assignments to us via internet. But in practice it is sometimes problematic because when students go out from our institution and especially when they are in their places where they work or live in rural areas or distant areas, it is difficult to access 'Nenasala' centres or internet facilities or even a computer. (IMEPNIASD)

A senior academic at the public university further commented that for e-learning purposes there should be access centres throughout the country with the purpose of providing facilities for students who did not have computer and internet facilities of their own. He suggested these access centres should employ staff members with IT knowledge. He said:

We don't have such centres. The Open University of Sri Lanka has some centres, but the Open University can't do this alone. (IMEPDETSS)

Nevertheless, different opinions were voiced. Two out of three e-learning providers held the opinion that the Sri Lankan government had strengthened the national infrastructure by implementing national level programmes, i.e., e-Sri Lanka (including Nenasala) and NODES (National Online Distance Education Service/NAC centres) to bridge the digital divide and increase computer literacy particularly in rural areas of Sri Lanka. Therefore, these participants believed that access to IT/ICT in the Sri Lankan context was not a big issue. They said the major problem was that students were not using these access centres, i.e., Nenasala and NODES. Among them one programme director from an e-learning provider said: 
If they (students) really want, there are access centres. I think access is not a major issue as such. But still they (students) are not used to it. They say we don't have the access. (EEPOUPD)

Participants from one e-learning provider organization offered a possible explanation for this. They said Nenasala and NAC centres did not provide the proper infrastructure facilities needed for e-learning. A member of the educational technology support team in that e-learning provider organization added:

Are those centres (NAC centres and Nenasalas) providing the required environment? Firstly, the bandwidth, secondly the environment needed for their (students') education. It is questionable. You can't do this sort of thing (educational activities) if the surroundings are not good enough. Most of the access centres are not in a position to provide good learning environments. (EEPUCMET)

Similarly, in the focus group discussion, one IM education programme participant from a rural area mentioned why they were not using existing centres. She noted:

There are different centres in different places in Sri Lanka. For example, NAC centres, Nenasala. Therefore, individuals have access at some level. But when we go to use those centres, again we face a number of inconveniences. For example the traditional problems like travelling, opening hours, are there as well as the problem of an unsuitable environment. (FGDIMW)

Moreover, as discussed in section 5.2.1, participants mentioned that the Nenasala telecentre project was not sustainable due to the lack of strategic planning as well as political influences and poor management practices. Surprisingly, Nenasalas' lack of sustainability was also reported by participants in the e-learning provider category, i.e., those who believed that access to IT/ICT in the Sri Lankan context was not a big issue as mentioned earlier in this section.

Analysis of the data reveals further reasons for the problem of unequal access to computers and internet facilities in rural parts of Sri Lanka. They are:

i. Lack of rural broadband internet services

ii. Lack of policy on national broadband

iii. Cost of access to internet and other technologies.

\subsubsection{Lack of rural broadband internet service}


As well as 12 out of 18 participants from the IM education provider category, academics also mentioned in the focus group discussion that there was a lack of access to broadband internet services especially in the rural sector. A technical support team member from a public university reported that in the e-learning system they could not only think about facilities inside the university. He said whether students had access to e-learning facilities also needed to be considered. He stated:

We can't be sure about all students having required facilities, such as internet, PC/laptop. Sometimes they have a PC but no internet facilities. Thus, lack of network connectivity is the main barrier. Connectivity is OK in the Colombo area. But this is a big problem in rural areas because not all are using ADSL connections. Most of them use dongles. Sometimes they get a signal properly but sometimes they do not. (IMEPDESST)

Another technical support team member in a private university explained the main reason for the lack of access to broadband internet services. He said:

At the moment, I think most of the service providers try to give us shared bandwidth. That means for example, Telecom providing a $2 \mathrm{Mbps}$ link. That one covered, I think, a 400 or 1000 circular area. And they are telling us they are trying to give us $2 \mathrm{Mbps}$ bandwidth but the reality is we share the bandwidth. I think about ten people are using that one (2Mbps link). Thus, ten people have shared bandwidth, not a true 2Mbps bandwidth. (IMEPSLSST)

The same reason was also reported by the two out of the three government officials interviewed in this study. This was also supported by the documentary evidence. For example, the World Bank report 'Broadband in Sri Lanka: Glass half full or half empty' drafted by Galpaya (2011) revealed that there were some hidden deals among internet service providers and that caused public displeasure about their service. For example, a major reason was fraudulent advertising which was promising broadband speeds that are possible theoretically but not in reality.

This study further found that most telecommunication service providers still targeted urban areas to promote their services rather than rural areas. For example, in the focus group discussion, one IM worker who also worked as an information manager in the telecommunication sector said: 
I personally know Sri Lanka Telecom (National Telecommunication Provider) has money but they are not utilizing it properly. Their major concern is only the Colombo area. (FGDIMW)

From the students' point of view, they reported how this lack of broadband internet service affected their educational activities. For example, in the focus group discussion one rural IM worker mentioned:

Let's think about what happens when I need to do a certification in a professional career. There are lots of IBM certifications offered online. We log into the system and do the certification online. While we are doing it, we click on next, next, and then for example in the 10th question we get an error message 'page cannot be found'. That means a problem with the infrastructure, insufficient internet bandwidth. (FGDIMW)

Therefore, IM workers as a student group in this study suggested "there should be an attempt from TRCSL (Telecommunications Regulatory Commission of Sri Lanka) to provide rural broadband internet service comparable with urban areas" (FGDIMW). Similarly, a government employee also commented "TRCSL should definitely ensure bandwidth penetration of the country" (SHGOIC).

\subsubsection{Lack of national broadband policy}

As discussed in section 5.3.1.1, there was general agreement among the participants of this study that there was a lack of access to broadband internet services especially in the rural parts of Sri Lanka. Analysis of the data further reveals there was also an issue regarding broadband internet in the tertiary-level IM education provider organizations as well as in the current e-learning provider organizations. These are discussed in section 6.2.2 in Chapter 6. Due to the above-mentioned situation, two-thirds of the participants in each category - i.e., IM education providers, current e-learning providers, other stakeholders (government officials) and IM education programme participants mentioned that they were in urgent need of high-speed broadband. They said a 'national broadband policy' was required to stimulate broadband development in all sectors in Sri Lanka to reduce barriers to internet access.

Further, IM education programme participants suggested "government or TRCSL should introduce a policy to control the telecommunication tariff in Sri Lanka" (FGDIMW). 
Thereby they believed as students they might be able to afford fixed broadband internet connection.

It is worth noting that at the time of the data collection of this study (September to December 2011) one programme director at a current e-learning provider said, "national broadband policy is already drafted and waiting for legal approval. Thus, it will be published during the fourth quarter of 2012" (EEPNOPD). The latest information about a national broadband policy will be discussed in section 7.2.1.3.

\subsubsection{Cost of access to internet and other technologies}

Eight out of 18 participants in the IM education provider category, two out of three participants in the stakeholders' category (government officials), and all the IM workers as students in this study pointed out that there was a problem with cost in regard to having internet connections and buying other related technologies, e.g., a computer/laptop.

One of the administrators at a private university mentioned that feasibility of access to the internet and other technologies depends on the socio-economic status of individuals. This point was also reflected in the views of staff at the same private university. Among them, a junior academic staff member provided an example:

Now some of the students use laptops but others don't. We have the Wi-Fi facilities here and most of the students still don't use that facility because they don't have the equipment in order to use that facility. We have the environment, but from the students' point of view, they face barriers. For example, most of students are middle class, and they are not in a position to spend money to buy a laptop. (IMEPSLTSJ)

As well as the students, even government workers also experienced economic problems when buying computers and other related technologies for their individual use. For example, a librarian at the public university expressed his personal view:

Today is the last day of the 'INFORTEL' exhibition (one of the well-known ICT exhibitions in Sri Lanka). I went there last Saturday. What I saw, I saw a small laptop or palmtop available for kids. So that is the trend, technologies coming like that. But I am still unable to buy a laptop because according to my budget I can't afford it. (IMEPDESSL) 
Furthermore, two out of the three government officials interviewed in this study also shared this common view. They felt that individuals (students or workers) who are keen on e-learning sometimes could not afford to pay for the necessary equipment and facilities, i.e., fixed broadband internet facilities because they were too expensive.

In the focus group discussion IM education programme participants explained why the cost was problematic in the use of e-learning. They said:

Compared to the price of mobile broadband, the price of fixed broadband service is very high due to the insufficient competition among internet service providers. Personally, we cannot afford fixed broadband service. Therefore, we are now using mobile broadband [dongles] because it is cheap compared to fixed broadband connections. However, we then face problems like broadband speed, and signals. (FGDIMW)

In addition to the above-mentioned views, only one IM worker from a rural area had different views.

Cost we can analyse like this. Bus fares and petrol costs increase frequently. Therefore, according to the time and thinking about other expenditures, because we have to spend money for travel to Colombo, we have to spend our valuable time travelling, and then elearning is cost-effective. Thus, if we bear the initial cost, then e-learning is very convenient for us. In that situation, I think individually/per person cost is nothing. (FGDIMW)

Even though current e-learning providers had not reported cost of access to internet as an issue, one programme director mentioned that "reduction of price of internet service and other required equipment would encourage users to use e-learning" (EEPUCPD).

The preceding data discussed in section 5.3.1 showed that lack of rural broadband internet service, lack of policy on national broadband, as well as cost of access to the internet and other technologies were perceived by participants in this study as having an influence on unequal access to IT/ICT in Sri Lanka. This unequal or lack of access to computer and internet facilities among students especially in rural areas had an impact on the use of e-learning in tertiary-level IM education. 


\subsection{Chapter summary}

In summary, this Chapter examined macro-level factors and identified socio-cultural factors as among the most important factors. Lack of readiness to move into studentcentred e-learning, lack of acceptance of e-learning programmes in Sri Lankan society and social exclusiveness issues had a strong influence on the introduction and use of elearning in tertiary-level IM education in Sri Lanka. This study further found that governmental factors, particularly lack of strategic planning, poor management practices, and lack of national policies (i.e., a national information policy and a national policy on elearning) also had an impact on the introduction and use of e-learning. This study finding confirmed that technological factors were also significant. For example, unequal or lack of access to IT/ICT including lack of rural broadband internet service, lack of policy on national broadband, and cost of access to the internet and other technologies affected the use of e-learning in tertiary-level IM education in Sri Lanka.

In the next Chapter, I discuss factors at the meso level and their impact on the introduction and use of e-learning. 


\section{CHAPTER 6: MESO-LEVEL FACTORS - PEDAGOGICAL CHANGE, STAFF AND OTHER RESOURCES, COLLABORATION, PERCEPTIONS AND \\ ATTITUDES}

In this Chapter, I identify and examine meso-level factors that have an impact on the introduction and use of e-learning in tertiary-level IM education in Sri Lanka (Figure 6.1). Together with the previous Chapter, this Chapter addresses the two research questions and contributes to the basis for assessing and revising the conceptual model.

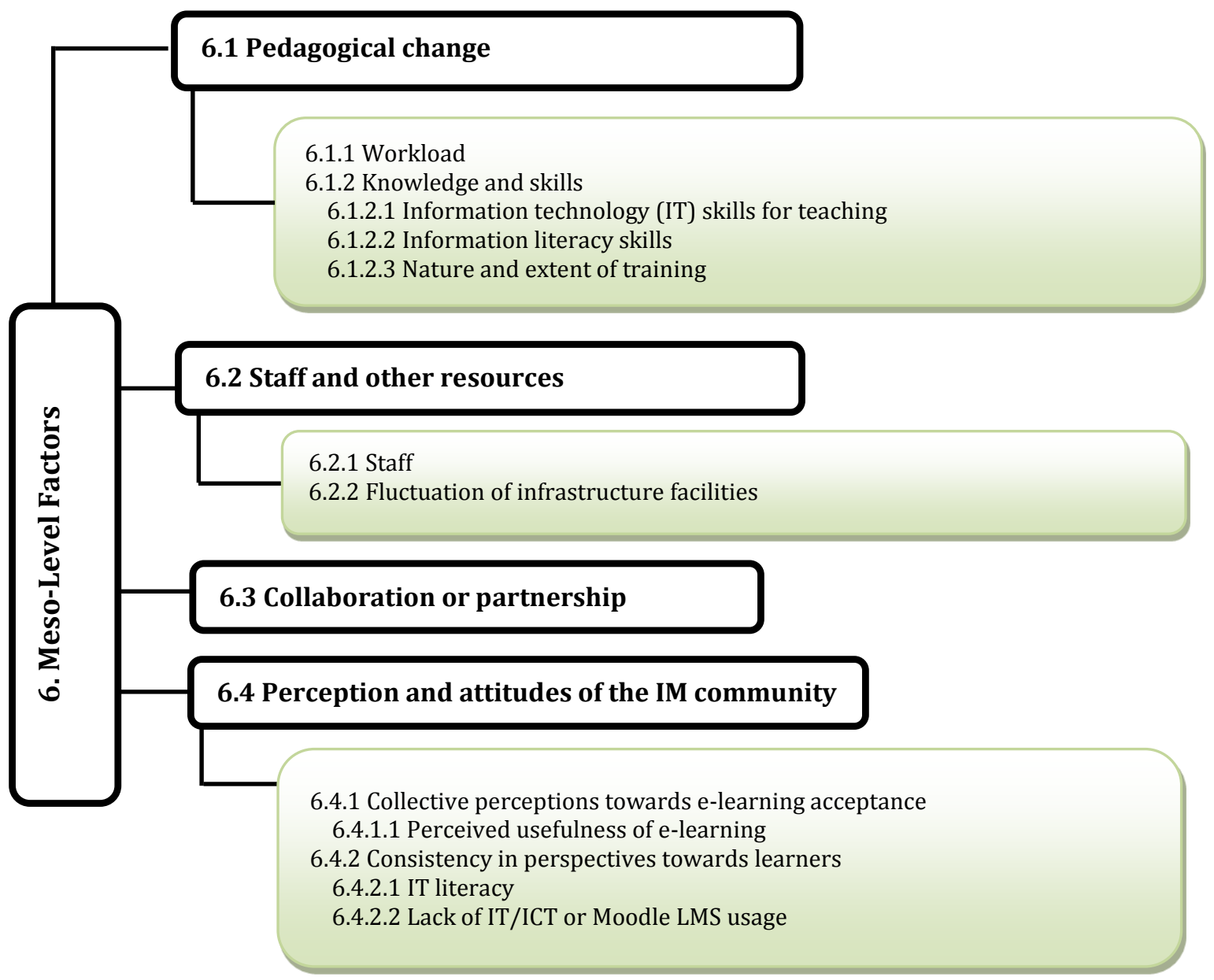

Figure 6.1 - Outline of Chapter 6 - Meso-level factors

\subsection{Pedagogical change (from instructivist to constructivist-based e-learning)}

As noted in section 5.1.1 in Chapter 5, this study found that at the macro level there was a lack of readiness to move towards pure student-centred (constructivist) e-learning in 
tertiary-level IM education in Sri Lanka. Analysis of the interview and focus group data reveals academics' resistance to pedagogical change (i.e., from instructivist to constructivist-based pedagogy). Table 6.1 summarizes participants' perceptions with regard to this.

\begin{tabular}{|l|l|}
\hline \multicolumn{1}{|c|}{ Contributing factors } & \multicolumn{1}{c|}{ Summary } \\
\hline 6.1.1 Workload & $\begin{array}{l}\text { Content-heavy syllabuses plus associated work (i.e., marking, } \\
\text { exam and thesis supervision, student counselling and mentoring, } \\
\text { and administration) and varying expectations among different } \\
\text { roles in the organization are perceived to have a strong influence } \\
\text { on academics' heavy workload. Due to this volume of work } \\
\text { academics lack time and this made it hard for them to learn } \\
\text { additional skills to change teaching methods. }\end{array}$ \\
\hline 6.1.2 Knowledge and skills & $\begin{array}{l}\text { Lack of knowledge of pedagogy, lack of understanding of how } \\
\text { technology and content influence and constrain one another, and } \\
\text { how teaching and learning change when particular technologies } \\
\text { are used are all perceived to have a strong influence on academics' } \\
\text { technology integration. }\end{array}$ \\
& $\begin{array}{l}\text { Academics and students are also not very information literate. } \\
\text { Absence of training (i.e., constructivist-based staff development } \\
\text { programmes, lack of continuing education or professional } \\
\text { development programmes, and competency building } \\
\text { programmes) was cited as the major reason for academics' lack of } \\
\text { knowledge and skills. }\end{array}$ \\
\hline
\end{tabular}

Table 6.1 Summary of the perceptions of lack of enthusiasm for change of pedagogy

The next two sections (6.1.1 and 6.1.2) discuss each of the factors and consider their influences on the introduction and use of e-learning in tertiary-level IM education in Sri Lanka.

\subsubsection{Workload}

Workload is one of the important organizational factors that participants emphasized as affecting their lack of interest in constructivist pedagogy. This factor mainly consists of content-heavy syllabuses plus associated work and varying expectations among different roles in the organization.

Twelve out of the 18 participants in the IM education provider category and five out of the nine participants in the e-learning provider category pointed out that heavy workload made it hard for academics to change the teaching methods in their organizations. All the academics who were interviewed across the three IM education provider organizations 
mentioned content-heavy syllabuses as a major reason for their heavy workload. Among them a junior academic at the public institute explained the problem as follows:

According to our syllabuses, we have to cover a lot of things during one semester. In that case, as a teacher I always try to cover my topics within a given time rather than giving an opportunity for students to do activities. The reason is if I am unable to cover my syllabus within a given time, I am not able to claim money from the institution for my teaching. (IMEPNITSJ)

All the academics who were interviewed in this study similarly suggested that the large amount of syllabus content needed to be reduced. This would then allow time to plan activity-based teaching in order to give more opportunity for students to learn by themselves.

A senior academic at the public institute also said that apart from the content-heavy syllabuses, lecturers also faced an overwhelming volume of work. Examples of this work were paper marking, exam and thesis supervision, and extra activities in the university such as student counselling and mentoring. He further said sometimes academics even had to deal with the administrative work in their departments. Due to the busy academic life, he noted "most academics including me are not interested in changing our familiar teaching method (instructivist-based pedagogy) because we do not have time to learn or practise new teaching methods" (IMEPNITSS).

In the focus group discussion, academics also affirmed that due to the volume of work they lack time and therefore are reluctant to undergo the additional training needed for moving towards new pedagogy.

The participants from the e-learning providers also reported how workload in the organization negatively affects the introduction and use of e-learning programmes. In particular, participants from one e-learning provider organization mentioned that they were mostly working seven days per week at the university. They run both weekday programmes for internal degree students and weekend programmes, i.e., certificate courses, diploma courses, and masters' degree programmes for part-time students while also continuing e-learning programmes. One director shared his experience while working as a visiting lecturer in this e-learning provider organization: 
We are doing lectures for internal students during weekdays. All Saturdays and Sundays we are actively engaging with other external students. Also we have to care about our elearning classes. This is too much for us. (EEPNOPD)

As discussed in Chapter 5, employees who work in e-learning support roles, i.e., learning resource support and educational resource support, expect some fully complete elearning materials from the academics to upload into the e-learning system. Thus, a member of the learning resource support team explained her personal experience regarding difficulties of getting support from academics for a particular e-learning programme. She said:

Our organization developed e-learning courses for psychology and sociology. Initially, we got some support from academics. But later on academics found that it was very hard work and they had to pay attention to every little detail because it was an interactive course. Then it did not work out, they refused to allocate time that we needed from them. (EEPUCMLRS)

Apart from the content-heavy syllabuses plus associated work, this study also found that there were varying expectations among different roles, i.e., administrators and support staff in the tertiary-level IM organizations, due to the absence of job/role descriptions. This was also a major reason for academics' heavy workload.

For example, four out of the six administrative staff as well as two out of the three technical support staff who were interviewed in this study expected academics to be responsible for not only the contents of their courses but also the interactive e-learning design plus all other integrated work. For example, a Dean of Faculty at the private university (where the e-learning system was used as a supplementary tool) expressed his dissatisfaction regarding LMS in the university. He complained academics did not do their job properly. Specifically, he said academics did not come up with innovative ideas and they did not update the LMS with interactive designs. He noted academics did not even find time to upload the materials into the system.

According to junior and senior academics at the same university, the problem was uncoordinated division of work among the different roles in their organization. For instance, a junior academic described her work situation. She said:

Except for my teaching, I do not know what my exact role and accountabilities are because I do not have a job description. Nor do other staff members. Therefore, I have to do 
everything. Without a job description, it is usually very difficult for a person to commit to, or be held accountable for, a role. (IMEPSLTSI)

This absence of defined roles was also a problem in the public universities. For example, in the public university a technical support team member who had experience of maintaining LMS mentioned that he was responsible for maintaining the overall infrastructure systems such as internet, power, and servers while academics were responsible for maintaining their e-learning programme. However, he noted academics were not happy with this situation. He said:

The workload is increasing day by day but the number of staff is the same. Because of this, most academics are unwilling to use collaborative e-learning based around constructivism because they think their workload may become even higher. (IMEPDESST)

In the focus group discussion, academics suggested that there should be a separate division in the organization for e-learning purposes. They said with the current workload they are not in a position to play other roles such as designer or interactive content developer. Among them, one academic who had experience of working with the LMS explained his own situation:

I don't have enough time to use my mind to think creatively and innovatively to develop the e-learning content because at the same time I have to engage with thousands of pieces of work. (FGDAC)

In the same focus group discussion, academics further noted that they also lack the knowledge and skills that are required to use new pedagogy or to perform new roles (this will be discussed in section 6.1.2).

It is interesting to note that participants from the current e-learning provider organizations also expected that academics to be responsible for almost everything in the e-learning programme. For example, one member of the learning resource support staff said her organization faced problems of managing the collaborative e-learning programme due to the academics' lack of commitment. She explained this situation:

There are more than 200 students registered with our e-learning programme. What academics do is only upload materials to the LMS. They are not in a position to post answers at the right time for everybody's queries because at the same time the lecturer is 
supposed to look after her or his external and internal classes as well as deal with other academic work. (EEPOUMLRS)

A member of the educational technology support team who also worked as a senior lecturer said:

I also don't have time to check my online class to see whether it is going smoothly or not because I have normal teaching to do as well as the other engagements. On the other hand, if our organization is not paying for these things, why should we allocate our time for developing e-learning content? (EEPUCMET)

This respondent suggested that there should be clearly divided responsibilities and workloads among different staff. He said that support at the organizational level may help to increase academics' motivation or interest in collaborative e-learning. This opinion was echoed by another member of the educational technology support team who also worked as a senior lecturer. He shared his experience in another country:

I have been to Malaysia and I saw how e-learning works. There are specialized people or experts responsible for the e-learning programme and academics are only slightly involved in helping them to develop the e-learning course materials. (EEPOUMET)

He suggested that division of labour had to be carefully organized within the organization.

Interestingly, all the programme directors at e-learning providers mentioned that there was a need for institutions to redistribute their academics' workload. One director explained how redistribution of academics' work may help the introduction and use of collaborative e-learning. He said:

At the moment there are no additional staff, not even tutors, to help the academics. If they have a separate set of staff to distribute their workload, it can be a motivational factor for them (academics) to use their time to deviate from traditional teaching methods and use new teaching methods. (EEPUCPD)

Even though programme directors understood that the redistribution of academics' workload could be an option for reducing it, programme directors were unable to do so due to the human resources constraints. This issue will be discussed in section 6.2.1 (lack of human resources). 
The next sub-section discusses other possible barriers against moving into constructivist-based e-learning.

\subsubsection{Knowledge and skills}

This study found that among academics there was a lack of knowledge and skills appropriate for moving towards constructivist e-learning in tertiary-level IM education in Sri Lanka. Analysis of the data reveals insufficient information technology (IT) skills for teaching in an online environment, information literacy (IL) skills applicable to elearning, and training to address these skills.

\subsubsection{Information technology (IT) skills for teaching}

As noted in Chapter 2, most IM education provider organizations have changed their syllabuses recently to keep up with technological advancements. However, they have not outlined how this will happen. For example, all the academics who were interviewed across the three IM education provider organizations mentioned that they did not feel competent enough to use advanced IT for teaching purposes. A junior academic at the public institute explained why he lacked advanced IT literacy skills. He suggested most lecturers were not encouraged to use IT when they were younger and therefore they now felt they were coming to IT quite late. That also affected their competency. He further explained this situation:

Many lecturers, including me, earned degrees at a time either when educational technology wasn't in around or was at a very different stage of development than it is today. Therefore, for many lecturers, acquiring or practising new IT skills is quite challenging. (IMEPNITSJ)

In the focus group discussion, one IM worker explained his experience of studying via elearning at one of the IM professional organizations in Sri Lanka. His e-learning course had been stopped by the organization because the teachers did not have the required skills to manage the system.

Analysis of the data further reveals that knowledge and skills among academics were particularly lacking in the area of integration of ICT with teaching. It was found that staff lack knowledge of pedagogy that is applicable to the teaching content. There was lack of understanding of how technology and content influence each other. There was also lack 
of understanding of how teaching and learning change when particular technologies are used.

\section{Knowledge of pedagogy that is applicable to the course content}

This study found that some academics working for IM education providers were incapable of transferring their subject knowledge to students, especially in the e-learning environment. For example, a senior academic at the private university shared her experience of teaching in an e-learning environment and highlighted this problem as a key issue. "For me, a challenge is how I can transfer my subject knowledge into explicit knowledge" (IMEPSLTSS).

As noted in section 6.1.1, academics in the three IM education provider organizations reported content-heavy syllabuses as a problem for planning student-centred forms of instruction. A junior academic at the public institute explained the nature of this problem. He said how to assess constructivist learning and transformation of the subject matter for activity-based teaching are relatively unfamiliar areas for him and other academics. Thus, he said "these unfamiliar areas are common problems in tertiary-level IM education" (IMEPNITSJ).

Like academics, librarians as support staff for IM education did not have a good understanding of pedagogy. Although they understood that they had a vital role in elearning by helping learners and academics to find, evaluate, and exploit resources (i.e., information literacy), they did not have the full set of skills that were required to teach information literacy skills whether face-to-face or via e-learning. One librarian explained the reason:

Due to the increasing number of electronic/digital resources, librarians have a crucial role as information professionals as well as teachers. Thus, we require teaching skills but we did not learn about learning theories, pedagogy, or even about e-learning. (IMEPNISSL)

The same librarian said "our syllabuses on library and information science are very traditional". So he suggested that the IM education curriculum itself needs revision to incorporate learning theories, pedagogy applicable to e-learning environments, as well as timely valuable knowledge. He said future librarians should have a full set of knowledge and skills to manage their professional tasks. 
Similar perspectives were also reported by the participants from the e-learning providers. Among them, one member of the educational technology support team emphasized that the learning design of the current curriculum was outdated. He said the present syllabuses were not evolving with the constructivist ideals. For example, learning content, learning goals and outcomes, and assessment criteria were not using activitybased teaching. Therefore, he was in doubt about how academics could attempt to use constructivist pedagogy for existing syllabuses.

\section{Understanding of how technology and content influence/constrain each other}

All the academics who were interviewed across the three IM education provider organizations mentioned that they did not have enough understanding of which specific technologies were best suited for addressing subject matter learning in IM education. Also they did not understand how the content integrated with technology. For example, a senior academic at the private university noted that although her organization used the e-learning system as a supplementary tool she still needed assistance from a person who had advanced IT skills. From her experience she felt that working with the e-learning system was not like data entry because she could not upload her materials directly into the LMS and needed to manage in advance how she could arrange activities aligned with her lesson. Therefore, she said she needed some form of technological knowledge. The same senior academic provided an example to show her lack of understanding of using or choosing technology for developing digital learning content. She said:

My problem is how my study materials transfer into the form of digital media. When it comes to text-based, it is obviously possible. But when it comes to visualizing something or showing the process of how something works ...I have no idea. (IMEPSLTSS)

The lack of understanding of how technology and content influence and constrain one another was also discussed in the academics' focus group. The following comment was echoed by many participants: "I don't know how to interact with the students using IT" (FGDAC). One academic in the focus group discussion mentioned that although most lecturers had expertise in classroom teaching, they did not have skills in using technology, especially in the e-learning mode. He therefore noted the nature of the failures they were currently experiencing: 
Most of the time we are accused by the students, saying that they cannot understand the developed materials. As developers of e-learning content we have something in our mind. But we are not capable enough to clearly communicate our ideas or present our piece of work using the variety of technologies in the e-environment. (FGDAC)

Academics' lack of understanding of how the delivery of subject matter can be changed by the application of technology was identified as a barrier against continuing the collaborative e-learning programme by all the programme directors in the e-learning provider category. Among them one programme director said, "now a lot of staff have experienced technological issues of not knowing how to build an interactive learning environment. Thus, some academics failed to convince the students of their subject matter" (EEPUCPD).

\section{Understanding of how teaching and learning change with the use of technologies}

Five out of the six academics who were interviewed across the three IM education provider organizations further reported that they did not have enough understanding of the limitations as well as affordability of technologies. Academics mentioned that there was no way to build a teacher-student relationship in the e-learning environment. Among them one senior academic at the public university held the view that "in the e-learning system students become lonely learners because there is no way to maintain constant contact with them. Therefore, no competition among students and they lost motivation and synergy whereas in the class..." (IMEPDETSS).

A senior academic at the private university mentioned that technology may not help to assess students' performance. For example, lack of visual cues made it difficult for her to judge whether students understood her lesson. Therefore, it was hard to understand what the students were lacking or what area they were good at. She therefore held the view that "in the e-learning system there is no way of understanding students" (IMEPSLTSS).

Academics' lack of understanding of the limitations and affordances of technologies were not reported by current e-learning providers and stakeholders (government officials). However, in the focus group discussion, IM education programme participants noted that they felt some of their lecturers were not innovative, or creative, as well as not open- 
minded about technology. They said that could be a problem for developing effective elearning programmes and managing and reaping all the benefits of today's technology.

\subsubsection{Information literacy (IL) skills}

This study found that some academics and students (IM workers) in tertiary-level IM education in Sri Lanka were not highly information literate. In the context of this study, the term 'information literacy' refers to "the ability of individuals or groups:

- to be aware of why, how, and by whom information is created, communicated, and controlled, and how it contributes to the construction of knowledge

- to understand when information can be used to improve their daily living or to contribute to the resolution of needs related to specific situations, such as at work or school

- to know how to locate information and to critique its relevance and appropriateness to their context

- to understand how to integrate relevant and appropriate information with what they already know to construct new knowledge that increases their capacity to improve their daily living or to resolve needs related to specific situations that have arisen" (Dorner and Gorman, 2006, p. 284).

Four out of the six academic staff members in the IM education provider category claimed that academics were not in a position to build a better e-learning environment for their students as a result of lack of information literacy (IL) skills. Among them a senior academic at the public institute stated:

...there are academic subject gateways. Not only students but sometimes lecturers also have no idea about this. Sometimes they do not even know how to evaluate web sites. Without having a simple understanding about these kinds of things how can lecturers apply e-learning to their teaching? (IMEPNITSS)

As noticed in section 6.1.2.1, academics had various difficulties in linking IT to their lecturing roles. A senior academic at the public institute said lack of IL skills was the reason. He noted, "to link IT with lecturing, IL is the linkage" (IMEPNITSS).

A junior academic at the same public institute affirmed the opinion that academics lack IL skills. He said: 
As a teacher, I am not an expert at searching information or disseminating information. But when I compare with other countries, people who are in a similar position to mine have very good knowledge and I am not at that level. (IMEPNITSI)

A similar view was voiced by a junior academic at the public university. He said when students or academics wanted the right information at the right time, they should know where they could get it. According to his experience in working with academics and students, he said, "at the moment not only students but also senior professors are not aware about IL" (IMEPDETSJ).

Academics also reported that many information workers lacked the skills required for retrieving relevant information. Among them, one senior academic at the public university noted:

Sometimes maybe students know about programming and working with other software packages. But if you ask them to find some information using the internet or databases they don't know how to retrieve relevant information. Thus, basic skills are missing. (IMEPDETSS)

Interestingly, in the focus group discussion, IM education programme participants also acknowledged that they lacked IL skills. Among them, one information worker who had e-learning experience expressed her own situation:

At the beginning of the e-learning programme, it was really hard for me because when I searched the internet for specific information, sometimes thousands of web pages would open. I didn't know what the correct things were and at that time I had no idea about how to specify my search terms in order to retrieve relevant information. Thus, that was the biggest problem I had. (FGDIMW)

All the information workers mentioned that they needed to improve their IL skills. For example, one IM worker said:

As a learner, I should know how to do internet and database searching and how to retrieve relevant information. If not, I am sure I won't be able to benefit from e-learning. (FGDIMW)

Moreover, four out of the six academics in the IM education provider category and all the IM education programme participants in the focus group discussion similarly mentioned that they did not receive sufficient support from the library to enhance their IL skills. 
Participants from the e-learning provider category did not mention lack of IL skills as a barrier against their continuing their current e-learning programmes. However, two out of the three government officials said there was a lack of IL skills in tertiary-level education in Sri Lanka. Among them, one government official shared his experience while closely working with university librarians as a chairman of the standing committee for his particular subject. He said:

Academics and students lack IL skills. Thus, their usage of currently available e-journals and databases are not at a satisfactory level. Even most librarians (including professionals, para-professionals, and other support staff) are far behind in using technology. This can be a negative factor for providing services in e-learning as well as for teaching IL to academics and students. (SHGOUG)

Because of this issue, this official was planning to lead a number of projects in order to minimize these barriers. This will be discussed further in the next section.

\subsubsection{Nature and extent of training}

Two-thirds of the participants in three categories - i.e., IM education providers, current e-learning providers, and other stakeholders such as government officials - mentioned that they were in urgent need of training.

All the academics who were interviewed across the three IM education provider organizations mentioned that although their organizations conducted staff development programmes, they still needed training on the use of ICT in teaching, learning, and evaluation. Moreover they required expert advice and training on preparation of ICTbased interactive learning materials. A junior academic at the private university explained the current problem with her staff development programme:

Our organization is sending us to training [staff development programme] but those programmes are still traditional, teacher-centred and do not integrate educational technologies. (IMEPSLTSJ)

The same reason was also reported by other academics in the IM education provider category. However, the head of a department at the private university mentioned that even though currently there were no constructivist-based training programmes established in his university, he anticipated that there would be opportunities for 
development of these programmes because his university had started a relationship with a number of international universities to learn from their experiences.

A lack of continuing education programmes was reported as another challenge. A senior academic at the public university said:

Each and every probationary or newly appointed lecturer undergoes a staff development programme. I also had that training but that is 25 or 30 years ago. After that I did not have any training. (IMEPDETSS)

The same senior academics suggested that there should be continuing education programmes to provide timely required knowledge and skills especially among academic staff, technical staff, and library staff.

The same problem - i.e., lack of continuing education programmes - was also reported by all the librarians who were interviewed as support staff across the three IM education provider organizations. As noticed in section 6.1.2.2, some academics and IM education programme participants were not proficient in information literacy and they did not receive sufficient support from the library to enhance their IL skills. All the librarians affirmed the opinion that they lacked skills to provide better IL programmes. As noted in section 6.1.2.1, librarians did not have enough understanding of pedagogy, which negatively affected teaching IL. One librarian from the public university explained this situation:

I graduated in library and information science 35 years ago. At that time I did not learn about IL or teaching and learning theories. But I am now trying to explore some of the new areas by myself because there are no such opportunities to gain the latest required knowledge and skills. (IMEPDESSL)

A similar view was expressed by other librarians who were interviewed in this study. They said most librarians in the university who tried to keep their professional knowledge current were driven by their own curiosity. Therefore, they said continuing education or professional development programmes were essential for moving towards supporting the introduction and use of e-learning.

Another librarian from a private university reported the need for competency-building programmes which cover both theoretical as well as practical training on relevant 
themes. She said librarians also needed a way to upgrade their competencies in order to cater for services to students who were more capable of using various technologies especially in the e-environment.

Four out of the six administrative staff members in the three IM education provider organizations agreed that they should offer more training facilities for their academic staff as well as support staff, i.e., library and technical staff. Among them, a head of department at a public university stated that a series of training programmes was the key to e-learning success. He said training was needed for all the groups involved in elearning programmes such as academics, students, library staff and technical staff as well as administrative staff to gain the theoretical and practical knowledge and skills required to use e-learning. He said that could be a motivational factor not only to adopt e-learning but also to develop a good e-learning programme.

Participants from one of the three e-learning provider organizations mentioned problems with the training programmes provided by their organization. For example, participants reported that those programmes were not helping them to improve skills. Among them a member of the educational technology support staff said:

We have a separate centre called 'educational technology and media' which is responsible for providing training on online learning and teaching. Although these training programmes are compulsory for every academic, most of them are still not aware of how to actually design the course, what sort of materials and what type of activities they have to add, as well as how to link all activities with the assessment. (EEPOUMET)

The same participant noted that not only is it important to provide training but that programmes must suit and meet the needs of the target audience.

Surprisingly, a programme director at the same organization (who is also one of those responsible for providing training in online teaching and learning) affirmed that the programme coverage was very simple and it may not contribute to producing quality and skills staff needed for e-learning. For example, she described their online course writing programme, saying they just touch on the topic and try to give an idea about what it is like. Thus, she believed their programmes were not advanced enough to produce socalled 'instructional designers'. 
It is worth noting that all the government officials who were interviewed in this study mentioned that they were now in the process of planning to provide various training facilities for students, academics, and library staff to enhance their knowledge and skills. Among them, one government official who was the chairman of the standing committee for tertiary-level IM education explained some of the current and future projects. He said his first priority was improving IL skills among academics and students. Following his direction, the university library staff were now in the process of developing two IL course modules. He explained how this would work:

One common IL module is for students, so irrespective of their degree programme, they have to take this. Another course module is for academics. That will be included as a core module in the mandatory staff development programme. (SHGOUG)

The same government official, as noted in the latter part of section 6.1.2.2, commented library staff were not competent enough to provide the required services in the eenvironment. Therefore, he was preparing another project called a 'competency-building in capacity enhancement programme' to run in the university libraries with the help of World Bank funds under the Higher Education for the Twenty-first Century (HETC) project.

The preceding data discussed in section 6.1 showed that heavy workload and lack of knowledge and skills were perceived by participants in this study to have an influence on academics' lack of enthusiasm for changing teaching methods from instructivist to constructivist-based pedagogy. This in turn had an impact on the introduction and use of e-learning in tertiary-level IM education in Sri Lanka.

\subsection{Staff and other resources needed to facilitate e-learning}

Participants mentioned that there was a lack of staff and lack of infrastructure facilities to facilitate e-learning. Table 6.2 summarizes participants' perceptions. 


\begin{tabular}{|l|l|}
\hline \multicolumn{1}{|c|}{ Factors } & \multicolumn{1}{c|}{ Summary } \\
\hline 6.2.1 Staff & $\begin{array}{l}\text { Lack of staff with relevant technological skills and } \\
\text { knowledge (i.e., network or system } \\
\text { administrators/managers, and LMS administrators), } \\
\text { absence of job market for instructional designers and } \\
\text { content developers were also major issues. }\end{array}$ \\
\hline 6.2.2 Reliability of infrastructure & $\begin{array}{l}\text { There was a noticeable gap among tertiary-level IM } \\
\text { education providers with regard to their infrastructure } \\
\text { facilities (see Table 6.3). }\end{array}$ \\
\hline
\end{tabular}

Table 6.2 - Summary of the perceptions of lack of staff and other resources

The next sections (6.2.1 and 6.2.2) discuss each of these factors and consider their influences on the introduction and use of e-learning in tertiary-level IM education in Sri Lanka.

\subsubsection{Staff}

Participants from two out of the three IM education provider organizations pointed out that there was a lack of staff with the necessary technology knowledge and skills. A senior academic at a public university said, "there is no person responsible for taking care of the system. For example, if the internet is disconnected in our department for some reason, sometimes we have to wait two or three days before it is fixed" (IMEPDETSS). He said although his university had an IT division, it did not provide sufficient support. Therefore, he suggested that at least there should be a dedicated technological role at the departmental level.

The same issue was reported by a junior academic and head of department at the same organization. The head of a department noted that maintenance issues were not only related to the network. Repairs of computers and other technological devices faced the same problems. Because of this situation, he said now only three or four computers were working in his departmental lab. Moreover, he said even his simple departmental web site was not being regularly updated.

A librarian from the same public university mentioned above said when his organization asks for some special task to be done - for example, to develop a digital documentary about the library - he may not be able to persuade the planners that he could do this because he does not have staff with the necessary technological skills. Therefore, he said, "as a librarian I cannot imagine how I can support e-learning" (IMEPDESSL). 
Similarly, participants from the public institute also mentioned that they lack some technology support staff, for example, network or system administrators/managers and LMS administrators. Conversely, the director of the public institute said:

We do not think we do not have the staff. We try to do our best using existing staff. (IMEPNIASD)

Different perceptions were reported by participants from the private university. Five out of the six participants said with the support of their IT division they had the opportunity to foster e-learning. Among them a librarian said:

There are more than 20 staff members working in our IT division. Also we have a separate software engineering section. Thus, our library is also automated by software developed in-house, it is unique in Sri Lanka. Thus, we can use it for the purpose of e-learning. (IMEPSLSSL)

However, a Dean of the Faculty in the same university said, "to develop e-learning material we still need capable people" (IMEPSLASD). He said e-learning materials should not be boring for the students. He therefore said that when developing interactive learning materials, staff with special skills were vital. This lack of capable people currently prevents his organization from moving towards pure e-learning.

In the focus group discussion, IM education programme participants commented that two segments of the workforce were missing from tertiary-level IM education for the introduction and use of e-learning. One group was technologically knowledgeable personnel to maintain the network, servers, and LMS. The other group was knowledgeable and skilled lecturers, tutors, or facilitators to develop the e-learning content and to maintain the interactive e-learning programme.

The participants from the e-learning provider category reported major issues due to insufficient staff for the introduction and use of e-learning. A member of the educational technology support team in one e-learning provider organization mentioned that five kinds of personnel were needed for e-learning. They were subject matter experts, instructional designers, content developers, interface designers, and LMS administrators. He said the absence of a job title for some of the positions in the Sri Lankan context was a major problem. He described the situation his organization was currently experiencing: 
Instructional designers and content developers are well-established positions in other countries. In the Sri Lankan context, we do not have a job market for these jobs because of the absence of job titles. Thus, we cannot specifically keep a salaried person as an instructional designer or content developer at the organizational level. (EEPNOMET)

A similar problem - i.e., no job market for instructional designers and content developers - was also reported by participants from two other e-learning provider organizations. Among them a member of the learning resource support team said:

We do not have vacancies to employ instructional designers and content developers permanently or on a contract basis. Thus, we have to get our work done on an individual basis. This is a limiting factor for most academics to engage in e-learning. (EEPOUMLRS)

A member of the educational technology support team in another e-learning provider organization emphasized that lack of qualified instructional designers and content developers was also a major problem in his organization. Although his organization employed these people on a contract basis, they were no longer available. He said they usually quit the job for two reasons. One reason was it was not a permanent job. The other one was they could easily find a better job with a high salary in the business sector either locally or overseas. He therefore noted, "finding good instructional designers or content developers is not an easy task" (EEPUCMET).

\subsubsection{Reliability of infrastructure and facilities}

Analysis of the interview and focus group data revealed that there is a noticeable gap among tertiary-level IM education providers with regard to their infrastructure facilities. IM education providers' perceptions will be examined first according to the type of the organization - i.e., public university, public institute, and private university - followed by the perceptions of current e-learning providers, other stakeholders (such as government officials), and IM education programme participants. In some cases, these perceptions will be discussed simultaneously.

Table 6.3 summarizes the lack of reliable infrastructure and facilities across the three IM education provider organizations. A tick $(\sqrt{ })$ means somebody mentioned this issue in 
the interviews while a cross $(\mathrm{x})$ means the issues were not raised or not mentioned in the interviews.

\begin{tabular}{|l|c|c|c|}
\hline \multicolumn{1}{|c|}{ Lack of reliable infrastructure and facilities } & \multicolumn{2}{c|}{ IM education providers } \\
\cline { 2 - 4 } & $\begin{array}{c}\text { Public } \\
\text { University }\end{array}$ & $\begin{array}{c}\text { Public } \\
\text { Institute }\end{array}$ & $\begin{array}{c}\text { Private } \\
\text { University }\end{array}$ \\
\hline Lack of broadband internet services / insufficient bandwidth & $\sqrt{ }$ & $\sqrt{ }$ & $\sqrt{ }$ \\
\hline $\begin{array}{l}\text { Problems with other physical resources (e.g. servers, } \\
\text { computers, other technological equipment, electricity) }\end{array}$ & $\sqrt{ }$ & $\times$ & $\times$ \\
\hline Unavailability of Wi-Fi facilities & $\sqrt{ }$ & $\sqrt{ }$ & $\times$ \\
\hline Lack of solution for power cuts & $\sqrt{ }$ & $\times$ & $\times$ \\
\hline Lack of funding & $\sqrt{ }$ & $\times$ & $\times$ \\
\hline Absence of automated libraries & $\sqrt{ }$ & $\times$ & $\times$ \\
\hline Lack of online databases/e-journals/e-books & $\sqrt{ }$ & $\times$ & $\times$ \\
\hline
\end{tabular}

Table 6.3 - Summary of the lack of infrastructure facilities

\section{Public university perspectives}

All the participants from the public university reported a number of issues relating to the lack of infrastructure. One of the major problems was slowness of internet services due to insufficient bandwidth. Among them, the head of a department explained the issue:

I am not satisfied with the present internet facilities. Sometimes I have to wait a long time to download a very simple document. It is worse when I download high quality video. Although I wait 10 to 20 minutes until it is finished downloading, a message will say 'the download failed'. It is embarrassing and wastes my time. (IMEPDEASH)

Apart from the slowness of internet services, there are some problems with other physical resources such as servers, computers, and other technological equipment and electric power. A technical support staff member was not happy with the capacity of servers in the IT division. He described a recent failure:

One of the departments in our university conducted an online exam for new entrants. Thus, students (more than 100) did the exam from inside the university. Students accessed the system all at the same time and our server crashed. We had to cancel the exam on that day and reschedule the same test across five time slots. (IMEPDESST)

Furthermore, a librarian commented, "no Wi-Fi facilities are available in the library or inside the university" (IMEPDESSL). He said although providing access to Wi-Fi facilities was a basic requirement in the modern world, his university was unable to do so because of the very basic infrastructure. 
All the participants from the public university further said they still did not have solutions for power cuts. For example, a junior academic noted a temporary interruption or reduction in the supply of electric power was common, especially in the dry season. He said they did not even have generators to overcome such issues. He therefore doubted their ability to provide a 24/7 accessible e-learning system.

Analysis of the interview and focus group data revealed a lack of funding and absence of strategic planning as major reasons for the lack of infrastructure in the public universities. For example, a technical support staff member, as noted earlier in this section, pointed out the capacity of the currently available servers was insufficient for the purposes of e-learning. Although he already understood the problem, he said given his university's limited budget he could not have the facilities that he wants to provide better service. He explained:

We receive funds only through the government budget. That means we have to buy any physical resources within the limited budget but not according to the standard that we require. (IMEPDESST)

The same participant further noted that the aim of other local private universities and foreign universities was to buy long-lasting brand new and required equipment with the necessary features, thinking of long-term benefits. Conversely, public universities buy the cheapest resources which do not last long. Thus, he suggested "as an organization it is vital to be given authority to buy necessary resources according to the requirements" (IMEPDESST).

Similarly, a senior academic at the public university said other countries, especially developed countries, buy expensive durable items while his university does the opposite: cheap short-lived items. For example, after two weeks or six months or one year his department had to discard computers since they bought low quality cheap items. As a result, they faced ongoing financial challenges to replace computers again and again. He said lack of strategic planning was the major reason. Therefore, he was sceptical about the management of the basic facilities that are required to facilitate e-learning.

Similar perspectives were reported by the head of a department, a librarian, and a junior academic at the public university. The head of a department said: 
At the moment, at university level we don't get much funding from the UGC to purchase online databases. Year by year they cut funds. They even cut money for ordering books and journals. (IMEPDEASH)

He therefore suggested the government needs to understand the importance of the knowledge industry.

The lack of continuing assured funds was also observed by the librarian. He explained this situation, "at the moment our funding does not allow us to procure high-demand online databases. Year by year, sometimes we get them, sometimes we do not get. No continuity" (IMEPDESSL). The same librarian said every year he therefore subscribed to fewer journals due to severe funding cuts.

A junior academic at the same university reported one possible reason for the severe funding cuts. He said it was due to the government and their administrative staffs' lack of appreciation and low regard for information professionals.

In the focus group discussion, academics also recognized that public universities have inadequate infrastructure. Among them one academic at the public university said without having sophisticated infrastructure such as high-speed broadband, Wi-Fi facilities, and online information services they could not even think about the e-learning mode.

Similarly, in the focus group discussion, IM education programme participants agreed that the public university faced significant infrastructure difficulties. Among them one IM worker who worked as an assistant librarian at the public university shared his experience, echoing the university librarian's comment:

One of the major barriers is lack of access to online databases, e-journals, and e-books because the annual budget allocation for our university library is not enough to purchase high- demand e-resources. Thus, our collection mainly includes printed local books and magazines. We are not even able to buy books from world-famous publishers. Thus, we always choose the cheapest resources without thinking about their quality or standard. (FGDIMW)

In the same focus group discussion, IM workers pointed out that they were unsure how many publishers in Sri Lanka were willing to publish their resources online. They said 
that could be a problem for libraries in the IM education provider organizations, especially the public university, in trying to support e-learning since their current collection mainly contained local publications. One IM worker in the focus group said lack of funding was the reason why most conventional university libraries depend on local publishers because they could not purchase high-quality international materials, i.e., books, journals, databases, etc. Moreover, he came up with the following queries:

Are government providing funds to public universities for recruiting new staff or for purchasing required resources or for training existing staff at a national or international level to use e-learning? (FGDIMW)

\section{Public institute perspectives}

Like participants' views about the public university, all the participants from the public institute (as one of the three IM education provider organizations) also mentioned that insufficient bandwidth was one of the major problems for the introduction and use of elearning. A director of the institute explained that his parent organization provided a slow internet connection, therefore he decided to get a separate direct internet connection (lk domain ["lk" refers to Sri Lanka and "domain" refers to the internet domain name]) for his institute. He said, after moving to a separate lk domain, the bandwidth was improving. However, now they had the problem of recognition of the institute because they were no longer under the parent organization's domain.

In contrast to the participants' views on the public university, participants from the public institute mentioned their positive perception of government support in terms of allocating funds for improving infrastructure facilities in their institution. Among them a librarian said after May 2009, when the Sri Lankan military defeated the Liberation Tigers of Tamil Elam (LTTE), thus ending 26 years of civil war, they have been receiving good support from the government to provide services according to the current requirements. He further noted that his institutional library had services from the main library attached to the parental organization that provided all the necessary services for students as well as staff. In addition, he expressed pride in his main library which had sufficient resources including e-resources to provide required services for e-learning.

The director of the institute explained how his institute survived without having financial difficulties: 
We are one of the 17 institutions under the university system. Therefore, we get money under the UGC. Also, we generate our own funds [for example, mainly through students' admission and course fees]. Based on these two sources we manage our requirements. (IMEPNIASD)

The same director noted that a national forum called 'Standing Committee of Library and Information Science' provided a platform for him to discuss most institutional issues related to the infrastructure facilities and come up with solutions. He therefore said:

From the UGC level we are getting good support as well as good direction to drive ourselves to do more work and to advertise ourselves to be very useful not only to the university system but to the entire country. (IMEPNIASD)

\section{Private university perspectives}

Participants from the private university as one of the three IM education provider organizations expressed pride in their workplace and were happy to work there because they were satisfied with their organizational infrastructure as compared to other public universities and institutions. For example, they said Wi-Fi facilities were available everywhere in the university and modern infrastructure was used in the lecture rooms, auditoriums, and computer labs. Even the university building was modern architecture. Therefore, they were comfortable working in the university. However, a junior academic said, despite the good infrastructure, her institution faced bandwidth problems. She explained this situation:

We have to try several times to upload the materials into the Moodle LMS. It is a big barrier that we have. Sometimes when all the students try to login concurrently the system may not work. (IMEPSLTSJ)

In contrast, a Dean of the Faculty said, "earlier we had problems related to the internet connection, it was messy. But recently we have introduced new servers and high-speed broadband internet facilities. Now things are getting better" (IMEPSLASD). However, he said as a university they still required additional technological equipment such as cameras to record and capture high quality videos. 
A librarian at the private university reported that her library services were automated and always provided good service for their customers:

Interactive learning space is provided with modern infrastructure. Wi-Fi facilities are available in the library as well as in the reading rooms (which are available in each faculty). Our books and periodical collections are quite small and totally subject-oriented. We also provide access to e-books, e-journals, and online databases. (IMEPSLSSL)

Participants did not mention that funding was a problem in the private university.

\section{E-learning providers' perspectives}

This study found that lack of high speed broadband internet services was also an issue among two out of the three e-learning providers. As a result, they used creative methods occasionally in order to minimize network issues. For example, one director explained the situation:

When more than 2,000 students (who are following different courses) are trying to submit online assignments on the due date in the last hour, our connection becomes slow. Also the server cannot cope with the huge load. Therefore, due dates of the assignments are now spread over two or three weeks. Thus, students can submit their assignments without having any difficulties. (EEPUCPD)

However, the director said these alternative ways to solve issues were not a permanent solution for their network problems. Therefore, he suggested there should be an attempt at the organizational level to have fast broadband facilities. He had two ideas on how it could be achieved. One suggestion was to negotiate with the University Grants Commission to have a fixed and sufficient budget for broadband access. Another suggestion was to negotiate with the Telecommunication Regulatory Commission to have fast broadband at the cheapest price especially for tertiary-level educational providers.

\section{Other stakeholders' perspectives}

All the three government officials who were interviewed in this study agreed that there was a huge gap between public and private universities with regard to availability of reliable infrastructure and facilities. Among them, one director who had experience in working with academics at the public and private universities mentioned that private universities had much better facilities for e-learning. 
Another government official, who was a chairman of the standing committee for his particular subject, explained that the Sri Lankan government placed priorities on other sectors, i.e., defence, health, and provincial councils, and that funding for higher education was low on the priority list. Figure 6.2 shows comparative budgetary allocations for certain sectors, particularly defence, health, education, and provincial councils in 2014 in Sri Lanka.

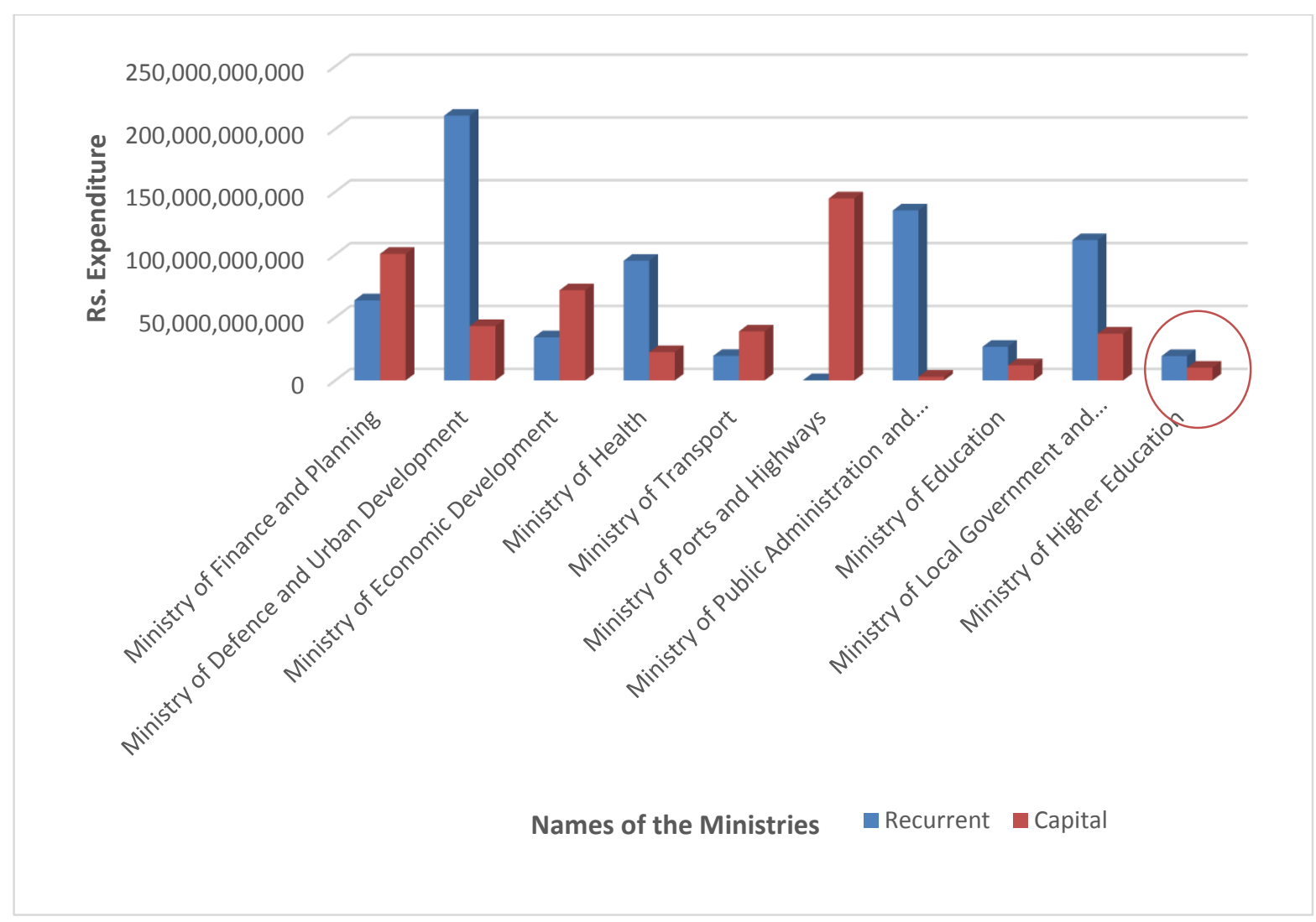

Figure 6.2 - Comparison of Appropriation Bills 2014

Adapted from the Gazette of the Democratic Socialist Republic of Sri Lanka, 2013

As shown in Figure 6.2, the budget allocations for education and higher education were far lower than the allocations for other sectors such as defence and urban development, ports and highways, health, economic development and provincial councils.

The same government official, who was also one of those responsible for providing funds for libraries, said that although IM education providers especially in the public university were in agreement that the government should provide funds and facilities, he had to work within the allocated funds for the university system and could not go beyond that. He continued: 
Although there is a difficulty in getting funds still we are helping them (university sector) to some extent. For example, on top of allocated funds, we have been continuously helping university libraries to automate their libraries. Also, little by little we are encouraging them to subscribe to e-journals and databases. (SHGOUG)

The same government official further said that, although UGC allocates the recurring grants for each university based on their number of students, most university libraries still have difficulties in subscribing to many online resources (i.e., e-journals, e-books, and databases) because within the allocation given to the university they must maintain everything, not only library facilities.

The preceding data discussed in section 6.2 showed that the absence of a job market for instructional designers and content developers was a major issue relating to the lack of staff. Moreover there was a noticeable gap among tertiary-level IM education providers with regard to their infrastructure's reliability and facilities. These issues affected the introduction and use of e-learning in tertiary-level IM education in Sri Lanka.

\subsection{Collaboration/partnership among stakeholders}

Participants from two out of the three IM education provider organizations and all the IM education programme participants in the focus group discussion mentioned the lack of collaboration or partnerships among the stakeholders and thought that could have an impact on the introduction and use of e-learning. All the participants who were interviewed from the two IM education provider organizations (public university and public institute) mentioned that the concept of collaboration was unknown in Sri Lanka and organizations had an individual work mentality. A junior academic at the public university explained the problem as follows:

In Sri Lanka, all the ministries, government departments, universities, and other higherlevel authorities act as isolated bodies and do not have communication with each other. Thus, we do not know what is really happening at the higher level. For example, sometimes ministries or the government plan national-level projects that are related to tertiary education without having consulted with universities. Even the government does not know what the research outputs from the universities are and does not use them for development of the country. Thus, what we do now is competition not collaboration. (IMEPDETSJ)

As mentioned in section 6.2.2, public universities as one of the three IM education provider organizations lacked online databases, e-journals, and e-books. A librarian at 
the same public university said lack of collaboration among university libraries was the problem. He said if there was a consortium approach, university librarians could jointly purchase online databases, e-resources and give access to all the users in the university sector. He therefore said collaboration is one of the innovative ways for minimizing infrastructure problems.

A head of department at the same public university explained how important collaboration or partnership was for the purpose of e-learning. He noted:

Without collaboration there will be many failures because if there is collaboration we can share facilities and resources. For example, we need to collaborate with stakeholders. We need to discuss what we can provide to them and what they can provide to us, what we can all provide for the learners in our society. For this purpose, organization-level and system-level collaboration is required. (IMEPDEASH)

In the focus group discussion, IM education programme participants also expressed similar perspectives. They said collaboration was needed among universities and stakeholders in public and private sectors because there were no institutional partnerships with outsiders. Among them, one IM worker further explained the importance of collaboration:

Collaboration is an important concept in the world. This means as a single unit it is impossible to survive in the present world. Thus, if IM education providers plan to offer e-learning programmes for information workers, they need to identify other resources in different places around the country and start to collaborate with them. If we have that partnership, then it will help to share knowledge, resources, experiences, and definitely will help to reduce issues that have an impact on the use of e-learning. (FGDIMW)

Participants in the e-learning provider organizations did not mention lack of collaboration as a barrier. Participants from one e-learning provider organization, which was established as one of the government initiatives to provide e-learning facilities, explained their external partnerships. They noted they had 30 partner institutes including Ministry-related institutes, public and private organizations, and some universities and institutes in Sri Lanka. However, they said their aim was to make higher profits and therefore collaborated with other private organizations rather than public universities and public institutions. For example, a member of the educational technology support staff said their main partnership was with businesses and private sector people: 
...considering the organizational perspectives, our deputy director is closely working with the private banking and industry sector people. Recently, we therefore started a huge project with the Union Assurance Bank including their branch networks. (EEPNOMET)

The data discussed in this section showed that participants in IM education provider organizations (except for the private university) identified lack of collaboration or partnership as a factor affecting the introduction and use of e-learning in tertiary-level IM education in Sri Lanka. It is also noteworthy that e-learning providers established their partnerships with private banking and industry sector people for financial reasons.

\subsection{Perceptions and attitudes of the IM community}

The first part of this section discusses participants' positive perceptions towards elearning acceptance while the second part discusses perceptions of different groups about learners. Table 6.4 provides a summary.

\begin{tabular}{|l|l|}
\hline \multicolumn{1}{|c|}{ Factors } & \multicolumn{1}{c|}{ Summary } \\
\hline $\begin{array}{l}\text { 6.4.1 Collective perceptions of e-learning } \\
\text { acceptance }\end{array}$ & $\begin{array}{l}\text { Most respondents were positive about e-learning. } \\
\text { They perceived that e-learning provided ease and } \\
\text { equity of access to IM education and benefits for } \\
\text { teaching and IM workers. }\end{array}$ \\
\hline 6.4.2 Alignment of perspectives on learners & $\begin{array}{l}\text { There were two contradictory views about } \\
\text { learners in IM education, i.e., IT literacy and } \\
\text { IT/ICT or Moodle LMS usage. }\end{array}$ \\
\hline
\end{tabular}

Table 6.4 - Summary of the perceptions and attitudes of the IM community

\subsubsection{Collective perceptions of e-learning acceptance}

Most respondents were positive about e-learning. Four out of the six administrative staff and all the support staff in the three IM education provider organizations had positive perceptions of e-learning acceptance. Among them, a librarian at the private university said she definitely accepted e-learning. She believed her profession required her to service the demand. A similar opinion was echoed by another librarian at the public university. He also expressed his positive perception and said willingly or unwillingly we 
should accept e-learning in order to continue librarianship in the $21^{\text {st }}$ century. He believed otherwise his profession would be at risk. He explained the reason:

Technology is improving and moving at an unbelievable rate. Thus, librarians have to play a pioneer role and, along with administrators and users, move towards e-learning. If we do not integrate technological advancement with our profession, we will fail and somebody will take our job. (IMEPDESSL)

He concluded by saying "at least we should try not to reject it. If we reject it, that is the end of the story" (IMEPDESSL).

A Dean of the Faculty in the public university said, "we are quite late in the use of elearning" (IMEPDEASD). He further noted that from generation to generation a lot of things were changing. For example, he said his generation preferred to read books but new generations preferred to use new technology to search for information via the internet rather than read a book. He therefore said that whether we like it or not we had to accept e-learning. He said:

Human beings need to change according to their environment for survival. Likewise we also have to change according to the technological developments in the world. (IMEPDEASD)

Academics at the public university and public institute mentioned that e-learning awareness-building programmes were necessary for e-learning acceptance. They believed e-learning was still a new concept for many students and staff in tertiary-level IM education and some aspects of it might be poorly understood. Therefore, academics from the public university and public institute similarly shared the view that raising awareness and improving understanding of the complete situation should help towards acceptance of e-learning.

Academics at the private university said although there were some problems with using e-learning (e.g. issues discussed in earlier sections) they had already adopted and are using e-learning in their university as a supplementary tool.

Participants from one of the three e-learning provider organizations pointed out that elearning was already accepted in Sri Lanka. For example, a member of the educational technology support team said the Sri Lankan government had initiated four major projects (particularly e-learning-related) with the help of Asian Development Bank (ADB) 
funds, namely: i) Distance Education Modernization Project; ii) Distance Education Partnership Programme; iii) Secondary Education Modernization Project; and iv) Education for Knowledge Society Project (Goals, components, and outcomes of these four projects are shown in Appendix 9). He said these programmes demonstrated the willingness to try as well as acceptance of e-learning in Sri Lanka.

However, one director with more than ten years of experience working in tertiary-level education mentioned that acceptance of changes was a little slow in the Sri Lankan context. He shared his experience and noted one example:

I had so many difficulties introducing quality assurance (QA) in the university sector. It took more than five years to change the mindset of the staff. (SHGOQA)

He also echoed the comments from academics at the public university and institute and noted acceptance was quick after understanding the value and advantages of using QA. Likewise he suggested there should be a formal way of educating academics and students about e-learning in order to bring e-learning acceptance to a satisfactory level.

This study found that participants perceived e-learning as a solution for some of the problems faced by tertiary-level IM education. This belief seemed to positively affect their perceptions of e-learning acceptance and the introduction and use of e-learning in IM education. This will be discussed in the following sub-section.

\subsubsection{Perceived usefulness of e-learning}

Two-thirds of the participants in each category - i.e., IM education providers, current elearning providers, other stakeholders (e.g., government officials), and IM education programme participants - mentioned that e-learning could be a great opportunity for providing ease and equity of access to IM education. For example, this comment was echoed by many participants in the IM education provider category: "e-learning is more useful for IM workers to get the required qualifications because they face distance barriers to accessing IM education". A Dean of the Faculty at the public university noted e-learning was a very convenient mode of education for IM workers in rural areas because he noticed in the current system IM workers were wasting time and money travelling to Colombo or the area around it. A junior academic at the public institute said 
if there was an e-learning system, IM workers would not need to apply for leave to attend the classes.

In the focus group discussion, IM education programme participants shared a number of examples to show some difficulties with the present IM education system. One IM worker from a rural area said:

I start my journey on Friday evening to attend the classes on weekends and I travel more than 8 hours by bus to reach Colombo. After my classes, I reach home early morning on Monday and the same day I have to go to my workplace too. This is terrible and so painful a thing for me. My weight has dropped from $45 \mathrm{~kg}$ to $32 \mathrm{~kg}$. (FGDIMW)

Another IM worker from a rural area shared her experience and said even though she was sick sometimes, she still had to attend the classes. If she missed one class then she could not catch up on the lessons of that day. She said most students (including her) travelled long distances; therefore, they had to come to the class on time and leave the class early. Therefore, she did not have time to meet other students and discuss lessons that she had not attended. She said the present IM education system was inconvenient as well as a waste of money, energy, and time.

Due to the inconvenience of the present IM education system, the focus group participants (i.e., IM education programme participants) similarly commented that if an institute or university introduced e-learning in IM education, they would be happy to use it. They said it would be a more feasible comfortable way to access IM education. For example, one IM worker pointed out that not only was there the problem of travelling long distances, but also there were IM workers with family and physical problems such as workers with babies or disabled workers. He therefore said e-learning would provide an equal opportunity for these groups of people to continue their lifelong learning.

Academics at the private university shared their experience of working with the elearning system as a supplementary tool at the internal level in their university and expressed how useful e-learning was in terms of their job performance. A senior academic said marking exams was easy through the e-learning mode. She continued:

We are conducting mid-term examinations through quizzes using Moodle LMS. At the end of the exam students get the results on the spot, they are so happy. We are also happy 
because we do not need to allocate time for marking and we can use that time for other academic purposes. (IMEPSLTSS)

A junior academic at the same private university said now their programmes were costeffective in terms of resources. She further noted since all the lecture handouts and reading materials were stored online they did not need to photocopy these materials before the lessons.

Similarly, ten out of the twelve participants in the e-learning provider category also noted e-learning programmes were cost-effective regarding resources. For example, one programme director explained that updating course materials was quick in the e-learning system. In her institution, they also issued printed course materials which are revised every 5 years. She therefore said supplements or updated versions could be made available online very quickly and all the resources could be viewed on one site which was a marvellous opportunity for students as well as academics.

In line with the academics' views, participants in the e-learning provider category and stakeholders' group pointed out that e-learning was useful for employees due to its flexibility in time and location. A member of the educational technology support staff said e-learning might improve students' skills if collaborative e-learning programmes include relevant activities and resources. He believed these types of programmes give hands-on experience to the students and that might help them to become innovative later in their workplaces. For example, he said IM workers could use their e-learning experiences for developing or organizing information literacy courses in their libraries, possibly delivered online.

One director in the stakeholder category shared his personal experience regarding elearning:

While I was doing my job, I did one diploma via e-learning with UNESCO. It was about quality assurance. There I participated in online discussions and group activities and submitted online assignments. That was a new and fantastic experience I had never had before. Within a short period I learned more than I did in my conventional undergraduate programme. (SHGOQA)

He therefore said for employees, e-learning was a good way of getting higher education (SHGOQA). 
Participants in the e-learning provider category further noted e-learning as one of the ways of broadening access to education which was an important factor for the development of the country. Among them one programme director explained a major problem they faced:

From the late 1990s the industry was complaining that we are not producing adequate IT graduates. The solution was not simply increasing the number of graduates from the traditional universities as we lacked space and had staff problems. (EEPUCPD)

The same programme director said they therefore started an e-learning programme in 2002 as a solution for increasing numbers of IT graduates. Moreover, he said there was still a huge demand for external degrees because university education is highly competitive and students want to get a degree as soon as possible while also doing a job. He concluded e-learning was vital to serve the demand because e-learning is flexible.

\subsubsection{Alignment of perspectives on learners}

Analysis of the interview and focus group data revealed that perceptions of different groups about their learners had an impact on the introduction and use of e-learning in tertiary-level IM education in Sri Lanka. These perspectives are discussed under two contradictory views: IT literacy, and IT/ICT or Moodle Learning Management System (LMS) usage. Table 6.5 summarizes participants' perceptions.

\begin{tabular}{|c|l|l|l|}
\hline $\begin{array}{c}\text { Contradictory } \\
\text { views }\end{array}$ & \multicolumn{1}{|c|}{$\begin{array}{c}\text { Academics' } \\
\text { perceptions }\end{array}$} & Students' perceptions & $\begin{array}{l}\text { Other participants' } \\
\text { perceptions* }\end{array}$ \\
\hline 6.4.2.1 IT literacy & $\begin{array}{l}\text { Students in rural } \\
\text { sectors had greater } \\
\text { computer literacy } \\
\text { problems than students } \\
\text { in urban sectors. }\end{array}$ & $\begin{array}{l}\text { Students' actual problem } \\
\text { was lack of access to } \\
\text { technology (individual } \\
\text { level) not the lack of IT } \\
\text { literacy. }\end{array}$ & $\begin{array}{l}\text { There was no difference in } \\
\text { IT literacy among students } \\
\text { in urban and rural sectors. } \\
\text { However, senior but older } \\
\text { academics' IT literacy was } \\
\text { questionable. }\end{array}$ \\
\hline $\begin{array}{c}\text { 6.4.2.2 IT/ICT or } \\
\text { Moodle }\end{array}$ & $\begin{array}{l}\text { Even though their } \\
\text { institution provides } \\
\text { computer and internet } \\
\text { facilities, students did } \\
\text { not use them and thus } \\
\text { did not benefit from } \\
\text { them. }\end{array}$ & $\begin{array}{l}\text { Although students } \\
\text { wanted to use computer } \\
\text { and internet facilities } \\
\text { they were unable to do so } \\
\text { due to time constraints. }\end{array}$ & $\begin{array}{l}\text { Students' usage of IT } / \text { ICT } \\
\text { Moodle LMS was at a } \\
\text { satisfactory level but } \\
\text { academics' usage of } \\
\text { technology was variable. }\end{array}$ \\
\hline
\end{tabular}

Table 6.5 - Summary of perceptions about learners

*Other participants include administrative and support staff in the IM education providers' category and all the participants in the e-learning provider category. 


\subsubsection{ICT literacy}

In the public university, academics' views about their learners were not consistent with the students' perspectives. For example, senior and junior academics at the public university who were interviewed in this study reported that students in rural areas had greater computer literacy problems than students in urban areas and these variations affected the introduction and use of e-learning in tertiary-level IM education. However, in the focus group discussion IM workers (as a student group) stated that their actual problem was lack of access to technology, not the lack of computer literacy. Among them one rural IM worker mentioned:

Although I am in a rural area and I do not have personal facilities to use information technology, I have basic IT literacy skills. Since a few years back there has been a trend among students to take computer and English courses during the time between A/L exams and university entrance. Thus, most students in my area are IT-literate. (FGDIMW)

Compared with students' perspectives, eight out of the twelve administrative and support staff in the IM education providers' category and all the participants in the e-learning provider category pointed out that presently, there was no difference in IT literacy among students in urban and rural areas. Among them a member of the educational technology support team in the e-learning provider category mentioned that most students had experience of using information technology. According to his personal experience, he noted:

I have conducted a workshop for students coming from urban and rural areas on how to use LMS. Students' attendance at that workshop was around $85 \%$ to $90 \%$. There I found that students are pretty good at using technology. According to my informal surveys, I also found that $90-95 \%$ have a Facebook account and they regularly use it. (EEPOUMET)

Similarly, a librarian at the public university from the IM education provider category conducted surveys in 2005-2006 and 2010-2011 and found that students' IT literacy has greatly improved. He therefore did not believe that students' IT literacy was an actual problem. Nevertheless, he believed that perhaps IT literacy could be a problem regarding senior or older academics.

Academics from the public institute and private university did not mention different levels of IT literacy among students in urban and rural areas or identify this as a barrier to the use of e-learning in tertiary-level IM education in Sri Lanka. Among them a male 
junior academic who worked as a librarian at the public institute and also had more experience engaging with IM students in rural areas said some rural students use computers better than urban students. He provided the following example:

...there is one teacher librarian [IM student] from Ananda College, Colombo [urban area]. She can't use computers. There is another teacher librarian from Kalawana [rural area]. She uses the computer very well. (IMEPNITSJ/SSL)

However, four out of the six senior and junior academics across the three IM education provider organizations who were interviewed in this study claimed that there was a lack of IT/ICT or Moodle LMS usage by students. These perspectives were also not consistent with the students' perspectives and this is discussed in the next section.

\subsubsection{Motivation to use IT/ICT or Moodle LMS}

A senior academic at the public institute claimed that even though their institution provides computer and internet facilities, students did not take advantage of them. He said, "we have two labs with internet connections, one with 20 computers and the other with 10 computers. But students hardly use those resources" (IMEPNITSS).

In the focus group discussion IM education programme participants offered a possible explanation. Among them one IM worker at the same public institute said although they wanted to use computer and internet facilities they were unable to do so due to time constraints. He explained this situation:

We have enough resources in this institution. The problem is we don't have enough time to use those resources. We come from faraway places and we come on time to our classes and at the end of the day we try to leave the class as soon as possible to catch a bus or train. Therefore, we only do the things we do in the classroom. We can't come on another day to use the resources since we have to do our job on weekdays. (FGDIMW)

Other junior and senior academics at the private university (where an e-learning system was used as a supplementary tool) claimed that students' usage of the Moodle LMS was not at a satisfactory level. Among them a junior academic explained this situation:

Even though we tell our students to go through the materials that are posted on the course web site, most students still do not use it. They are pretty reluctant to use these facilities. Most of the time when we post something on Moodle, they normally say we didn't see it or we didn't know it was there. (IMEPSLTSJ) 
Nevertheless, different opinions were voiced by other participants (administrative and support staff) at the same private university. Among them a Dean of the Faculty expressed a totally different view from his academics. He said:

I am very happy about our students' Moodle LMS usage. Not only do they use it after classes and lab hours, they also access our LMS outside of the university. For example, sometimes we get complaints about the LMS from our students. If something happens to our system, we get most of the complaints simultaneously. That means they are quite frequently accessing the materials in our Moodle LMS. (IMEPSLASD)

A technical support staff member at the same private university also said students were curious about what was uploaded on the Moodle LMS. He further noted:

Students like to have lecture materials before the lecture is delivered because they are used to taking notes on the downloaded materials during the lectures. (IMEPSLSST)

The same participant further said, however, that students sometimes lose their motivation to use Moodle because of sometimes not having learning materials in advance. As he explained:

Even though a particular link has been allocated for academics for their particular course, some academics do not upload materials to Moodle. They are used to providing handouts for students within the classroom. (IMEPSLSST)

Seven out of nine participants from the e-learning provider category mentioned that students' enthusiasm regarding the Moodle LMS was increasing year by year. Among them a member of the learning resource support team expressed her view based on her personal observation. She said:

If we get delays in opening up the online class, students contact us. 'Ah...this is not available', 'when will that be available?' because they are looking forward to taking that information from the Moodle class. (EEPOUMLRS)

There was another example given by the other member of the learning resource support team who said that in his view over the years students were becoming more familiar with the technological environment which could be a problem with the current academics' lack of interest in moving to new technology-based education. 
One director in the e-learning provider category also mentioned that his problem was senior academics' technology usage. He said although their institution was given facilities such as laptop and home internet connections in order for senior academics to improve their e-learning system, nothing has happened. He noted:

Except for the improvement of email communication, from the e-learning aspect, I am not exactly sure to what extent it has helped because from the students' point of view getting the results on time or availability of course materials on time is still not achieved. (EEPUCPD)

As discussed in section 6.1.2.1, academics affirmed that they did not feel competent enough to use advanced IT for teaching purposes. Moreover, academics noted that they lack knowledge and skills particularly in three areas of including technology in teaching, i.e., lack of knowledge of pedagogy, lack of understanding of how technology and content influence and constrain one another, and how teaching and learning change when particular technologies are applied.

The preceding data discussed in section 6.4.1 showed that most respondents were positive about e-learning. In section 6.4.2, the findings showed that academics' views on their learners, e.g., lack of IT literacy among rural students and lack of IT/ICT or Moodle LMS usage, were not consistent with the students' as well as other participants' (administrative and support staff) perspectives. These incorrect assumptions may have a negative impact on the introduction and use of e-learning in tertiary-level IM education in Sri Lanka. Further, other participants (administrative and support staff) in the IM education provider and e-learning provider categories identified senior (and older) academics' lack of IT literacy and IT usage as a potential factor affecting the introduction and use of e-learning.

\subsection{Chapter summary}

In this Chapter four main meso-level factors that had significant impact on the introduction and use of e-learning in tertiary-level IM education in Sri Lanka have been discussed: lack of enthusiasm for changing pedagogy, lack of staff and other resources, lack of collaboration, and perceptions and attitudes of the IM community. 
According to the study findings, heavy workload and lack of knowledge and skills had an influence on academics' lack of enthusiasm for changing teaching methods from instructivist to constructivist-based pedagogy. This study found that absence of a job market for instructional designers as well as content developers was a major issue relating to the lack of suitable staff. There was also a notable gap among tertiary-level IM education providers regarding the reliability of their infrastructure and facilities. Moreover, this study found that collaboration was absent in Sri Lanka and an individual work mentality was dominant. This lack of partnership also existed among stakeholders and that could have an impact on the use of e-learning. This study further found that academics' incorrect assumptions (i.e., lack of IT literacy among rural students and lack of IT/ICT or Moodle LMS usage) about learners were negatively affecting the use of elearning in tertiary-level IM education in Sri Lanka. Apart from these barriers, more importantly most participants of this study were positive about e-learning because they recognized that e-learning provides ease and equity of access to IM education and benefits for teaching and IM workers. 


\section{CHAPTER 7 - DISCUSSION}

This Chapter synthesizes and discusses the findings presented in Chapters 5 and 6, underlining the macro-level and meso-level factors that have an impact on the introduction and use of e-learning in tertiary-level IM education in Sri Lanka. It uses the findings to address the research questions. The conceptual model presented in Chapter 3 is revised according to the findings and the discussion and presented in the next Chapter. The theoretical and practical implications of the findings are discussed in this Chapter.

The study addresses the following research questions:

1. What are the contextual factors that have significant impact on the introduction and use of e-learning in tertiary-level IM education in Sri Lanka?

2. How do these factors affect the introduction and use of e-learning in tertiary-level IM education in Sri Lanka?

Each of these research questions is discussed in the following sub-sections. Discussion of each sub-section is related to the literature review in Chapter 2, theoretical considerations in Chapter 3, and the findings that emerged from the data analysis in Chapters 5 and 6. Discussion of some of the factors will also relate to the recent studies which have identified critical success factors for e-learning implementation with a particular focus on the developing country context.

\subsection{The contextual factors that have an impact on the introduction and use of e-learning in tertiary-level IM education in Sri Lanka}

From my analysis of the data, I developed a two-level table (Table 7.1) of factors. This two-level table outlines the contextual factors that are perceived to have an impact on the introduction and use of e-learning in tertiary-level IM education in Sri Lanka. These contextual factors are categorized into two levels: macro-level and meso-level factors. 


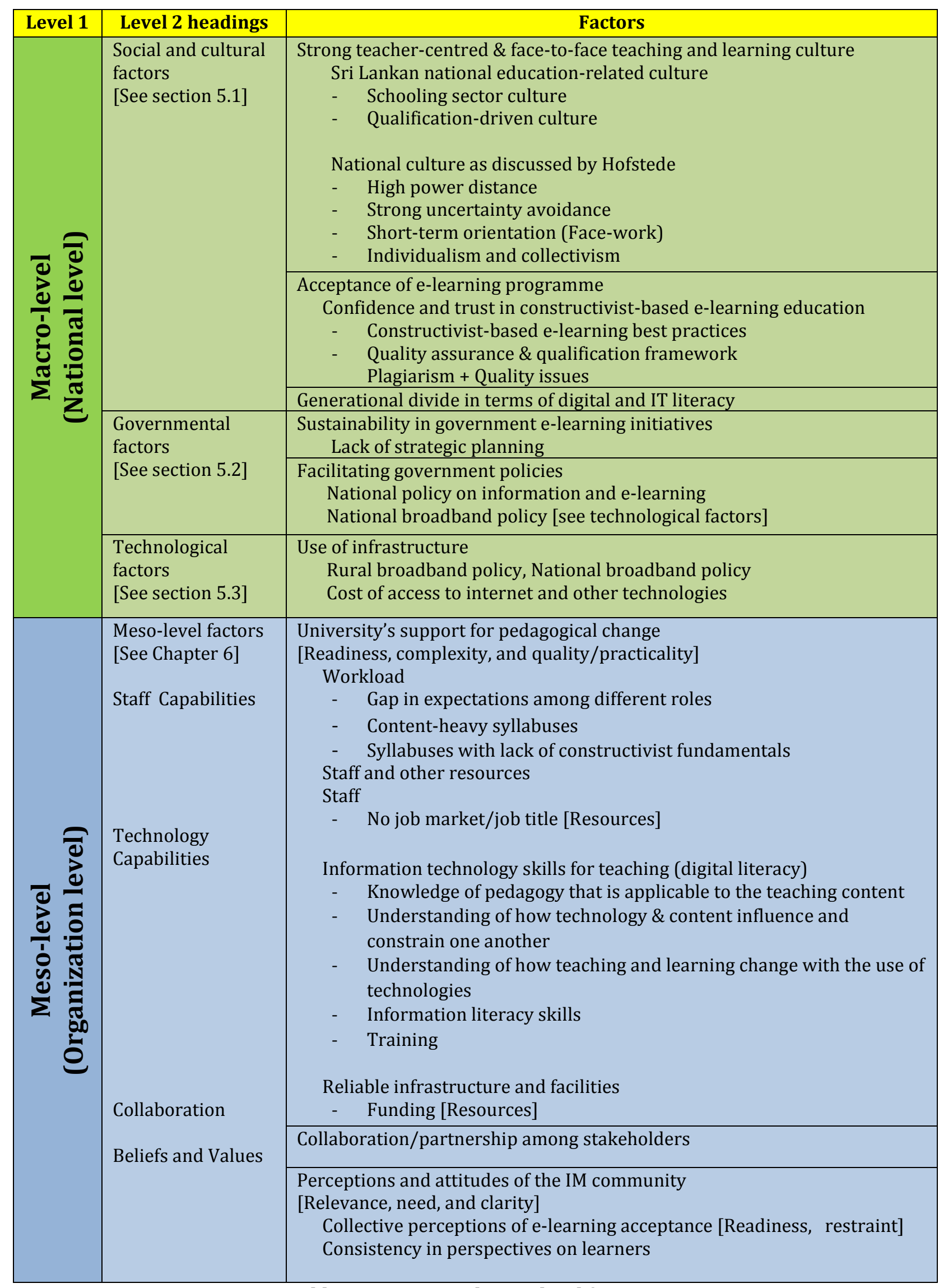

Table 7.1: Macro- and meso-level factors 
Chapters 5 and 6 provided specific examples from the interview data that demonstrate how each of these contextual factors in Table 7.1 is perceived to have an impact on the introduction and use of e-learning. The following section will discuss each of these factors (as well as the inter-connectedness of each factor) in relation to the literature review and theories used in this study.

\subsection{How contextual factors affect the introduction and use of e-learning in tertiary-level IM education in Sri Lanka}

\subsubsection{Macro-level factors}

Macro-level factors include social and cultural factors, governmental factors, and technological factors.

\subsubsection{Social and cultural factors}

This study found that social and cultural factors are among the key barriers to the introduction and use of constructivist e-learning. As shown in Table 7.1, social and cultural factors include the entrenched teacher-centred and face-to-face teaching and learning culture, lack of acceptance of e-learning programmes in Sri Lankan society, and a generational divide in digital and IT literacy.

\section{Entrenched teacher-centred and face-to-face teaching and learning culture}

In my analysis of the data, I found that there is a lack of readiness to move towards the use of student-centred pedagogy because of the long-standing teacher-centred and faceto-face teaching and learning culture in the Sri Lankan context. The majority of interviewees in all groups described how Sri Lankan national education-related cultures and national cultures as discussed by Hofstede contribute to this highly teacher-centred teaching and learning culture.

Previous studies have identified critical success factors for e-learning implementation based on the organizational level. In this study, I identified factors from the macro level (national level) as well as meso level. As a result, I discovered that unique cultural aspects of the education environment in the Sri Lankan context matter greatly when introducing or using e-learning. Section 5.1.1.2 in Chapter 5 provided some specific examples of interview data describing how unique cultural aspects (e.g. the schooling sector culture 
and the qualifications-driven culture) reinforce teacher-centred education. The same section also gave examples of how this unique cultural aspect has an effect on the student's learning approach especially in an e-learning environment. These unique national culture aspects in turn affect students' lack of experiences and skills that would otherwise suit constructivist education. This situation has been described in the New Educational Act for General Education in Sri Lanka as follows:

The youth leaving our schools today demonstrate weakness in both critical and creative thinking. They lack social skills of working in groups, communicating with others, listening empathetically to others, caring for and sharing with others, and taking leadership and followership as necessary in group situations. Emotional balance, stress management, initiative, orientation to change, responsibility, accountability, commitment and self-discipline are some personal skills that our youth have failed to develop while in school. (National Educational Commission, Sri Lanka, 2009, p. 76)

This characteristic of schooling sector culture has therefore influenced students' entire lives. For example, as noted in section 5.1.1.2.1, IM workers as a student group in this study explained that they had been conditioned by the school culture (where a teachercentred method is dominant) for more than 13 years before they came to the university. As a result, the experience they had during their school time had influenced their approach to tertiary education. IM workers, therefore, suggested that school curricula need to be revised according to present-day requirements and thereby to develop students' skills from school level. To overcome the problems like students' lack of experiences and skills, the New Education Act for General Education (National Educational Commission, Sri Lanka, 2009) introduced a set of new student-centred education approaches to learning and teaching into the Sri Lankan system. Previous literature indicated that e-learning promotes active learning by providing many opportunities for media-based, student-centred, as well as interactive learning environments (Huffaker \& Calvert, 2003; Zhang, Zhao, Zhou, \& Nunamaker, 2004). Therefore, e-learners must be active in the process and should have relevant skills to move towards constructivist e-learning.

As discussed in the literature review in Chapter 2, one of the fundamental requirements of the Sri Lankan government is also to move towards constructivist and collaborative elearning. There is an implicit assumption among government officials that moving towards constructivist and collaborative e-learning will fix the problems that were 
outlined in Chapter 1, but to date, there is no empirical evidence to confirm this. However, the government has initiated several projects at national level as well as in the secondary and tertiary-level education systems to help move towards constructivist and collaborative e-learning (See Appendix 9). Among them, the Ministry of Education with the help of the Asian Development Bank started two phases of the Secondary Education Modernization project (SEMP), Phase I 2001-2006, and Phase II 2005-2009. This project established a web portal called 'SchoolNet' that brings all organizations related to school education online and provides a novel learning and teaching environment for students and teachers. Moreover, the government of Sri Lanka has formulated the National Policy on Information Technology in School Education (NPITSE) with the following vision but there is no indication of how this vision will be facilitated.

A generation of Sri Lankans empowered with Information and Communication Technology and to facilitate the planning, implementation, and sustenance of information technology education in schools to enhance students' learning and quality of teaching. (Ministry of Education, Sri Lanka, 2001)

Followed by the NPITSE, in 2001, the subject General Information Technology (GIT) was introduced for G.C.E. advanced-level examinations while in 2008 the subject Information Technology (IT) was included in General Certificate of Education (G.C.E.) ordinary-level examinations. Although the government has taken steps to encourage constructivist and IT education from school level, previous literature has identified some of the ongoing issues. For example, De Silva (2007) identified that students' performance has not improved as the government wants it to due to the following issues:

1. Lack of initiatives to improve the capabilities, motivation, and classroom practice of teachers

2. Insufficient computer laboratories for practical work

3. Insufficient number of well-trained, specialized teachers in IT in the school system

4. Insufficient teaching and learning material in the form of books, tutorials, instruction manuals and e-learning content

5. Insufficient number of periods allocated in the school timetable for teaching IT (De Silva, 2007, p. 5)

The evidence above suggests that lack of strategic planning by the government to achieve project and programme goals may be the reason why schooling sector culture still reinforces teacher-centred education and why students are lacking experiences and skills that suit constructivist education. Evaluation of government initiatives related to 
secondary or tertiary education on improving constructive and collaborative learning and teaching culture was not the focus of my study, but this has emerged as an aspect that warrants investigation.

The literature has suggested that one of the fundamental requirements of constructivist e-learning is that students should be active learners, not passive recipients of packaged information (Andersson, Hedstorm, \& Gronlund, 2009). Constructivist philosophy accommodates a family of closely-related pedagogies, which optimize the potential of elearning environments. These include collaborative learning (McConnell, 2001), activitybased learning (Macdonald \& Twining, 2002), resource-based learning (Macdonald, Heap, \& Mason, 2001) and problem-solving learning (Ronteltap \& Eurelings, 2002). These pedagogies provide opportunities for students to learn by engaging in activities that may involve collaborative work, and shared problem solving. In my study, I found that a lack of experiences and skills that suit constructivist education and a lack of familiarity with student-centred education affect information workers as learners in elearning in IM education. This is in line with a previous study conducted by Fernando (2008), who found that socio-cultural settings in South Asian countries affect how people engage in learning activities such as verbal and physical interaction, and their attitudes towards e-learning. The findings are consistent with Hofstede, Hofstede, and Minkov's (2010) cultural dimensions, and those of Toland, Frank, and Schenk (2005), Siritongthaworn et al. (2006), and Kawachi (2003). All of these scholars have found that high power-distance countries and highly collectivist cultures lead to passive learning rather than active or collaborative learning.

This passive learning style in turn affects online discussion forums, one of the major features of an e-learning platform. As identified in section 5.1.1, students were hesitant to post answers in online discussion forums because they assumed that someone might be criticizing their work. As described by Hofstede, Hofstede, and Minkov (2010), Wang (2007), and Strother (2003), in high power distance societies, students learn passively and they feel uncomfortable answering questions in front of their peers and performing other interactive tasks. Strother (2003) argues that in e-learning environments, however, such students can contribute to the forums, chats, and virtual whiteboards somewhat anonymously and may feel safe doing so. However in my research, I found that current elearning providers still face the same problem of getting students to actively participate 
in online discussions. This may be due to the influence of the unique national culture. For example, as I discussed earlier in this section, students have been conditioned by the teacher-centred learning culture over a long period of time and this may be influencing students to play a passive role in online discussions in e-learning programmes. I found that some organizational factors, including the way syllabuses and courses are designed and taught, also affect students' lack of contribution to the online discussion forums and these will be discussed under the meso-level factors in section 7.2.2.

In the Sri Lankan social culture, there is also a noticeable respect for teachers. This is another reason why students play a passive role. A programme director of an e-learning provider who had years of experience working with academic staff said that some teachers see students asking questions or students becoming more active as challenges to their authority. As a result, even during a face-to-face class there are no discussions between teacher and students. However, in my analysis of the data, I found that conversations took place privately outside the classroom teaching. This is an indication that, due to the higher degree of respect for the teaching profession in Sri Lankan society, students do not want to threaten the 'face' of their teachers. Similarly, Young, Kuo and Myers (2012) found that in a strong collectivist culture having conversations with teachers is to do with 'face-work'. This cultural characteristic has been defined as 'shortterm orientation' by Hofstede, Hofstede, and Minkov (2010). Although they ranked Sri Lankan social culture in the middle level of the LTO (long-term orientation) scale, my study data suggested that Sri Lankan education culture is more short-term oriented and more concerned with 'face' and respect for traditions. This does not necessarily mean, though, that there is no student-centred teaching and learning environment. It is happening outside classes. For example, students meet their teachers after a class if they want to ask questions or to clarify something. This raises a further question as to how elearning platforms could emulate this type of 'out-of-classroom' discussion area for students in e-learning.

Existing traditions of private discussion could potentially be simulated by new technology. For example synchronous Skype sessions such as audio/video chat produce private discussions (Strang, 2012). McCalla (2004) introduced an open peer system called 'I-Help' to support e-learning. This has two components: I-Help Pub (public discussion component) and I-Help 1-on-1 (private discussion component). Chat rooms in 
the virtual learning environments (VLEs) also allow for private conversation (Ellaway \& Masters, 2008; New Zealand Council for Education Research, 2004). It is evident that there is a lack of awareness about recent technologies among academics in tertiary-level IM education. As a result, private discussion areas do not exist in current e-learning programmes in Sri Lanka.

Respect for teachers also has an impact on a specific aspect of e-learning: collaboration. If teachers change their pedagogical approach from instructivist to constructivist, the teachers' role moves to more of a facilitator role. For example, as discussed in section 5.1.1.1, a librarian at the public institute (a support staff member) commented how the 'students' style' changed from passive learning to active learning when the teacher experimented with a constructivist approach in the face-to-face teaching and learning environment. I further found that changing pedagogy depends on governmental and organizational support as well as teachers' ability to change their pedagogical approach. This will be discussed further under the meso-level factors in section 7.2.2.

Being part of the unique national culture, some interviewees in my study commented that at all levels of education (i.e., primary, secondary, and tertiary) in Sri Lanka there was a preference for a structured learning environment with definite objectives, detailed assignments, and strict timetables. In this situation, students expect their teachers to be experts who have all the answers. Students then follow the teachers' instruction $100 \%$ with the objective of answering examination questions and thereby getting a certificate or a degree. Employees in the IM industry mostly seek qualifications to help them gain promotions at work. However, they often do not necessarily take a course to help improve their knowledge and skills to perform better in their role. This cultural characteristic has been defined as 'strong/high uncertainty avoidance' by Hofstede, Hofstede, and Minkov (2010). These authors found that Sri Lanka has a relatively high-level value on uncertainty avoidance. For example, avoiding student-led 'answer' discovery, and adapting to unfamiliar systems or methods (i.e., student-centred method) would confront teachers as well as students with considerable uncertainty. This could be one of the reasons for the established teacher-centred and face-to-face teaching and learning culture in Sri Lanka. My study findings therefore suggest that there is a need for enhancing the awareness of student-centred learning culture in the Sri Lankan education system. This suggestion is closely in line with Strother (2003) who claimed that once the 
students get over issues of adapting to a new and unfamiliar system or methods (i.e., student-centred method), they can adjust to new conditions.

The Sri Lankan government introduced a new Educational Act in 2009 to change the Sri Lankan general education system as well as the higher education system to reflect a policy of student-centred education. In my analysis of the data, I found that academics are happy to retain full control of the classroom and its activities (i.e., retain a role as the centre of instruction). They prefer to use teacher-centred pedagogy and they lack confidence in their students' abilities to undertake independent studies without having academics' guidance and their instruction. This may be the reason why academics express inconsistent perspectives on their learners. For example, as explained in Summary Table 6.5 in section 6.4 .2 , academics claimed that their students were lacking in IT literacy and they were not motivated to use IT/ICT or the Moodle Learning Management System. However, the students' actual problem was lack of individual-level access to technology and their lack of time to access institutional-level IT facilities. Most academics reported that their administrative staff (Deans of the Faculties and other relevant staff) generally believe the teacher-centred style is the established method in the Sri Lankan context. Fullan (2001) has explained that leaders need to understand the change process and they need to inform their staff about the meaning of the change (i.e., vision/mission) because staff have to know what the purpose of the change is. This takes into consideration both the means and end of the change process. Makrakis (2010) has suggested that pedagogical leaders include not only administrative personnel, but also ordinary teachers/academics because they are the leaders who need to change their pedagogy and to change their students' learning style. The evidence above suggests that there is a lack of change management perspectives and lack of change agents in the Sri Lankan education system to move from teacher-centred to student-centred pedagogy.

As discussed in the above paragraph, this study suggests that academics in IM education still prefer to use their familiar traditional instructivist pedagogy. This pedagogical tradition has also been identified by other researchers (Moussa \& Moussa, 2009; Andersson \& Gronlund, 2009; Oroma, Wanga, \& Fredrick, 2012) as one of the main problems in establishing constructivist e-learning in developing countries. Among them Andersson and Gronlund (2009) reviewed 60 research papers on e-learning challenges in developing countries. They identified teachers' instructivist pedagogy as a major 
challenge for e-learning course design as well as a challenge for teachers' competence in online teaching. Academics' instructivist pedagogical tradition can be seen as strongly aligned with power distance and uncertainty avoidance as discussed by Hofstede, Hofstede, and Minkov (2010). For example, in high power distance countries teachers/academics are likely to control the instruction process and content and prefer to keep themselves as the 'centre of instruction'. People in strong uncertainty avoidance countries are unlikely to accept unfamiliar risks, and learning a new way of teaching would confront teachers with considerable uncertainty. Similarly, administrative-level staff (including Deans of Faculty, and other staff) in the tertiary-level IM education provider organizations are also very likely to continue to assert and accept the teachercentred style as an appropriate method in Sri Lankan society. This absence of leaders to act as change agents to move towards student-centred teaching and learning is perceived by academics to be a barrier for putting policy into practice. The evidence above therefore suggests that there is a lack of change management perspectives or strategic planning at the national level to see the policy through into practice. The government officers who were interviewed in this study said that they had only recently understood the requirement for significant change management and strategic planning if Sri Lanka is to move towards constructivist pedagogy.

From my analysis of the data, I found that instructivist e-learning is dominant in tertiarylevel IM education. However, the aim of the Sri Lankan government is to promote elearning with a student-centred approach. The Sri Lankan national educational culture and national culture as discussed by Hofstede emerged as a barrier that must be addressed in order to successfully introduce and use constructivist e-learning in tertiarylevel IM education in Sri Lanka.

\section{Acceptance of e-learning programmes}

The majority of interviewees stated that low acceptance of e-learning programmes and lack of policies and strategies to establish recognition for qualifications gained through e-learning in Sri Lankan society was an important factor that affected the introduction and use of e-learning programmes in tertiary-level IM education.

The dominant teacher-centred and face-to-face teaching and learning culture are perceived to have a significant impact on the lack of acceptance of e-learning 
programmes. For example, 'needing to see' teachers and fellow students or 'physical presence' is an integral part of the traditional method of teaching and learning culture in Sri Lanka. As explained by Hall $(1976,2000)$ communication in high-context societies/cultures (Asian countries including Sri Lanka) is more indirect and words are less important than context. Meaning is gathered through tone of voice, use of silence, facial expression, body language and the status of the speaker. This cultural influence may be the reason why 'needing to see' is important which results in a lack of recognition for the qualifications gained through e-learning. However, previous studies have shown that new technologies can create an e-learning environment to emulate a real classroom. For example, Di Lecce, Giove and Quarto (2009) identified that virtual classroom tools including conferencing applications can create the sense of social presence between students and teachers. This virtual classroom allows for a high level of interaction by means of video, chat, lecture presentation, application sharing, and questionnaires. Combinations of all these elements can create classroom-like interaction between students and teacher in an e-learning environment. Similarly, Strang (2012) found that a synchronous Skype session including audio/video chat and document sharing can produce face-to-face contact very easily in an e-learning environment. The evidence above suggests that there is a lack of awareness about the latest technologies among academics and e-learning providers in the Sri Lankan context. As a result, face-to-face interaction (synchronous sessions) does not exist in most of the current e-learning programmes in Sri Lanka which in turn affects recognition for the qualifications gained through e-learning.

There is also a lack of policies and strategies in the Sri Lankan education system to establish equal recognition for qualifications gained through the traditional education system and those gained through e-learning. The literature has suggested that traditional quality measures associated with accreditation do not match the new climate of internetbased teaching and learning (Parker, 2004). McPherson and Nunes (2006) argue that there should be support at the institution level for increasing the quality assurance in elearning such as gaining accreditation for the new delivery mechanism. However, as I discussed in section 5.1.2.1 in Chapter 5, I found that government-level support (nationallevel support) is critical for establishing recognition for qualifications (or certification) gained through e-learning in Sri Lanka. Institutional support is still needed for granting 
approval to start an e-learning programme in the institution. The government (Ministry of Higher Education, University Grants Commission) is the lead organization for tertiarylevel IM organizations; therefore, the tertiary-level IM organizations require government support. My findings are also similar to those of Khafagi (2004) who identified that Iran has been slow to take up e-learning due to lack of acceptance of distance education, and lack of accreditation and certification standards for e-learning. My findings also revealed that absence of quality assurance/qualification frameworks for e-learning contributed to lack of confidence and trust in constructivist-based e-learning education in Sri Lanka which affects the acceptance of e-learning in tertiary-level IM education. Previous studies confirmed the importance of implementing quality assurance for e-learning in developing countries (Moussa \& Moussa, 2009; Bhuasiri et al., 2012; Omidinia, Masrom, \& Selamat 2011). For example, Moussa and Moussa (2009) have shown that quality assurance needs to be adapted to the modern education system (i.e., e-learning) under globalization and to help assure the quality of education in general. Given the educational culture of developing countries, they recommended intensive support from the government for implementing quality assurance in e-learning.

Some interviewees in my study reported that the absence of constructivist-based elearning best practices and the absence of a quality assurance framework are contributing factors to the lack of confidence and trust in e-learning-based education. For example, current e-learning providers have problems with plagiarism, copying, and lack of authentication. As explained in section 5.1.2.2 in Chapter 5, these e-learning providers' programmes are at the initial stage and the courses are not designed in a way that promotes interactivity. Their programmes currently include pages and pages of text. It seems existing tertiary-level e-learning programmes in Sri Lanka are not well-integrated with higher-level learning processes and that academics just use the basic capabilities of the e-learning tools (communication tools, e.g., email, and presentation tools, e.g. PowerPoint). The reasons behind this could be academics' lack of specific skills needed to design and develop an e-learning programme (see section 7.2.2) and lack of familiarity with constructivist-based pedagogy. Previous studies have shown that the constructivist pedagogy/approach is the basis of functional requirements for designing and developing an e-learning environment (Mishra, 2002; Alley \& Jansak, 2001). It is also important not to design e-learning sites as a 'document dump' and not to flood the student with 
information (Hamid, 2002; Gunawardena, Linder-VanBershot, LaPointe, \& Rao, 2010). Otherwise users could be disappointed, they become dissatisfied with their e-learning experience, and the e-learning programme might not achieve its purpose. Previous studies confirmed that individuals who are less satisfied with their experiences are less likely to take part in future e-learning initiatives (Lim, 2001; Carswell \& Venkatesh, 2002).

Tertiary-level e-learning providers in Sri Lanka used the e-learning system in an instructivist way to provide simple student support. They used e-learning as a supplementary tool. For example, rather than using e-learning as the main teaching method, e-learning providers as well as IM education providers at the private university used it as an instruction-enhancing technology. With the current experience of existing e-learning programmes, it is evident that there is lack of constructivist e-learning best practices in the Sri Lankan context which in turn affect IM education providers' confidence to use e-learning. Previous literature shows the importance of having best practices in place that could be used to guide the development and implementation of elearning. For example, Olson et al. (2011) analysed e-learning impacts and best practices in developing countries (Algeria, Lebanon, Pakistan, Chile, Malaysia, and South Africa). They argued that those who need to improve e-learning practice should examine successful e-learning programmes. They should identify key components of already successful e-learning programmes in order to plan, develop, and implement their own elearning programme.

The participant quotes in section 5.1.2.2 in Chapter 5 demonstrate how lack of customization of existing e-learning programmes affects the quality of e-learning content in Sri Lanka. The findings of my study are consistent with those of Engelbrecht (2003), Ehlers (2004), and Chen, Lee, and Chen (2005). They found that an e-learning environment must be customized to enhance quality of e-learning content or educational values. Gregg (2007) identified that interactive learning and customized accessibility is required to fulfil unique learner needs. This includes screen reader support, language translation, or alternative devices (p. 303). McGorry (2003) suggested that to maintain the quality of e-learning programmes, e-learning providers must address issues of flexibility, responsiveness, interaction, student learning, technical support, technology, and student satisfaction. 
In this study, I found that implementation of policies and strategies to establish recognition for qualifications gained through e-learning, and implementation of the quality assurance framework for e-learning, are vital for the acceptance of e-learning programmes in the Sri Lankan context. Similarly, improving academics' skills in designing and developing e-learning programmes and enhancing academics' awareness of constructivist-based pedagogy are also critical to the introduction and use of e-learning in tertiary-level IM education in Sri Lanka.

\section{Generational divide in digital and IT literacy}

From the analysis of interviews and focus group data in my study, it became evident that the generational divide in digital and IT literacy in Sri Lankan society is perceived to have an impact on the introduction and use of e-learning. Based on recent statistics on IT/computer literacy in Sri Lanka, and in my analysis of the qualitative data, I found that older academics as well as older students experienced greater computer literacy problems than young academics and young students. This age gap and gap in technology usage are discussed by Prensky (2001) who refers to the two groups as 'digital natives' and 'digital immigrants'. The younger generation who have grown up with computers and the internet are called digital natives, while the older generation who were not born into the digital world and have encountered digital technologies later in their life are called digital immigrants. This older generation or digital immigrants are likely to be more challenged by technology, showing less technological literacy than the younger generation (Prensky, 2005, 2001a).

However, some authors critique Prensky's categorization. For example, Martinez and Prensky (2011) had a debate on digital native and Martinez argued that 'digital native' is a myth because young people still need teachers' or parents' guidance to use technological tools wisely and purposefully. Similarly, Bayne and Ross (2011) argued that the term 'immigrant' highlights a tendency to de-privilege the role of the teacher. Wang, Myers, and Sundaram (2013) argued that there is a continuum rather than a rigid dichotomy between digital natives and digital immigrants. They have conceptualized this continuum as 'digital fluency'. They outlined age, psychological, organizational, social and cultural, and accessibility factors that have an impact on digital fluency. White and Cornu (2011) used the terms 'visitors' and 'residents' as a new typology for online engagement. Some other authors also use alternative terminologies for digital natives such as net 
generation (Oblinger, 2003), digital generation/technological generation (Monereo, 2004), and Google generation (JISC, 2008).

Although there have been explorations and criticisms of Prensky's categorization, Prensky argued that his distinction is much more about culture (Martinez \& Prensky, 2011). It is about younger people's comfort with digital technology and their beliefs that digital technology is easy, useful, and also a fun partner, which the older generation does not share. This age gap and gap in technology usage are similar to what has been found in my study. This lack of computer literacy has resulted in problems with effective use of learning management systems (i.e., Moodle) as well as academics' unwillingness to integrate new technologies to develop interactive/creative learning environments. This age gap and gap in technology usage have significant influence on academics' IT skills for teaching as well as students' IT skills for learning which in turn have affected the introduction and use of e-learning. This will be discussed under the meso-level factors in section 7.2.2.

Lack of Nenasala telecentre facility usage by Sri Lankan adults could be another reason why older generations experience greater computer literacy problems than the younger generations. As I discussed in Chapter 2, 'Nenasala' is an e-Sri Lanka major telecentre development programme which aims to empower the population of Sri Lanka through affordable community access to technologies and provide basic computer literacy training services. The outcome evaluation report of the Nenasala (2010) programme indicated that $76 \%$ of their users are youth (12-25 years) while $22 \%$ are adults. These statistics indicate that Nenasala is used by and is popular among the young generation but that Nenasala island-wide telecentres and their programmes have not been successfully used by the older generation of Sri Lankan society. This requires investigation. Literature has shown that it is possible for adults to become digital natives, especially in the area of learning, by obtaining relevant skills and experience in interacting with ICT (Helsper \& Eynon, 2010).

The evidence above suggests that lack of adult uptake of the Nenasala programme might be a contributing factor to the generational divide. This identified generational divide in the Sri Lankan context also influences IM education organizations and will be discussed in section 7.2.2. 
The summary of social and cultural factors (including within-level and cross-level influence) is shown in Figure 7.1. 


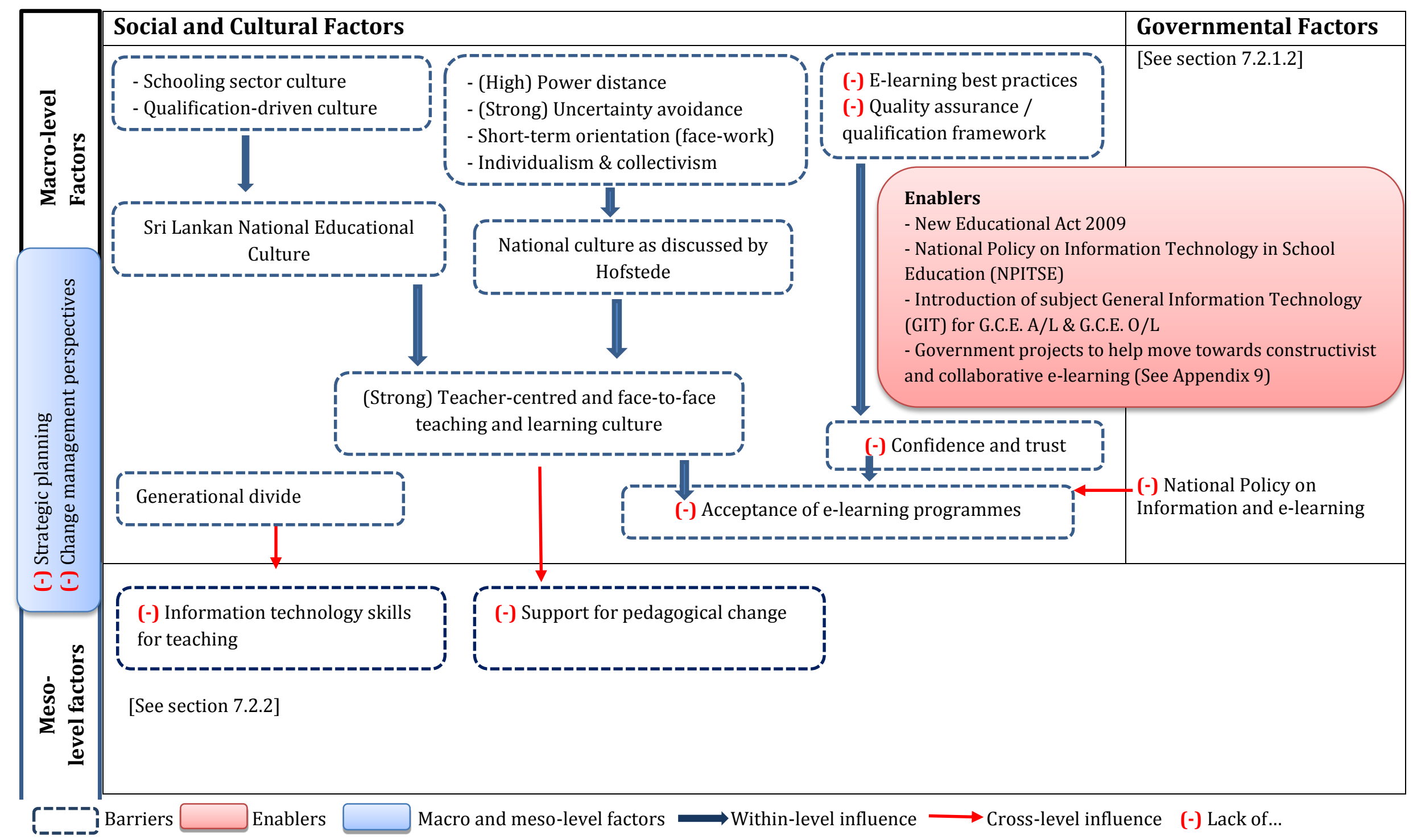

Figure 7.1 - Summary of social and cultural factors (including within-level and cross-level influence) 


\subsubsection{Governmental factors}

This study found a number of governmental factors that are also key barriers to the introduction and use of constructivist e-learning. As shown in Table 7.1, governmentrelated factors include lack of sustainability in governmental e-learning initiatives and lack of facilitating government policies.

\section{Sustainability of governmental e-learning initiatives}

The majority of interviewees in all groups described lack of sustainability as a common issue in most government-level e-learning initiatives due to the absence of strategic planning. As I discussed in Chapter 2, there are two major government initiatives that focused on bridging the gap between rural and urban sectors and providing equal access to IT, thereby providing platforms to use e-learning: e-Sri Lanka (including Nenasala) and NODES (National Online Distance Education Service). Currently, there are 766 Nenasala centres established island-wide out of the 1000 intended under the Nenasala project. About 30 Nenasala centres (out of the 766) were closed in 2010 however (ICTA, 2010). Although there are limited up-to-date statistics about the number of closed Nenasala centres, as a researcher in the Sri Lankan context, I have noticed that a significant number of Nenasala centres are currently closed. As I discussed in section 5.2.1.1 in Chapter 5, Nenasala centres can only operate properly as long as they receive funds from the government or from the project. During the period of self-funding some Nenasala centres have closed because there has been no strategic planning for the next steps and no continuing operational funding. The ongoing sustainability of Nenasala is therefore questionable.

In 2010, the sustainability of Nenasala centres was also discussed by ICTA (2010) from technical, social, economic, financial, and management aspects. This agency found that the sustainability of Nenasala was largely determined by the availability, functioning, and maintenance of hardware and equipment at the Nenasala centres. ICTA also found that about $51 \%$ of the Nenasala centres do not have operational and maintenance funds. This evidence therefore shows that lack of strategic planning is a major problem for the Nenasala telecentre programmes and has influenced the sustainability of Nenasala centres as a major government e-learning initiative. 
The Nenasala centres aim to empower the population in urban as well as rural areas in Sri Lanka, by facilitating more balanced access to ICT. IM workers who are part-time students and who do not have the required ICT facilities could use the Nenasala centres to access their e-learning programmes. However, the above identified lack of sustainability may be the reason for IM workers' lack of usage of Nenasala centres (other reasons will be discussed in the section on technological factors). This lack of sustainability therefore has an impact on the introduction and use of e-learning in tertiary-level IM education in Sri Lanka.

More importantly, government officials who were interviewed in this study agreed that they did not have a proper plan and did not know what to do. Therefore, they do not get the maximum use of the resources in the educational system. Sri Lanka's National Higher Education Strategic Management Plan 2012-2015, for example, has no action plan that explains how goals will be accomplished. As a researcher who is experienced in the Sri Lankan context, I also noticed strategic planning is absent in most government projects.

Apart from the lack of strategic planning, I found that there was a lack of awareness about two major initiatives - e-Sri Lanka (including Nenasala) and NODES - within the Sri Lankan community, including the IM community. For example, one senior academic at the public university was unfamiliar with government e-learning projects. He attributed operation of these projects to the university rather than the government. He said "Unfortunately for e-learning purposes I think there should be centres throughout the island (to access technology). But we don't have such centres. The Open University of Sri Lanka has some centres but the Open University can't do this alone (to provide access to technology island-wide)". This academic did not seem to be fully aware of government programmes. The government has established 766 Nenasala centres and 26 NODES access centres throughout the country, but he said that there is a lack of centres throughout the island to access technology. Furthermore, he said that the Open University has some centres. The reality is NODES has opened 26 access centres in the Open University study centre premises. These centres are operated by NODES, not by the Open University of Sri Lanka. This type of comment demonstrates a lack of awareness about government initiatives among participants in IM organizations. 
As a researcher, I also identified lack of awareness about NODES access centres among IM communities when trying to understand the government support for use of e-learning in Sri Lanka. Some research participants recognized the NODES name but they did not know what its role and benefits are. This view was also affirmed by a member of the learning resource support team at the NODES who said "Yes, it is true. The thing is that the message [about NODES and its benefits] has not gone to the public sector or private sector or out and about. It is only a concept. ...that's the real disaster". Thus, this problem affects the IM community and prevents it from reaping benefits from government programmes to use e-learning. For example, as I discussed in section 5.2.1.1, usage of video conferencing facilities in 26 NODES access centres (NAC centres) by the Sri Lankan community including educational institutes is very rare. This low use of NAC centre facilities has negatively affected their income. The evidence below demonstrates poor management practices in NAC centres which also has an impact on the sustainability of NODES access centres.

The other reason for lack of awareness about NAC centre facilities is poor management practices. As expressed by interviewees in this study, politically-motivated appointments are the problem. As a result, NAC centre assistants are not competent at using the facilities or at spreading the message to the community. Moreover, they are inexperienced at assisting people to use NAC centre facilities.

This lack of awareness and lack of strategic planning discussed above may be why two major government e-learning initiatives -i.e., e-Sri Lanka (including Nenasala) and NODES - have not yet performed as major a role in the Sri Lankan context as they were expected to.

Lack of/unsuccessful publicity and awareness campaigns for the government programmes appear to be a key reason why most participants were not aware of the Sri Lankan government initiatives. For example, the outcome evaluation report of the Nenasala project (2010) reported that the Nenasala awareness programme which was broadcast through mass media had failed. Therefore, media such as television and radio have not been creating awareness of Nenasala among the Sri Lankan community. The same failures were reported by Gamage and Halpin (2006). They found that the broadcasting hours of Nenasala publicity and awareness programmes in the media were 
inappropriate. Particular channels could not be viewed in certain areas of the country and therefore they did not reach desired clients. Even though previous research has reported the failures of publicity and awareness programmes, there has still been no concerted action taken to minimize these barriers. Therefore, although the Sri Lankan government has introduced worthwhile programmes to improve ICT usage and e-learning use among students in urban and rural areas, their goals have not yet been fully achieved.

Lack of collaboration or partnership between government and tertiary-level organizations may be another reason why the IM community is failing to take up government programmes to use e-learning. For example, although government has started the various programmes to bridge the digital divides in Sri Lanka and to provide more opportunities to use e-learning, those programmes are running individually without collaboration or partnership with tertiary-level IM organizations. Therefore, some of the programmes which need collaboration from these two sectors have not been successful. For example, 'Nenasala' - the telecentre development programme - was established with the aim of providing parallel distance e-learning and basic computer literacy training services to a broader population that also includes urban and semiurban disadvantaged groups, i.e., students, disabled people and marginalized groups. However, due to the lack of partnership between government initiatives and tertiarylevel IM organizations, Nenasala involvement in e-learning was significantly low $(7.17 \%)$ as shown in Table 7.2. Only a small number of users (7.2\%) used Nenasala internet services for educational purposes (See Table 7.3). As discussed in section 7.4.2.1 in Chapter 7, IM education programme participants reported that lack of access to IT (or ICT) was a major barrier to using e-learning.

The statistics in Tables 7.2 and 7.3 were taken from the outcome evaluation report of the Nenasala project conducted in 2010. This survey was conducted by the Information Communication Technology Agency (ICTA), the implementing organization of the e-Sri Lanka major governmental initiatives. The survey sample was 237 Nenasala centres and 1010 Nenasala users. 


\begin{tabular}{|l|r|}
\hline \multicolumn{1}{|c|}{$\begin{array}{c}\text { Nenasala involvement in Development } \\
\text { Interventions of the Community }\end{array}$} & Percentage* \\
\hline Adult literacy programmes & 36.29 \\
\hline Computer literacy training for students & 26.58 \\
\hline Micro-enterprise development programmes & 7.59 \\
\hline Sustainable agriculture and organic agriculture & 7.59 \\
\hline E-learning & 7.17 \\
\hline Telemedicine and health programmes & 5.06 \\
\hline E-governance & 2.95 \\
\hline
\end{tabular}

Table 7.2 - Nenasala involvement in the development interventions of the community (ICTA, 2010)

\begin{tabular}{|l|r|}
\hline \multicolumn{1}{|c|}{ Nenasala Services used by users } & Percentage* \\
\hline Use computer to record your bio-data, create a resume, CV, etc. & 50.8 \\
\hline Use computers for self-learning/to get ICT skills & 18.6 \\
\hline Use internet for educational services & 7.2 \\
\hline Use internet to search for jobs & 1.9 \\
\hline Access government information and services & 7.9 \\
\hline Use computer to read newspapers/magazines & 6.5 \\
\hline Use computer to chat or send email with/to people & 8.9 \\
\hline Use computer to write letters to authorities & 2.0 \\
\hline For computer skills training class & 14.2 \\
\hline For making local calls & 1.2 \\
\hline For making international calls & 0.8 \\
\hline Other services & 1.7 \\
\hline
\end{tabular}

Table 7.3 - Nenasala services used by Nenasala users (ICTA, 2010)

* Total is not equal to 100 but used percentage as shown in the original report.

It is evident that strategic planning is vital for the sustainability of government e-learning initiatives. This study further suggests that to enhance the awareness of government elearning initiatives, it is necessary to introduce successful publicity and awareness campaigns for government programmes as well as improve collaboration or partnership between government and tertiary-level IM organizations in order to reap benefits from government programmes designed to help people to use e-learning. 
Previous studies have identified that an institutional-level e-learning policy is vital for elearning implementation (Ozkan \& Koseler, 2009; Porcaro, 2011). These previous studies have identified critical success factors for e-learning implementation based on the organizational level. In this study, I identified factors from the macro level (national level) as well as the meso level. As a result, I discovered that not only institutional policies but also national-level policies, especially in the Sri Lankan context, matter greatly when introducing or using e-learning.

Section 5.1.2 in Chapter 5 provided some specific participant quotes describing the need for government policies to promote acceptance of e-learning programmes in Sri Lankan society. Interviewees noted that government policies are vital for establishing recognition for the qualification framework as well as for establishing confidence and trust in e-learning-based education. As discussed in section 5.2.2 in Chapter 5, the majority of interviewees referred to the importance of national policies on information and e-learning and a national broadband policy for the introduction and use of e-learning. The lack of a national broadband policy (including a rural broadband policy) was also identified as a reason for the problem of unequal/lack of access to internet facilities. (This will be discussed under technological factors in Section 7.2.1.3).

Similarly, Lee, Yoon, and Lee (2009) identified that government policy is a key driving force behind the introduction and use of e-learning in the context of South Korea. However, in this study, I found that there is a huge gap in policy-making in the Sri Lankan context. According to interviewees, the absence of a national-level effort to draft the required policy may be one reason for underdeveloped national policies. Therefore, how development of a national-level policy process should proceed in Sri Lanka is a question that needs answering. Since e-learning is new to Sri Lanka, and it is at an early stage, the policy would probably be generated from the top down. This is in line with what has been suggested by Siriwardena (2010). He recommended that the Sri Lankan government should take a leading role in broadband promotion and development because most countries in the world achieved positive socio-economic growth through their government-backed broadband promotion initiatives. 
Overall, the findings discussed in this section are consistent with Fullan and Stiegelbauer's (1991) external factors in the implementation stage. For example, as discussed in Chapter 3, external factors include government and other agencies and their role in implementation.

A summary of governmental factors (including within-level and cross-level influence) discussed in this section is shown in Figure 7.2. 


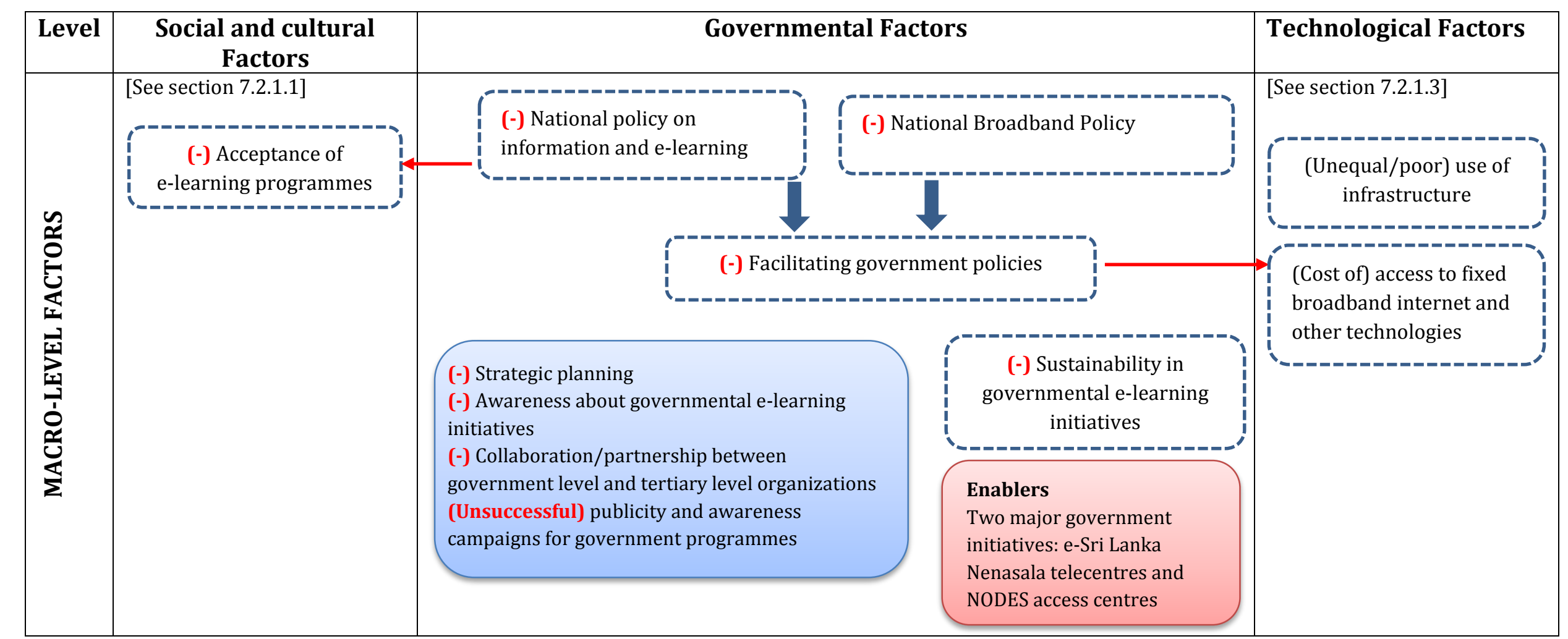

Enablers $\longrightarrow$ Both macro and meso-level factors $\longrightarrow$ Within-level influence $\longrightarrow$ Cross-level influence (-) Absence of/Lack of

Figure 7.2 - Summary of governmental factors (including within-level and cross-level influence) 


\subsubsection{Technological factors}

This study found that technological factors are also key barriers to the introduction and use of constructivist e-learning. As shown in Table 7.1, technological factors include unequal/poor use of infrastructure.

\section{Use of infrastructure}

Some interviewees from the e-learning provider category reported access to IT/ICT was not a big issue because the Sri Lankan government has been strengthening the national infrastructure through major development programmes like Nenasala and NODES access centres. However, the majority of interviewees reported that there was a gap in access to computers and internet facilities in the Sri Lankan context. According to the network readiness index in 2014 (Bilbao-Osorio, Dutta, \& Lanvin, 2014), individual usage of IT/ICT in Sri Lanka is very low and it ranked as 112 out of 148 countries. The low number of households with personal computers and internet access is identified as a factor that affected this lack of IT/ICT usage.

The evidence above shows that although the government has provided public facilities for those who cannot afford a home computer and internet access, the gap in access to IT/ICT in the Sri Lankan context remains. The point I am making is that the benefits from government initiatives have not been fully gained by the Sri Lankan community. As discussed in section 7.2.1.2, unskilled and inexperienced staff in some government projects (e.g. NAC centres) may be a reason for low uptake of public facilities. Moreover, as discussed in sections 7.2.1.1 and 7.2.1.2, lack of awareness about government initiatives and unsuccessful publicity and awareness campaigns may be other reasons why the Sri Lankan community (including the IM community) has not been reaping the benefits from government programmes designed to facilitate use of IT/ICT or e-learning. Similarly, during the focus group discussion, IM education programme participants mentioned that they were reluctant to use Nenasala and NODES access centres. The typical reason they cited was "...the problem is when we are going to use those centres, again we face traditional problems like travelling". However, key statistics (adapted from Nenasala and NODES official web sites) on the spreading of Nenasala and NODES access centres across the country contradicted students' views (Table 7.4). For example, every district has more than six Nenasala centres (the majority of districts have more than 20 
Nenasala centres) and except for Mannar, Matale, Mullativu, Kilinochchi, and NuwaraEliya districts, other districts also have at least one NODES access centre (Table 7.4). Further, the Nenasala outcome evaluation report (2010) indicated that Nenasala are located at convenient locations that facilitate easy access. For example, $65 \%$ of the users are able to travel to Nenasala in less than 15 minutes and another $21 \%$ in less than 30 minutes (Figure 7.3). This shows students' lack of awareness about these centres. Thus, this has an impact on the use of e-learning in IM education in Sri Lanka.

\begin{tabular}{|l|c|c|}
\hline \multicolumn{1}{|c|}{ District } & $\begin{array}{c}\text { Number of } \\
\text { Nenasala centres }\end{array}$ & $\begin{array}{c}\text { Number of NODES } \\
\text { access centres }\end{array}$ \\
\hline Ampara & 37 & 01 \\
\hline Anuradhapura & 59 & 01 \\
\hline Badulla & 45 & 01 \\
\hline Batticaloa & 23 & 01 \\
\hline Colombo & 19 & 01 \\
\hline Galle & 36 & 02 \\
\hline Gampaha & 21 & 02 \\
\hline Hambantota & 31 & 02 \\
\hline Jaffna & 29 & 01 \\
\hline Kalutara & 24 & 01 \\
\hline Kandy & 55 & 02 \\
\hline Kegalle & 63 & 01 \\
\hline Kurunegala & 58 & 01 \\
\hline Mannar & 06 & - \\
\hline Matale & 20 & - \\
\hline Matara & 33 & 01 \\
\hline Moneragala & 37 & 01 \\
\hline Mullativu & 07 & - \\
\hline Kilinochchi & 06 & - \\
\hline Nuwara-Eliya & 26 & - \\
\hline Polonnaruwa & 28 & 01 \\
\hline Puttalam & 21 & 01 \\
\hline Ratnapura & 43 & 03 \\
\hline Trincomalee & 28 & 01 \\
\hline Vavuniya & 11 & 01 \\
\hline Total numbers & $\mathbf{7 6 6}$ & $\mathbf{2 6}$ \\
\hline
\end{tabular}

Table 7.4 - Distribution of Nenasala and NODES access centres across the country Adapted from Nenasala (2014) and NODES (2014) official web sites 


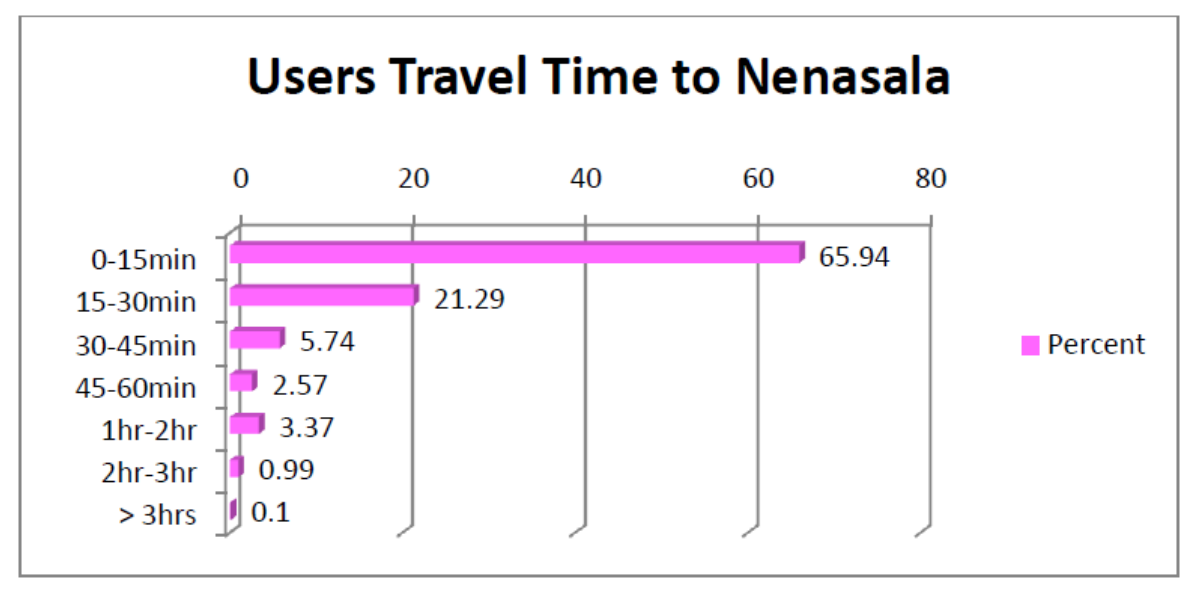

Figure 7.3 - Percentage of users by travel time to Nenasala (ICTA, 2010)

There seems little doubt that government involvement is vital for the implementation of a national broadband policy. Some of the interviewees reported that lack of rural broadband internet services was another reason for the problem of unequal access to computers and internet facilities. However, as I discussed in the literature review in Chapter 2, although fixed broadband has not changed for a long time due to poor competition as well as technical and cost differences in technologies, since 2009 there has been rapid mobile broadband growth nationwide (ITU, 2012). This development of mobile broadband exists as a result of increasing competition among operators in the mobile broadband market. For example, mobile broadband providers have introduced 3G technology as well as the 4G/ LTE (Long Term Evolution) network which has decreased the price per GB within a short period of time. However, some interviewees described misleading advertising which creates dissatisfaction with internet services. For instance, internet service providers are promising broadband speeds that do not reflect what happens in reality. The evidence above suggests that there is a hidden agenda among internet service providers. The present findings seem to be consistent with previous research which found that, compared to the developed world, Sri Lankan consumers get less value for money on broadband (Galpaya, 2011). For example, the broadband service is cheap but also of low quality. It is therefore vital to have the government's involvement in implementation of a national broadband policy in Sri Lanka to create favourable conditions for all. 
In other countries, governments have played a key role in the implementation of national broadband policy or strategy. For example, the Argentine government played a major role in developing a broadband plan as well as ensuring balanced growth of broadband and thus spread the benefits of such growth across regions and social groups (Horton, 2012). Similarly, the Malaysian government implemented a national broadband strategy including Broadband for the General Population (BBGP) and High Speed Broadband (HSBB) (Anuar, 2014). The US government has designed policies and reformed laws, policies, standards, and incentives to maximize the benefits of broadband in that country (Federal Communication Commission, 2010). Some countries like Germany, Kenya, Tanzania, France, Thailand, and UK adopted a public-private partnership (PPP) implementation model to speed up implementation of their broadband strategies (Merz, 2014). It is evident that the public-private partnership could prove to be a useful way of implementing national broadband policy or strategy in Sri Lanka.

Previous literature indicated that policy-makers, especially in developing countries, should help to enhance internet quality (Bhuasiri et al., 2012). For this purpose, they suggested three implementation strategies. They are: "1) enhance the broadband internet infrastructure that links all institutes and universities, 2) promote and increase e-learning awareness to society, and 3) increase infrastructure and system reliability through well-designed e-learning systems" (p. 852).

In Sri Lanka, there appears to be an attempt to implement a national broadband policy. For example, as discussed in section 5.3.1.2, at the time of this study's data collection some interviewees reported that a Sri Lankan national broadband policy had already been drafted and it was planned to publish this during the fourth quarter of 2012 . Previous literature also reported that. For example, ITU (2012) and Galpaya (2011) pointed out that a main focus of the drafted national broadband policy (which was expected to be released in 2012) is to expand Sri Lanka's telecommunication infrastructure facilities in order to facilitate the delivery of high-speed broadband services. However, at the time of writing it is late 2015, and this draft broadband policy has still not been published. My study data therefore suggests lack of strategic planning or lack of decisiveness in strategic planning at the government level may be a factor delaying the process of publishing a national broadband policy in Sri Lanka. 
Some interviewees suggested that the TRCSL (Telecommunications Regulatory Commission of Sri Lanka) should ensure penetration of broadband into the country. As discussed in section 5.3.1.1, there is a disparity between urban and rural broadband internet services in Sri Lanka which affects students' educational activities. Previous literature shows the current problems related to TRCSL and its broadband subscriptions. For example, Galpaya (2011) identified three main problems. They are:

1.) TRCSL does not publish data on fixed broadband subscriptions and has only recently begun publishing data for mobile broadband subscriptions

2.) Not all of the operators report the number of broadband subscriptions

3.) There are methodological issues related to the definition of mobile broadband (i.e., differences between the theoretical capability to use a mobile broadband network and active use) (Galpaya, 2011, p. 14).

The evidence above suggests that the absence of a national broadband policy could be a reason for the disparity between urban and rural broadband internet services.

Some interviewees reported that there was a problem with cost in regard to fixed broadband internet connections and buying other related technologies such as computers/laptops. As identified by the Network Readiness Index in 2014, relatively few households in Sri Lanka have personal computers and internet access (Bilbao-Osorio, Dutta, \& Lanvin, 2014). High cost may be a reason for not having individual access to IT/ICT. My findings are also similar to those of Omidinia, Masrom, and Selamat (2011) who identified expensive low bandwidth satellite technology and lack of high speed internet access were significant barriers to the success of e-learning projects in Iran. My study findings are also consistent with those of Oroma, Wanga, and Fredrick (2012). They found that inequality in access to technology is a challenge for higher education institutions in Uganda. They concluded that this is because infrastructure penetration of electricity, telephone connectivity, and the internet highway is inadequate in developing countries.

However, IM education programme participants in this study reported that they use mobile broadband because it is cheaper than a fixed broadband connection. The findings of my study are consistent with those of the Telecommunication Regulatory Commission 
of Sri Lanka (TRCSL, 2013). As shown in Figure 2.6 in Chapter 2, the number of internet and email subscribers exponentially increased after mobile broadband arrived in 2009 . It is possible that the use of e-learning in IM education in Sri Lanka could be positively affected by increasing numbers of internet users via mobile broadband connections. The use of mobile broadband connections is growing even faster due to WCDMA (Wideband Code Division Multiple Access) and HSPA (High Speed Packet Access) connections (Galpaya, 2011).

Some of the interviewees reported that although mobile broadband is cheap, they are still facing problems with lack of speed and connection stability. As discussed earlier in this section, due to the absence of any national broadband policy, internet service providers' misleading advertising may be a reason for not having guaranteed broadband speed and signals. However, these problems could be addressed if the Sri Lankan government takes steps to widen network coverage. For example, under the government's ICT development goals, in 2013 Sri Lanka Telecom (SLT) was licensed to build and operate a National Broadband Network (NBN) (Telecompaper, 2013). This project plans to cover all the 329 divisional secretariats and 24 districts in Sri Lanka with high-speed broadband connectivity over the NBN, within the period of 2013-2018 (Telecompaper, 2013).

These issues suggest that a government policy such as a national broadband policy is necessary to create and enhance broadband internet infrastructure in Sri Lanka. Government involvement with proper strategic planning is vital for the implementation of a national broadband policy. My study strongly suggests that it is important for enhancing the awareness of government e-learning initiatives in order to reap benefits from government programmes to use e-learning.

A summary of technological factors (including within-level and cross-level influence) discussed in this section is shown in Figure 7.4. 


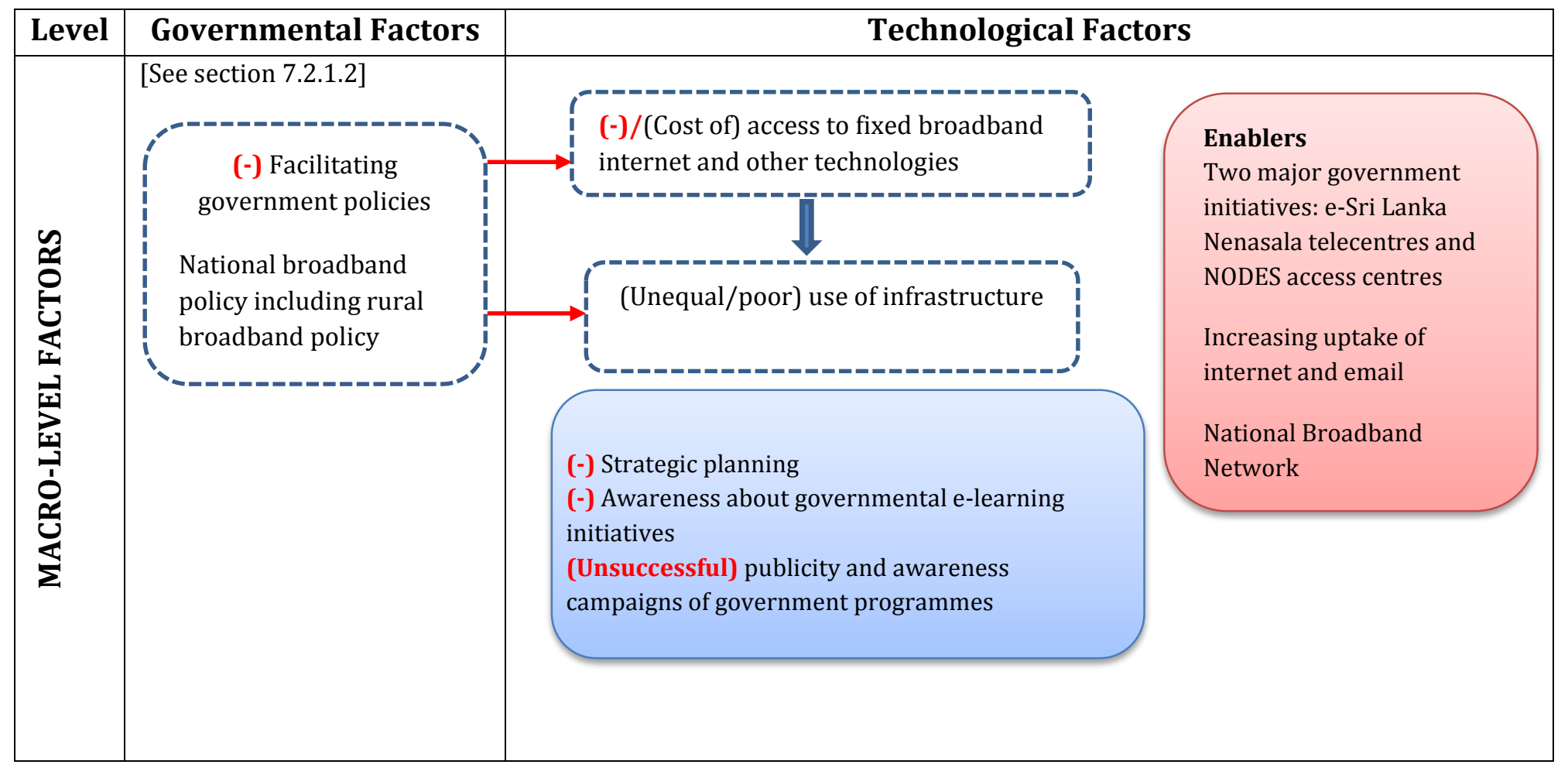

Enablers $\square$ Both macro and meso-level factors $\longrightarrow$ Within-level influence $\longrightarrow$ Cross-level influence $(-)$ Absence /Lack of...

Figure 7.4 - Summary of technological factors (including within-level and cross-level influence) 


\subsubsection{Meso-level factors}

Meso-level factors include staff capabilities, technology capabilities, collaboration, and beliefs and values.

\subsubsection{Staff capabilities}

University support for pedagogical change

Previous studies have identified critical success factors for e-learning implementation based on the organizational level. As discussed in section 7.2.1.1, in this study I identified factors from the macro level (national level) as well as the meso level. As a result, I found that the Sri Lankan national educational culture and national culture as discussed by Hofstede contribute to a highly teacher-centred teaching and learning culture. These aspects of national culture also have an effect on academics' pedagogy at the organizational level. As a result, instructivist-based pedagogy is still practised by academics at the tertiary-level IM education provider organizations. This study found that lack of university support for pedagogical change is among the key barriers to the introduction and use of constructivist e-learning. As shown in Table 7.1, apart from the national culture dimensions, roles, responsibilities, workload issues and lack of training are affecting academics' interest in constructivist pedagogy.

Roles, responsibilities, and workload issues

As discussed in section 6.1.1 in Chapter 6, I found that content-heavy syllabuses based on instructivism plus associated work are perceived to have a strong influence on academics' heavy workload. These elements make it hard for academics to change their teaching methods as well as to plan activity-based teaching. According to Pham (2010), in Vietnam, there is also pressure on lecturers (from government and organizational levels) to change their familiar teacher-centred pedagogy to constructivist-based pedagogy and to move to more interactive teaching. However, as in Sri Lanka, Vietnamese curricula are mostly designed for examination purposes, and have not evolved with constructivist ideas. Thus, creativity and practicality are not addressed and academics find it difficult to plan activity-based teaching (Pham, 2010; Ministry of Education and Training, 2006). To overcome these issues, some interviewees in my study suggested that there is an urgent requirement for revising syllabuses to incorporate constructivist 
techniques of hands-on, activity-based, and collaborative teaching and learning. This is in line with a previous study conducted by Bhuasiri et al. (2012) who interviewed 82 elearning experts from 25 developing countries (i.e., Asia, Middle East, South America, and Europe) to identify critical success factors for e-learning in developing countries. They found that curriculum design for learning performance is vital for successful e-learning implementation. It is evident that change management is required because as identified by Fullan (2007), use of new or revised materials is one of the aspects of educational change.

As discussed in section 6.1.1 in Chapter 6, I further found that gaps in expectations among different roles in the organizations were also perceived to have a strong influence on academics' heavy workload which made it hard for them to adjust their teaching methods. Hase and Ellis (2001) argued that change of pedagogy is the most important factor when teachers shift from traditional classroom to online teaching. Due to the heavy workload in tertiary-level IM organizations, academics lack time. As a result, academics face a number of issues that have an impact on the introduction and use of e-learning. For example, they are reluctant to undergo the additional training needed to change pedagogy. Academics do not prioritize their time to develop creative and innovative elearning content, to upload the materials onto the e-learning system or to provide quick and continuous responses to students' online queries. Khan (2005) pointed out that, in particular, instructors (or academics) should have enough time to interact with students in their e-learning processes.

Researchers (Fullan, 1993; Handal \& Herrington, 2003, Handal, Bobis, \& Grimison, 2001; Lovat \& Smith, 1995) argued that teachers' instructional beliefs and other values and beliefs have a strong impact on teaching and learning. For example, if teachers' beliefs do not match an educational reform (i.e., integrating technology), it is likely that new ideas will not be accepted and adopted in the classroom (Handal \& Herrington, 2003). Thus, resistance will be created and this may be one reason why academics in IM organizations are reluctant to meet the additional learning needs and do not find time for other creative and innovative activities in e-learning. As identified by Fullan (2007), new teaching strategies and beliefs are also major dimensions of educational change. Teachers may not be able to modify their teaching practices until they start changing their values and beliefs 
(Fullan \& Stegelbauer, 1991). Therefore, teachers' values and beliefs must be recognized and agreed on whether they are appropriate or not (Handal \& Herington, 2003).

To overcome roles, responsibilities, and workload issues, some interviewees suggested that there is an urgent requirement for defining roles, designing role descriptions, and redesigning work allocation models. McPherson and Nunes (2006) identified workload issues of academics or tutors as a barrier to using e-learning. They said academics' or tutors' workloads need to be balanced and clearly recognized as well as rewarded by the university. The point I am making is that an appropriate change management process is vital to facilitate the introduction and use of e-learning in tertiary-level IM education in Sri Lanka. This suggestion is consistent with that of Fullan (2007). He stated that changes of materials, teaching strategies, and beliefs are essential to sustain new educational practices. Hence, there is a need for reconsideration of roles, issues around reasonable workload, and responsibilities at the organizational level. This suggestion is closely in line with McPherson's (2003) assertion that the introduction of e-learning, especially in higher education, represents a significant change in teaching practice which needs to be carefully managed. Ahmed (2013) suggested that organizations must provide incentives and create a supportive e-learning culture to motivate academics to change their pedagogical approach.

\section{Staff and other resources}

The majority of IM education provider participants stated in the interviews that lack of staff with the necessary technological knowledge and skills had an impact on the introduction and use of e-learning. This study found a unique problem: the absence of new roles or a job market for instructional designers and content developers in the Sri Lankan context. Good instructional design is required for creating a good e-learning programme (Mingail, 2004). Martinez, Cummins, Savenye, and Shewell (2012) claimed that 'e-learning is a core component of the instructional design profession' (p. 37). Previous literature further indicated the importance of instructional design in e-learning in terms of course content, interaction, user interface, feedback and student involvement (Hussin, Bunyarit, \& Hussein, 2009). It is evident that human resources planning is vital for introducing new roles (i.e., instructional designers, and content developers) to the tertiary-level education system with the help of UGC. The issues discussed in the earlier 
section - lack of knowledge and skills - also relate to lack of staff to facilitate constructivist-based e-learning.

Among the three IM education providers, participants from the only public university reported many maintenance issues related to the network and repairing the computers and other technological devices. Lack of organizational-level support may be a reason for the issues at this public university. Alexander, McKenzie, and Geissinger (1998), and Soong, Chan, Chua, and Loh (2001) argued that if the technical advice and support is lacking, the e-learning will not succeed. For this purpose, they said, university administration support of e-learning was important. Selim (2007) also identified that institutional support in terms of technical support, computer availability, and learner material accessibility was one of the critical success factors for e-learning. Motaghian, Hassanzadeh, and Moghadam (2013) found that sufficient and efficient technical support as well as availability of training opportunities had a positive impact on academics' use of e-learning. Therefore, universities must decide what systems, resources, and infrastructure are required to support use of e-learning and whether they are adequate.

This study found a noticeable gap among tertiary-level IM education providers with regard to reliable infrastructure and facilities which in turn affected the introduction and use of e-learning. For example, as discussed in section 6.2.2 in Chapter 6, a public university reported poor infrastructure and facilities. Participants from this university said lack of resource management or strategic planning in their organization was a major reason. For example, this public university spent money on the cheapest resources but they were not durable and for the individual departments there was no authority to buy necessary resources according to their requirements.

Among the three IM education provider organizations only participants from the public university reported that lack of government funding was related to their organization's lack of reliable infrastructure and facilities. The public institute and private university provided $75 \%$ of their own funding. However, more than $95 \%$ of the public university's income was received from the government. As shown in Figure 6.2, the budget allocation for higher education was far lower than the allocations for other sectors such as defence and urban development, ports and highways. This may be why the public university lacked funds. A junior academic at the public university reported that the government 
and the administrative-level staffs' lack of appreciation and low regard for information professionals might have been one possible reason for the severe funding cuts. This suggestion needs further investigation. For example, it would be worthwhile to identify whether these problems are made worse by the general low regard for the IM profession in Sri Lanka, and if Thus, how to address them.

Despite the funding issues at the public university, as discussed in section 6.2.2, the public institute receives valuable support from a national-level forum called 'Standing Committee of Library and Information Science-SCOLIS' to solve their institutional issues related to infrastructure. This committee consists of the Chairman and Secretary of UGC, librarians of public universities, and two directors of public institutions. A librarian from the public university is also part of this committee but he did not mention SCOLIS support. As mentioned by the director of the public institute, they received significant support from SCOLIS because they conducted many projects and advertised that the public institute was very useful not only to the university system but also to the entire country. The absence of such active projects at the public university may be why it did not receive such support from SCOLIS. Further, since 2011 SCOLIS has stopped departmental academic representation on the committee. This may be another reason why IM education providers at the public university did not receive SCOLIS support: this academic department in the public university has no opportunity to participate in national-level forums to discuss their issues.

However, given the national context in Sri Lanka (discussed in section 7.2.1.3), lack of broadband internet services with sufficient bandwidth was a common issue faced by all the IM education providers and current e-learning providers. As identified by Selim (2007), university IT infrastructure needs to be extensive, reliable, and capable in order to provide the courses with the necessary IT tools. These IT tools included "network bandwidth, network security, network accessibility, audio and video plug-ins, courseware authoring applications, internet availability, instructional multimedia services, video conferencing, course management systems, and user interface" (p. 399). This comprehensive IT infrastructure makes the delivery process easy as a part of successful e-learning (Selim, 2007). 
The absence of institutional-level policies may be a reason for the lack of reliable infrastructure and facilities across the three IM education provider organizations. Czerniewicz and Brown (2009) identified that e-learning policy was associated with frequency of use, better support, and more available resources. In the interviews, a director from an e-learning provider suggested two ways of obtaining fast broadband facilities for their organizations. These suggestions are to negotiate with the UGC to have fixed and sufficient budget for broadband access and to negotiate with the Telecommunication Regulatory Commission to have fast broadband at a cheap price especially for tertiary-level educational providers.

The findings discussed in this section are consistent with Fullan and Stiegelbauer's (1991) three Rs. For example, as discussed in Chapter 3, the resources factor concerns the accumulation and provision of support as a part of the change process. Thus, the issues highlighted in this section - lack of staff to facilitate constructivist-based e-learning and lack of reliable infrastructure and facilities - explain the tertiary-level IM organizations' current situation and their level of support for the introduction and use of e-learning. According to Fullan and Stiegelbauer (1991), at the initiation stage resources must first be considered and provided because resources are critical during implementation. E-learning providers in Sri Lanka still face critical issues like lack of staff and lack of high speed broadband internet services (discussed in section 6.2). Hence, IM education providers as well as current e-learning providers must allocate sufficient resources and infrastructure to support the use of e-learning.

\subsubsection{Technological capabilities}

\section{Training needs}

From the analysis of interviews and focus group data in my study, it became evident that academics' lack of teaching-related information technology skills have an impact on the introduction and use of e-learning. The participant quotes in section 6.1.2.1 in Chapter 6 demonstrate that academics as well as support staff (i.e., librarians) lack knowledge of pedagogy. They lack understanding of how technology and content influence and constrain one another. Moreover, their lack of understanding of how teaching and learning change with the use of technologies affects the design and development of 
constructivist e-learning programmes. Academics' lack of specific skills also affected low acceptance of e-learning programmes in Sri Lanka. As discussed in section 6.2.1.1, existing tertiary-level e-learning programmes in Sri Lanka are not well-integrated in the higher level learning process. My findings are also similar to those of Koehler and Mishra (2008) who developed a framework called 'Technological Pedagogical Content Knowledge - TPCK'. They argue that TPCK is a form of knowledge which integrates knowledge of technology, pedagogy, and content that can be used in effective teaching with technology. Koehler and Mishra have highlighted the equal importance of interactions among these three bodies of knowledge. As shown in Figure 7.5, the interactions of the three bodies of knowledge can be represented as Pedagogical Content Knowledge (PCK), Technological Content Knowledge (TCK), Technological Pedagogical Knowledge (TPK), and Technological Pedagogical Content Knowledge (TPCK).

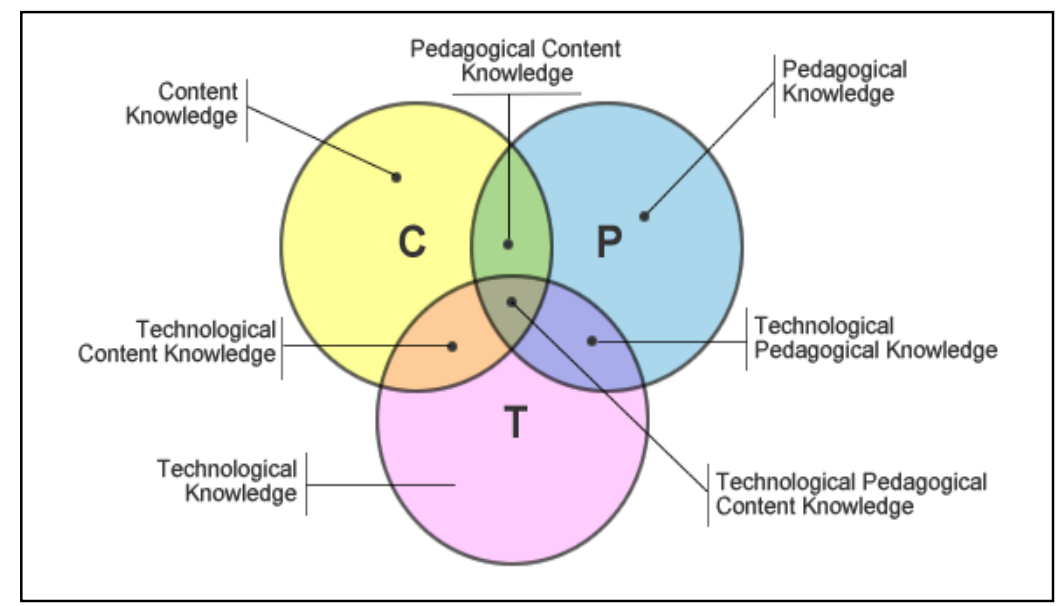

Figure 7.5 - Technological Pedagogical Content Knowledge (TPCK)

Source: Handbook of Technological Pedagogical Content Knowledge (TPCK) for educators (2008) (copied with permission)

Previous literature further indicated the importance of these three types of knowledge. For example, Martinez, Del Bosch, Herrero, and Nuno (2007) emphasized that academics' knowledge of pedagogy is vital because pedagogical design of the e-learning programme affects students' acceptance of e-learning. Sun, Cheng, and Finger (2009) identified instruction presentation (i.e., e-syllabus, electronic whiteboard) and students' learning management (i.e., online forums, thread discussions, assignment management) as critical functional requirements of the e-learning system for instructors. These requirements highlight the importance of academics' technology, pedagogy, and content knowledge to manage instruction presentation and students' learning management. Selim (2007) 
found that instructors' (or academics') attitude towards and control of the e-learning technologies, their teaching style, and e-learning course content and structure were critical success factors of e-learning. Literature has indicated that content quality and service quality have a significant influence on the effectiveness of e-learning (Wang, Wang, \& Shee, 2007). Content quality means whether e-learning contents (presentations or lecture notes) are up-to-date, have rich content, are easily understandable or use appropriate degree of breadth. Service quality means service support from the staff. This content quality or service quality of e-learning depends on academics' or instructors' characteristics such as their IT competency, teaching style, and teaching materials (Lee, Yoon, \& Lee, 2009). Johnson, Hornik, and Salas (2008) emphasized the importance of academics' IT skills in an e-learning environment. For example, they noted that simply sending and receiving emails or posting does not alone create an interaction. An effective e-learning environment, therefore, requires IT skills and digital literacy. Thus, the development of high-quality student-centred teaching material is critical and the greatest challenge for academics who do not have required IT skills (Lee, Yoon, \& Lee, 2009; Mahdizadeh, Biemans, \& Mulder, 2008). Therefore, academics must have technological, pedagogical, and content knowledge to build an interactive e-learning environment.

Academics and support staff in the IM education provider category in this study reported two main reasons for their lack of technological, pedagogical, and content knowledge (discussed in sections 6.1.2.1.1 and 6.1.2.3): limited training and content-heavy syllabuses.

Through the analysis of documents from the government (i.e., circulars) in this study, I found that training programmes were implemented across the universities and higher educational institutes. For example, the University Grants Commission (UGC) in Sri Lanka has identified university staff development as one of its statutory responsibilities. As a result, in 2010, UGC strengthened the staff development activities with three specialized functional areas: staff development, educational technology, and e-learning and IT literacy (UGC, 2010) (See Appendix 10 for further detail about staff development activities). This revised or redesigned staff development programme has six target groups: higher management, academic staff, executive staff, academic support staff, technical support staff, and other non-academic, non-administrative staff. 
Despite these advances, as discussed in section 6.1.2.3, academics and support staff from the IM education provider category claimed that existing staff development programmes were still teacher-centred and did not integrate advanced technologies. This view suggests that although at a national level, UGC has initiated the staff development programme with special functional areas, at the operational level, staff development centres (SDC) in each university are not running training programmes in student-centred teaching. Further, participants from one of the e-learning providers reported that the training programmes provided by their organization were not helping them to improve skills.

The evidence above suggests a lack of regular review of the SDC and their programmes as well as lack of specialized trainers to deliver these programmes. This could be why staff development programmes in universities are still teacher-centred and why these programmes are not tailored for the specialized functional areas suggested by the UGC in Sri Lanka. The majority of interviewees stated that they were in urgent need of training. A member of the educational technology support team suggested that not only is it important to provide training but that programmes must meet the needs of the target audience. Previous literature has also suggested organizational support is vital in order for lecturers to change and improve their teaching methods (Richards, Gallo, \& Renandya, 2001). Therefore educational institutions must provide relevant training to help academic staff to create an interactive e-learning environment (Lee, Yoon, \& Lee, 2009; Johnson, Hornik, \& Salas, 2008).

Some academics, support staff, and students in tertiary-level IM education were not very information literate, which in turn affected their technological skills. As a result, academics and other support staff had various difficulties in linking IT to their roles and IM workers as part-time students had difficulties in searching or reviewing relevant information via the internet or databases.

Since 1980, Information literacy (IL) has been recognized as an important field in the higher education sector around the world. However, IL did not come to be recognized and discussed in Sri Lanka until late 2004 (Ranaweera, 2010). Moreover, this concept was developed in a disorganized manner in the universities in Sri Lanka (p. 3). For example, several individual university libraries conducted information literacy programmes 
without any collaboration with the teaching faculty and they were not successful (p. 3). Literature indicates that cooperation is required between the classroom and library, when it comes to helping students master information skills (Breivik, 2005). For example, the lecturers and librarians can jointly determine the kind of assignments that can best facilitate students' mastering of the information literacy skills (p. 26). This is essential in the e-learning environment because e-learning courses with constructivist approaches will lead students to learn by engaging in activities that require information literacy skills. These skills help with problem solving or access to electronic resources.

It is evident that collaboration between university libraries and academics is vital to develop and to conduct successful information literacy programmes. As a Sri Lankan growing up in the society and working with IM professional groups over a number of years, my own experience has been that librarians did not recognize their role as crucial players in this growing profession of learning support staff working in partnership with learning technologists, instructional designers, IT staff, and academic staff. Some of the research participants also shared the same view with me when I had some informal conversations with them outside of the interview settings.

Two-thirds of participants in all categories noted an urgent need for proper training programmes in order to enhance their knowledge and skills. These training programmes included constructivist-based staff development programmes, Continuing Education Programmes (CEP), Professional Development Programmes (PDP), and Competency Building Programmes (CBP). Ranaweera (2010) also identified that lack of trained staff and proper guidance are other barriers for best IL practices in the universities. However, government officials in this study reported that they were then (at the time of data collection, September to December 2011) in the process of planning to provide various training facilities for students, academics, and library staff. For example, the governmentlevel plan is to develop IL course modules for students and staff, and to plan another project called Competency Building in Capacity Enhancement Programme. It is possible that the use of e-learning in IM education in Sri Lanka could be positively affected by enhancing students', academics' and support staff's knowledge and skills through future governmental training initiatives. 
Overall it is evident that the late recognition of IL in the university sector, lack of collaboration between libraries and teaching faculty to develop useful courses as well as limited training may be the reasons why academics, support staff, and students in tertiary-level IM education have inadequate IL skills.

Overall, the findings discussed in this section are consistent with Fullan and Stiegelbauer's (1991) three Rs and characteristics of change. For example, as discussed in Chapter 3, the readiness factor in the three Rs involves organizations' practical and conceptual capacity to initiate, develop, or adopt e-learning or capacity to reform which needs to be identified at the initiation stage. Thus, lack of university support for pedagogical change as well as roles, responsibilities and workload issues that were identified in this study highlight the IM organizations' current situation and their level of practical and conceptual capacity to introduce and use e-learning. According to Fullan and Stiegelbauer (1991), at the initiation stage these identified issues must first be considered and addressed. However, they further stated that issues cannot be resolved only at the initiation stage and need to carry over into the implementation stage. The factors that I discussed in section 7.2.2.1 are influenced by changes in practice, such as knowledge (technological, pedagogical, and content) and skills required for teaching and the extent of alterations in beliefs, teaching strategies, and use of materials. Fullan and Stiegelbauer (1991) categorized these factors as 'complexity' under the characteristics of change in the implementation stage. The evidence above suggests that appropriate change management processes and training programmes are critical to the introduction and use of e-learning in tertiary-level IM education in Sri Lanka.

\subsubsection{Collaboration}

This study identified that collaboration or partnership among stakeholders was an important factor for the introduction and use of e-learning, an influence other studies have not identified. For example, as discussed in section 7.2.1.2, the IM community is failing to take up government programmes such as Nenasala to use e-learning due to the lack of collaboration between government and tertiary-level organizations.

Lack of collaboration or partnership is an existing problem among the organizations. As noticed in section 6.2.2 in Chapter 6, the public university as one of the three IM education 
provider organizations lacked reliable infrastructure and facilities including online databases, e-journals, and e-books. A librarian at the same public university stated that lack of collaboration among the university libraries was the problem. If there is a consortium approach, university librarians could jointly purchase online databases and other e-resources to give access to all the users in the university sector. Interestingly, this study found that there is no collaboration within the organizations. For example, as discussed in section 7.2.2.1, information literacy programmes are not successful due to the lack of collaboration between university libraries and teaching faculty.

Above, the absence of collaboration across the different levels such as government level and organizational level, as well as the inter-organizational level, was discussed as the reason why all the participants across the two IM education provider organizations (public university and public institute) may have claimed that the concept of collaboration was a total myth in Sri Lanka and organizations had an individual work mentality. However, as demonstrated in interview extracts in section 6.3 in Chapter 6, participants in IM organizations understood the importance of organization-level and system-level collaboration to minimize some of the barriers that have an impact on the introduction and use of e-learning. Therefore, IM organizations may be keen on collaboration but the lack of coordination or support from a high level or government level may be a barrier.

\subsubsection{Beliefs and values}

\section{Collective perceptions of e-learning acceptance}

Despite the barriers discussed in this Chapter, most participants who were interviewed in this study were positive about e-learning. Some of their collective perceived advantages of e-learning were "we should accept e-learning", "at least we should try not to reject it". The majority of interviewees including managers and government officials perceived that e-learning provides a solution to problems faced by tertiary-level IM education, for example, increasing ease and equity of access to IM education. As discussed in section 6.4.1.1, they also perceived that e-learning provides benefits for teaching and IM workers. For example, e-learning programmes were perceived to be cost-effective 
regarding developing up-to-date learning materials and sharing resources, and elearning was useful for IM workers as full-time employees due to its flexibility in time and location. My findings can be considered similar to Fullan and Stiegelbauer's (1991) three Rs and characteristics of change. For example, as discussed in Chapter 3, 'relevance' in the three Rs explains what e-learning can potentially offer teachers, information workers, and others in IM organizations. Similar issues were also revisited under the characteristics of change (need and clarity) in Fullan and Stiegelbauer's (1991) implementation stage because they argued issues cannot be resolved only at the initiation stage and therefore carry over into the implementation stage. Thus, 'need' explains highpriority needs for e-learning while 'clarity' explains essential features/goals of e-learning. Literature has indicated that perceived usefulness is a most important, powerful and significant factor affecting intention and actual use of e-learning (Motaghian, Hassanzadeh, \& Moghadam, 2013). It is evident that perceived usefulness of e-learning could have a positive influence on the introduction and use of e-learning in tertiary-level IM education in Sri Lanka.

Participants also emphasized the importance of e-learning awareness-building programmes for improving understanding of the opportunities and benefits afforded by e-learning. This is in line with Ahmed (2012), who identified that increasing awareness about the importance of e-learning is vital to achieve educational goals of the universities as well as those of academics. Ahmed argued that academics in higher education in developing countries are not well-informed about the importance of e-learning compared to academics in developed countries, where e-learning systems are mature.

A summary of meso-level factors (including within-level and cross-level influence) discussed in this section is shown in Figure 7.6. 


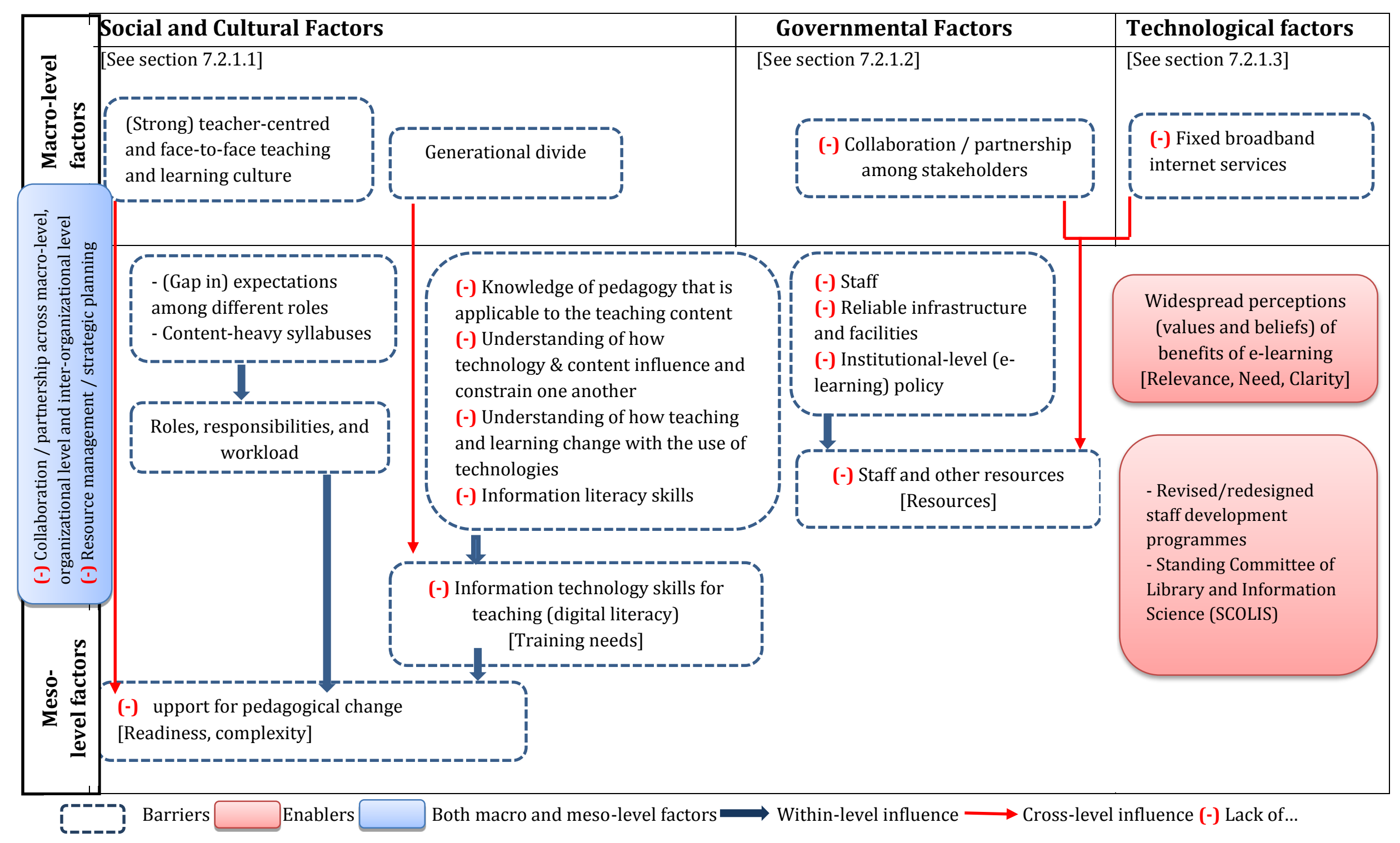

Figure 7.6 - Summary of organizational factors (including within-level and cross-level influence) 


\section{CHAPTER 8 - CONCLUSIONS}

In this Chapter, I present and discuss a revision of the conceptual model presented in Chapter 3 which can be used as a guide to help plan and adopt e-learning in the developing country context. The revision takes into consideration the findings discussed in Chapters 5, 6, and 7. Then practical and theoretical contributions of this study are presented. Finally, potential for future related research is also presented.

As discussed in Chapter 3, I developed a conceptual model by combining insights from the two theories - Hofstede's cultural dimensions to gain cultural understanding and Fullan's educational change theory for the educational aspect of this study - with insights gained from the literature review. This conceptual framework provided me with a useful guide to the conduct of a study, for example, to guide the process of data collection and analysis in this study.

As discussed in Chapter 4, the interpretivist paradigm was selected as the philosophical context of this study while qualitative methodology was selected as the research approach. They assisted me to gain deep insights, in-depth understanding of the unique context and to achieve meaning and enhance my understanding of the factors that have an impact on the introduction and use of e-learning in tertiary-level IM education in Sri Lanka. I used the case research strategy. Qualitative methods (i.e., semi-structured interviews, focus group discussions, and documentary evidence) were applied using the methodological framework of Hennink, Hutter, and Bailey. For the overall research project, the Hutter-Hennink qualitative research cycle was a useful tool for providing structure and transparency and it helped me with the combination of deductive and inductive analysis as well as interpretation, and thereby to revise the conceptual model.

\subsection{Contributions of the research}

The initial conceptual model of factors was developed by combining insights from the two theories: Fullan's educational change theory and Hofstede, Hofstede, and Minkov's cultural dimensions, and insights from the literature review. It was then revised, based on inductive analysis of the data which was based on the perspectives of IM education 
providers, IM education programme participants, current e-learning providers, and stakeholders. To identify the new insights, the factors in the conceptual model (Figure 3.3) are compared with the factors that I found in the data and are presented in Table 8.1.

The revised conceptual model of factors is then illustrated in Figure 8.1.

\begin{tabular}{|c|c|c|}
\hline \multicolumn{2}{|c|}{ Factors in the conceptual model [Figure 3.3] } & \multirow[t]{2}{*}{ Factors found in the data } \\
\hline Insights from Theory & Insights from literature review & \\
\hline \multicolumn{3}{|c|}{$\begin{array}{c}\text { Macro-level/National level: Social and cultural factors } \\
\text { Findings presented in section 5.1/ factors discussed in section 7.2.1.1/ } \\
\text { summary of social and cultural factors presented in Figure 7.1 }\end{array}$} \\
\hline $\begin{array}{l}\text { - Power distance } \\
\text { - Individualism \& collectivism } \\
\text { - Uncertainty avoidance } \\
\text { - Long-term vs. short-term } \\
\text { orientation } \\
\text { - Indulgence vs. restraint }\end{array}$ & $\begin{array}{l}\text { - Way of communication } \\
\text { - Face-work }\end{array}$ & $\begin{array}{l}\text { - Yes } \\
\text { - Yes } \\
\text { - Yes } \\
\text { - Yes } \\
\text { - No } \\
\text { - Yes (discussed under } \\
\text { power distance) } \\
\text { - Yes (discussed under } \\
\text { uncertainty avoidance) } \\
\text { - National educational } \\
\text { culture } \\
\text { - Acceptance of e-learning } \\
\text { programmes } \\
\text { - generational divide }\end{array}$ \\
\hline \multicolumn{3}{|c|}{$\begin{array}{c}\text { Macro level/National level: External factors renamed as Governmental factors } \\
\text { Findings presented in section 5.2/ factors discussed in section 7.2.1.2/ } \\
\text { summary of governmental factors presented in Figure 7.2 }\end{array}$} \\
\hline $\begin{array}{l}\text { - Government and other } \\
\text { agencies } \\
\quad \text { - Facilitating } \\
\quad \text { government policies }\end{array}$ & & $\begin{array}{l}\text { - Yes } \\
\text { - Yes } \\
\text { Sustainability in } \\
\text { governmental e-learning } \\
\text { initiatives }\end{array}$ \\
\hline \multicolumn{3}{|c|}{$\begin{array}{l}\text { Macro level/National level: Technological factors } \\
\text { Findings presented in section 5.3/ factors discussed in section 7.2.1.3/ } \\
\text { summary of technological factors presented in Figure 7.4 }\end{array}$} \\
\hline & $\begin{array}{l}\text { Technological factors } \\
\text { presented under both levels of } \\
\text { factors }\end{array}$ & $\begin{array}{l}\text { Technology and } \\
\text { infrastructure }\end{array}$ \\
\hline \multicolumn{3}{|c|}{$\begin{array}{l}\text { Meso level/Organizational level: Staff capabilities; Technology capabilities; collaboration; } \\
\text { beliefs and values } \\
\text { Findings presented in Chapter 6/ factors discussed in section 7.2.2/ } \\
\text { summary of meso-level/organizational-level factors presented in Figure 7.6 }\end{array}$} \\
\hline $\begin{array}{l}\text { - Relevance } \\
\text { - Readiness }\end{array}$ & - Resistance to change & $\begin{array}{l}\text { - Yes (discussed under } \\
\text { beliefs and values) } \\
\text { - Yes (discussed under } \\
\text { university's support for } \\
\text { pedagogical change) }\end{array}$ \\
\hline
\end{tabular}




\begin{tabular}{|c|c|c|}
\hline $\begin{array}{l}\text { - Resources } \\
\text { - Need } \\
\text { - Clarity } \\
\text { - Complexity } \\
\text { - Quality/practicality } \\
\text { - Local roles } \\
\text { [Academics, administrative- } \\
\text { level staff, support staff, } \\
\text { current e-learning providers] }\end{array}$ & $\begin{array}{l}\text { - Lack of } \\
\text { infrastructure/insufficient } \\
\text { support system/resources }\end{array}$ & $\begin{array}{l}\text { - Yes (discussed under staff } \\
\text { and other resources) } \\
\text { - Yes (discussed under } \\
\text { beliefs and values) } \\
\text { - Yes (discussed under } \\
\text { beliefs and values) } \\
\text { - Yes (discussed under } \\
\text { university's support for } \\
\text { pedagogical change) } \\
\text { - Yes } \\
\text { Used these roles as } \\
\text { participants in this study to } \\
\text { explore and understand the } \\
\text { factors that have an impact } \\
\text { on the introduction and use } \\
\text { of e-learning rather than } \\
\text { identifying their individual } \\
\text { roles in educational change } \\
\text { - Roles, responsibilities, and } \\
\text { workload } \\
\text { - Information technology } \\
\text { skills for teaching (digital } \\
\text { literacy) }\end{array}$ \\
\hline \multicolumn{3}{|c|}{$\begin{array}{l}\text { Macro and meso-level factors } \\
\text { Findings presented in Chapters } 5 \& 6 / \text { factors discussed in Chapter } 7 \text { / } \\
\text { summary of macro and meso-level factors presented in Figures } 7.1,7.2,7.4, \& 7.6\end{array}$} \\
\hline & $\begin{array}{l}\text { - Lack of access to IT, digital } \\
\text { divide, internet access, } \\
\text { expertise \& experience }\end{array}$ & $\begin{array}{l}\text { - Strategic planning } \\
\text { - Resource management } \\
\text { - Change management } \\
\text { perspectives } \\
\text { - Awareness about } \\
\text { government e-learning } \\
\text { initiatives } \\
\text { - Publicity and awareness } \\
\text { campaigns of government } \\
\text { programmes } \\
\text { - Collaboration/partnership } \\
\text { among stakeholders \& } \\
\text { across organizational and } \\
\text { inter-organizational levels } \\
\text { - Yes }\end{array}$ \\
\hline
\end{tabular}

Table 8.1 - Comparison of factors identified in the conceptual model and this study

In Table 8.1, the suggested main factors in the conceptual model, namely, macro-level factors (social and cultural factors, and governmental factors), organizational factors, and both macro and meso-level factors all remain valid. However, the indulgence versus 
restraint dimension was absent from the findings in my study and therefore this dimension has been excluded from the revised model.

In my study, people in local roles (academics, managers, support staff, and current elearning providers) have been used as participants to explore and understand the factors that have an impact on the introduction and use of e-learning. I used their collective perceptions to identify all these factors rather than identify their individual roles in educational change. Thus, local roles have also been excluded from the revised model.

As illustrated in Table 8.1, insights from the theory such as readiness and complexity are discussed under university support for pedagogical change while resources is discussed under staff and other resources, and relevance, need, and clarity are discussed under beliefs and values which reflect the meanings provided by research participants.

As a result of deep data analysis in this study, I found a number of new insights (main factors and sub-factors [see Table 8.1]) that have provided a deeper understanding of the factors affecting the introduction and use of e-learning.

The revised model of factors is presented in Figure 8.1. 


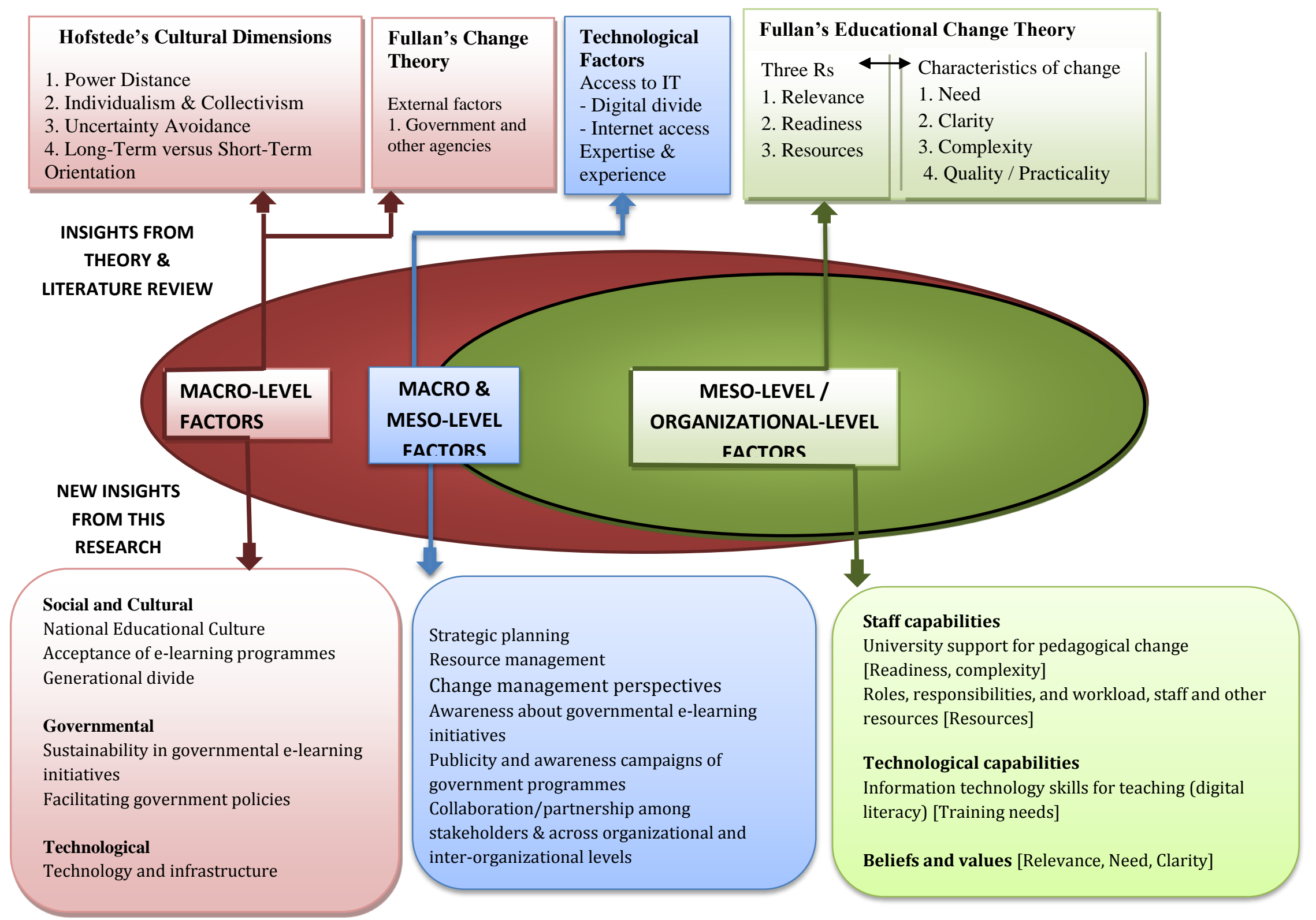

Figure 8.1 - Contextual model of factors that have an impact on the introduction of e-learning 
As discussed in section 1.3, this research was inspired by the Sri Lankan government's call for better understanding of the factors that have an impact on the introduction and use of e-learning. This study has made a significant contribution to addressing this gap. In this section, first, I discuss the factors/influences that have been perceived as applicable to the Sri Lankan education system and government to help clarify which factors should be considered in the introduction and use of e-learning. I then discuss its broader contribution to theory and research literature.

\subsubsection{Practical contribution to the Sri Lankan education system and government}

The model presented in Figure 8.1 consists of two levels: macro-level (including social and cultural factors, governmental factors, and technological factors), and meso-level factors. Some factors are relevant at both macro and meso levels. How these factors affect the introduction and use of e-learning in tertiary-level IM education in Sri Lanka was discussed in Chapter 7.

The factors in Figure 8.1 have been identified by considering tertiary-level IM education in the context of Sri Lanka and can be used as a guide to help/plan and adopt e-learning in the country. Hence this model can be beneficial to not only IM education providers but also other education providers in Sri Lanka as well as the higher education system and Sri Lankan government in general. Its use has potential to help clarify which factors should be considered in the introduction and use of e-learning. Awareness of these factors and their influences is likely to assist organizational-level staff and government officials at the system level to review their policies, strategies, and allocations of funding and other resources.

The factors in Figure 8.1 highlight the following needs that stakeholders and government officials need to be more aware of:

- Management practices, especially change management and strategic planning at national level, to see the policy (i.e., educational policy, e-learning policy) through into practice. This includes a requirement for change agents in the Sri Lankan education system to enhance the awareness of a student-centred learning culture and to thereby move towards constructive and collaborative e-learning. 
- Collaboration or partnership between government-level and tertiary-level IM education provider organizations to take up government e-learning initiatives. For this purpose there is also a need to enhance the awareness of government elearning initiatives through successful publicity and awareness campaigns. As discussed in sections 6.3 and 7.2.2.3, the collaboration/partnership between government-level and tertiary-level IM education provider organizations may help in minimizing infrastructure problems as well as improving awareness about appropriate use of technologies among academics and e-learning providers in the Sri Lankan context.

- Government involvement (with strategic planning) in the implementation of national policies such as a national policy on information and e-learning and national broadband policy to create favourable conditions for all concerned.

As discussed in section 5.2.2, a national information policy is vital to the implementation and operation of information resources, services, and systems to access up-to-date, relevant and reliable data and information. The added value of a national policy on e-learning includes provision of support and guidance for learners, and professional development and support for academics. An e-learning policy is also required to monitor and assure the quality of e-learning and to recognize e-learning qualifications in Sri Lanka. A national broadband policy is required to stimulate broadband development in all regions of Sri Lanka to create and enhance broadband internet infrastructure and to reduce barriers to internet access.

- Improving national infrastructure, i.e., rural (fixed) broadband internet services, in Sri Lanka to provide easy access to IT/ICT. Lack of access to broadband internet services is also a critical problem in the world today. Mark Zuckerberg, CEO and cofounder of Facebook, has identified three major challenges that need to be addressed by developing countries to improve access to IT/ICT or the internet. They are:

I. Business - making the data cheap enough that people in developing countries can pay for it. 
II. Technology - simplifying the content and/or services on offer so that they work in ultra-low-bandwidth situations and on a mixture of old, low-end hardware.

III. Content - coming up with content and/or services compelling enough to people the third world that they would go through the trouble of going online to get them. (Grossman, 2014, p. 38)

Among these challenges, business and technology are relevant to this study. For example as discussed in sections 5.3 and 6.2.2, there is an urgent need to provide low cost (fixed) broadband internet services especially in rural areas of Sri Lanka to enable easy access to IT/ICT.

A national infrastructure plan is therefore important and required to ensure Sri Lanka has the infrastructure to support e-learning. Technology and infrastructure are important but as the findings of this study have also revealed, other factors (see Figure 8.1) are equally important for successful e-learning. These should therefore be considered and included in the planning and development stages.

The factors in Figure 8.1 also highlight the following needs that IM education provider organizations need to be more aware of:

- Institutional-level policy and resource management/strategic planning for improving staff and other resources in organizations wanting to use e-learning. For example, strengthening staffing by introducing new roles such as instructional designers and content developers. Institutional-level e-learning policy is required to enable the creation of an effective environment with better support and sufficient resources in which to use e-learning. Collaboration is needed across the different levels - government level and organizational level as well as inter-organizational level - to minimize the barriers discussed in sections 6.3 and 7.2.2.3. For example, collaboration between government-level and tertiary-level IM education provider organizations is vital for the uptake of government e-learning initiatives. This partnership must also explore e-learning best practices to plan, develop, and implement e-learning programmes. Similarly, collaboration or partnership among organizations is required to jointly purchase or use reliable infrastructure and facilities including online databases, e-journals, and e-books. As discussed in section 
7.2.2.1, there is also a need for collaboration between teaching faculty and libraries to develop and conduct successful e-learning programmes and information literacy programmes. Information literacy has been recognized as essential in the e-learning environment. Information literacy and digital literacy skills help with effective information searching and access to electronic resources, problem-solving and learning by engaging in activities.

- Change management processes at the organizational level to introduce the use of constructivist e-learning. This includes for example, revision of syllabuses with constructivist fundamentals, changes to teaching strategies, and beliefs. There is also a need for defining roles, designing role descriptions and redesigning work allocation models. The result of doing this will be to balance and clearly recognize academics' work and motivate them to enhance their teaching methods to facilitate constructivist e-learning.

- Training programmes are necessary to help academic staff to improve their technological, pedagogical, and content knowledge (TPCK) to create interactive elearning programmes. These training programmes must meet the current needs of the academics. This kind of help and support is required to enable academics to improve their skills in designing and developing e-learning programmes as well as to enhance their awareness of constructivist-based pedagogy for the introduction and use of e-learning in tertiary-level IM education in Sri Lanka.

\subsubsection{Contribution to the theory and research literature}

The model presented in Figure 8.1 also highlights the contribution to the theory and research literature.

This study used Fullan's educational change theory and Hofstede, Hofstede, and Minkov's cultural dimensions in a developing country context. For example, how cultural dimensions and factors from Fullan's educational change theory affect the introduction and use of e-learning was discussed in the context of tertiary-level IM education in Sri 
Lanka in Chapter 7. This study demonstrates that Fullan's educational change theory alone may be insufficient to provide full insights or to identify complex issues in the context of a developing country or in a cultural context different from the one in which Fullan developed the theory.

For example, as discussed in section 3.1.1.1, Fullan's educational change theory has been widely used in studies at the organizational level. In this study, I used the initiation stage and the implementation stage of Fullan's change theory as a lens to help identify the factors at national level as well as at organizational level, that have an impact on the adoption of educational programmes (i.e., e-learning). Thus, this might be the first research that applies Fullan's theory at a national level. As discussed in section 2.3.3 in Chapter 2, previous studies have identified critical success factors for e-learning implementation at the organizational level. However, this study also used Hofstede, Hofstede, and Minkov's cultural dimensions (2010) as a lens to help understand the Sri Lankan cultural context and to identify its impact on the introduction and use of elearning. As a result, this study revealed that cultural context must be understood in order to identify complex issues that have an impact on the adoption of educational programmes. For example, as shown in Figure 8.1, this study identified meso-level (organizational level) and macro-level (national level) factors. This study further identified factors that are relevant at both macro and meso levels. As discussed in Chapter 7, all these factors significantly affect the introduction and use of e-learning in tertiarylevel IM education in Sri Lanka.

This study demonstrates that national education-related culture (schooling sector culture and qualification-driven culture) in the Sri Lankan context matter highly when introducing or using e-learning. As discussed in section 7.2.1.1, Sri Lankan national culture including the current national education-related culture appears not to be supportive of constructivist e-learning. For example, I found that conversations between teacher and student took place privately outside the classroom because of the respect for the teaching profession in Sri Lankan society. Students do not want to threaten the 'face' of their teachers and therefore students play a passive role in shared spaces/group contexts. As discussed in section 7.2.1.1, literature indicated that the existing tradition of private discussion could potentially be simulated by new technology but again it requires students to play an active role. Hence, students' very active role in a private setting 
(outside the classroom) could be a critical enabler of the ability to move into a more constructivist e-learning environment. However, the higher education system needs to make a distinction between the use of public space and private space and look at means of utilizing both 'spaces' to foster a high level of student engagement with their teachers by effective use of digital technologies for learning and teaching.

Further, as I discussed in sections 7.2.1.1 and 7.2.2.1, Sri Lankan national educational culture and national culture, as discussed by Hofstede, both contribute to the strong teacher-centred teaching and learning culture. These aspects of national cultures also have an effect on academics' pedagogy at the organizational level.

This study therefore argues that Fullan's educational change framework as applied will benefit from adding a social and cultural dimension. For example, Fullan's educational change theory can be applied at a national level when it is supplemented by understanding of the social and cultural context. This contribution is reflected in Figure 8.2 .

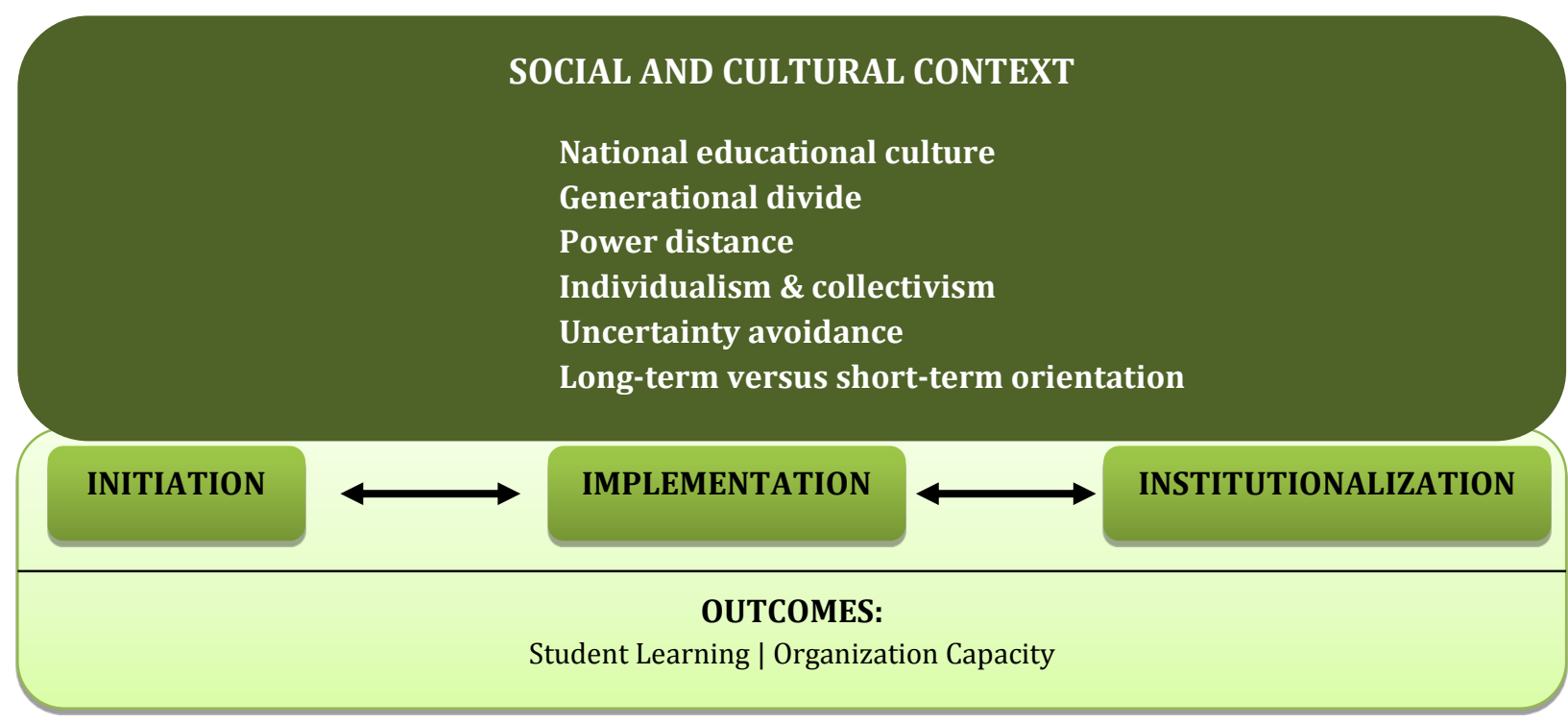

Figure 8.2 - This study's contribution to Fullan's simplified overview of the change process (Adapted from Fullan, 1991, p. 48)

This study only used the initiation and implementation stages of Fullan's change theory. Fullan's three stages of change process is not a linear process as shown by the two-way arrows (See Figure 8.2). Thus, once social and cultural factors have been embedded, 
considered, and used to inform the initiation and implementation, it may then inform the institutionalization stage.

This study further argues that the factors in Figure 8.1 may be transferable to other contexts with similar socio-cultural and educational backgrounds, such as countries in the South Asian region or South East Asian region and contribute to the introduction and use of e-learning. For example, e-learning has been widely used as a popular medium for teaching and learning in some parts of India, i.e., Bangalore, New Delhi, and Jamshedpur (Chawla \& Joshi, 2012). However, as I showed in Table 3.4 in Chapter 3, similar to Sri Lankan social and cultural background, Indian culture also has a high degree of power distance (77). Rao (2011) conducted a study to understand the role of national cultural dimensions on e-learning practices in India and found that Indian culture contributed to teacher-centred teaching and learning culture with a great deal of authority and power, and students are passive recipients of knowledge. This influences e-learning practices in terms of constructing and developing knowledge as well as autonomy and responsibility for learning which high power distance cultures may not prefer. Thus, the factors that are identified in this study are perhaps more relevant to the parts of India (and possibly other countries) with a similar socio-cultural and educational background to Sri Lanka to clarify which factors should be considered in the introduction and use of e-learning.

\subsection{Suggestions for further research}

Further research in the following areas may increase understanding of the introduction and use of e-learning in Sri Lanka.

As discussed in sections 7.2.1.1 and 8.2, this research found that in tertiary-level IM education, students frequently meet their teachers after a class if they want to ask questions or to clarify something. This raises a further question which needs answering as to how these 'private discussions' could be emulated in e-learning.

As discussed in section 7.2.1.1, there are government initiatives in the secondary and tertiary-level education systems to help move towards constructivist and collaborative e-learning. These government e-learning initiatives are heavily dependent on foreign aid such as Asian Development Bank (ADB) funds (See Appendix 9). Although studying the 
outcome of these government e-learning initiatives was not the focus of this study, this area has emerged as an aspect that warrants investigation. For example, as discussed in section 7.2.1.2, some of the government e-learning initiatives were not successful and their involvement in tertiary-level e-learning was significantly low. There is a need to investigate the reasons for the lack of success and involvement and what could be done to address these. Such a study could utilize the framework (Figure 8.1) developed in this research as an analytical lens.

This study highlighted the effects of the lack of government policies on the introduction and use of e-learning in tertiary-level IM education in Sri Lanka. As discussed in sections 5.2.2 and 7.2.1.2, this study found that absence of national-level coordination or collaboration to draft the required policies may be one reason for underdeveloped national policies in Sri Lanka. Literature has suggested that in other countries, governments and their national-level agencies have played a key role in the implementation of national policies (See section 7.2.1.3). In New Zealand, policy development processes are conducted in collaboration and coordination with a number of local government representatives (Department of Internal Affairs, 2014). For example, the governance groups and their teams support the ICT leader for the development and reviews of the ICT legislative framework in New Zealand. In the Sri Lankan context, the Ministry of Higher Education, University Grants Commission, and National Education Commission could form a partnership to facilitate the tertiary-level education policy development process. Therefore, a study on a potential pathway to guide the development and subsequent reviews of a national-level policy process should proceed in Sri Lanka.

As discussed in Chapter 7, some of the factors appear to indicate cross-level influence/relationships. For example, at the macro level, I identified that Sri Lankan national educational culture and national culture as discussed by Hofstede contribute to a strong teacher-centred teaching and learning culture. These aspects of national culture also have an effect on academics' pedagogical change at the organizational level. This study further found that, although the Sri Lankan government has implemented elearning related projects and provided public facilities to access IT/ICT, the Sri Lankan community including the tertiary-level IM community have not been reaping the benefits from the government programmes in order to use IT/ICT or use e-learning. For example, 
as one of the interesting areas, further investigation of national educational culture's influence on academics' pedagogical change and teaching and learning culture at the organizational level may help to understand the interrelationships among factors that were identified in this study (See Figure 8.1). Although investigating the interactions between these two levels, macro level and meso level, is outside the scope of this study, it would be an interesting area for further research.

As discussed in Chapter 7, this study found that lack of strategic planning was an overarching barrier/issue for the introduction and use of e-learning in tertiary-level IM education in Sri Lanka. This study identifies key elements necessary for strategic planning. Further research needs to be done, for example, to develop a road map with priority action areas (each priority action area may include actions, expected outcomes, main stakeholders, and status of the action) to guide Sri Lanka's IM education sector's transition into e-learning.

As discussed in section 8.1.2, based on this study's findings, social and cultural context has been added to the initiation and implementation stages of Fullan's change theory. This study did not discuss the institutionalization stage. Therefore, the impact of social and cultural context on the institutionalization stage needs further investigation. Since Fullan's three stages of the change process are not linear, once social and cultural factors have been embedded, considered, and used to inform the initiation and implementation, they may also inform the institutionalization stage.

\subsection{Limitations of the study}

I have identified three limitations of my study. Firstly, the data of this study was collected in a limited period of time (from September to December 2011).

Secondly, this research was focused on a single case 'tertiary-level IM education in Sri Lanka'. The findings are therefore specific to Sri Lanka and tertiary-level IM education. However, some of the findings could be relevant to other contexts such as developing countries with similar resource constraints that are looking to implement e-learning but also the context of a shift from instructivist to constructivist teaching. 
Thirdly, participants' perceptions of e-learning are limited to distance education. As a researcher, I have done my best to address them. For example, before I started the focus group discussions and interviews, I explained to my research participants why I was doing the research, my objectives and what e-learning means. Likewise, I made an effort to explain what I was investigating about e-learning. In order to cross-check their understanding of e-learning, at the beginning of the interview I also asked some broad questions about what e-learning is and that helped me to gain some insights into participants' perceptions of e-learning.

In summary, this study has contributed to the research literature and the relevant body of knowledge by identifying factors that have an impact on the introduction and use of e-learning.

In this Chapter, I have also discussed contributions to the research literature and considered the potential value of these findings to information management practice including practitioners and researchers. I have also suggested possible opportunities for future research. I trust that this contribution will be of future use to the IM community and other stakeholders. 


\section{References}

Abeywardane, N. S. (2009). Message from director Distance Education Modernization Project (DEMP), Sri Lanka. In K. Rama, A. Hope, \& U. Coomaraswamy (Eds.), Quality Assurance Toolkit for Distance Higher Education Institutions and Programmes. Columbia: Commonwealth of Learning. Retrieved from http://www.col.org/PublicationDocuments/pub HE QA Toolkit web.pdf

Abrami, P. C., Bernard, R. M., Wade, C. A., Borokhovski, E., Tamim, R., Surkes, M., \& Zhang, D. (2006). A Review of e-Learning in Canada: Rejoinder to Commentaries. Canadian Journal of Learning and Technology, 32(3). Retrieved from http://www.cjlt.ca/index.php/cjlt/article/view/48/45

Adelman, C. (2000). A parallel universe, expanded: Certification in the information technology guild. For a Change, 32(3).

Adeoye, B., \& Wentling, R. M. (2007). The relationship between national culture and the usability of an e-learning system. International Journal of E-Learning, 6(1), 119146.

Ahmed, T. T. (2013). Toward successful e-learning implementation in developing countries: A proposed model for predicting and enhancing higher education instructos' participation. International Journal of Academic Research in Business and Social Sciences, 3(1). Retrieved from http://www.hrmars.com/admin/pics/1485.pdf

Alexander, B. (2006). Web 2.0: A new wave of innovation for teaching and learning. EDUCAUSE Review, 41(2), 32-44.

Alexander, S. (2000). Higher education markets and providers. In K. Fry (Ed.), The Business of E-Learning, Bringing your Organization in the Knowledge E-conomy. Sydney: University of Technology.

Alexander, S. (2001). E-learning developments and experiences. Education + Training, 43(4/5), 240-248. doi:10.1108/00400910110399247

Alexander, S., McKemzie, J., \& Geissinger, H. (1998). An evaluation of information technology projects for university learning. Australian Government Publishing Services, Canberra: Department of Employment, education and training and youth affairs. Retrieved from http://services.canberra.edu.au/CUTSD/announce/ExSumm.html

Allen, C. (2004, October 13). Tracing the evolution of social software. Retrieved from http://www.lifewithalacrity.com/2004/10/

Alley, L. R., \& Jansak, K. E. (2001). The Ten Keys to Quality Assurance and Assessment in Online Learning. Journal of Interactive Instruction Development, 13(3), 3-18

Ally, M. (2008). Foundations of educational theory for online learning. In T. Anderson (Ed.), The theory and practice of online learning. Edmonton: AU Press.

Alonso, F., Lopez, G., Manrique, D., \& Vines, J. M. (2005). An instructional model for webbased e-learning education with a blended learning process approach. British Journal of Educational Technology, 36(2), 217-235. doi:10.1111/j.14678535.2005.00454.x

Ameen, K. (2011). Changing scenario of librarianship in Pakistan: managing with the challenges and opportunities. Library Management, 32(3), 171-182. doi:10.1108/01435121111112880 
Andersson, A. (2008). Letters from the field: e-learning students change of learning behaviour in Sri Lanka and Bangladesh. Presented at the 7th European conference on e-learning, Academic Publishing Limited.

Andersson, A., \& Gronlund, A. (2009). A Conceptual Framework for E-Learning in Developing Countries: A Critical Review of Research Challenges, 38(8), 1-16.

Andersson, A., Hedstorm, K., \& Gronlund, A. (2009). Learning from elearning: emerging constructive learning practice. In International Conference on Information Systems ICIS 2009 Proceedings (pp. 1-17). Phoenix: Association for Information Systems. Retrieved from http://aisel.aisnet.org/icis2009/51

Anuar, M. R. (2014). National broadband initiatives in Malaysia. Presented at the ITUACMA International Training Programme, Sydney, Australia.

Arbaugh, J. B., \& Duray, R. (2002). Technological and structural characteristics, student learning and satisfaction with web-based courses: An exploratory study of two online MBA programmes. Management Learning, 33(3), 331-347.

Arunatilake, N. (2006). Education participation in Sri Lanka-Why all are not in school. International Journal of Educational Research, 45(3), 137-152. doi:10.1016/j.ijer.2006.11.001

Asgary, N., \& van den Heuvel, W. J. (2013). Educating the Next Generation of Global Information Managers. GSTF Journal on Business Review (GBR), 2(4), 150-154. doi:10.5176/2010-4804_2.4.265

Asian Development Bank. (2009). Asian Development Bank \& Sri Lanka : Fact sheet. Asian Development Bank. Retrieved from http://www.adb.org/Documents/Fact Sheets/SRI.pdf

Baskerville, R. F. (2003). Hofstede never studied culture. Accounting, Organizations and Society, 28(1), 1-14. doi:10.1016/S0361-3682(01)00048-4

Bates, A. W. (1999). Managing Technological Change: Strategies for Academic Leaders. San Francisco: Jossey-Bass.

Bates, A. W. (2001). National strategies for e-learning in post-secondary education and training. Paris: International Institute for Educational Planning, UNESCO.

Bates, T. (2009). Managerial perspectives on e-learning. In E-learning (pp. 14-27). New Delhi: IGNOU.

Bates, T. (2009). Managerial perspectives on e-learning. In E-learning (pp. 14-27). New Delhi: IGNOU. Retrieved from http://webserver.ignou.ac.in/institute/STRIDE Hb8 webCD/STRIDE Hb8 Full.p $\underline{\mathrm{df}}$

Bayne, S., \& Ross, J. (2011). "Digital Native" and "Digital Immigrant" Discourses. In R. Land \& S. Bayne (Eds.), Digital Difference (pp. 159-169). Rotterdam: Sense Publishers. Retrieved from http://www.springerlink.com/index/10.1007/97894-6091-580-2 12

Becker, K., Newton, C., \& Sawang, S. (2013). A learner perspective on barriers to elearning. Australian Journal of Adult Learning, 53(2), 211-233.

Bednar, A. K., Cunningham, D., Duffy, T. M., \& Perry, J. D. (1991). Theory into practice: how do we link? In G. Anglin (Ed.), Instructional Technology: Past, Present, and Future (pp. 100-112). Englewood: Libraries Unlimited.

Beeharry-Konglar, M. (2013). Using ICT in the teaching of Visual Arts. A situational analysis at secondary level in Mauritius. Proceedings of the 21st International Conference on Computers in Education 2013 (pp. 941-946). Presented at the The 21st International Conference on Computers in Education 2013, Bali, Indonesia: 
Asia-Pacific Society for Computers in Education. Retrieved from http://icce2013bali.org/datacenter/ICCE2013-MainConferenceProceedings.pdf

Bernath, U., \& Hulsmann, T. (2004). Low cost/ high outcome approaches in open, distance, and e-learning. In U. Bernath \& A. Szcus (Eds.), Supporting the learner in distance education and e-learning: proceedings of the third EDEN research workshop (pp. 485-491). Oldenburg: University of Oldenburg.

Bhuasiri, W., Xaymoungkhoun, O., Zo, H., Rho, J. J., \& Ciganek, A. P. (2012). Critical success factors for e-learning in developing countries: A comparative analysis between ICT experts and faculty. Computers \& Education, 58(2), 843-855. doi:10.1016/j.compedu.2011.10.010

Bilbao-Osorio, B., Dutta, S., \& Lanvin, B. (2014). The Global Information Technology Report 2014: Rewards and risks of big data. World Economic Forum. Retrieved from

http://www3.weforum.org/docs/WEF GlobalInformationTechnology Report 2 $\underline{014 . p d f}$

Blicker, L. (2005). Evaluating quality in the online classroom. In Encyclopedia of Distance Learning (pp. 882-890). Hershey: Idea Group Reference. Retrieved from http://www.igiglobal.com/gateway/contentowned/Chapters.aspx?TitleId=351

Bloor, M., Frankland, J., Thomas, M., \& Robson, K. (2001). Focus groups in social research. London: Sage.

Blumenstyk, G. (2003, March 14). For-profit colleges attract a gold rush for investors. The Chronicle of Higher Education.

Boer, W., \& Collis, B. (2002). A changing pedagogy in E-learning: From acquisition to contribution. Journal of Computing in Higher Education, 13(2), 87-101. doi:10.1007/BF02940967

Boston University School of Public Health. (2013). Diffusion of Innovation Theory. Retrieved January 18, 2015, from http://sphweb.bumc.bu.edu/otlt/MPHModules/SB/SB721-Models/SB721-Models4.html

Breivik, P. S. (2005). 21st century learning and information literacy. Change: The Magazine of Higher Learning, 37(2), 21-27. doi:10.3200/CHNG.37.2.21-27

Bronfenbrenner, U. (2005). Making Human Beings Human: Bioecological Perspectives on Human Development. Thousand Oaks: Sage publications, Inc.

Brummelhuis, A. C. A. ten. (1995). Models of educational change: The Introduction of computers in Dutch secondary education. University of Twente, Netherlands. Retrieved from http://doc.utwente.nl/26312/1/t0000004.pdf

Bryant, T. (2006). Social software in academia. The EDUCAUSE Quarterly, 29(2), 61-64.

Bryman, A. (2008). Social Research Method (3rd ed.). New York: Oxford University Press.

Burn, J., \& Thongprasert, N. (2005). A culture-based model for strategic implementation of virtual education delivery. International Journal of Education and Development Using Information and Communication Technology, 1(1), 32-52.

Cairns, G. (1994). Marketing Information Managers in Organizations - The Missing Link. Executive Development, 7(2), 14-15.

Carswell, A. D., \& Venkatesh, V. (2002). Learners outcomes in a distance education environment. International Journal of Human-Computer Studies, 56(5), 475-494.

Catterick, D. (2007). Do the philosophical foundations of online learning disadvantage non-western students? In A. Edmundson (Ed.), Globalized e-learning cultural challenges (pp. 116-129). Hershey: Information Science Publishing. 
Central Bank of Sri Lanka. (2014). Sri Lanka Socio-Economic Data 2014. Central Bank of Sri Lanka. Retrieved from http://www.cbsl.gov.lk/pics n docs/10 pub/ docs/statistics/other/Socio Econ \%20Data 2010 e.pdf

Chawla, D., \& Joshi, H. (2012). Management education through e-learning in India: an empirical study. Campus-Wide Information Systems, 29(5), 380-393. http://doi.org/10.1108/10650741211275134

Chen, C.-M., Lee, H.-M., \& Chen, Y.-H. (2005). Personalized e-learning system using Item Response Theory. Computers \& Education, 44(3), 237-255. doi:10.1016/j.compedu.2004.01.006

Childs, S., Blenkinsopp, E., Hall†, A., \& Walton, G. (2005). Effective e-learning for health professionals and students-barriers and their solutions. A systematic review of the literature-findings from the HeXL project. Health Information and Libraries Journal, 22(2), 20-32.

Chumley-Jones, H. S., Dobbie, A., \& Alford, C. L. (2002). Web-based Learning: Sound Educational Method or Hype? A Review of the Evaluation Literature. Academic Medicine, 77(10), S86-S93.

Chung, H. Y., Lee, G. G., \& Liu, S. H. (2014). Policy and barriers related to implementing adult e-learning in Taiwan. Australian Journal of Adult Learning, 54(3), 389-414.

Clarke, A. (2004). E-learning skills. Hampshire: Palgrave Macmillan.

Collis, B., \& Moonen, J. (2001). Flexible learning for a digital world: experiences and expectations. London: Kogan Page.

Collis, B., \& Moonen, J. (2005). Collaborative learning in a contribution-oriented pedagogy. In Encyclopaedia of Distance Learning (pp. 277-283). Hershey: Idea Group Reference. Retrieved from http://www.igiglobal.com/gateway/contentowned/Chapters.aspx?TitleId=351

Collis, B., \& van der Wende, M. (2002). Models of Technology and Change. In Higher Education: An international comparative survey on the current and future use of ICT in Higher Education. Netherlands: Centre for Higher Education Policy Studies. Retrieved from http://doc.utwente.nl/44770/1/Collis02models.pdf

Copeland, R. (2001). The usual rules apply online. Times Higher Education Supplement. Cranefield, J. (2009). Online communities of practice and professional change: A threetier view of the knowledge embedding process. Victoria University of Wellington, New Zealand. Retrieved from http://hdl.handle.net/10063/1147

Creswell, J. W. (2003). Research design: qualitative, quantitative, and mixed methods approaches (2nd ed.). Thousand Oaks: Sage publications.

Czerniewicz, L., \& Brown, C. (2009). A study of the relationship between institutional policy, organisational culture and e-learning use in four South African universities. Computers \& Education, 53(1), 121-131. doi:10.1016/j.compedu.2009.01.006

D'Alfonso, J., \& Halvorson, C. K. (2002). E-learning in perioperative education. Surgical Services Management, 8, 20-22.

Dabbagh, N. (2005). Pedagogical models for E-Learning: A theory-based design framework. International Journal of Technology in Teaching and Learning, 1(1), 25-44.

Daniel, J., West, P., D’Antoni, S., \& Uvalic-Trumbic, S. (2006). eLearning and Free Open Source Software: the Key to Global Mass Higher Education? Retrieved January 16, 2015, from 
http://www.col.org/resources/speeches/2006presentations/Pages/2006-01$\underline{05 . a s p x}$

Daugherty, M., \& Funke, B. L. (1998). University faculty and student perceptions of webbased instruction. Journal of Distance Education, 13(1), 21-29.

Davenport, T. (1993). Process innovation: Reengineering work through information technology. Boston: Harvard Business School Press.

De Silva, C. H. (2007). Information Technology Education in the Sri Lankan School System: Challenges and perspectives. In Conference ICL2007 (pp. 26-28). Villach, Austria: Kassel University Press.

De Silva, W. I., Kodikara, P., \& Somarathne, R. (2013). Sri Lankan youth and their exposure to computer literacy. Sri Lanka Journal of Advanced Social Studies, 3(1). doi:10.4038/sljass.v3i1.7127

Department of Census and Statistics of Sri Lanka. (2014). Computer Literacy Statistics 2014. Retrieved from

http://www.statistics.gov.lk/ComputerLiterarcy/Annual\%20BuletinComputerLi teracy-2014.pdf

Department of Census and Statistics of Sri Lanka. (2012). Population. Department of Census and Statistics. Retrieved from http://www.statistics.gov.lk/PopHouSat/PopulationAtla 2012/04 DSLevelMaps LMap\%20P3.12.4.1\%20Gampaha\%20\%20Population\%20by\%20Ethnicity\%20by\%20DS.pdf

Department of Government printing of Sri Lanka. The Gazette of the Democratic Socialist Republic of Sri Lanka (2013).

Detlor, B. (2010). Information Management. International Journal of Information Management, 30(2), 103-108. doi:10.1016/j.ijinfomgt.2009.12.001

Dewey, J. (1916). Democracy and education: an introduction to the philosophy of education. New York: Cosimo.

Di Lecce, V., Giove, A., \& Quarto, A. (2009). A virtual classroom interface for student participation measurement (pp. 255-260). IEEE. doi:10.1109/VECIMS.2009.5068904

Dineen, F., Mayes, J. T., \& Lee, J. (1999). Vicarious learning through capturing taskdirected discussions. Learning Technologies Journal, 7(3), 33-43.

Do, V. H. (2015). Contextual factors affecting the development of digital library education in Vietnam. Victoria University of Wellington, New Zealand. Retrieved from http://researcharchive.vuw.ac.nz/bitstream/handle/10063/4390/thesis.pdf?se quence $=2$

Dominic, M., Francis, S., \& Pilomenraj, A. (2014). E-Learning in web 3.0. IJ Modern Education and Computer Science, 2, 8-14.

Dorner, D. G., \& Gorman, G. E. (2006). Information Literacy Education in Asian Developing Countries: cultural factors affecting curriculum development and programme delivery. IFLA Journal, 32(4), 281-293. doi:10.1177/0340035206074063

Downes, S. (2005, October). Feature: E-learning 2.0. eLearn Magazine, 2005(10), 1.

Downey, S., Wentling, R. M., Wentling, T., \& Wadsworth, A. (2005). The Relationship between National Culture and the Usability of an E-learning System. Human Resource Development International, 8(1), 47-64. doi:10.1080/1367886042000338245 
Dunkin, M. J. (1987). Introduction to section 4: Classroom practices. In M. Dunkin (Ed.), The International Encyclopaedia of Teaching and Teacher Education (pp. 313326). Oxford: Pergamon press.

Earl, K., \& Forbes, D. (2008). Information communication technology: destinations, highways, signposts and speed bumps. In C. McGee \& D. Fraser (Eds.), The professional practice of teaching (3rd ed., pp. 189-203). Melbourne: Cengage.

Earl, M. J. (1989). Management strategies for information technology. Hemel Hempstead: Prentice Hall.

Efimova, L. (2004). Discovering the iceberg of knowledge work: A weblog case. Presented at the 5th European Conference on Organizational Knowledge, Learning and Capabilities (OKLC 2004), Innsbruck, Austria. Retrieved from https://doc.telin.nl/dsweb/Get/Document-34786/

Ehlers, U. D. (2009). Web 2.0 - e-learning 2.0 - quality 2.0? Quality for new learning cultures. Quality Assurance in Education, 17(3), 296-314. doi:10.1108/09684880910970687

Ehlers, U.-D. (2004). Quality in e-Learning from a Learner's Perspective. Retrieved

February 8, 2011, from

http://www.eurodl.org/materials/contrib/2004/Online Master COPs.html

Eke, H. N. (2010). The perspective of e-learning and libraries in Africa: challenges and opportunities. Library Review, 59(4), 274-290. doi:10.1108/00242531011038587

Ellaway, R., \& Masters, K. (2008). AMEE Guide 32: e-Learning in medical education Part 1: Learning, teaching and assessment. Medical Teacher, 30(5), 455-473. doi:10.1080/01421590802108331

Ellsworth, J. B. (2000). Surviving change: A survey of educational change models. New York: ERIC Clearinghouse on Information and Technology.

Ely, D. P. (1990). Conditions that facilitate the implementation of educational technology innovations. Journal of Research on Computing in Education, 23(2), 298-305.

Engelbrecht, E. (2003). A look at e-learning models: investigating their value for developing an e-learning strategy. Progressio, 25(2), 38-47.

Essam, S., \& Al-Ammary, J. (2013). The Impact of Motivation and Social Interaction on the E-Learning at Arab Open University, Kingdom of Bahrain. Creative Education, 04(10), 21-28. http://doi.org/10.4236/ce.2013.410A004

Esterberg, K. G. (2002). Qualitative methods in social research. Boston: McGraw-Hill.

Fang, T. (2003). A Critique of Hofstede's Fifth National Culture Dimension. International Journal of Cross Cultural Management, 3(3), 347-368. doi:10.1177/1470595803003003006

Feather, J. (2004). The information society: A study of continuity and change. London: Facet publishing.

Federal Communication Commission. (2010). National Broadband Plan: connecting America. Washington, DC: Federal Communication Commission. Retrieved from https://www.fcc.gov/national-broadband-plan

Fernando, S. (2008). Issues of e-learning in third world countries. In L. Tomei, Online and Distance Learning : Concepts, Methodologies, Tools, and Applications (pp. 1880-1887). Hershey: Idea Group Publishing.

Fischer, F., Troendle, P., \& Mandl, H. (2003). Using the internet to improve university education: problem-oriented web-based learning with MUNICS. Interactive Learning Environment, 11(03), 193-214. 
Fitzgerald, B., \& Howcroft, D. (1998). Competing dichotomies in IS research and possible strategies for resolution. Retrieved from http://delivery.acm.org/10.1145/360000/353066/p155fitzgerald.pdf?key1=353066\&key2=1991124921\&coll=DL\&dl=ACM\&CFID=5011 530\&CFTOKEN $=73544494$

Flick, U. (2006). An introduction to qualitative research (3rd ed.). London: Sage.

Forman, D., Nyatanga, L., \& Rich, T. (2002). E-learning and educational diversity. Nurse Education Today, 22, 76-82. doi:10.1054/nedt.2001.0740

Forrester Research. (2000). Online training needs a new course (Research Report). Retrieved from http://www.forrester.com/ER/Research/Report/Excerpt/0,1338,10060,FF.html

Foster, J., Bowskill, N., Lally, V., \& McConnell, D. (1999). Preparing for networked collaborative learning: An institutional view. Presented at the European Conference on Educational Research, Finland. Retrieved from http://www.leeds.ac.uk/educol/documents/00001335.htm

Freire, P. (1970). Pedagogy of the oppressed. New York: Continuum.

Freitas, D. S., \& Oliver, M. (2005). Does e-learning policy drive change in higher education?: A case study relating models of organisational change to e-learning implementation. Journal of Higher Education Policy and Management, 27(1), 8196. doi:10.1080/13600800500046255

Fry, K. (2000). Forum focus and overview. In K. Fry (Ed.), The Business of E-Learning, Bringing your Organization in to the Knowledge E-conomy. Sydney: University of Technology.

Fry, K. (2001). E-learning markets and providers: some issues and prospects. Education + Training, 43(4/5), 233-239. doi:10.1108/EUM0000000005484

Fullan, M. (1982). The Meaning of Educational Change. Ontario: OISE Press/The Ontario Institute for Studies in Education.

Fullan, M. (1993). Changing forces: probing the depths of educational reform. London, UK: Falmer Press.

Fullan, M. (2001). The New Meaning of Educational Change (3rd ed.). New York: Teachers College Press.

Fullan, M. (2007). The New Meaning of Educational Change (4th ed.). New York: Teachers College Press.

Fullan, M., \& Stiegelbauer, S. (1991). The New Meaning of Educational Change (2nd ed.). London: Cassell Educational Limited.

Gagnon, Y. (2010). The case study as research method: a practical handbook. Quebec: University of Quebec Press.

Galliers, R. D., \& Baker, B. S. H. (1994). Strategic information management: Challenges and strategies in managing information systems. Oxford: Butterworth Heineman.

Galpaya, H. (2011). Broadband in Sri Lanka: Glass half full or half empty?. Washington, DC.: InfoDev/World Bank. Retrieved from http://wwwwds.worldbank.org/external/default/WDSContentServer/WDSP/IB/2012/05/2 9/000427087 20120529123341/Rendered/PDF/691820ESW0P1200oadband0 in0Sri0Lanka.pdf

Gamage, P., \& Halpin, E. F. (2007). E-Sri Lanka: bridging the digital divide. The Electronic Library, 25(6), 693-710. http://doi.org/10.1108/02640470710837128

Garrison, D. R., \& Anderson, T. (2003). E-learning in the 21st century: A framework for research and practice. London: Routledge Falmer. 
Gerring, J. (2007). Case study Research: principles and practices. New York: Cambridge university press.

Gibbons, A., \& Fairweather, P. (2000). Computer-based instruction. In S. Tobias \& J. Fletcher (Eds.), Training and Retraining: A Handbook for Business, Industry, Government, and the Military (pp. 410-442). New York: Macmillan Reference.

Gladieux, L. E., \& Swail, W. S. (1999). The virtual university and educational opportunity: issues of equity and access for the next generation. Washington: The College Board.

Gladieux, L. E., \& Swail, W. S. (1999). The virtual university and educational opportunity: issues of equity and access for the next generation. Washington: The College Board.

Goddard, A. (1998). Facing up to market forces. Times Higher Education Supplement. Retrieved from http://www.timeshighereducation.co.uk/story.asp?storyCode $=109862 \&$ sectionc $\underline{\text { ode }=26}$

Goddard, A. (2000). Big brands key to e-university. Times Higher Education Supplement. Retrieved from http://www.timeshighereducation.co.uk/story.asp?storyCode=152083\&sectionc $\underline{\text { ode }=26}$

Gonce-Winder, C., Kidd, R. O., \& Lenz, E. R. (1993). Optimizing computer-based system use in health professions' education programs. Computers in Nursing, 11(4), 197202.

Gorman, G. E., \& Clayton, P. (2005). Qualitative research for the information professional: a practical handbook. London: Facet publishing.

Gorman, G. E., \& Corbitt, B. J. (2002). Core competencies in information management education. New Library World, 103(11/12), 436-445. doi:10.1108/03074800210452969

Goswami, P. R., \& Jain, P. K. (2008). Information Professionals in the South Asian Region: The Challenges Ahead. Bulletin of the American Society for Information Science and Technology, 34(3), 26-29.

Govindasamy, T. (2002). Successful implementation of e-Learning: Pedagogical considerations. The Internet and Higher Education, 4(3-4), 287-299. doi:10.1016/S1096-7516(01)00071-9

Greenhalgh, T., Robbert, G., Macfarlane, F., Bate, P., \& Kyriakidou, O. (2004). Diffusion of Innovations in Service Organizations: Systematic Review and Recommendations. Milbank Quarterly, 82(4), 581-629. doi:10.1111/j.0887-378X.2004.00325.x

Gregg, D. G. (2007). E-learning agents. The Learning Organization, 14(4), 300-312. http://doi.org/10.1108/09696470710749245

Grigg, P., \& Stephens, C. D. (1998). Computer-assisted learning in dentistry: a view from the UK. Journal of Dentistry, 26(5-6), 387-395. doi:10.1016/S03005712(98)00012-8

Grossman, G. M. (2013). Developing social capital through national education: the transformation of teacher education in Turkey. In I. R. Haslam, M. S. Khine, \& I. M. Saleh (Eds.), Large scale school reform and social capital building. UK: Routledge.

Grossman, L. (2014, December). The man who wired the world: Mark Zuckerberg's crusade to put every single human being online. Time International, 184(23), 3442. 
Guba, E. G., \& Lincoln, Y. S. (1994). Competing paradigms in qualitative research. In N. K. Denzin \& Y. S. Lincon (Eds.), Handbook of qualitative research. Thousand Oaks: Sage.

Gulati, S. (2008). Technology-Enhanced Learning in Developing Nations: A review. International Review of Research in Open and Distance Learning, 9(1), 1-16.

Gunasekaran, A., McNeil, R. D., \& Shaul, D. (2002). E-learning: research and applications. Industrial and Commercial Training, 34(2), 44-53. doi:10.1108/00197850210417528

Gunawardana, K. D. (2005). An Empirical Study of potential challenges and Benefits of Implementing E-learning in Sri Lanka. In Proceedings of the Second International Conference on eLearning for Knowledge-Based Society (pp. 33.1-33.8). Bangkok, Thailand. Retrieved from http://www.elearningap.com/eLAP2005/Proceeding/PP33.pdf

Gunawardena, C. N., Linder-VanBerschot, J. A., LaPointe, D. K., \& Rao, L. (2010). Predictors of Learner Satisfaction and Transfer of Learning in a Corporate Online Education Program. American Journal of Distance Education, 24(4), 207-226. http://doi.org/10.1080/08923647.2010.522919

Gunn, C. (2000). Identity, control, and change reality. Retrieved from http://www.ascilite.org.au/conferences/coffs00/papers/cathy gunn keynote.pd $\underline{f}$

Guri-Rosenblit, S. (2001). Virtual universities: current models and future trends. Higher Education in Europe, XXVI(4), 487-499.

Guri-Rosenblit, S. (2002). A top down strategy to enhance information technologies into Israeli higher education. International Review of Research in Open and Distance Learning, 2(2).

Guri-Rosenblit, S. (2004). Distance Education Teachers in the Digital Age: New Roles and Contradictory Demands. In J. E. Brindley, C. Walti, \& O. Zawacki-Richter (Eds.), Learner Support in Open, Distance and Online Learning Environments (Vol. 9, pp. 63-70). Oldenburg: BIS-Verlag der. Retrieved from http://www.mde.uni-oldenburg.de/download/asfvolume9 ebook.pdf\#page $=64$

Guri-Rosenblit, S. (2005a). "Distance education" and "e-learning": Not the same thing. Higher Education, 49, 467-493. doi:10.1007/s10734-004-0040-0

Guri-Rosenblit, S. (2005b). Eight paradoxes in the Implementation process of e-learning in higher education. Higher Education Policy, 18, 5-29.

Hall, E. T. (1976). Beyond culture. New York: Doubleday.

Hall, E. T. (2000). Context and meaning. In L. A. Samovar \& R. E. Porter (Eds.), Intercultural Communication: A reader (9th ed., pp. 34-43). Belmont: Wadsworth Publishing Co.

Hall, G., Wallace, R., \& Dossett, W. (1973). A development conception of the adoption process within educational institutions ( No. 3006). Texas: The University of Texas at Austin, Research and Development Centre for Teacher Education.

Hall, R. A. (2013). Assessment of wide-scale educational reform initiatives: opportunities in social capital building. In I. R. Haslam, M. S. Khine, \& I. M. Saleh (Eds.), Large scale school reform and social capital building. UK: Routledge.

Hamid, A. A. (2002). e-learning, is it the "e" or the learning that matters. Internet and Higher Education, 4, 311-316.

Hampden-Turner, C., \& Trompenaars, A. (1993). The seven cultures of capitalism : value systems for creating wealth in the United States, Japan, Germany, France, Britain, Sweden, and the Netherlands (1st ed.). New York: Doubleday. 
Handal, B. (2004). Teachers' Instructional Beliefs about Integrating Educational Technology. E-Journal of Instructional Science and Technology, 17(1), 1-10.

Handal, B., \& Herrington, A. (2003). Mathematics Teachers' Beliefs and Curriculum Reform. Mathematics Education Research Journal, 15(1), 59-69.

Handal, B., Bobis, J., \& Grimison, L. (2001). Teachers' mathematical beliefs and practice in teaching and learning thematically. In J. Bobis, B. Perry, \& M. Mitchelmore (Eds.), Numeracy and Beyond (pp. 265-272). Sydney: MERGA: Research Group of Australasia Inc.

Hansson, H., Mozelius, P., Gaiani, S., \& Meegammana, N. (2010). Women empowerment in rural areas through the usage of telecentres - a Sri Lankan case study. In 2010 International Conference on Advances in ICT for Emerging Regions (ICTer) (pp. 510). Colombo, Sri Lanka. doi:10.1109/ICTER.2010.5643279

Hargreaves, A. (2005). Educational Change Takes Ages: Life, Career and Generational Factors in Teachers' Emotional Responses to Educational Change. Teaching and Teacher Education, 21, 967-983.

Harley, D., Henke, J., Lawrence, S., Maher, M., Gawlik, M., \& Muller, P. (2002). An analysis of technology enhancement in a large lecture course at UC Berkeley: costs, cultures, and complexity. Berkeley: Centre for Studies in Higher Education.

Harper, K. C., Chen, K., \& Yen, D. C. (2004). Distance learning, virtual classrooms, and teaching pedagogy in the Internet environment. Technology in Society, 26(4), 585-598. doi:10.1016/j.techsoc.2004.08.002

Harris, A., \& Jones, M. (2013). System improvement through capacity building: the power and potential of professional learning. In I. R. Haslam, M. S. Khine, \& I. M. Saleh (Eds.), UK: Routledge.

Hase, S., \& Ellis, A. (2001). Problems with online learning are systemic not technical. In J. Stephenson (Ed.), Teaching and Learning Online: Pedagogies for New Technologies. UK: Kogan Page.

Hassan, W. S. (2010). Teachers' Adoption of Information and Communication Technology for Learning in Malaysia: an Ecological-Complexity Analysis of a Professional Development Innovation. Victoria University of Wellington, New Zealand. Retrieved from http://hdl.handle.net/10063/1580

Havelock, R., \& Zlotolow, S. (1995). The change agent's guide (2nd ed.). New Jersey: Educational Technology Publications, Inc.

Hayne, Y. (1989). Instructional computing in Alberta nursing programs as perceived by program leaders. AARN Newsletter, 45(1), 29-32.

Helsper, E. J., \& Eynon, R. (2010). Digital natives: where is the evidence? British Educational Research Journal, 36(3), 503-520. doi:10.1080/01411920902989227

Henderson, J. V. (1998). Comprehensive, Technology-Based Clinical Education: The "Virtual Practicum." The International Journal of Psychiatry in Medicine, 28(1), 41-79.

Hennink, M., Hutter, I., \& Bailey, A. (2011). Qualitative Research Methods. London: Sage.

Henry, P. (2001). E-learning technology, content and services. Education + Training, 43(4/5), 249-255. doi:10.1108/EUM0000000005485

Hofstede, G. (1980). Culture's Consequences: International differences in work-related values. Beverly Hills: Sage publications.

Hofstede, G. (1991). Cultures and Organizations: software of the mind. New York: McGraw-Hill. 
Hofstede, G. (2001). Culture's consequences: Comparing values, behaviours, institutions and organizations across nations (2nd ed.). Thousand Oaks: Sage.

Hofstede, G. (2003). What is culture? A reply to Baskerville. Accounting, Organizations and Society, 28(7-8), 811-813. doi:10.1016/S0361-3682(03)00018-7

Hofstede, G., \& Hofstede, G. J. (2005). Cultures and organizations: software of the mind (2nd ed.). New York: McGraw-Hill.

Hofstede, G., Hofstede, G. J., \& Minkov, M. (2010). Cultures and organizations: software of the mind (3rd ed.). New York: McGraw-Hill.

Horton, B. (2012). Setting National Broadband Policies, Strategies and Plans. In Trends in Telecommunication Reform 2012. Geneva: ITU.

House, R. J., Hanges, P. J., Javidan, M., Dorfman, P. W., \& Gupta, V. (2004). Culture, leadership, and organizations: The GLOBE study of 62 Societies. Thousand Oaks: Sage publications.

Hrtoňová, N., Kohout, J., Rohlíková, L., \& Zounek, J. (2015). Factors influencing acceptance of e-learning by teachers in the Czech Republic. Computers in Human Behavior, 51, 873-879. http://doi.org/10.1016/j.chb.2014.11.018

Huan, N. B. (2013). Beliefs about support for teacher change in English for specific purposes university classes. New Zealand Studies in Applied Linguistics, 19(2), 36-48.

Huffaker, D. A., \& Calvert, S. I. (2003). The new science of learning:Active learning, metacognition,and transfer of knowledage in e-learning applications. Journal of Educational Computing Research, 29(3), 325-334.

Hulsmann, T. (2004). The two-pronged attack on learner support:costs and centrifugal forces of convergence. In U. Bernath \& A. Szcus (Eds.), Supporting the learner in distance education and e-learning: proceedings of the third EDEN research workshop (pp. 498-504). Oldenburg: University of Oldenburg.

Hussin, H., Bunyarit, F., \& Hussein, R. (2009). Instructional design and e-learning: Examining learners' perspective in Malaysian institutions of higher learning. Campus-Wide Information Systems, 26(1), 4-19. doi:10.1108/10650740910921537

Huwe, T. K. (2004). Keep those web skills current. Computers in Libraries, 24(8), 40-42. ICTA. (2010). Outcome evaluation report of Nenasala project ICTA, Sri Lanka. Colombo, Sri Lanka: Information Communication Technology Agency (ICTA).

ICTA. (2014). Transforming the nation: programs. Retrieved January 14, 2015, from http://www.icta.lk

Inglis, A. (1999). Is online delivery less costly than print and is it meaningful to ask? Distance Education, 20(2), 220-239. doi:10.1080/0158791990200204

International Telecommunication Union (ITU). (2012). Strategies for the promotion of broadband services and infrastructure: A case study on Sri Lanka. Switzerland: ITU International Telecommunication Union. Retrieved from www.itu.int/ITUD/treg/publications/BB MDG SriLanka Final.pdf

IRQUE. (2009). Improving relevance and quality of undergraduate education: a World Bank assisted project. Retrieved February 10, 2011, from http://www.irque.lk/index.php

Ismail, S. A. (2014). Factors affecting the implementation of information literacy education in Malaysian primary schools. Victoria University of Wellington, New Zealand. Retrieved from http://researcharchive.vuw.ac.nz/bitstream/handle/10063/3681/thesis.pdf?se quence $=2$ 
ITU International Telecommunication Union. (2012). Strategies for the promotion of broadband services and infrastructure: A case study on Sri Lanka.

Jaen, X., Bohigas, X., \& Novell, M. (2007). The need for virtual information managers in education. Computers \& Education, 49(2), 254-268. doi:10.1016/j.compedu.2005.06.015

Jasinski, M., \& Thiagarajan, S. (2000). Virtual games for real learning: Learning online with serious fun. Educational Technology, 40(4), 61-63.

Jenkins, H. (2006). Fans, bloggers, and gamers: Exploring participatory culture. New York: New York University Press.

JISC. (2008, January). Information behaviour of the researcher of the future. Retrieved from http://www.webarchive.org.uk/wayback/archive/20140614113419/http://w ww.jisc.ac.uk/media/documents/programmes/reppres/gg_final_keynote_11012 008.pdf

Johnson, N. A., Zhang, D., \& Gallagher, M. (2002). Book Review. Journal of Information Techology for Teacher Education, 11(3), 355-359. http://doi.org/10.1080/14759390200200142

Johnson, R. D., Hornik, S., \& Salas, E. (2008). An empirical examination of factors contributing to the creation of successful e-learning environments. International Journal of Human-Computer Studies, 66(5), 356-369. doi:10.1016/j.ijhcs.2007.11.003

Karim, N., \& Hussein, R. (2008). Managers' perception of information management and the role of information and knowledge managers: The Malaysian perspectives. International Journal of Information Management, 28(2), 114-127. doi:10.1016/j.ijinfomgt.2007.08.003

Katz, R. (2001). Campus champs tackle heavies. Times Higher Education Supplement. Retrieved from http://www.timeshighereducation.co.uk/story.asp?storyCode $=166174 \&$ sectionc $\underline{\text { ode }=26}$

Katz, Y. J. (2000). The Comparative Suitability Of Three ICT Distance Learning Methodologies For College Level Instruction. Educational Media International, 37(1), 25-30. doi:10.1080/095239800361482

Katz, Y. J. (2002). Attitudes affecting college students' preferences for distance learning. Journal of Computer Assisted Learning, 18(1), 2-9. doi:10.1046/j.02664909.2001.00202.x

Kawachi, P. (2003). Asia-specific scaffolding needs in grounded design e-learning : Empirical comparisons among several institutions (p. R2937). Presented the 17th Annuual Conference of the Asian Association of Open Universities, Bangkok. Retrieved from http://www.open-ed.net/library/R2937.pdf

Kaye, D. (1995). The importance of information. Library Management, 16(5), 6-15. doi:10.1108/01435129510772283

Keller, C., Lindh, J., Hrastinski, S., Casanovas, I., \& Fernandez, G. (2009). The impact of national culture on e-learning implementation: a comparative study of an Argentinean and a Swedish university. Educational Media International, 46(1), 67-80. http://doi.org/10.1080/09523980902781253

Khafagi, B. (2004). Education is the key-Middle Eastern countries invest in the future. Retrieved from http://tojde.anadolu.edu.tr/tojde19/news/interview.htm

Kirkman, B. L., Lowe, K. B., \& Gibson, C. B. (2006). A quarter century of Culture's Consequences: a review of empirical research incorporating Hofstede's cultural 
values framework. Journal of International Business Studies, 37(3), 285-320. doi:10.1057/palgrave.jibs.8400202

Kitzinger, J. (1995). Qualitative Research: Introducing focus groups. British Medical Journal, 311, 299-302.

Klein, H. K., \& Myers, M. D. (1999). A Set of Principles for Conducting and Evaluating Interpretive Field Studies in Information Systems. MIS Quarterly, 23(1), 67-94.

Koehler, M. J., \& Mishra, P. (2008). Introducing TPCK. In AACTE Committee on Innovation and Technology (Ed.), The handbook of technological pedagogical content knowledge (tpck) for educators. Mahway, New Jersey: Lawrence Erlbaum Associates.

Krueger, R. A. (1994). Focus groups: A practical guide for applied research. Thousand Oaks: Sage.

Krueger, R. A., \& Casey, M. A. (2000). Focus groups: A practical guide for applied research (3rd ed.). Thousand Oaks: Sage.

Krumbholz, M., \& Maiden, N. (2001). The implementation of enterprise resource planning packages in different organisational and national cultures. Information Systems, 26(3), 185-204. doi:10.1016/S0306-4379(01)00016-3

Kularatne, E. D. T. (1997). Information Needs and Information Provision in Developing Countries. Information Development, 13(3), 117-121. doi:10.1177/0266666974238708

Kung-Ming, T., \& Khoon-Seng, S. (2005). Asynchronous and synchronous interaction. In Encyclopedia of Distance Learning (pp. 104-113). Hershey: Idea Group Reference. Retrieved from http://www.igi-global.com/gateway/contentowned/Chapters.aspx?TitleId=351

LaMaster, K., \& Tannehill, D. (1999). Pre-service teachers as mentors using telecommunications. International Journal of Educational Telecommunications, 5(1), 25-46.

Latchem, C., \& Jung, I. (2010). Distance and blended learning in Asia. New York \& London: Routledge.

Laurillard, D. (2000). New technologies, students and the curriculum: the impact of communications and information technology on higher education. In P. Scott (Ed.), Higher Education Re-formed (pp. 133-153). London: Palmer Press.

Lee, B.-C., Yoon, J.-O., \& Lee, I. (2009). Learners' acceptance of e-learning in South Korea: Theories and results. Computers \& Education, 53(4), 1320-1329. doi:10.1016/j.compedu.2009.06.014

Li, Y., Duan, Y., Fu, Z., \& Alford, P. (2012). An empirical study on behavioural intention to reuse e-learning systems in rural China: A study on intention to reuse e-learning in rural China. British Journal of Educational Technology, 43(6), 933-948. http://doi.org/10.1111/j.1467-8535.2011.01261.x

Liamputtong, P. (2009). Qualitative research methods (3rd ed.). Australia: Oxford.

Lim, C. K. (2001). Computer self-efficacy, academic self-concept, and other predictors of satisfaction and future participation of adult distance learners. American Journal of Distance Education, 15(2), 41-51.

Lin, A. C. (1998). Bridging positivist and interpretivist approaches to qualitative methods. Policy Studies Journal, 26(1), 162-180. doi:10.1111/j.15410072.1998.tb01931.x

Lincoln, Y. S., \& Guba, E. G. (2000). Paradigmatic controversies, contradictions, and emerging confluences. In N. K. Denzin \& Y. S. Lincon (Eds.), Handbook of qualitative research (2nd ed., pp. 163-188). Thousand Oaks: Sage. 
Littleton, K., \& Light, P. (Eds.). (1999). Learning with computers: Analysing productive interaction. London: Routledge.

Lopez,J. (2010). Review of All systems go: The change imperative for whole system reform by M. Fullan. Education Review,13. Retrieved 15 Nov. 2013 from http://www.edrev.info/reviews/rev994.pdf

Lovat, T. J., \& Smith, D. (1995). Curriculum: Action on reflection revisited. Australia: Social Science Press.

Lyytinen, K., \& Damsgaard, J. (2001). What's Wrong with the Diffusion of Innovation Theory: The Case of a Complex and Networked Technology. In M. A. Ardis \& B. L. Marcolin (Eds.), Diffusing Software Product and Process Innovations (pp. p.1-20). Boston: Kluwer Academic Press.

Ma, J. (2010). Implementing e-learning in traditional universities: drivers and barriers? A comparative study of two Chinese universities and one Swedish university. Jonkoping University, Jonkoping. Retrieved from http://www.diva-portal.org/smash/get/diva2:323234/FULLTEXT01.pdf

Macan Markar, D., Madurapperuma, A. P., \& Maroulis, J. (2006). Problem-based learning - is it right for Sri Lanka? (pp. 1-24). Presented at the APERA Conference 2006, Hong Kong. Retrieved from http://edisdat.ied.edu.hk/pubarch/b15907314/full paper/971571749.pdf

Macdonald, J., \& Twining, P. (2002). Assessing activity-based learning for a networked course. British Journal of Educational Technology, 33(5), 603-618. doi:10.1111/1467-8535.00295

Macdonald, J., Heap, N., \& Mason, R. (2001). “Have I learnt it?" Evaluating skills for resource-based study using electronic resources. British Journal of Educational Technology, 32(4), 419-433. doi:10.1111/1467-8535.00211

Mahdizadeh, H., Biemans, H., \& Mulder, M. (2008). Determining factors of the use of elearning environments by university teachers. Computers \& Education, 51(1), 142-154. doi:10.1016/j.compedu.2007.04.004

Makrakis, V. (2010). Strategies for change towards sustainability in tertiary education supported by ICT. In ICT in Teacher Education: Policy, Open Educational Resources and partnership (pp. 152-165). St. Petersburg, Russian Federation: UNESCO Institute of Information Technologies in Education. Retrieved from http://iite.unesco.org/pics/publications/en/files/3214684.pdf

Mamary, E. M., \& Charles, P. (2000). On-site to on-line: Barriers to the use of computers for continuing education. Journal of Continuing Education in the Health Professions, 20(3), 171-175. doi:10.1002/chp.1340200306

Maps of World. (2009). Sri Lanka Political Map. Retrieved November 13, 2010, from http://www.mapsofworld.com/sri-lanka/sri-lanka-political-map.html

Marshall, C., \& Rossman, G. B. (2006). Designing qualitative research (4th ed.). Thousand Oaks: Sage.

Martinez, R. A., del Bosch, M. M., Herrero, H. P., \& Nuno, A. S. (2007). Psychopedagogical components and processes in e-learning, Lessons from an unsuccessful on-line course. Computers in Human Behavior, 23(1), 146-161.

Martinez, S., \& Prensky, M. (2011). Is the digital native a myth? Learning \& Leading with Technology, 39(3), 6-7.

Martinez, T., Cummins, P., Savenye, W., \& Shewell, J. (2012). E-Learning as a Core Component of the Instructional Design Profession. International Journal of Advanced Corporate Learning (iJAC), 5(3), 37-42.

Mason, J. (2002). Qualitative researching (2nd ed.). London: Sage. 
Matkin, G. W. (2002). The Whys and Hows of Online Education at UC: A Dean's Perspective. UCLtC News. Retrieved from http://www.ucop.edu/tltc/news/2002/06/matkin.php

McAuley, R. J. (1998). Requiring students to have computers: questions for consideration. Academic Medicine, 73(6), 669-673.

McCalla, G. (2004). The Ecological Approach to the Design of E-Learning Environments: Purpose-based Capture and Use of Information About Learners. Journal of Interactive Media in Education, 7(7).

McConnell, D. (2001). Implementing computer supported co-operative learning. London: Kogan Page.

McGee, J. V., \& Prusak, L. (1993). Managing information strategically. Toronto: John Wiley \& Sons, Inc.

McGorry, S. Y. (2003). Measuring quality in online programs. The Internet and Higher Education, 6(2), 159-177. doi:10.1016/S1096-7516(03)00022-8

McLoughlin, C. (1999). Culturally responsive technology use: Developing an on-line community of learners. British Journal of Educational Technology, 30(3), 231243. doi:10.1111/1467-8535.00112

McLoughlin, C., \& Lee, M. J. W. (2007). Social software and participatory learning: Pedagogical choices with technology affordances in the Web 2.0 era. In ICT: Providing choices for learners and learning (pp. 664-675). Singapore. Retrieved from

http://www.ascilite.org.au/conferences/singapore07/procs/mcloughlin.pdf

McPherson, M. A. (2003). Organizational critical success factors for managing the implementation of e-learning in higher education. In M. A. McPherson, L. Henderson, \& L. Kinshuk (Eds.), Proceedings of the workshop on the changing face of HE in the 21st century: Critical success factors for implementing e-learning (pp. 8-14). New Zealand: Massey University.

McPherson, M., \& Nunes, M. B. (2006). Organisational issues for e-learning: Critical success factors as identified by HE practitioners. International Journal of Educational Management, 20(7), 542-558. doi:10.1108/09513540610704645

McSweeney, B. (2002). Hofstede's Model of National Cultural Differences and their Consequences: A Triumph of Faith - a Failure of Analysis. Human Relations, 55(1), 89-118. doi:10.1177/0018726702551004

Megatrends Project 2007. (2007a). Analyses of European Megaproviders of E-Learning (1st ed.). Norway: NKI Publishing House. Retrieved from http://nettskolen.nki.no/in english/megatrends/Book4.pdf

Megatrends Project 2007. (2007b). E-Learning initiatives that did not reach targeted goals (1st ed.). Norway: NKI Publishing House. Retrieved from http://nettskolen.nki.no/in english/megatrends/Book3.pdf

Mertens, D. M. (1998). Research methods in education and psychology: Integrating diversity with quantitative and qualitative approaches. Thousand Oaks: Sage.

Merz, H. (2014). Superfast Broadband Highway to Socio-Economic Transformation. Retrieved from http://www.radio-electronics.com/articles/telecomsnetworks/superfast-broadband-highway-to-socio-economic-transformation-127

Meso, P., Musa, P., Straub, D., \& Mbarika, V. (2009). Information infrastructure, governance, and socio-economic development in developing countries. European Journal of Information Systems, 18(1), 52-65. doi:10.1057/ejis.2008.56

Meyer, S. M. (2001). The adoption of technology in higher/nursing education. Curationis, $24,32-36$. 
Miles, M. B., \& Huberman, A. M. (1994). Qualitative data analysis: A sourcebook of new methods (2nd ed.). Thousand Oaks: Sage.

Mingail, S. (2004). Good e-learning built on good instructional design. Canadian HR Reporter, 17(6), 12.

Ministry of Education and Training. (2006). Education developing strategic plan 20012010. Hanoi, Vietnam: Ministry of Education and Training.

Ministry of Education of New Zealand. (2002). Digital Horizons: learning through ICT. New Zealand: Ministry of Education.

Ministry of Education of New Zealand. (2006). Enabling the 21st Century Learner: An elearning action plan for schools 2006-2010. Learning Media Ltd. Retrieved from http://www.minedu.govt.nz/ /media/MinEdu/Files/EducationSectors/Primar ySecondary/PolicyAndStrategy/ELearningActionPlan.pdf

Ministry of Education Sri Lanka. (2012). Sri Lanka Education Information 2012. Colombo, Sri Lanka: Ministry of Education, Sri Lanka.

Ministry of Higher Education of Sri Lanka. (2015a). HETC-Higher Education for the Twenty-first century. Retrieved January 15, 2015, from http://www.mohe.gov.lk/index.php/hetc

Ministry of Higher Education of Sri Lanka. (2015b). Our vision and mission. Retrieved January 15, 2015, from http://www.mohe.gov.lk/index.php/en/about-ministry/vision-and-mission

Ministry of Higher Education, Sri Lanka. (2011). National Higher Education Srategic Management Plan of Sri Lanka: 2012-2015 Mid Term Plan. Colombo, Sri Lanka: Ministry of Higher Education.

Minkov, M. (2007). What makes us different and similar: A new Interpretation of the world values survey and other cross-cultural data. Bulgaria: Klasika still publishing house.

Mishra, S. (2002). A design framework for online learning environments. British Journal of Educational Technology, 33(4), 493-496.

Mishra, S. (Ed.). (2009). E-learning. New Delhi: IGNOU. Retrieved from http://webserver.ignou.ac.in/institute/STRIDE Hb8 webCD/STRIDE Hb8 Full.p $\underline{\mathrm{df}}$

Monereo, C. (2004). The virtual construction of the mind: the role of educational psychology. 32 Interactive Educational Multimedia, 9, 32-47.

Mont, R. D. (2005). E-learning as organizational strategy. In Encyclopaedia of Distance Learning (pp. 750-760). Hershey: Idea Group Reference. Retrieved from http://www.igi-global.com/gateway/contentowned/Chapters.aspx?TitleId=351

Moore, J. L., Dickson-Deane, C., \& Galyen, K. (2011). e-Learning, online learning, and distance learning environments: Are they the same? The Internet and Higher Education, 14(2), 129-135. http://doi.org/10.1016/j.iheduc.2010.10.001

Moore, M. (1989). Editorial: Three types of interaction. American Journal of Distance Education, 3(2), 1-7. doi:10.1080/08923648909526659

Moore, M. G. (1993). Three types of interaction. In K. J. Harry \& D. Keegan (Eds.), Distance Education: new perspectives (pp. 19-24). London: Routledge.

Moore, M. G. (2000). Is Distance Teaching More Work or Less? American Journal of Distance Education, 14(3), 1-5.

Moore, M., \& Kearsley, G. (1995). Distance Education: A systems view. Belmont: Wadsworth. 
Moran, L., \& Myringer, B. (1991). Flexible learning and university challenge. In K. Harry (Ed.), Higher Education through Open and Distance Learning (pp. 57-71). New York \& London: Routledge.

Motaghian, H., Hassanzadeh, A., \& Moghadam, D. K. (2013). Factors affecting university instructors' adoption of web-based learning systems: Case study of Iran. Computers \& Education, 61, 158-167. doi:10.1016/j.compedu.2012.09.016

Moussa, N., \& Moussa, S. (2009). Quality assurance of e-learning in developing countries. Nonlinear Analysis: Theory, Methods \& Applications, 71(12), e32-e34. http://doi.org/10.1016/j.na.2008.10.003

National Education Commission of Sri Lanka. (1991). National Education Commission Act, No. 19 of 1991. Government of Sri Lanka. Retrieved from http://www.nec.gov.lk/web/images/pdf/NEC Act.pdf

National Education Commission of Sri Lanka. (1996). National policy on University education. Retrieved from http://www.nec.gov.lk/web/images/pdf/policies/National Policy 1996.pdf

National Education Commission of Sri Lanka. (1997). University education reforms. Retrieved from http://nec.gov.lk/wp-content/uploads/2014/04/National Policy 1997.pdf

National Education Commission of Sri Lanka. (2009). New Education Act for General Education in Sri Lanka. Colombo, Sri Lanka: National Education Commission.

National Policy on Information Technology in School Education. (2001). Ministry of Education, Sri Lanka.

Neuman, W. L. (1994). Social research methods: qualitative and quantitative approaches (2nd ed.). Boston: Allyn and Bacon.

Neumann, J. W. (2013). Critical pedagogy's problem with changing teachers' dispositions towards critical teaching. Interchange, 44, 129-147. doi:10.1007/s10780-013-9200-4

Newton, D., \& Ellis, A. (2005). Effective implementation of e-learning: a case study of the Australian Army. The Journal of Workplace Learning, 17(5/6), 385-397. doi:10.1108/13665620510606797

Newton, D., Hase, S., \& Ellis, A. (2002). Effective implementation of online learning: a case study of the Queensland mining industry. Journal of Workplace Learning, 14(4), 156-165. doi:10.1108/13665620210427285

New Zealand Council for Education Research. (2004). Critical success factors and effective pedagogy for e-learning in tertiary education: Background paper for ITP New Zealand. New Zealand Council for Education Research. Retrieved from http://www.minedu.govt.nz/ /media/MinEdu/Files/EducationSectors/Tertiar yEducation/NZCERFinalReport.pdf

Nicaise, M., \& Crane, M. (1999). Knowledge constructing through hypermedia authoring. Educational Technology Research and Development, 47(1), 29-50. doi:10.1007/BF02299475

NODES. (2014). Our services. Retrieved from http://www.nodes.lk

O’Donoghue, J., \& Singh, G. (2001). A Study of Social-Learning Networks of Students Studying an On-Line Programme. In icalt (p. 0263). Madison, Wisconsin.

O’Neill, K., Singh, G., \& O’Donoghue, J. (2004). Implementation elearning programmes for higher education: A review of the literature. Journal of Information Technology Education, 3, 313-323.

O'Reilly, T. (2005). What Is Web 2.0 Design Patterns and Business Models for the Next Generation of Software. O’Reilly. Retrieved from 
http://facweb.cti.depaul.edu/jnowotarski/se425/What $\% 20$ Is $\% 20$ Web $\% 202 \% 2$ 0point\%200.pdf

Oblinger, D. (2003). Boomers, gen-Xers and millennials: Understanding the new students. Educause Review. Retrieved from http://er.educause.edu/ /media/files/article-downloads/erm0342.pdf

Olaniran, B. (2007). Challenges to implementing e-learning in lesser-developed countries. In A. Edmundson (Ed.), Globalized E-Learning Cultural Challenges (pp. 18-34). Hershey, PA: Information Science Publishing.

Oliver, G. (2011). Organisational culture for information managers. Oxford: Chandos Publishing.

Oliver, R. (1999). Exploring strategies for online teaching and learning. Distance Education, 20(2), 240-254. doi:10.1080/0158791990200205

Olson, J., Codde, J., deMaagd, K., Tarkelson, E., Sinclair, J., Yook, S., \& Egidio, R. (2011). An Analysis of e-Learning Impacts \& Best Practices in Developing Countries With Reference to Secondary School Education in Tanzania. Michigan State University. Retrieved from http://cas.msu.edu/wp-content/uploads/2013/09/E-LearningWhite-Paper oct-2011.pdf

Omekwu, C. O. (2006). Managing information and technology: critical roles for librarians in developing countries. The Electronic Library, 24(6), 847-863. doi:10.1108/02640470610714260

Omidinia, S., Masrom, M., \& Selamat, H. (2011). Review of E-Learning and ICT infrastructure in developing countries (case study of Iran). American Journal of Economics and Business Administration, 3(1), 120-125.

Orly, M. (2007). Multicultural e-learning project and comparison of teachers', student teachers' and pupils' perceptions about e-learning. Multicultural Education \& Technology Journal, 1(3), 178-191. doi:10.1108/17504970710822377

Oroma, J. O., Wanga, H., \& Fredrick, N. (2012). Challenges of e-learning in developing countries: The Ugandan experience. http://doi.org/10.13140/2.1.4754.1448

Oubenaissa, L., Giardina, M., \& Bhattacharya, M. (2002). Designing a framework for the implementation of situated online, collaborative, problem-based activity: operating within a local and multi-cultural learning context. International Journal of E-Learning, 1(3), 41-46.

Ouellette, P. (2000). Moving Toward Technology-Supported Instruction in Human Service Practice: The "Virtual Classroom." Journal of Technology in Human Services, 16(2), 97-111. doi:10.1300/J017v16n02_08

Ouellette, P., \& Briscoe, R. (2002). Walking Through the Fire: Integrating Technology to Enhance the Research Skills of Minority Mental Health Student Researchers. Journal of Technology in Human Services, 19(2), 91-107. doi:10.1300/J017v19n02_07

Owen, M., Grant, L., Sayers, S., \& Facer, K. (2006). Social software and learning. Bristol: Futurelab. Retrieved from http://archive.futurelab.org.uk/resources/documents/opening education/Socia l Software report.pdf

Ozkan, S., \& Koseler, R. (2009). Multi-dimensional students' evaluation of e-learning systems in the higher education context: An empirical investigation. Computers \& Education, 53(4), 1285-1296. doi:10.1016/j.compedu.2009.06.011

Pagram, P., \& Pagram, J. (2006). Issues in e-learning: A Thai case study. The Electronic Journal of Information Systems in Developing Countries, 26(6), 1-8. 
Pailing, M. (2002). E-learning: is it really the best thing since sliced bread? Industrial and Commercial Training, 34(4), 151-155. doi:10.1108/00197850210429138

Pajo, K., \& Wallace, C. (2001). Barriers to the uptake of web-based technology by university teachers. Journal of Distance Education, 16(1), 70-84.

Paloff, R., \& Pratt, K. (1999). Building learning communities in cyberspace. San Francisco: Jossey-Bass.

Pallegedara, A. (2011). Demand for private tuition classes under the free education policy: Evidence based on Sri Lanka. National graduate institute for policy studies, Tokyo, Japan. Retrieved from http://mpra.ub.uni-muenchen.de/31969/1/MPRA paper 31969.pdf

Parker, N. (2004). Theory and Practice of Online Learning. In T. Anderson (Ed.), The quality dilemma in online education (pp. 385-421). Canada: Athabasca.

Patton, M. Q. (1987). How to use qualitative methods in evaluation. California: Sage publications, Inc. Retrieved from http://books.google.co.nz/books?hl=en\&lr=\&id=shxPj6FxQSoC\&oi=fnd\&pg=PA5 \&dq=Patton+1987\%2Bqualitative\&ots $=$ gQsPnWBmdS\&sig=JUapd-kA413yLPqlNme7wJRiY\#v=onepage \&q=Patton $\% 201987 \% 2$ Bqualitative $\& \mathrm{f}=$ false

Patton, M. Q. (1990). Qualitative evaluation and research methods (2nd ed.). Newbury Park: Sage publications.

Petrusa, E. R., Issenberg, S. B., Mayer, J. W., Felner, J. M., Brown, D. D., Waugh, R. A., ... McGaghie, W. C. (1999). Implementation of a four-year multimedia computer curriculum in cardiology at six medical schools. Academic Medicine, 74, 123-129.

Pham, T. N. (2010). The higher education reform agenda: A vision for 2020. In G. Harman \& T. N. Pham, Reforming higher education in Vietnam: Challenges and priorities (Vol. 29, pp. 51-64). New York: Springer.

Pickard, A. J. (2007). Research Method in Information. London: Facet publishing.

Porcaro, D. (2011). Applying constructivism in instructivist learning cultures. Multicultural Education \& Technology Journal, 5(1), 39-54. doi:10.1108/17504971111121919

Powell, R. R., \& Connaway, L. S. (2004). Basic research methods for librarians. Westport: Libraries Unlimited.

Prensky, M. (2001a). Digital Natives, Digital immigrants Part 1. On the Horizon: The Strategic Planning Resource for Educational Professionals, 9(5).

Prensky, M. (2001b). Digital Natives, Digital Immigrants, Part II: Do They Really Think Differently? On the Horizon.

Prensky, M. (2005). Listen to the Natives. Educational Leadership, 63(4), 8-13.

Price, K. (2006). Web 2.0 and education: what it means for us all. Presented the Australian Computers in Educational Conference, Australia.

Prytherch, R. (Ed.). (2000). Harrod's Librarians' Glossary and Reference Book (9th ed.). Aldershot: Gower Publishing.

Quality Assurance and Accreditation Council of Sri Lanka (QAAC). (2008). Subject Review Report: Department of Library and Information Science. Colombo, Sri Lanka. Retrieved from http://www.qaacouncil.lk/qaa doc/subj review/reports/KLN/Dep library\%20i nformation $\% 20$ sciences.pdf

Rafferty, J. (2003). Update on elearning Project. Southampton: University of Southampton. 
Rajasingham, L. (2009a). Breaking boundaries: Quality e-learning for the global knowledge society. International Journal of Emerging Technologies in Learning, $4(1), 58-65$.

Rajasinghham, L. (2009b). The E-Learning Phenomenon: A New University Paradigm? IGI Global. Retrieved from http://64.225.152.8/downloads/excerpts/33409.pdf

Ramanayake, A., \& Jayamanne, I. (2012). Graduand Employment Census 2012. Colombo, Sri Lanka: Ministry of Higher Education Sri Lanka.

Ranaweera, P. (2010). Information Literacy Programmes Conducted by the Universities in Sri Lanka. Journal of the University Librarians Association of Sri Lanka, 14(1). doi:10.4038/jula.v14i1.2688

Rao, P. (2011). E-learning in India: the role of national culture and strategic implications. Multicultural Education \& Technology Journal, 5(2), 129-150. http://doi.org/10.1108/17504971111142664

Reeves, T. C., \& Reeves, P. M. (1997). Effective dimension of interactive learning on the World Wide Web. In B. H. Khan (Ed.), Web-based instruction (pp. 59-66). Englewood Cliffs: Educational Technology Publications, Inc. Retrieved from http://books.google.co.nz/books?hl=en\&lr=\&id=natcmen0I gC\&oi=fnd\&pg=PA5 9\&dq=Reeves\%2BReeves\%2Beffective+dimension\&ots=frFGrEYmRs\&sig=LPtQ q6pnkehjiKpwsbysR5dDTsE\#v=onepage\&q\&f=false

Reigeluth, C., \& Garfinkle, R. (Eds.). (1994). Systematic change in education. New Jersey: Educational Technology Publications.

Reitz, J. M. (2010). Information Management. ODLIS Online Dictionary for Library and Information Science. Retrieved from http://www.abc-clio.com/ODLIS/odlis A.aspx

Reviere, R. (Ed.). (1996). Needs Assessment: A creative and practical guide for social scientists. Washington: Taylor and Francis.

Richards, J. C., Gallo, P. B., \& Renandya, W. A. (2001). Exploring Teachers' Beliefs and the Processes of Change. PAC Journal, 1(1), 41-58.

Richardson, V., \& Placier, P. (2001). Teacher Change. In V. Richardson (Ed.), Handbook of Research on Teaching (4th ed., pp. 905-947). Washington, DC.: American Educational Research Association.

Richardson, W. (2006). Blogs, Wikis, Podcasts, and other powerful tools for classrooms. Thousand Oaks: Sage.

Roberts, K. (2010). Book Review of Surviving Change: A Survey of Educational Change Models. Retrieved from http://kimcroberts.weebly.com/uploads/1/6/1/8/16182300/book_review.pdf

Robinson, S., \& Guernsey, L. (1999, October 6). Microsoft and MIT to launch I-campus. International Harlod Tribune.

Rogers, E. M. (1962). Diffusion of innovations. New York: The Free Press.

Rogers, E. M. (1995). Diffusion of innovations (4th ed.). New York: The Free Press.

Rogers, E. M. (2003). Diffusion of Innovations (5th ed.). New York: The Free Press.

Ronteltap, F., \& Eurelings, A. (2002). Activity and Interaction of Students in an Electronic Learning Environment for Problem-Based Learning. Distance Education, 23(1), 11-22. doi:10.1080/01587910220123955

Rossiter, D. E. (2006). Embedding e-learning in universities: Analysis and conceptualisation of change process. Queensland University of Technology, Australia. Retrieved from http://eprints.qut.edu.au/16223/1/Darien Rossiter Thesis.pdf 
Rovai, A. P. (2004). A constructive approach to online college learning. The Internet and Higher Education, 7(2), 79-93.

Ruiz, J. G., Mintzer, M. J., \& Leipzig, M. (2006). The impact of teaching in medical education. Academic Medicine, 81(3), 207-212.

Ryan, S., Scott, B., Freeman, H., \& Patel, D. (2000). The virtual university: the internet and resource based learning. London: Kogan Page.

Ryan, Y. (2002). Emerging indicators of success and failure in borderless higher education. London: Higher Education.

Salmon, G. (2005). Flying not flapping: a strategic framework for e-learning and pedagogical innovation in higher education institutions. ALT-J, 13(3), 201-218. doi:10.1080/09687760500376439

Sangra, A., Vlachopoulos, D., \& Cabrera, N. (2012). Building an inclusive definition of elearning: An approach to the conceptual framework. The International Review of Research in Open and Distance Learning, 13(2), 145-158.

Sarmento, M., \& Durão, D. (2009). Ethics dimension in e-learning. Revista de Administração FACES Journal, 8(2), 44-53.

Schensul, J. J., Lecompte, M. D., Nastasi, B. K., \& Borgatti, S. P. (1999). Enhanced ethnographic methods: audio visual techniques, focused group, interviews, and elicitation techniques. Walnut Creek: AltaMira Press.

Schittek, M., Mattheos, N., Lyon, H. C., \& Attstrom, R. (2001). Computer assisted learning. A review. European Journal of Dental Education, 5, 93-100.

Schleyer, T. (1998). Assessing outcomes of an academic computing initiative. Journal of Dental Education, 62(6), 432-440.

SchoolNet Sri Lanka. (2006). SchoolNet web portal. Retrieved January 14, 2015, from http://www.schoolnet.lk/

Scott, H., Chenette, J., \& Swartz, J. (2002). The integration of technology into learning. Liberal Education, 88(2), 30-36.

Scott, R., \& Robinson, B. (1996). Managing technological change in education-what lessons can we all learn? Computers \& Education, 26(1-3), 131-134. doi:10.1016/0360-1315(96)00007-3

Selim, H. M. (2007). Critical success factors for e-learning acceptance: Confirmatory factor models. Computers \& Education, 49(2), 396-413. doi:10.1016/j.compedu.2005.09.004

Singh, J., \& Wijetunge, P. (2006). Library and information science education in South Asia: Challenges and opportunities (pp. 1-7). Presented at the Asia-Pacific Conference on Library \& Information Education \& Practice, Singapore.

Siritongthaworn, S., \& Krairit, D. (2006). Satisfaction in e-learning: the context of supplementary instruction. Campus-Wide Information Systems, 23(2), 76-91. doi:10.1108/10650740610654465

Siritongthaworn, S., Krairit, D., Dimmitt, N. J., \& Paul, H. (2006). The study of e-learning technology implementation: A preliminary investigation of universities in Thailand. Education and Information Technologies, 11(2), 137-160. doi:10.1007/s11134-006-7363-8

Skyrme, D. J. (2004). Information Managers - Do We Need Them? Retrieved from http://www.kmpro.org/docs/skyrme/sunset.pdf

Skyrme, D. J., \& Earl, M. J. (1990). Hybrid managers: What should you do? British Computer Society Report. 
Smith, D. C., \& Hardaker, G. (2000). E-learning innovation through the implementation of an internet supported learning environment. Journal of Educational Technology and Society, 3(3), 422-432.

Smith, S. Z., Smith, M. E., \& Williams, S. R. (2005). Elaborating a Change Process Model for Elementary Mathematics Teachers' Beliefs and Practices. Current Issues in Education [On-line], 8(19). Retrieved from http://cie.asu.edu/volume8/number19/

Smythe, D. (1999). Facing the future: Preparing new information professionals. Information Management Journal, 33(2), 44-48.

Somekh, B., \& Davis (Eds.). (1997). Using information technology effectively in teaching and learning. London: Routledge.

Somogyi, E. K., \& Galliers, R. D. (1994). Information technology in business: from data processing to strategic information systems. In R. D. Galliers \& B. S. H. Baker, Strategic Information Management: Challenges and strategies in managing information systems. Oxford: Butterworth Heinemann.

Søndergaard, M. (2002). In my opinion-Mikael Søndergaard on Cultural differences. International Business Center Website. Retrieved from http://www.international-business-center.com/geertgofstede/Sondergaard.shtml

Sonwalkar, N. (2002). A new methodology for evaluation: The pedagogical rating of online courses. Syllabus, 15(6), 18-21.

Soong, M. H. B., Chan, H. C., Chua, B. C., \& Loh, K. F. (2001). Critical success factors for online course resources. Computers \& Education, 36(2), 101-120. http://doi.org/10.1016/S0360-1315(00)00044-0

Sosabowski, M. H., Herson, K., \& Lloyd, A. W. (1998). Implementation and student assessment of Intranet-based learning resources. American Journal of Pharmaceutical Education, 62(3), 302-306.

Sraku-Lartey, M. (2006). Developing the Professional Skills of Information Managers in the Forestry Sector in Africa. Quarterly Bulletin of the International Association of Agricultural Information Specialists, 51(2), 75-78.

Stake, R. E. (1995). The art of case study research. Thousand Oaks: Sage publications.

Strang, K. D. (2012). Skype Synchronous Interaction Effectiveness in a Quantitative Management Science Course: Skype Experiential Interaction. Decision Sciences Journal of Innovative Education, 10(1), 3-23. doi:10.1111/j.15404609.2011.00333.x

Strother, J. B. (2003). Cross-Cultural Issues for Asian e-Learners: An Analysis Based on Hofstede's Cultural Dimensions. Retrieved from http://my.fit.edu/ strother/downloads/Issues for Asian ELearners.pdf

Sun, P., Cheng, H. K., \& Finger, G. (2009). Critical functionalities of a successful e-learning system - An analysis from instructors' cognitive structure toward system usage. Decision Support Systems, 48(1), 293-302. doi:10.1016/j.dss.2009.08.007

Sun, P., Tsai, R., Finger, G., Chen, Y., \& Yeh, D. (2008). What drives a successful eLearning? An empirical investigation of the critical factors influencing learner satisfaction. Computers \& Education, 50(4), 1183-1202. doi:10.1016/j.compedu.2006.11.007

Suri, G., \& Sharma, S. (2012). Impact of age and internet access and usage on student's attitude towards e-learning: A study on Panjab University. International Journal of Applied Services Marketing, 1(2), 188-194. 
Svensson, L., Ellström, P.-E., \& Åberg, C. (2004). Integrating formal and informal learning at work. Journal of Workplace Learning, 16(8), 479-491. doi:10.1108/13665620410566441

Takalani, T. (2008). Barriers to e-learning amongst postgraduate black students in higher education in South Africa. Retrieved from https://scholar.sun.ac.za/bitstream/handle/10019.1/3114/Takalani\%2c\%20T. pdf? sequence $=1$

Taylor, M. C. (2005). Interviewing. In I. Holloway (Ed.), Qualitative Research in Health Care. Berkshire: Open University Press.

Telecommunication Regulatory Commission of Sri Lanka. (2014, September). Statistics 2014 September. Retrieved January 14, 2015, from http://www.trc.gov.lk/201405-13-03-56-46/statistics.html

Telecompaper. (2013). Sri Lanka Telecom to operate national backbone network. Retrieved from http://www.telecompaper.com/news/sri-lanka-telecom-tooperate-national-backbone-network--947580

Thiele, J. E., Allen, C., \& Stucky, M. (1999). Effects of Web-based instruction on learning behaviors of undergraduate and graduate students. Nursing and Health Care Perspectives, 20(4), 199-203.

Thowfeek, M. H., \& Jaafar, A. (2012). Instructors' View about Implementation of Elearning System: An Analysis based on Hofstede's Cultural Dimensions. Procedia - Social and Behavioral Sciences, 65, 961-967. http://doi.org/10.1016/j.sbspro.2012.11.227

Toland, J., Frank, J., \& Schenk, K. D. (2005). Culture, interaction, and online learning. In Encyclopedia of Distance Learning (pp. 485-491). Hershey: Idea Group Reference. Retrieved from http://www.igiglobal.com/gateway/contentowned/Chapters.aspx?TitleId=351

Tondeur, J., Devos, G., Houtte, M. V., Braak, J. V., \& Valcke, M. (2009). Understanding structural and cultural school characteristics in relation to educational change: the case of ICT integration. Educational Studies, 35(2), 223-235

Trentin, G. (1997). Telematics and on-line teacher training: the Polaris Project. Journal of Computer Assisted Learning, 13(4), 261-270. doi:10.1046/j.13652729.1997.00029.x

Tsai, C. C., Lin, S. S. J., \& Yuan, S. M. (2002). Developing science activities through a networked peer assessment system. Computers \& Education, 38, 241-252.

Turchin, A., \& Lehmann, C. U. (1999). Active Learning Centre: utilization patterns of an interactive educational World Wide Web site. In Proceedings of the AMIA Symposium (pp. 627-631). Retrieved from https://www.ncbi.nlm.nih.gov/pmc/articles/PMC2232840/

UNESCO. (2002). Open and Distance Learning: trends, policy and strategy considerations. France: UNESCO. Retrieved from http://unesdoc.unesco.org/images/0012/001284/128463e.pdf

University Grants Commission Sri Lanka. (2015a). Sri Lanka University Statistics 2013. Retrieved from http://www.ugc.ac.lk/en/component/content/article/1418-srilanka-university-statistics-2013.html

University Grants Commission Sri Lanka. (2015b). Universities and Higher Educational Institutions. Retrieved January 14, 2015, from http://www.ugc.ac.lk/en/universities-and-institutes.html 
University Grants Commission. (2010). Strengthening of staff development in universities and higher educational institutes (Commission Circular No. 937). Colombo, Sri Lanka: University Grants Commission UGC.

University of Leeds. (2001). Report of the national committee. Retrieved August 20, 2010, from http://www.leeds.ac.uk/educol/ncihe/natrep.htm

Usun, S. (2004). Factors affecting the application of Information and communication technologies (ICT) in distance education. The Turkish Online Journal of Distance Education, 5(1).

Van der Wende, M. C. (2002). The role of US higher education in the global e-learning market. Berkeley: University of California at Berkeley.

Van Lee, R., Bhattacharya, S., Nelson, T., \& Kihn, M. (2002). Re-Learning e-learning. Retrieved from http://www.boozallen.com/media/file/108290.pdf

Walsham, G. (2006). Doing interpretive research. European Journal of Information Systems, 15, 320-330.

Wang, M. (2007). Designing online courses that effectively engage learners from diverse cultural backgrounds. British Journal of Educational Technology, 38(2), 294-311. doi:10.1111/j.1467-8535.2006.00626.x

Wang, Q., Myers, M. D., \& Sundaram, D. (2013). Digital Natives and Digital Immigrants: Towards a Model of Digital Fluency. Business \& Information Systems Engineering, 5(6), 409-419. http://doi.org/10.1007/s12599-013-0296-y

Wang, Y.-S., Wang, H.-Y., \& Shee, D. Y. (2007). Measuring e-learning systems success in an organizational context: Scale development and validation. Computers in Human Behavior, 23(4), 1792-1808. doi:10.1016/j.chb.2005.10.006

Warnapala, W. (2009). Foreword. In K. Rama, A. Hope, \& U. Coomaraswamy (Eds.), Quality Assurance Toolkit for Distance Higher Education Institutions and Programmes. Columbia: Commonwealth of Learning. Retrieved from http://www.col.org/PublicationDocuments/pub HE QA Toolkit web.pdf

Watkins, R. (2009). e-Learning. In R. Watkins \& D. Leigh (Eds.), Handbook of Improving Performance in the Workplace: Selecting and Implementing Performance Interventions (pp. 577-597). Hoboken, NJ, USA: John Wiley \& Sons, Inc. Retrieved from http://doi.wiley.com/10.1002/9780470587102.ch24

Watson, B., \& Omrani, D. (1988). Information resource management. DCE Information Management Consultancy.

Weber, R. (2004). The Rhetoric of Positivism versus Interpretivism: A Personal View. MIS Quarterly, 28(1), iii-xii.

Weistra, H. (2000). E-learning, what are we doing? Retrieved from http://www.sbo.nl

Welsh, E. T., Wanberg, C. R., Brown, K. G., \& Simmering, M. J. (2003). E-learning: emerging uses, empirical results and future directions. International Journal of Training and Development, 7(4), 245-258. http://doi.org/10.1046/j.13603736.2003.00184.x

Wesley, D. (2002). A critical analysis on the evolution of e-learning. International Journal on E-Learning, 1(4), 41-48.

What is electronic learnig. (n.d.). Retrieved from http://www.mup.com.au/uploads/files/pdf/978-0-522-85130-4.pdf

White, D. S., \& Cornu, A. L. (2011). Visitors and residents: A new typology for online engagement. First Monday, 16(9).

Wijetunge, P. (2008). A critical analysis of the equity of LIS education programmes in Sri Lanka. Journal of Education for Library and Information Science, 49(4), 243-263. 
Wijetunge, P. (2011). Fifty years of LIS education in Sri Lanka: a retrospective examination. Sri Lanka Library Review, 25, 1-14.

Wijetunge, P., \& Willson, J. (1998). Perceptions of LIS education and training in Sri Lanka. Presented at the 64th IFLA General Conference, Amsterdam: IFLA. Retrieved from http://archive.ifla.org/IV/ifla64/056-140e.htm

Wild, R. H., Griggs, K. ., \& Downing, T. (2002). A framework for e-learning as a tool for knowledge management. Industrial Management \& Data Systems, 102(7), 371380. doi:10.1108/02635570210439463

Williams, M. D., \& Williams, J. (2007). A change management approach to evaluating ICT investment initiatives. Journal of Enterprise Information Management, 20(1), 3250. doi:10.1108/17410390710717129

Williamson, K. (2002). Research methods for students, academics, and professionals: Information management and systems (2nd ed.). New South Wales: Center for Information Studies.

Wilson, T. D. (2005). The nonsense of knowledge management. In E. Maceviciute \& T. D. Wilson (Eds.), Introducing Information Management (pp. 151-164). London: Facet publishing.

Wong, E. M. L., Li, S. S. C., Choi, T.-H., \& Lee, T. N. (2008). Insights into Innovative Classroom Practices with ICT: Identifying the Impetus for Change. Educational Technology \& Society, 11(1), 248-265.

World Bank (2007). Advancing Sri Lanka's Education System through Quality Inputs (pp. 53-69). Retrieved from http://siteresources.worldbank.org/SOUTHASIAEXT/Resources/2235461206318727118/4808502-1206318753312/slknowledgeChapter5.pdf

World Bank (2009). The towers of learning: performance, peril and promise of higher education in Sri Lanka. The World Bank Colombo Office. Retrieved from http://siteresources.worldbank.org/SOUTHASIAEXT/Resources/Publications/T OLreportfinal.pdf

World Bank (2005). Treasures of the education system in Sri Lanka: Restoring performance, expanding opportunities and enhancing prospects. World Bank South Asia Region. Retrieved from http://siteresources.worldbank.org/INTSOUTHASIA/Resources/TreasuresInTh eEducationSystem February2005.pdf

World Bank. (2012). Knowledge Economy Index. Retrieved March 22, 2011, from http://info.worldbank.org/etools/kam2/KAM page5.asp\#c48

Wright, N. (2010). E-Learning and Implications for New Zealand Schools: a literature review. New Zealand Ministry of Education. Retrieved from http://www.educationcounts.govt.nz/ data/assets/pdf file/0006/77667/948 ELearnLitReview.pdf

Wu, J. P., Tsai, R. J., \& Chen, C. C. (2006). An integrative model to predict the continuance use of electronic learning systems: hints for teaching. International Journal on ELearning, 5(2), 287-302.

Yin, R. K. (2009). Case study research: design and methods (4th ed., Vol. 5). Thousand Oaks: Sage.

Young, M.-L., Kuo, F.-Y., \& Myers, M. D. (2012). To share or not to share: a critical research perspective on knowledge management systems. European Journal of Information Systems, 21(5), 496-511. doi:10.1057/ejis.2012.10

Zaltman, G., \& Duncan, R. (1977). Strategies for planned change. New York: John Wiley and Sons. 
Zhang, D., Zhao, J. L., Zhou, L., \& Nunamaker, J. F. (2004). Can e-learning replace classroom learning? Communications of the ACM, 47(5), 75-79.

doi:10.1145/986213.986216 
Appendix 1

\section{Selected relevant studies that have cited Fullan's educational change theory}

\begin{tabular}{|c|c|c|c|}
\hline Source & About the study & Methodology & Context of the use of Fullan's work \\
\hline $\begin{array}{l}\text { Do, Van Hung } \\
(2015)\end{array}$ & $\begin{array}{l}\text { The aim of this study was to identify } \\
\text { contextual factors affecting the development } \\
\text { of digital library education in Vietnam }\end{array}$ & $\begin{array}{l}\text { Qualitative research approach was } \\
\text { employed and conducted } 18 \text { interviews } \\
\text { and } 11 \text { focus group involving } 70 \\
\text { participants and also used documentary } \\
\text { evidence }\end{array}$ & $\begin{array}{l}\text { Used Fullan's educational change theory as } \\
\text { one of the sources to develop an initial } \\
\text { conceptual model of factors affecting digital } \\
\text { library education }\end{array}$ \\
\hline Ismail, S.A. (2014) & $\begin{array}{l}\text { The aim of this study was to identify factors } \\
\text { affecting the implementation of information } \\
\text { literacy education in Malaysian primary } \\
\text { schools }\end{array}$ & $\begin{array}{l}\text { Qualitative research approach was } \\
\text { employed i.e., focusing on cases and used } \\
\text { semi-structured interviews and } \\
\text { documentary analysis }\end{array}$ & $\begin{array}{l}\text { Used Fullan's educational change theory as } \\
\text { one of the sources to develop a preliminary } \\
\text { model to explore potential factors internal } \\
\text { and external to the school ecology }\end{array}$ \\
\hline $\begin{array}{l}\text { Beeharry-Konglar, } \\
\text { M. (2013) }\end{array}$ & $\begin{array}{l}\text { The aim of this study was to understand the } \\
\text { use of ICT in secondary visual arts classrooms } \\
\text { in Mauritius. } \\
\text { Three key issues were examined, } \\
\text { - Use of ICT tools in teaching visual arts } \\
\text { - How ICT tools are used in the in teaching } \\
\text { visual arts } \\
\text { - Scope and barriers using ICT in the teaching } \\
\text { of visual arts }\end{array}$ & $\begin{array}{l}\text { A mixed method was employed i.e., } \\
\text { questionnaire, focused group discussion, } \\
\text { and classroom observation } \\
\text { - Questionnaires were administrated } \\
\text { among } 70 \text { visual arts teachers in public } \\
\text { and private schools. } \\
\text { - } 40 \text { classroom observations (observed } \\
\text { teachers) were carried out in both lower } \\
\text { and upper secondary school visual arts } \\
\text { classes. } \\
\text { - A focus group discussion was held with } \\
15 \text { visual arts teachers to understand } \\
\text { their beliefs and attitudes }\end{array}$ & $\begin{array}{l}\text { Based on a review of the literature, a } \\
\text { conceptual framework for the study was } \\
\text { developed. Fullan's study (including other } \\
\text { literature) used to identify factors that } \\
\text { influence teacher's decision to use ICT in the } \\
\text { classroom. For example, teachers resistance } \\
\text { to change. Teacher's values, beliefs, and } \\
\text { attitudes are therefore identified as } \\
\text { significant contributors to their } \\
\text { preparedness to use e-learning. This was } \\
\text { also confirmed by study findings. }\end{array}$ \\
\hline $\begin{array}{l}\text { Neumann, J.W. } \\
\text { (2013) }\end{array}$ & $\begin{array}{l}\text { The goal of this study was to examine critical } \\
\text { pedagogy problem with changing teachers' } \\
\text { dispositions towards critical teaching }\end{array}$ & Reviewed literature on successful change & $\begin{array}{l}\text { Based on review of the literature, this study } \\
\text { identified four changes critical educators } \\
\text { must make in their approach towards } \\
\text { teachers if criticalists hope to influence } \\
\text { more teachers' dispositions towards critical } \\
\text { teaching. They are; }\end{array}$ \\
\hline
\end{tabular}




\begin{tabular}{|c|c|c|c|}
\hline & & & $\begin{array}{l}\text { 1. Advocacy for critical teaching must begin } \\
\text { by appreciating the knowledge that teachers } \\
\text { already have } \\
\text { 2. Critical educators should begin their work } \\
\text { 'small' } \\
\text { 3. Critical educators should work with } \\
\text { teachers in ways that are practical } \\
\text { 4. Educational change should be approached } \\
\text { with sustainability in mind } \\
\text { Third and fourth areas were identified based } \\
\text { on Fullan's study. }\end{array}$ \\
\hline Huan, N.B. (2013) & $\begin{array}{l}\text { The aim of this study was to understand the } \\
\text { beliefs about the support needed for teacher } \\
\text { change in English for Specific Purposes (ESP) } \\
\text { classes within a university context in Vietnam. } \\
\text { In particular, this study aimed to examine how } \\
\text { ESP lecturers conceptualised and managed } \\
\text { change to include more interactive teaching to } \\
\text { enhance active learning. }\end{array}$ & $\begin{array}{l}\text { Qualitative action research approach was } \\
\text { utilised i.e., interviews, planning } \\
\text { meetings, and participants observations. } \\
\text { - Two lecturers with similar levels of } \\
\text { seniority, academic knowledge, English } \\
\text { proficiency, and research experience } \\
\text { were selected as participants for this } \\
\text { study. }\end{array}$ & $\begin{array}{l}\text { This study confirmed the findings of Fullan's } \\
\text { study of educational change i.e., benefit of } \\
\text { collaboration with others to improve the } \\
\text { teaching situations, importance of policy } \\
\text { makers and education administrators } \\
\text { support to ensure that change occurs and } \\
\text { becomes part of teachers' personal and } \\
\text { professional growth. }\end{array}$ \\
\hline $\begin{array}{l}\text { Tondeur, J., Devos, } \\
\text { G., Houtte, M.V., } \\
\text { Braak, J.V., and } \\
\text { Valcke, M. (2009) }\end{array}$ & $\begin{array}{l}\text { The goal of this study was to explore both } \\
\text { structural school characteristics (i.e., } \\
\text { infrastructure, planning and support) and } \\
\text { cultural school characteristics (i.e., leadership, } \\
\text { goal orientedness and innovativeness) and } \\
\text { how they contribute to ICT integration in the } \\
\text { classroom. }\end{array}$ & $\begin{array}{l}\text { A survey was done among } 527 \text { ( } 428 \text { were } \\
\text { female) teachers in } 68 \text { primary schools in } \\
\text { Flanders, Belgium. }\end{array}$ & $\begin{array}{l}\text { Fullan (2001) stated that educational } \\
\text { improvement or innovation efforts should } \\
\text { consider to a large extent - the 'power of site } \\
\text { or place'. Therefore, this study centred on } \\
\text { the hypothesis that school characteristics } \\
\text { affect the integration of ICT at classroom } \\
\text { level. } \\
\text { The study findings re-emphasised how } \\
\text { important and influential school-related } \\
\text { characteristics are to establish educational } \\
\text { change. This study also confirmed that } \\
\text { structural and cultural school characteristics } \\
\text { are relevant vehicles to promote educational } \\
\text { change in general and ICT integration in } \\
\text { particular. }\end{array}$ \\
\hline $\begin{array}{l}\text { Wong, E.M.L., Li, } \\
\text { S.S.C., Choi, T-H., } \\
\text { and Lee, T. (2008) }\end{array}$ & $\begin{array}{l}\text { The study aimed to identify contextual factors } \\
\text { that impact on the teaching and learning and } \\
\text { how these factors interact with each other, in }\end{array}$ & $\begin{array}{l}\text { A qualitative case study approach was } \\
\text { adopted i.e., lesson observations, } \\
\text { interviews, and focus-group interviews. }\end{array}$ & $\begin{array}{l}\text { Followed by Fullan's (1991) view, } \\
\text { innovation cannot be assimilated unless its } \\
\text { meaning is shared, this study used }\end{array}$ \\
\hline
\end{tabular}




\begin{tabular}{|c|c|c|c|}
\hline & $\begin{array}{l}\text { particular the relationship between } \\
\text { technological innovations and pedagogical } \\
\text { innovations. }\end{array}$ & $\begin{array}{l}\text { - Study sample was eight schools in Hong } \\
\text { Kong and Singapore } \\
\text { - Lesson observations of English, Chinese, } \\
\text { general studies, and mathematics at } \\
\text { primary level while English, geography, } \\
\text { physics, and mathematics at secondary } \\
\text { level } \\
\text { - Semi-structured interviews were } \\
\text { conducted with teachers and heads of } \\
\text { department } \\
\text { - } 30 \text { minute focus group interview was } \\
\text { conducted with six students (three active } \\
\text { participants vs three passive } \\
\text { participants) }\end{array}$ & $\begin{array}{l}\text { comparative case study with a view to } \\
\text { understanding the processes of change in } \\
\text { different education system, and how } \\
\text { technological innovations can be successful. }\end{array}$ \\
\hline $\begin{array}{l}\text { Williams, M.D. and } \\
\text { Williams, J. (2007) }\end{array}$ & $\begin{array}{l}\text { This study aimed to understand the change } \\
\text { management aspects of ICT investments }\end{array}$ & $\begin{array}{l}\text { A single case study method was } \\
\text { employed - i.e., public sector } \\
\text { organization in UK, and received its } \\
\text { funding (indirectly) from the UK central } \\
\text { government. } \\
\text { - Observation, semi-structured and } \\
\text { informal interviews with } 6 \text { departmental } \\
\text { heads, } 17 \text { administrative staff, and } 7 \\
\text { technicians and document analysis } \\
\text { (ranging from minutes of meetings to } \\
\text { individual memos and emails) were used } \\
\text { to gather data. }\end{array}$ & $\begin{array}{l}\text { Based on a review of the literature relating } \\
\text { to ICT evaluation and to the concept of } \\
\text { change, a conceptual framework for the } \\
\text { study was developed. For this purpose, they } \\
\text { used Fullan's educational change theory i.e., } \\
\text { initiation, implementation, and } \\
\text { institutionalisation as a part of their change- } \\
\text { based evaluative framework. Moreover, } \\
\text { Fullan's three Rs of relevance, readiness, and } \\
\text { resources were also used to show } \\
\text { management team, and the user-base } \\
\text { commitment toward the innovation. }\end{array}$ \\
\hline $\begin{array}{l}\text { Hargreaves, A. } \\
\text { (2005) }\end{array}$ & $\begin{array}{l}\text { This study examined the relationship of the } \\
\text { emotions of teaching to teachers' age career } \\
\text { stages based on experiences of educational } \\
\text { change }\end{array}$ & $\begin{array}{l}50 \text { interviews were conducted among } \\
\text { elementary, middle, and high school } \\
\text { teachers of varying ages, different grades } \\
\text { and a variety of subjects across } 15 \\
\text { schools in Ontario, Canada. }\end{array}$ & $\begin{array}{l}\text { Used Fullan's educational change theory to } \\
\text { ground some of the findings of the current } \\
\text { study i.e., importance of identifying } \\
\text { personality types of teacher whether they } \\
\text { are early or late adopters of change, } \\
\text { provides leaders with tools to improve the } \\
\text { improvement process. }\end{array}$ \\
\hline
\end{tabular}




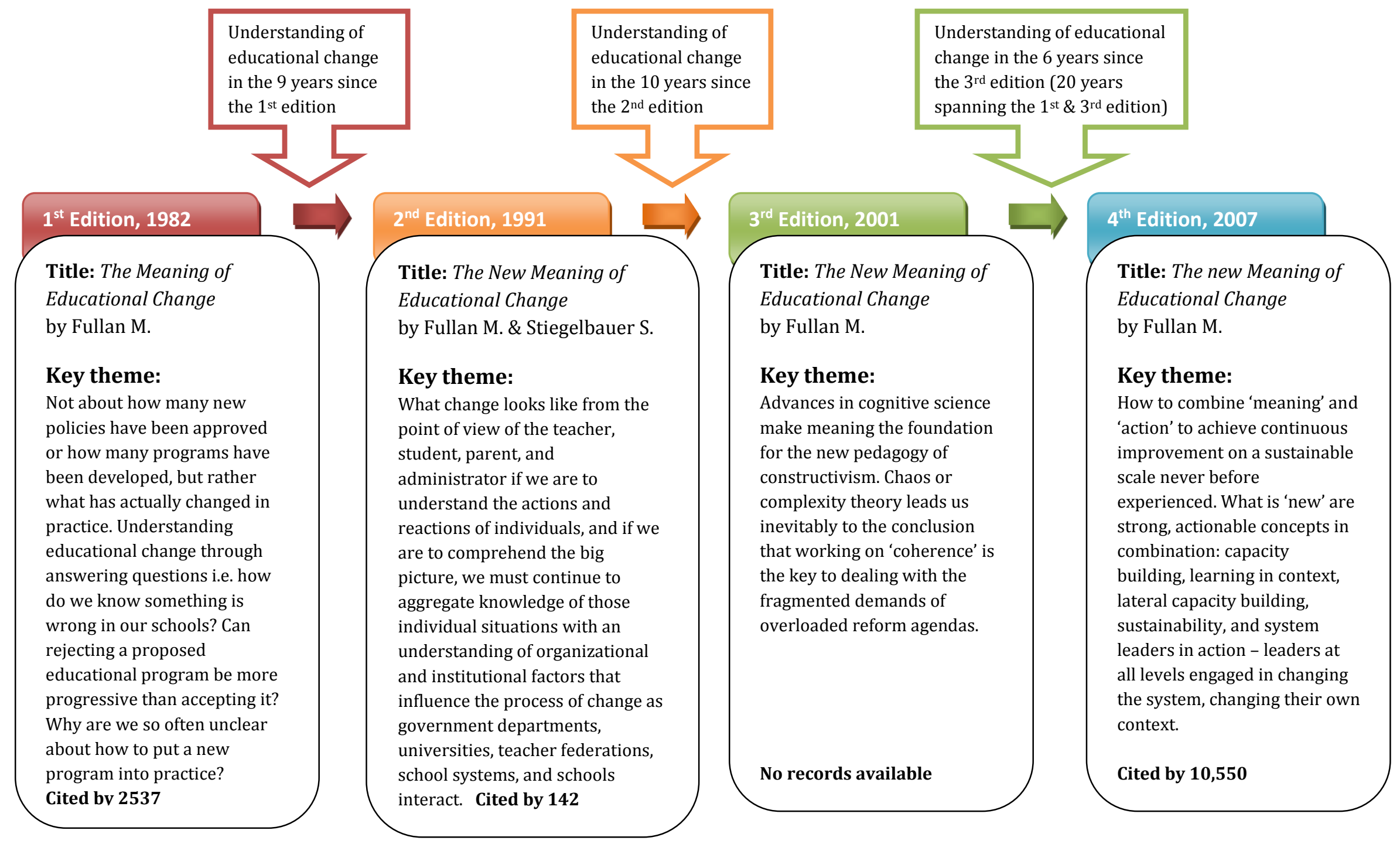

Adapted from New Meaning of Educational change, Fullan $(1982,1991,2001,2007)$ 


\section{Appendix 3}

\section{Evolution of Hofstede's Cultural Dimensions}

Hofstede's culture related study was first carried out (with IBM - at the time identified as HERMES) around 1967 - 1969 and repeated around 1971 -1973. The study comprised 117,000 questionnaires with over 88,000 different respondents from over 66 countries. Based on this survey results, Hofstede published;

Included discussion of the many replications by other researchers that had appeared since 1980
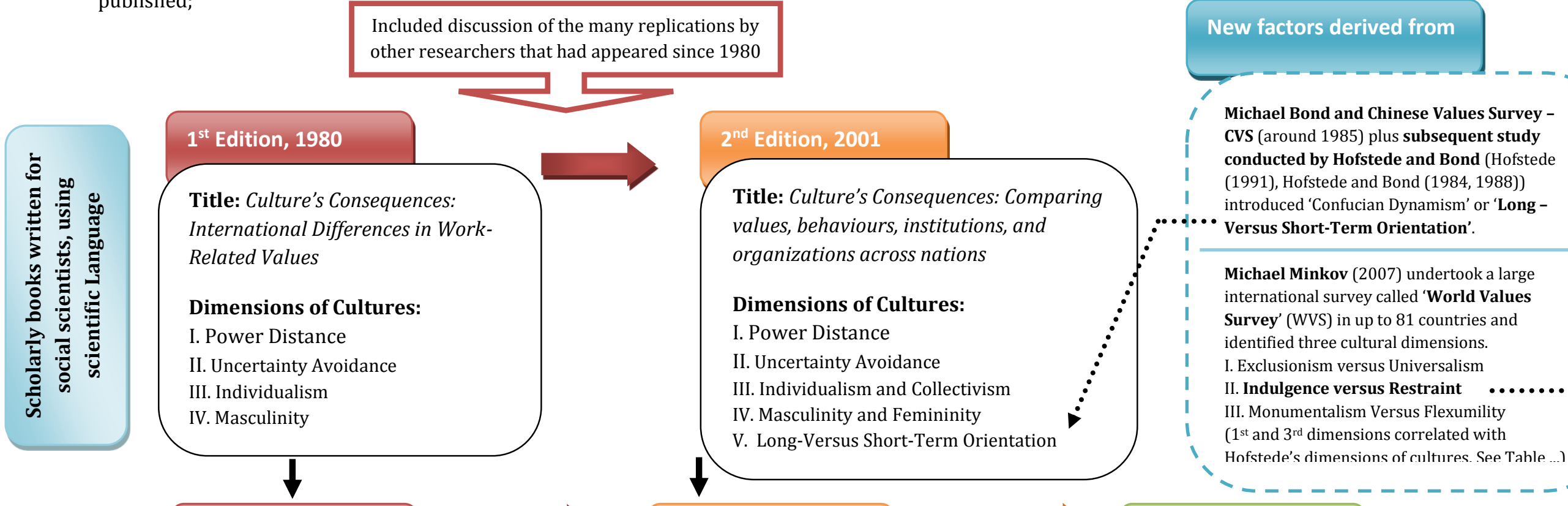

Michael Bond and Chinese Values Survey CVS (around 1985) plus subsequent study conducted by Hofstede and Bond (Hofstede (1991), Hofstede and Bond $(1984,1988)$ ) introduced 'Confucian Dynamism' or 'Long $\because \cdots \cdot$ Versus Short-Term Orientation'.

International Differences in Work

Related Values

$1^{\text {st }}$ Edition, 1991

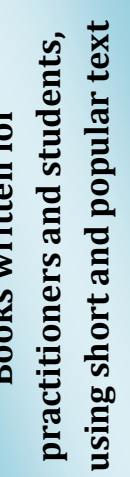

Title: Cultures and Organizations: Software of the Mind

By Geert Hofstede

\section{Dimensions of Cultures (04):}

I. Power Distance

II. Uncertainty Avoidance

III. Individualism and Collectivism

IV. Masculinity and Femininity

Slightly updated paperback editions published in 1994 and 1997

\section{$2^{\text {nd }}$ Edition, 2005}

Title: Cultures and Organizations:

Software of the Mind

By Geert Hofstede, Gert Hofstede

\section{Dimensions of Cultures (05):}

I. Power Distance

II. Uncertainty Avoidance

III. Individualism and Collectivism

IV. Masculinity and Femininity

V. Long-Versus Short-Term Orientation
Michael Minkov (2007) undertook a large international survey called 'World Values Survey' (WVS) in up to 81 countries and identified three cultural dimensions. I. Exclusionism versus Universalism II. Indulgence versus Restraint III. Monumentalism Versus Flexumility $\left(1^{\text {st }}\right.$ and $3^{\text {rd }}$ dimensions correlated with Hofstede's dimensions of cultures. See Tahle ...) $-\ldots$

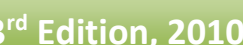

Title: Cultures and Organizations: Software of the Mind

By Geert Hofstede, Gert Hofstede, \& Michael Minkov

\section{Dimensions of Cultures (06):}

I. Power Distance

II. Uncertainty Avoidance

III. Individualism and Collectivism

IV. Masculinity and Femininity

V. Long-Versus Short-Term Orientation

VI. Indulgence versus Restraint 


\section{Appendix 4}

\section{Focus group interview protocol}

1. Check list of resources for interviews

1. Recorder - audio and video

2. Extra batteries for the recorder

3. Pens

4. Notebooks/papers

5. Copy of signed interview consent form

6. Extra copies of letter of information, interview consent form to be provided to interviews in case the researcher has not received signed consent form.

2. Procedure of semi-structured interviews

\section{Step I - Setting up the group discussion}

1. Contact the participants.

2. Select and book the appropriate venue and time for group discussion.

3. Prepare and send information sheet, consent form, and invitation with venue location and time in advance.

\section{Step II - Getting started}

1. Room and the resources for interview must be set up and checked at least 30 minutes before.

2. Welcome research participants

3. Introduce the researcher

4. Ask the participants to introduce themselves.

5. Explain the purpose of the study as well as purpose of the group discussion.

6. Explain why the participants have been selected and why they are important to the study.

7. Explain the roles of the facilitator and the recorders.

8. Explain the ground rules for the discussion.

- Everyone should participate

- All ideas are equally valid

- There are no right or wrong answers

- Each participant's view should be heard and respected.

\section{Step III - Interviewing}

1. Start the discussion with broad opening questions

2. Ask specific questions and follow-up questions.

3. Ask open-ended questions.

4. Encourage all the participants to share the discussion.

5. Keep the discussion on track 


\section{Step IV - Ending up the group discussions}

1. Ask closing questions.

2. Ask post-discussion questions and any additional ideas.

3. Thank participants for their participation and ask their future help for checking the transcript of the discussion.

4. Clearly number the recording with group identification number, date, and time of the discussion.

3. Sample focus group interview questions

1. What are the key factors that have an impact on the introduction and use of e- learning? [researcher will note down all the factors on the whiteboard]

2. How are you grouping these factors?

3. From the factors of the whiteboard, can you choose what the most important factors are?

4. From the factors of the piece of paper, can you choose what the most important factors are?

5. How do they affect the use of e-learning in tertiary-level IM education?

6. Are there other factors (enablers or barriers) that have an impact on the introduction and use of e- learning? 


\section{Appendix 5}

\section{Solutions in order to troubleshoot some problems while researcher is conducting}

focus group interviews

\begin{tabular}{|c|c|}
\hline Problem & Solution \\
\hline $\begin{array}{l}\text { Some members of the group do } \\
\text { not speak }\end{array}$ & $\begin{array}{l}\text { The facilitator calls on each group member one by one, repeating } \\
\text { the question or someone else's response. He or she makes sure to } \\
\text { ask individuals who have not contributed, 'What do you think about } \\
\text { X?' }\end{array}$ \\
\hline $\begin{array}{l}\text { Some members of the group } \\
\text { speak too much }\end{array}$ & $\begin{array}{l}\text { The facilitator asks those individuals to wait for their turn, to 'hold } \\
\text { their idea' for a moment, or to wait until others have had an } \\
\text { opportunity to speak. }\end{array}$ \\
\hline $\begin{array}{l}\text { One group member dominates } \\
\text { the conversation by speaking } \\
\text { too often, too loudly, for too } \\
\text { long, or in a coercive or } \\
\text { intimidating manner }\end{array}$ & $\begin{array}{l}\text { The facilitator reminds the group of the ground rules and the } \\
\text { purpose of the focus group. If the offending individual does not } \\
\text { understand or change behaviour, the facilitator asks the } \\
\text { participation directly to conform to the ground rules, either during } \\
\text { the group session or during a break. }\end{array}$ \\
\hline $\begin{array}{l}\text { Group members talk to people } \\
\text { next to them but not with the } \\
\text { group }\end{array}$ & $\begin{array}{l}\text { The facilitator first determines the cause of the problem: for } \\
\text { example, the group may be too big; some participants may feel } \\
\text { uncomfortable speaking in a large group; respondents may not have } \\
\text { received enough opportunity to express their opinions; the } \\
\text { conversation may be difficult to follow; or some groups may not be } \\
\text { able to understand the way that others express themselves. Some } \\
\text { participants may feel uncomfortable with a subtopic, or they may } \\
\text { disagree with what someone said but feel uneasy saying so in public. } \\
\text { The facilitator should take a few moments to observe and discuss } \\
\text { with the individuals what the problem is. A solution then can be } \\
\text { devised. }\end{array}$ \\
\hline $\begin{array}{l}\text { Group members begin to take } \\
\text { sides on an issue }\end{array}$ & $\begin{array}{l}\text { The facilitator reminds group members that everyone's opinion is } \\
\text { valued and that differences of opinion are important as } \\
\text { opportunities for learning. The facilitator encourages participants } \\
\text { to state their opinions and to discuss and debate different point of } \\
\text { view, but to avoid open conflict, because it can divide a group and } \\
\text { preclude further open discussion, which disrupts the intention of } \\
\text { the focus group. }\end{array}$ \\
\hline $\begin{array}{l}\text { Group discussion diverges } \\
\text { from the interview focus }\end{array}$ & $\begin{array}{l}\text { The facilitator returns group members to the topic with a polite } \\
\text { reminder and/or a shift in questioning. If group members do not } \\
\text { wish to return to the topic scheduled for discussion right away, they } \\
\text { can be invited to postpone the new topic until after the session is } \\
\text { over, at which point they can remain and continue to discuss the } \\
\text { new topic for as long as they wish. Divergence can happen very } \\
\text { quickly. Facilitators should exercise care when letting discussion } \\
\text { flow, even if they are trying to avoid offending respondents by } \\
\text { cutting off discussion. The facilitator should remember that each } \\
\text { formal focus group interview member was selected because he or } \\
\text { she was known to have experience and opinions on the topic to be } \\
\text { discussed, and that because of their expertise, they are receiving } \\
\text { incentives for their participation. }\end{array}$ \\
\hline $\begin{array}{l}\text { Participants have ideas } \\
\text { relevant to the topic, but either } \\
\text { have not though them out } \\
\text { clearly or cannot express } \\
\text { themselves well }\end{array}$ & $\begin{array}{l}\text { Facilitators probe by asking additional questions but avoid } \\
\text { suggesting likely extensions of the respondent's thoughts. Some } \\
\text { people work best from the basis of concrete examples; facilitators } \\
\text { can ask such respondents to give some examples of what they mean } \\
\text { and then question them for clarity. Facilitators can also ask other } \\
\text { group members to describe similar situations that may stimulate } \\
\text { the thoughts of the struggling group member. }\end{array}$ \\
\hline
\end{tabular}

Source: Schensul et al., 1999, p.84-85 


\section{Appendix 6}

\section{Interview protocol}

1. Check list of resources for interviews

1. Recorder - audio

2. Extra batteries for the recorder

3. Pens

4. Notebooks

5. Copy of signed interview consent form

6. Extra copies of letter of information, interview consent form to be provided to interviews in case the researcher has not received signed consent form.

2. Procedure of semi-structured interviews

\section{Step I - Setting up the interviews}

1. Contact the interviewees.

2. Select and book the appropriate venue and time for interviews.

3. Prepare and select information sheet, consent form, and invitation with venue location and time in advance.

\section{Step II - Getting started}

1. Room and the resources for interview must be set up and checked at least 30 minutes before.

2. Introduce the researcher.

3. Explain the purpose of the study as well as purpose of the interview.

4. Explain why the interviewee has been selected and why he/she is important to the study.

\section{Step III - Interviewing}

1. Starting with focal questions

2. Ask follow-up questions.

3. Ask open-ended questions.

\section{Step IV - Ending up the interviews}

1. Ask the interviewee if there any additional ideas

2. Thank the interviewee for participation and ask he/she's future help for checking the transcript of the interview.

3. Clearly number the recording with interviewee's identification number, date, and time of interview 


\section{Sample interview questions}

(Note: Researcher will initially conduct the interviews based on significant factors identified in focus group discussions).

1. From your perception, how do these factors affect the introduction and use of e-learning in tertiary-level IM education in Sri Lanka? (Researcher will clarify each identified factors indepth).

2. Are there other factors (enablers or barriers) that have an impact on the introduction and use of e- learning in tertiary-level IM education in Sri Lanka? If so, how do these factors affect the use of e-learning in tertiary-level IM education in Sri Lanka? 


\section{Appendix 7}

\section{INFORMATION SHEET - FOCUS GROUP DISCUSSIONS}

RESEARCHER: Namali Suraweera

School of Information Management

Faculty of Commerce and Administration

Victoria University of Wellington

$<$ Date $>$

Dear Sir/Madam

I am a PhD student at the School of Information Management, Faculty of Commerce and Administration, Victoria University of Wellington, New Zealand. I am undertaking a research project as a requirement of this degree, leading to a thesis. This research project is entitled: ELearning in Information Management Education in Sri Lanka: An Examination of Needs and Issues. This research explores how e-learning can be utilized to facilitate tertiary-level IM education in Sri Lanka. Prior to conducting the proposed interview, Victoria University of Wellington requires that I obtain your written informed consent.

\section{Purpose of the study}

The purpose of this study is to understand how e-learning can be utilized to facilitate tertiarylevel information management (IM) education for information workers in Sri Lanka. The research project also aims to identify significant contextual factors that have an impact on the use of elearning and how do these factors affect the use of e-learning in tertiary-level IM education in Sri Lanka. This will help to modify preliminary model of this study thereby will create a better understanding of contextual factors and how these factors need to be considered when planning and adopting e-learning in IM education in Sri Lanka. The research is also being undertaken for the purposes of completing the degree of $\mathrm{PhD}$ in Information Management.

\section{Data collection and handling}

This study will use qualitative data collection techniques such as semi-structured interviews, focus group discussions and documentary evidence. The data collection will continue for a period of approximately three months from Mid-September to Mid-December 2011. During that time you will be take part in focus groups.

I will conduct focus group discussions with IM workers who work in rural and urban areas. Semistructured interviews will conduct with IM education providers including their teaching staff, administrative staff, and supportive staff, and stakeholders including officials from government, Quality Assurance and Accreditation Council and employers in public and private sector.

Each focus group discussion is expected to last approximately one to two hours and will be digitally recorded (audio and video) and then transcribed. Initially all data collection will be take place in natural setting according to your convenience and all these activities will be arranged at a time that suits you. 


\section{Confidentiality and anonymity}

Confidentiality of information shared within each focus group session is of fundamental importance. It is essential that any information discussed within the focus groups will be treated as confidential by all research participants. Throughout the project, all raw data will be kept confidential. The collected, collated and analysed data may be published in case studies, academic journals and/or presented at conferences. Any information and opinions that you provide will not be attributed to you, and you will not be able to be identified in any way. There will be an opportunity for you to review any written notes or transcripts of recorded sessions that result from the interviews, to ensure that material is recorded accurately. You will also have the opportunity to review and comment on the preliminary findings of the focus groups (via email).

Throughout the project, hard copies of data and interview recordings will be kept in a locked cupboard in my office at Victoria University. Electronic files will be stored in password protected files, with access being restricted to myself and my $\mathrm{PhD}$ supervisor. The data will be destroyed two years after the conclusion of the project.

\section{Contact details}

If you need further information or have any enquiries, please feel welcome to contact me or for further clarification you also can contact my supervisors. Their contact details as well as my contact details are given below.

Supervisors contact details:

Dr. Chern Li Liew / Dr. Jocelyn Cranefield

School of Information Management

Faculty of Commerce and Administration

Victoria University of Wellington

E-mail: chernli.liew@vuw.ac.nz Telephone: +64 4635213

jocelyn.cranefield@vuw.ac.nz Telephone: +64 4636887

Researcher's contact details:

Namali Suraweera

School of Information Management

Victoria University of Wellington

E-mail: namali.suraweera@vuw.ac.nz

Telephone: +64 212630334 (mobile New Zealand))/+94 716894652 (mobile Sri Lanka)

If you agree to participate in the focus group discussion, kindly fill in the attached consent form. Should you feel the need to withdraw from the project, you may do so before start the discussion since you cannot withdraw information provided by you from the focus group once it is recorded.

Yours sincerely,

Namali Suraweera

Signed: 


\section{INFORMATION SHEET - SEMI-STRUCTURED INTERVIEWS}

RESEARCHER: Namali Suraweera

School of Information Management

Faculty of Commerce and Administration

Victoria University of Wellington

$<$ Date $>$

Dear Sir/Madam

I am a PhD student at the School of Information Management, Faculty of Commerce and Administration, Victoria University of Wellington, New Zealand. I am undertaking a research project as a requirement of this degree, leading to a thesis. This research project is entitled: ELearning in Information Management Education in Sri Lanka: An Examination of Needs and Issues. This research explores how e-learning can be utilized to facilitate tertiary-level IM education in Sri Lanka. Prior to conducting the proposed interview, Victoria University of Wellington requires that I obtain your written informed consent.

\section{Purpose of the study}

The purpose of this study is to understand how e-learning can be utilized to facilitate tertiarylevel information management (IM) education or information workers in Sri Lanka. The research project also aims to identify significant contextual factors that have an impact on the use of elearning and how do these factors affect the use of e-learning in tertiary-level IM education in Sri Lanka. This will create a better understanding of contextual factors and how these factors need to be considered when planning and adopting e-learning in IM education in Sri Lanka. The research is also being undertaken for the purposes of completing the degree of $\mathrm{PhD}$ in Information Management.

\section{Data collection and handling}

This study will use qualitative data collection techniques such as semi-structured interviews, focus group discussions and documentary evidence. The semi-structured interviews will take place from late October to late December 2011. During that time you will be interviewed.

I will conduct semi-structured interviews with IM education providers including their teaching staff, administrative staff, and supportive staff, with stakeholders including officials from government, Quality Assurance and Accreditation Council and employers in public and private sector in rural and urban areas, and with existing e-learning providers including programme directors and member of educational technology support as well as learning resource support.

Each interview is expected to last approximately one hour and will be recorded and then transcribed. All data collection will take place in a workplace according to your convenience and all these activities will be arranged at a time that suits you.

\section{Confidentiality and anonymity}

All raw data will be kept confidential. The collected, collated and analysed data may be published in case studies, academic journals and/or presented at conferences. Any information and opinions that you provide will not be attributed to you, and in the research report individuals will be described using generic role descriptions. Kindly note however, that it may be possible to infer 
from the information provided, the identity of the individual interviewee. The name of your organization may also be used in the reporting of the findings. There will be an opportunity for you to review any written notes or transcripts of recorded sessions that result from the interviews, to ensure that material is recorded accurately.

Throughout the project, hard copies of data and interview tapes will be kept in a locked cupboard in my office at Victoria University. Electronic files will be stored in password protected files, with access being restricted to myself and my PhD supervisor. The data will be destroyed two years after the conclusion of the project.

\section{Contact details}

If you need further information or have any enquiries, please feel welcome to contact me or for further clarification you also can contact my supervisors. Their contact details as well as my contact details are given below.

Supervisors contact details:

Dr. Chern Li Liew / Dr. Jocelyn Cranefield

School of Information Management

Faculty of Commerce and Administration

Victoria University of Wellington

Wellington 6041

E-mail: chernli.liew@vuw.ac.nz Telephone: +64 4635213

jocelyn.cranefield@vuw.ac.nz Telephone: +64 4636887

Researcher's contact details:

Namali Suraweera

School of Information Management

Faculty of Commerce and Administration

Victoria University of Wellington

Wellington 6041

E-mail: namali.suraweera@vuw.ac.nz

Telephone: +64 212630334 (mobile New Zealand)/+94 716894652 (mobile Sri Lanka)

If you agree to participate in the interview, kindly fill in the attached consent form. Should you feel the need to withdraw from the project, you may do so at any time by informing me before $31^{\text {st }}$ December 2011. If you do so, all information provided by you will be removed from the study and all records of your participation deleted.

Yours sincerely,

Namali Suraweera

Signed: 


\section{Appendix 8}

\section{Consent to Participation in Research (Focus Group Discussions)}

\section{E-Learning in Information Management Education in Sri Lanka: An Examination of Needs and Issues}

[Please mark each box with a $\sqrt{ }$ to indicate agreement]

1. I have been given and have understood an explanation of this research project and the confidentiality conditions

2. I have had an opportunity to ask questions and have them answered to my satisfaction

3. I agree to be interviewed by Namali Suraweera for the purpose of this research, and I consent to the use of my perceptions, experiences, opinions and information in this research provided they are not attributed to me.

4. I understand that all data collected (recordings and interview transcripts) will be destroyed two years after the completion of the project.

5. I understand that I may withdraw from this project before start the discussion since I cannot withdraw information provided by me from the focus group once it is recorded.

6. I would like to receive feedback on this research, in the form of a research summary.

7. I agree to have interviews digitally recorded (audio and video) YES

Name:

Signed:

Date: 


\section{Consent to Participation in Research (Semi-structured interviews)}

\section{E-Learning in Information Management Education in Sri Lanka: An Examination of Needs and Issues}

[Please mark each box with a $\sqrt{ }$ to indicate agreement]

1. I have been given and have understood an explanation of this research project and the confidentiality conditions

2. I have had an opportunity to ask questions and have had them answered to my satisfaction

3. I agree to be interviewed by Namali Suraweera for the purpose of this research, and I consent to the use of my perceptions, experiences, opinions and information in this research provided they are not attributed to me.

4. I understand that I will be given the opportunity to review and comment on the summary of the interviews.

5. I understand that all data collected (tapes and interview transcripts) will be destroyed two years after the completion of the project.

6. I understand that I may withdraw from this project at any time up until $31^{\text {st }}$ December 2011, and that in this instance, all data collected (tapes and interview transcripts) will be immediately destroyed and excluded from the study.

7. I would like to receive feedback on this research, in the form of a research summary.

8. I understood that the collected, collated and analysed data will be published in case studies, academic journals and/or presented at conferences.

9. I confirm that I DO

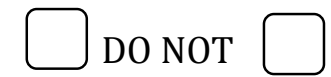
have the approval of my employer to participate in this research project.

10. I agree to have interviews digitally-recorded (audio) YES NO

Name:

Signed: Date: 


\begin{tabular}{|c|c|c|c|c|}
\hline Project Name & $\begin{array}{c}\text { Start and } \\
\text { finish date } \\
\text { of the } \\
\text { project }\end{array}$ & Project goals & Project Components & Project outcome \\
\hline $\begin{array}{l}\text { Distance } \\
\text { Education } \\
\text { Modernization } \\
\text { Project (DEMP) }\end{array}$ & On going & $\begin{array}{l}\text { To help the Government } \\
\text { of Sri Lanka implement } \\
\text { its human resource } \\
\text { strategy by modernizing } \\
\text { the postsecondary } \\
\text { education system, } \\
\text { especially through the } \\
\text { introduction of distance } \\
\text { education and the } \\
\text { promotion of public- } \\
\text { private partnerships } \\
\text { (PPPs). }\end{array}$ & $\begin{array}{l}\text { (i) Establishment of the } \\
\text { Distance Education } \\
\text { Partnership Programme } \\
\text { (DEPP) to increase } \\
\text { educational opportunities, } \\
\text { to raise quality and } \\
\text { enhance capacity. } \\
\text { DEPP - Part A } \\
\text { Establishment of the DEPP } \\
\text { office to provide } \\
\text { curriculum development, } \\
\text { training, research, } \\
\text { marketing, and contract } \\
\text { outsourcing management } \\
\text { services for on-line } \\
\text { distance education } \\
\text { academic course for up to } \\
\text { 150 public and private } \\
\text { postsecondary institutes. } \\
\text { DEPP - Part B } \\
\text { Establishment of the } \\
\text { National Distance } \\
\text { Education Network (NDEN) } \\
\text { under DEPP. The NDEN is } \\
\text { the hardware side of the } \\
\text { DEPP and includes } \\
\text { consultants, some } \\
\text { equipment, and recurrent } \\
\text { operating costs to }\end{array}$ & $\begin{array}{l}\text { According to project completion report (2013), it found the } \\
\text { project to be less effective, less efficient, less successful, and less } \\
\text { likely to be sustainable. } \\
\text { Although the project created a platform for ICT-based } \\
\text { postsecondary distance education, the project suffered from } \\
\text { limited utilization. The limited utilization will not encourage } \\
\text { hardware and software upgrades, and the system could be } \\
\text { irrelevant within a few years. While the concept of online } \\
\text { learning and a workable system was established, there was not } \\
\text { enough effort to ensure widespread acceptance of distance } \\
\text { learning as a respectable alternative to face-to-face education. } \\
\text { Ref. } \\
\text { http://www.adb.org/sites/default/files/PVR-277.pdf }\end{array}$ \\
\hline
\end{tabular}




\begin{tabular}{|c|c|c|c|c|}
\hline & & & $\begin{array}{l}\text { configure, install, and } \\
\text { operate the national } \\
\text { distance education system } \\
\text { needed to support DEPP } \\
\text { service delivery of on-line } \\
\text { learning. } \\
\text { (Later on DEPP renamed } \\
\text { as National Online } \\
\text { Distance Education } \\
\text { Service NODES) } \\
\text { (ii) Establishment } \\
\text { of a consortium of PPPs to } \\
\text { improve standards } \\
\text { (iii) Upgrading of the Open } \\
\text { University of Sri Lanka } \\
\text { (OUSL, central and regional } \\
\text { centres). }\end{array}$ & \\
\hline $\begin{array}{l}\text { Secondary } \\
\text { Education } \\
\text { Modernization } \\
\text { Project I (SEMP I) }\end{array}$ & $2001-2006$ & $\begin{array}{l}\text { To assist the } \\
\text { Government in } \\
\text { modernizing Sri Lanka's } \\
\text { secondary school system. } \\
\text { The expected outcomes } \\
\text { were to } \\
\text { (a) improve the quality of } \\
\text { teaching and learning in } \\
\text { secondary schools, (b) } \\
\text { provide educational } \\
\text { opportunities for } \\
\text { disadvantaged students } \\
\text { (c) Improve management } \\
\text { efficiency in secondary } \\
\text { school education. }\end{array}$ & $\begin{array}{l}\text { a) modernizing secondary } \\
\text { schools by introducing } \\
\text { modern teaching, learning, } \\
\text { and evaluation } \\
\text { methods to improve } \\
\text { quality; } \\
\text { (b) broadening educational } \\
\text { opportunities for } \\
\text { disadvantaged students by } \\
\text { expanding the } \\
\text { number of full-curriculum } \\
\text { schools in rural areas, } \\
\text { extending stipend } \\
\text { programmes to enable the } \\
\text { poor to attend these } \\
\text { schools, introducing career } \\
\text { guidance programmes to } \\
\text { increase career }\end{array}$ & $\begin{array}{l}\text { The project completion report (2009) rated the Project as } \\
\text { successful. It found the Project to be highly relevant, effective, } \\
\text { efficient, and likely to be sustainable. } \\
\text { The most successful subcomponent of the Project was the } \\
\text { establishment of the computer learning centres, and other } \\
\text { successful components include curriculum strengthening, } \\
\text { school upgrading with science laboratories, the stipend } \\
\text { programme, involvement of the private sector in various aspects } \\
\text { of the education system, and capacity development of NETS and } \\
\text { NIE. The capacity development of MOE and the career guidance } \\
\text { programme were considered partly achieved. } \\
\text { Ref. http://www.adb.org/sites/default/files/in135-09.pdf }\end{array}$ \\
\hline
\end{tabular}




\begin{tabular}{|c|c|c|c|c|}
\hline & & & $\begin{array}{l}\text { information for expanded } \\
\text { opportunities and mobility, } \\
\text { and conducting research } \\
\text { studies to } \\
\text { determine cost-effective } \\
\text { ways to accommodate } \\
\text { public-private } \\
\text { partnerships in secondary } \\
\text { education; and } \\
\text { (c) improving the delivery } \\
\text { of educational services } \\
\text { through improving quality } \\
\text { assurance within } \\
\text { the Ministry of Education } \\
\text { (MOE) and school-based } \\
\text { management; school-based } \\
\text { assessment in grades 10- } \\
\text { 13, including modernizing } \\
\text { the national examination } \\
\text { administration at the } \\
\text { National Evaluation and } \\
\text { Testing Service (NETS); } \\
\text { and the National } \\
\text { Institute of Education's } \\
\text { (NIE) in-service training } \\
\text { curriculum in the new } \\
\text { technology education } \\
\text { stream, career guidance, } \\
\text { and computer training. } \\
\end{array}$ & \\
\hline $\begin{array}{l}\text { Secondary } \\
\text { Education } \\
\text { Modernization } \\
\text { Project II (SEMP } \\
\text { II) }\end{array}$ & $2005-2009$ & $\begin{array}{l}\text { (I) To support the } \\
\text { government's strategy to } \\
\text { improve the quality, } \\
\text { equity and management } \\
\text { efficiency of secondary } \\
\text { education and make it } \\
\text { more responsive to } \\
\text { labour market } \\
\text { requirements }\end{array}$ & $\begin{array}{l}\text { 1. Improving quality of and } \\
\text { equity of access to } \\
\text { secondary education } \\
2 \text {. Strengthening the } \\
\text { capacity of provincial and } \\
\text { zonal offices } \\
\text { 3. Supporting the } \\
\text { implementation of }\end{array}$ & $\begin{array}{l}\text { No data available } \\
\text { Ref. } \\
\text { http://www.adb.org/sites/default/files/projdocs/2010/35192- } \\
\text { sri-pprr.pdf }\end{array}$ \\
\hline
\end{tabular}




\begin{tabular}{|c|c|c|c|c|}
\hline & & $\begin{array}{l}\text { (II) To contribute to the } \\
\text { government's long term } \\
\text { policy on peace building } \\
\text { by increasing equity of } \\
\text { access to quality } \\
\text { education and promoting } \\
\text { education for social } \\
\text { cohesion. }\end{array}$ & $\begin{array}{l}\text { government policies and } \\
\text { reforms in education. }\end{array}$ & \\
\hline $\begin{array}{l}\text { Education for } \\
\text { Knowledge } \\
\text { Society Project } \\
\text { (EKSP) }\end{array}$ & $2008-2012$ & $\begin{array}{l}\text { To ensure establishing a } \\
\text { nationwide resource } \\
\text { base irrespective of } \\
\text { gender, ethnicity and } \\
\text { geographic location, for } \\
\text { improved access to } \\
\text { secondary and tertiary } \\
\text { education. }\end{array}$ & $\begin{array}{l}\text { 1.Increased equity of access } \\
\text { to education } \\
2 . \text { Enhanced quality and } \\
\text { relevance of education } \\
\text { 3. Improved policy, } \\
\text { governance, and service } \\
\text { delivery }\end{array}$ & $\begin{array}{l}\text { - Upgrading \& Development of } 150 \text { Secondary Schools (ISURU } \\
\text { School Programme) } \\
\text { - Local Training } \\
\text { - Development of Centre of Excellence in English Education } \\
\text { (CEIEE) } \\
\text { - Upgrading of Sri Lanka Institute of Advanced } \\
\text { Technological Education (SLIATE) } \\
\text { - Implementation of Centre for Education Leadership } \\
\text { Development (CELD) in Meepe } \\
\text { - Career Guidance and Social Marketing Programmes } \\
\text { - ICT facilities for } 2125 \text { Type II schools } \\
\text { - Provision of Consultancies services for educational quality } \\
\text { improvement. } \\
\text { - Provision of 30,000 Scholarships (Sisudiriya \& Special } \\
\text { Scholarship for School Leavers) } \\
\text { - HIV AIDS and Health Education Programmes } \\
\text { - Special Programme PILL (ICT Excellence Awarding System) } \\
\text { - Providing ICDL/CAL (International Computer Driving License) } \\
\text { Capacity building training for 10600 Teachers } \\
\text { - Providing IPICT International Pedagogical ICT License } \\
\text { 18000 Teachers } \\
\text { - Strength SBA (School Based Assessment) } \\
\text { - Established MIS (Management Information System) } \\
\text { - Special Financial Grant for Higher Order Learning Processes in } \\
\text { Isuru Schools } \\
\text { Ref. http://www.eksp.sch.lk }\end{array}$ \\
\hline
\end{tabular}




\section{Appendix 10}

\section{Core activities of the specialized functional areas of Staff Development}

\begin{tabular}{|l|l|}
\hline \multicolumn{1}{|c|}{ Specialty } & \multicolumn{1}{c|}{ Core activities } \\
\hline a. Staff Development & 1. Induction training for all categories of staff - i) \\
Legislations, Acts Ordinances and By-Laws, Government \\
Administrative and Financial Regulations (AR \& FR) giving \\
guidelines on how to govern and manage state institutions, \\
ii) recruitment and performance evaluation, increments \\
and promotions, iii) disciplinary procedures, iv) general \\
administrative and financial management procedures, v) \\
office management, vi) time management, vii) generic or \\
soft skills, viii) codes of practices and ethics, ix) \\
management of work stress and x) strategic planning and \\
management. \\
2. Continuing education programmes aimed at improving \\
knowledge and skills in core areas required for different \\
categories of staff - i) higher management, ii) executive \\
staff, iii) academic staff, iv) technical staff, v) clerical staff \\
and vi) other specialized categories
\end{tabular}

Ref: http://www.ugc.ac.lk/attachments/791 Commission\%20Circular\%20No\%20937.pdf 